\title{
EXPLORING THE RELATIONSHIP BETWEEN TOURISM AND CONCERN FOR THE GLOBAL NATURAL ENVIRONMENT: \\ A CASE STUDY OF WELLINGTON RESIDENTS
}

by

\section{Tina Rønhovde Tiller}

\author{
A thesis \\ Submitted to the Victoria University of Wellington \\ in partial fulfilment of the \\ requirements of the degree of \\ Master of Tourism Management
}

Victoria University of Wellington 2010 
Til mine kjare foreldre - utan dykkar kjorleik og støtte hadde dette aldri gått. 


\section{Abstract}

Climate change has been a concern for well over thirty years, but there has been limited research within the field of tourism with respect to climate change. In the last few years, there have been changes in the public perception of climate change, and an increasing awareness of the importance of addressing the problems that the world may face as a result of climate change. At current, the GHG emissions attributable to tourism are in the range of 4-6\% of total global emissions, and rising. People are travelling ever more frequent, and to destinations far away from their residence. The world cannot sustain these trends, and thus research is needed to identify means to change tourism behaviours and reduce the impact of tourism on the global natural environment.

This study aimed to explore the relationship between concern for the environment and tourism by taking recent holiday behaviours of Wellington residents into account. 308 residents returned useable questionnaires from the household surveys which were distributed to Wellington dwellings in July and August 2009. The study took the following steps to reach its aim: Firstly, recent holiday behaviours among Wellington residents were accounted for, including participation in leisure travel, distances travelled, and transport modes and accommodation used. Minimum emissions of $\mathrm{CO}_{2}$-E emissions caused by transportation to and from the main destination on the two most recent holidays taken by the respondents were estimated. Also, factors influencing choice of destination, transportation and accommodation were explored in relation to concern for the environment. Secondly, residents' perception of the significance of impact that climate change will have on their lives was explored. It was established that most people in the sample think that climate change will affect their lives to some extent. Thirdly, frequency of participation in carbon offsetting schemes and purchase of ecolabeled tourism products was explored to contribute to the knowledge about consumer awareness and attitudes towards tourism ecolabels and carbon offsetting schemes. Awareness and consumption was found to be low among the respondents. Fourthly, the study explored people's level of concern for the global natural environment, by investigating opinions held by the respondents about tourism and climate change and the impact of their holiday behaviours. Concern was established among the respondents. Concern for the environment was then explored in relation to holiday behaviours to establish whether environmental concern had an influence on the behaviours displayed by the respondents. No such relationship was found, and it was concluded that concern for the environment does not have an influence on people's behaviours. Lastly, preferred policy options were investigated. The people in the sample preferred voluntary policy measures, however very few are currently making use of the voluntary initiatives that are 
available to the public. The study concludes by highlighting the fact that more strict measures are needed in order to change current behaviours, seeing as concern for the environment does not affect the tourism behaviours of the people included in the sample.

Key words: concern for the environment, climate change, tourism ecolabels, carbon offsetting, holiday behaviour 


\section{Acknowledgements}

Firstly, I would like to extend my sincerest thanks to my supervisor, Dr Christian Schott. Thank you for being the Kaitiaki of my thesis, and for gently guiding me on the way to completion. Your support has been invaluable to me.

Many thanks also to Victoria Management School who funded my field research, and to Sophia Lum who has been of great support, patiently leading me through the jungle of paperwork.

Dennis Lawson at Student Learning Support has been a very good support to me throughout my statistical analysis.

There are also a number of people in my life who deserve my thanks for contributing to my thesis and to my general wellbeing, not all can be mentioned here but some deserve special attention. Many thanks to:

My parents, Torill Rønhovde and Torkel Tiller. You guys are awesome. Thank you for always being there for me.

Travis Lealand-Maplesden, who has kept me alive through countless dinners and encouraging words, and who proofread the whole thesis. I owe you more than one.

Christine Böcher, who has been an amazing friend, helping me with envelope filling and driving me out to the suburbs to mail out my surveys and keeping me alive and sane, among other things.

Thanks also to my flatmates Jo, Ants, Lizzy, Rob and Jen, who have tolerated all my odd behaviours, cooked dinner on Sundays and been supportive throughout. Special thanks to Antony Blackett for technical support!

Last but not least, thanks to my study mates in the office and in the VMS masters room, who have encouraged me throughout the study, and been a good support. To Alexander, Alex Jamie, Chris, Felicia, Geeta, Laura, Odny, Renate, Uschi, and all my other friends who are still here at the end of it, I feel very lucky to have you in my life. 


\section{Table of content}

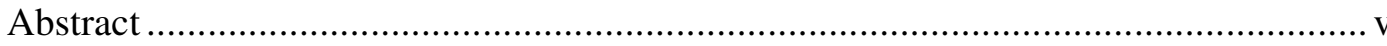

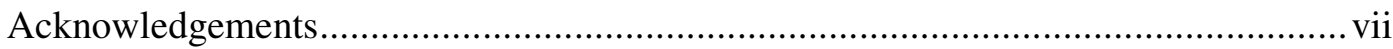

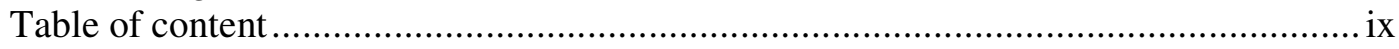

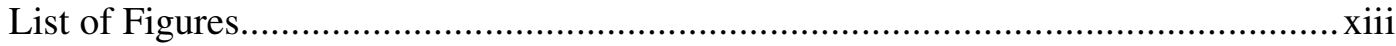

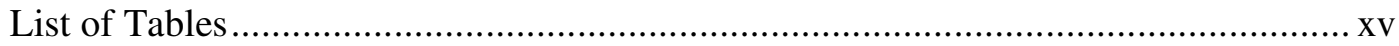

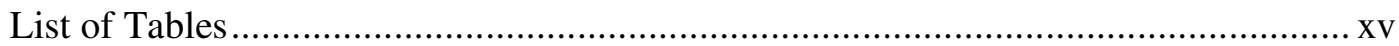

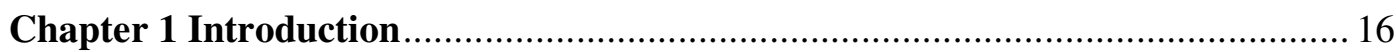

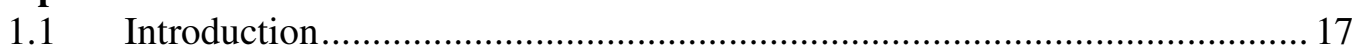

1.2 Climate change and tourism .............................................................. 21

1.2.1 Major future changes to the global climate, as projected in the fourth assessment report (AR4) by the IPCC in 2007 ................................................ 22

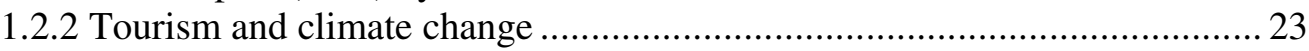

1.3 New Zealand and Wellington City ............................................................ 24

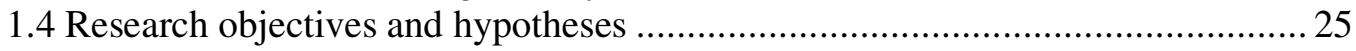

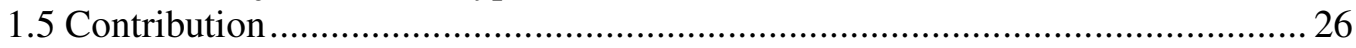

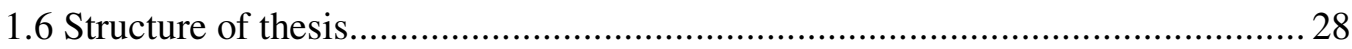

Chapter 2. Literature Review............................................................................................... 30

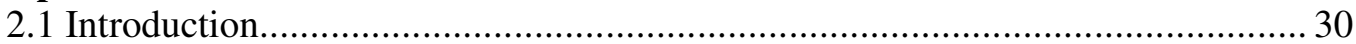

2.2 Current knowledge about climate change and its causes .............................. 32

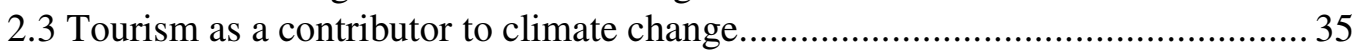

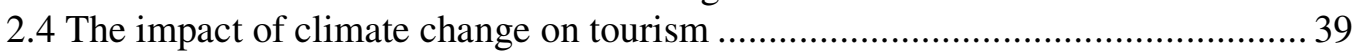

2.5 Concern for the environment and tourism behaviour ................................... 41

2.5.1 Role of concern for the environment in holiday destination choice ............. 41

2.5.2 Holiday behaviour and concern for the environment ............................... 43

2.6 Environmental certifications and carbon offsetting .................................... 46

2.6.1 Environmental certifications for tourism or 'tourism ecolabels' .................. 46

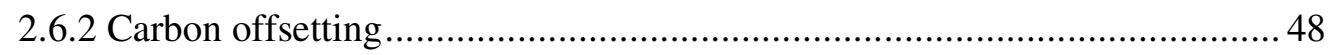

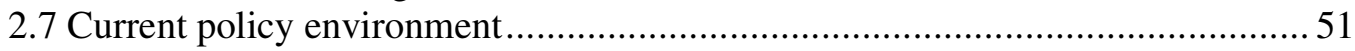

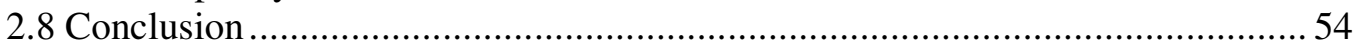

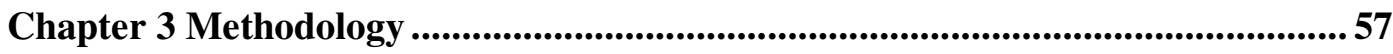

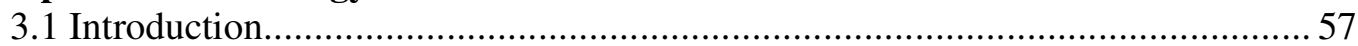

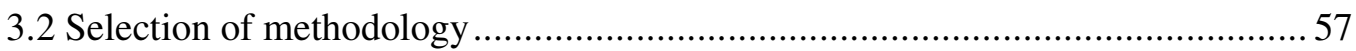

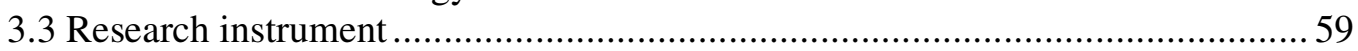

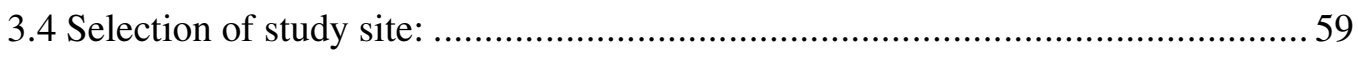

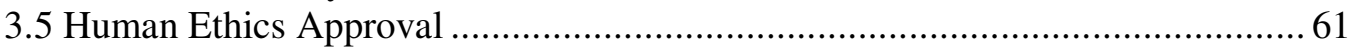

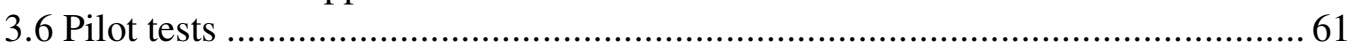

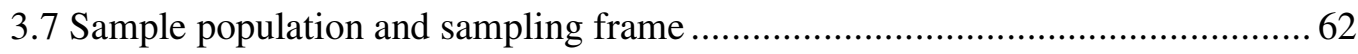

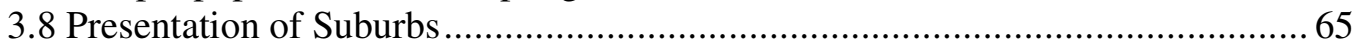

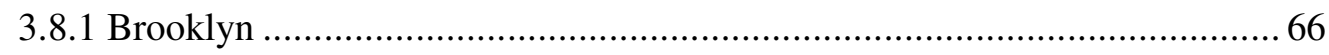

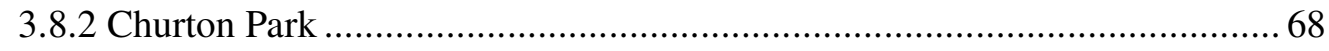

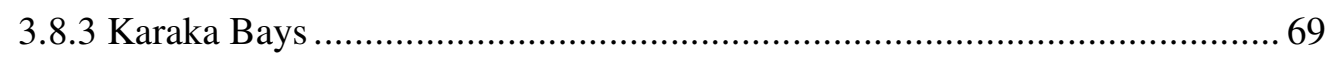

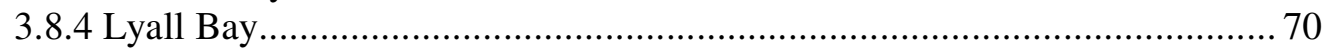

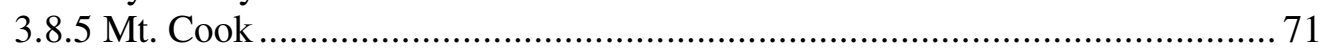

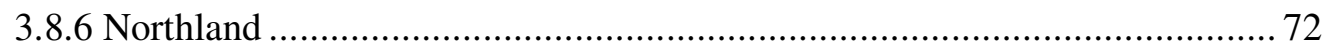

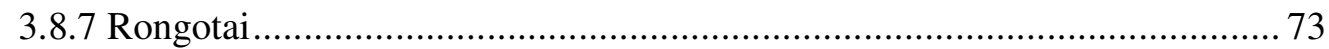

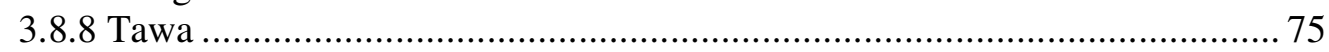




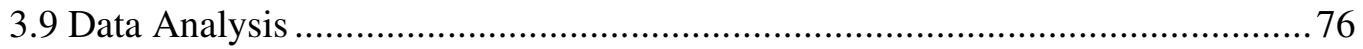

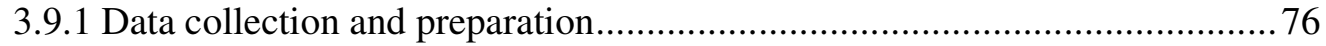

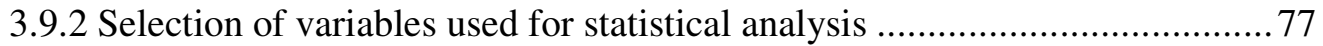

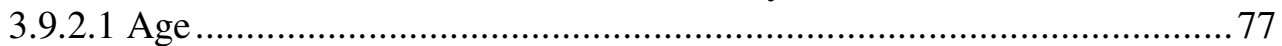

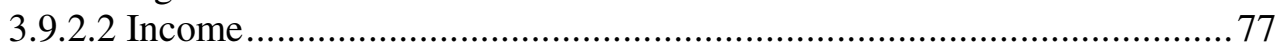

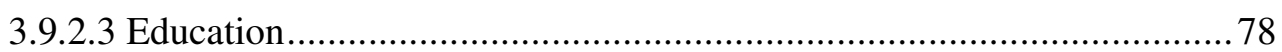

3.9.2.4 Participation in carbon offsetting................................................... 78

3.9.2.5 Likelihood that climate change will have a negative effect on daily life in

New Zealand within the next 20 years ................................................. 78

3.9.2.6 Trip Frequency and $\mathrm{CO}_{2}$-E emissions made on trips........................ 79

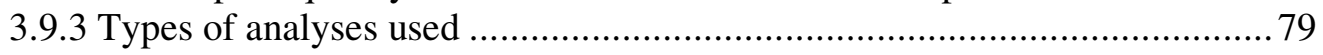

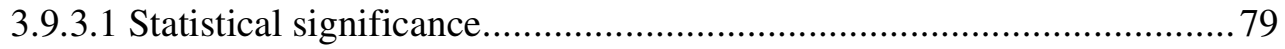

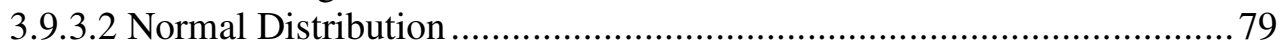

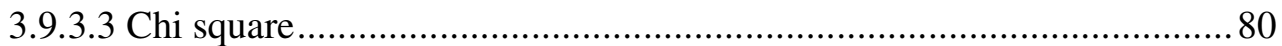

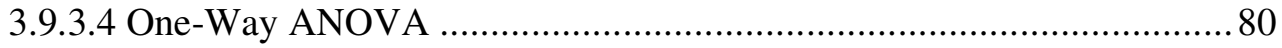

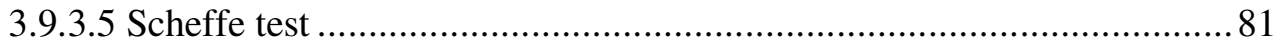

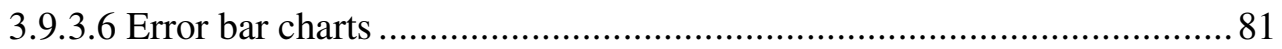

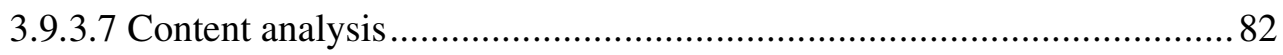

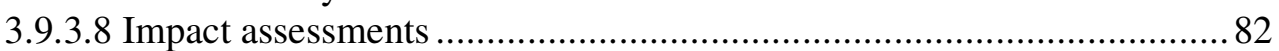

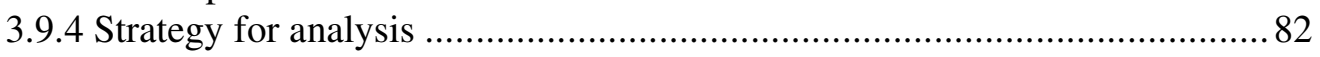

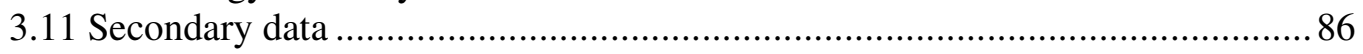

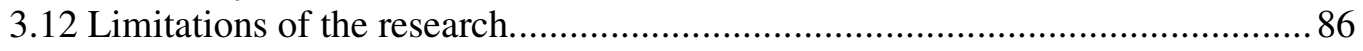

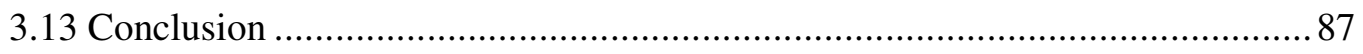

Chapter 4 Sample population, participation in leisure travel and trip

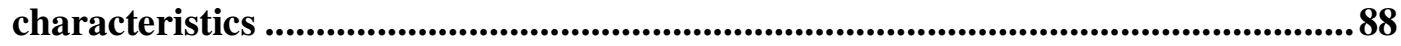

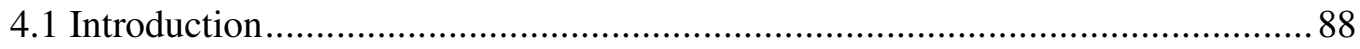

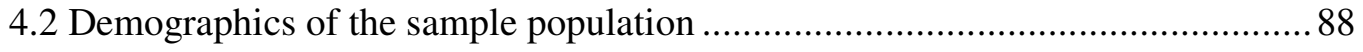

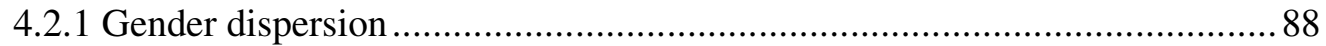

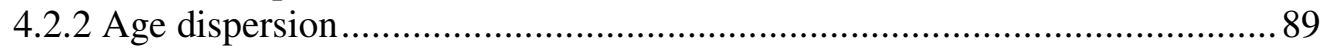

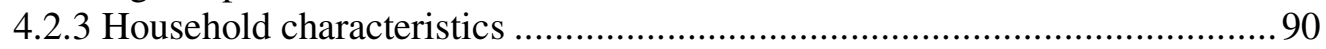

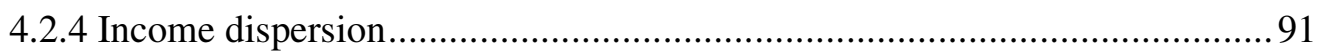

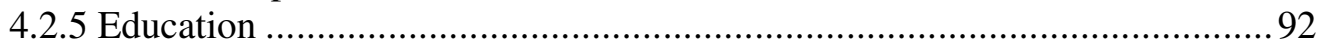

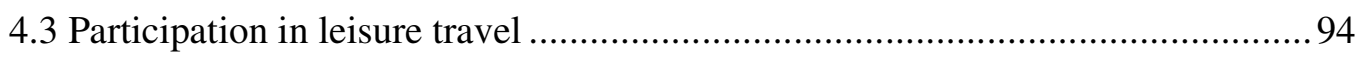

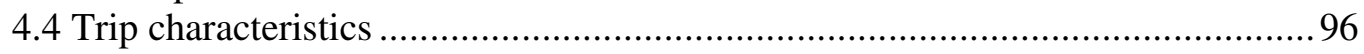

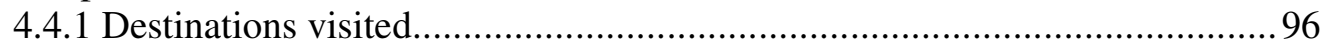

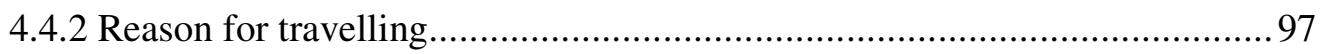

4.4.3 Transport modes and accommodation used ............................................98

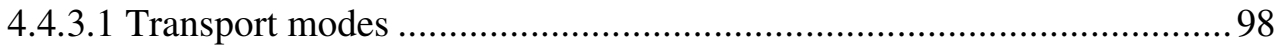

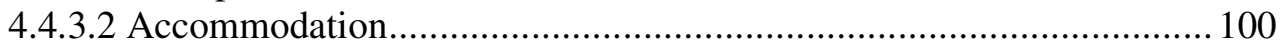

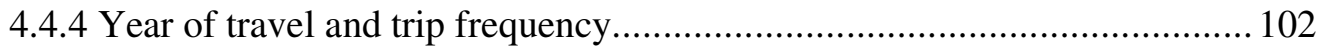

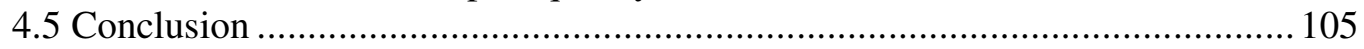

Chapter 5. Reported behaviours and observations of climate change ..................106

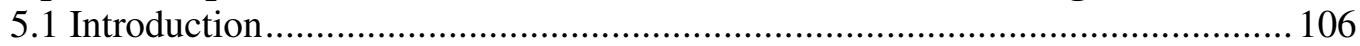

5.2 The role of environmental concern in choice of destination, transport mode and

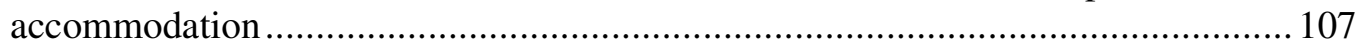

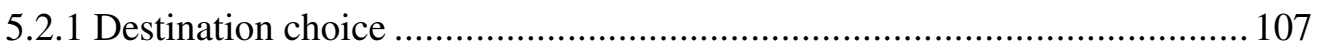

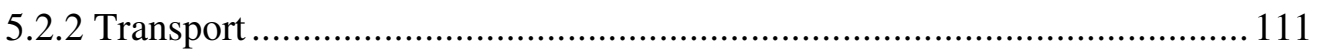

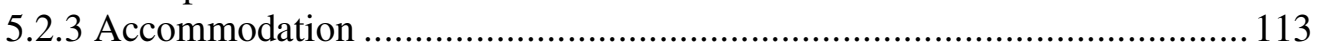

5.3 Reported observations and effects on behaviour ....................................... 115 
5.3.1 Observations of climate change in home environment ............................ 115

5.3.2 Effects of observations on behaviour ................................................ 117

5.3.3 Perceived likelihood that climate change will have a negative impact on daily

life in New Zealand within the next 20 years ................................................... 121

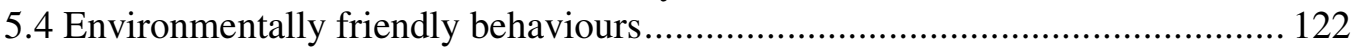

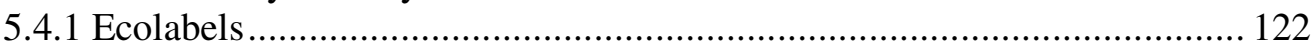

5.4.2 Carbon offsetting ...................................................................... 125

5.4.2.1 Awareness and participation .................................................... 125

5.4.2.2 Reasons for participation or non participation ............................. 127

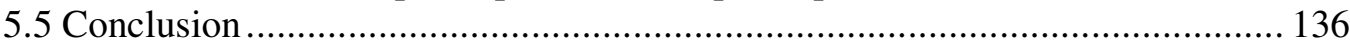

Chapter 6 Relationship between environmental concern and behaviours ............ 137

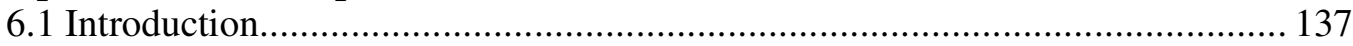

6.2. Distances travelled and calculations of environmental impact of transport modes

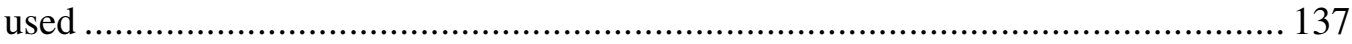

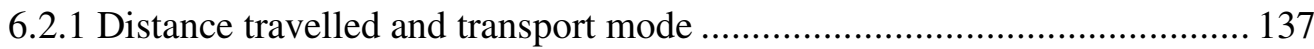

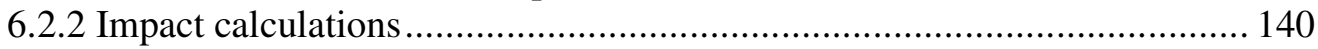

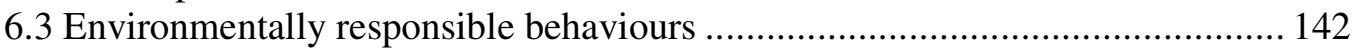

6.3.1 Environmentally responsible behaviours when on holiday ....................... 142

6.3.2 Perceived difficulty of knowing how to behave environmentally friendly

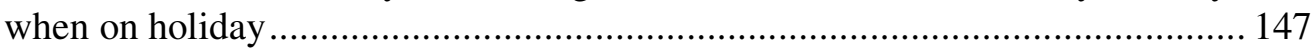

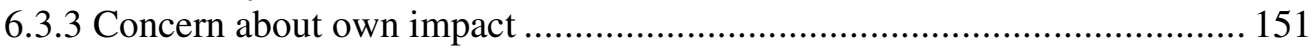

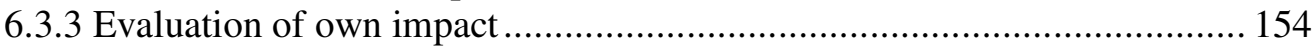

6.3.4 The relationship between tourism and contribution to global climate change

6.3.5 The effectiveness of buying environmentally friendly products in limiting negative impacts of tourism on the environment........................................... 159

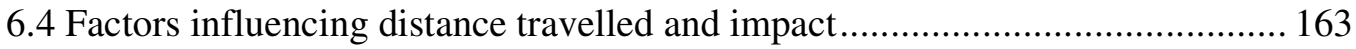

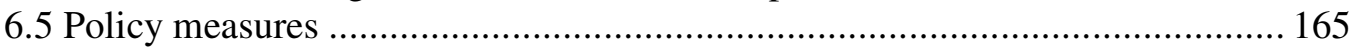

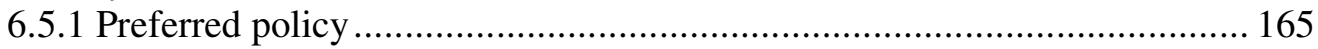

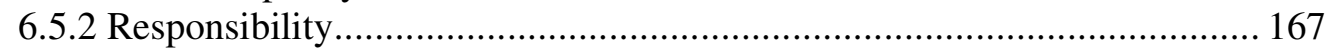

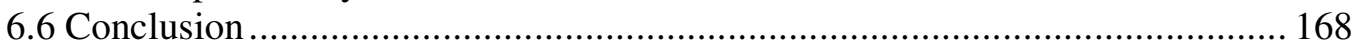

Chapter 7 Discussion \& conclusion .................................................................. 170

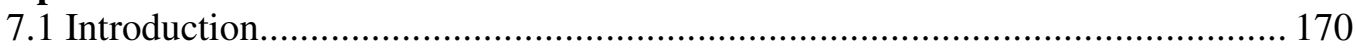

7.2 Role of environmental concern in choice of accommodation, transport and

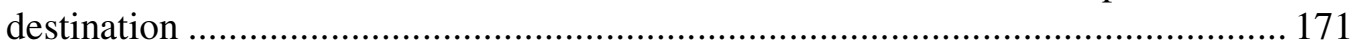

7.3 Reported observation and effects on behaviour........................................ 173

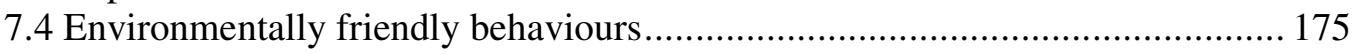

7.5. Analysing the influence of environmental concern on behaviour ................... 178

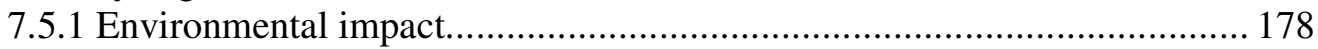

7.5.2 Opinions about respondents' own behaviours and impact ....................... 180

7.5.3 Environmentally responsible behaviours - opinions \& reported actions .... 181

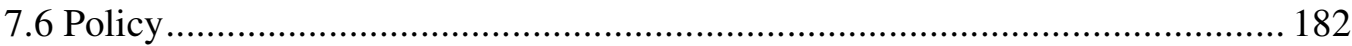

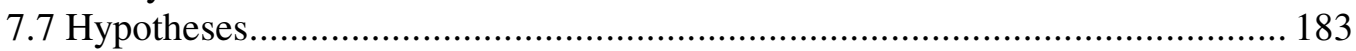

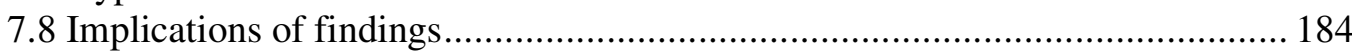

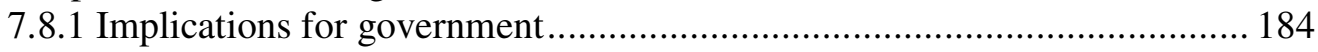

7.8.2 Implications for the private sector.................................................... 186

7.8.3 Challenges in providing information about tourism and climate change.... 187

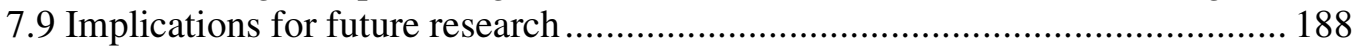

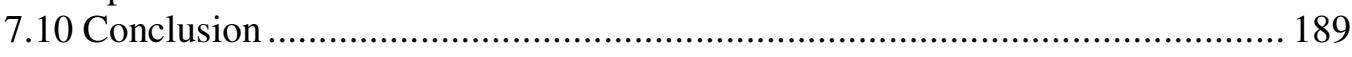




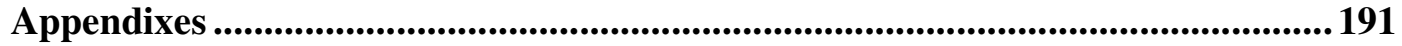

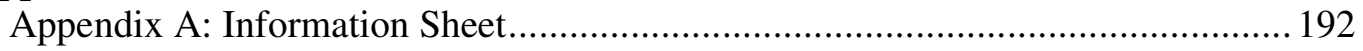

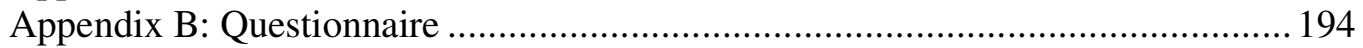

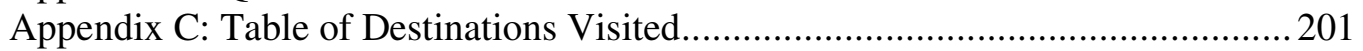

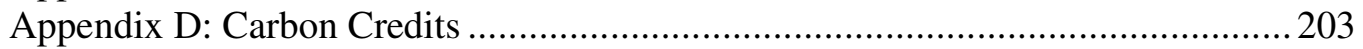

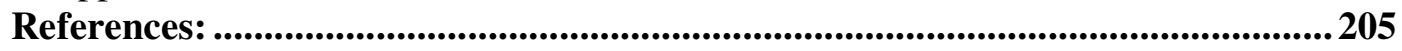




\section{List of Figures}

Figure 2.1 Significant changes to the NZ climate over the last 20 years.................... 34

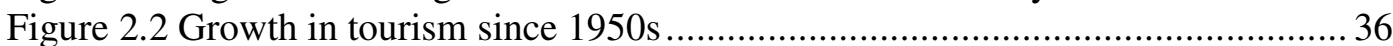

Figure 2.3 The vulnerability of tourism to climate change .................................... 40

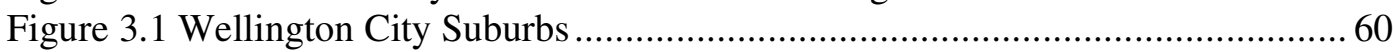

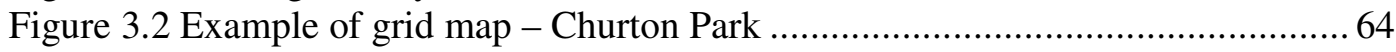

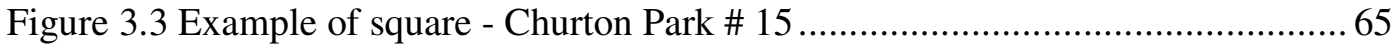

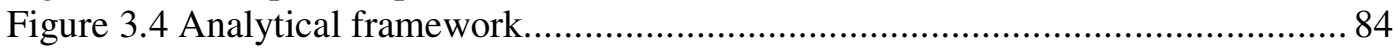

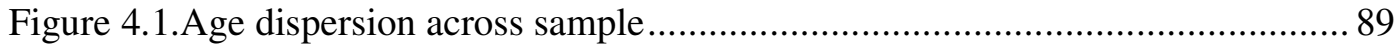

Figure 4.2 Age of total population in Wellington City according to 2006 census......... 90

Figure 4.3 Household income dispersion across sample .......................................... 91

Figure 4.4 Income dispersion among Wellington residents according to 2006 census.. 92

Figure 4.5 Level of education within sample ....................................................... 93

Figure 4.6 Level of Education of Wellington residents according to 2006 census ........ 94

Figure 4.7 Reasons given for not travelling for leisure purposes.............................. 95

Figure 4.8 Main reason for travelling - all holidays compiled................................... 97

Figure 4.9 Purpose of travel to all countries year ended 2007 ................................ 98

Figure 4.10 Transport modes used on holidays........................................................... 99

Figure 4.11 Transport modes used domestically and internationally ......................... 100

Figure 4.12 All trips compiled - year travelled ................................................. 102

Figure 4.13 Number of trips taken for leisure in the last three years ......................... 103

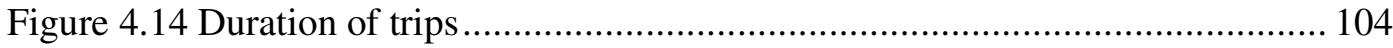

Figure 5.1 Importance of destination's commitment to protect the environment when

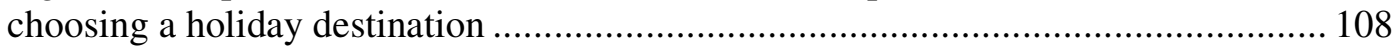

Figure 5.2 Importance of activities and events when choosing a holiday destination . 109

Figure 5.3 Importance of climate when choosing a holiday destination .................... 109

Figure 5.4 Importance of unspoiled landscape/scenery when choosing a holiday

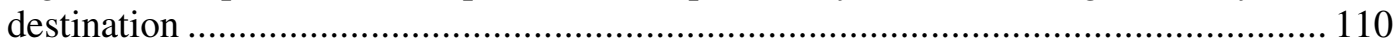

Figure 5.5 Importance of value for money when choosing a holiday destination ....... 110

Figure 5.6 Factors influencing choice of transport for domestic trips...................... 112

Figure 5.7 Factors influencing choice of transport for international trips .................. 113

Figure 5.8 Two most important factors influencing accommodation choice............... 114

Figure 5.9 Observation of climate change in people's home environments ............... 115

Figure 5.10 Changes to the environment observed by the respondents....................... 116

Figure 5.11 Perceived likelihood that climate change will have a negative impact on daily life in NZ within the next 20 years ............................................................ 121

Figure 5.12 Consumption of ecolabeled products on two most recent trips ............... 123

Figure 5.13 Types of ecolabeled tourism products purchased by the respondents ...... 124

Figure 5.14 Level of education among respondents who were aware of carbon offsetting

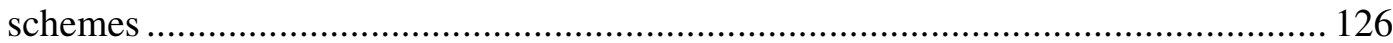

Figure 5.15 Willingness to pay for carbon offsetting .......................................... 134

Figure 5.16 Belief in carbon offsetting across age groups .................................... 135

Figure 6.1 Distance travelled on reported holidays ............................................. 138

Figure 6.2 Groups of respondents according to distance travelled........................... 139

Figure 6.3 Transport modes used related to distance travelled ................................ 140

Figure 6.4 Impact in terms of $\mathrm{kgs}$ of $\mathrm{CO}_{2}$-E emissions produced by trips across sample 
Figure 6.5 When I am home I behave environmentally responsible

Figure 6.7 Confidence intervals showing differences in holiday behaviours among groups

Figure 6.8 When I am on holiday, I tend not to worry as much about the environment as

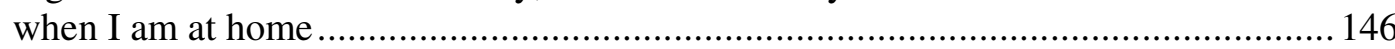

Figure 6.9 Relaxing more when at holiday than when at home ............................... 147

Figure 6.10 It is difficult to know how to act environmentally responsible when travelling on holiday

Figure 6.11 Difficulty of knowing how to behave environmentally responsible when travelling on holiday

Figure 6.12 It is important to me to make sure that my travels are as environmentally sustainable as possible

Figure 6.13 Importance of limiting own negative impact on the environment ............ 153

Figure 6.14 The impact of my travelling on the environment is insignificant ............. 154

Figure 6.15 Tourism in New Zealand does not contribute to global climate change ... 156 Figure 6.16 Tourism within New Zealand does not contribute to global climate change

Figure 6.17 Belief that tourism contributes to climate change across various age groups

Figure 6.18 It makes little difference buying environmentally friendly tourism products

Figure 6.19 It makes little difference buying environmentally friendly tourism products

- Effect of annual household income

Figure 6.20 Effectiveness of buying environmentally friendly products.

Figure 6.21 Preferred policy measures

Figure 6.22 Preferred policy options compared with perceived likelihood that climate

change will have a direct impact on people's lives

Figure 6.23 Who should take the main responsibility for mitigation of the negative impacts that tourism has on the environment? 


\section{List of Tables}

Table 2.1 Review of literature concerning climate change and tourism...................... 31

Table 3.1 Overview of income data collected from Brooklyn respondents................... 67

Table 3.2 Overview of education data collected from Brooklyn respondents ............... 67

Table 3.3 Overview of age data collected from Brooklyn respondents........................67

Table 3.4 Overview of income data collected from Churton Park residents ...................68 68

Table 3.5 Overview of education data collected from Churton Park residents...............68 68

Table 3.6 Overview of age data collected from Churton Park residents .......................68 68

Table 3.7 Overview of income data collected from Karaka Bays residents ..................69

Table 3.8 Overview of education data collected from Karaka Bays residents ..............69

Table 3.9 Overview of age data collected from Karaka Bays residents ...................... 70

Table 3.10 Overview of income data collected from Lyall Bay residents.................... 70

Table 3.11 Overview of education data collected from Lyall Bay residents ................ 71

Table 3.12 Overview of age data collected from Lyall Bay residents........................ 71

Table 3.13 Overview of income data collected from Mt Cook residents ...................... 71

Table 3.14 Overview of education data collected from Mt Cook residents................... 72

Table 3.15 Overview of age data collected from Mt Cook residents ........................... 72

Table 3.16 Overview of income data collected from Northland residents .................... 73

Table 3.17 Overview of education data collected from Northland residents................. 73

Table 3.18 Overview of age data collected from Northland residents ......................... 73

Table 3.19 Overview of income data collected from Rongotai residents..................... 74

Table 3.20 Overview of education data collected from Rongotai residents ................. 74

Table 3.21 Overview of age data collected from Rongotai residents .......................... 74

Table 3.22 Overview of income data collected from Tawa residents ........................ 75

Table 3.23 Overview of education data collected from Tawa residents....................... 75

Table 3.24 Overview of age data collected from Tawa residents .............................. 76

Table 4.1 Adults and children in the sample households............................................ 90

Table 4.2 Impact made by various transport modes .................................................. 99

Table 4.3 Impact made by various accommodation types ........................................ 101

Table 4.4 Accommodation types used on holidays across sample............................. 101

Table 4.5 Trip duration of holidays in relation to distance travelled.......................... 104

Table 5.1 Factors influencing choice of holiday destination .................................... 107

Table 5.2 Change in travel and decision making after observing effects of climate

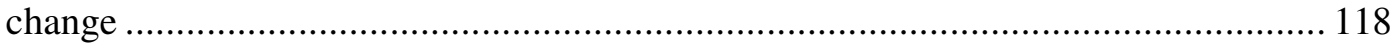

Table 5.3 Respondents' descriptions of ecolabels ............................................... 124

Table 5.4 Names of carbon offsetting schemes mentioned..................................... 127

Table 5.5 Reasons for participating or not participating in carbon offsetting ............ 128

Table $6.1 \%$ share of $\mathrm{kgs}$ of $\mathrm{CO}_{2}-\mathrm{E}$ emissions made by transport modes domestically 142

Table 6.2 Reported holiday behaviour versus home behaviour .............................. 144

Table 6.3 It is difficult to know how to act environmentally responsibly when on

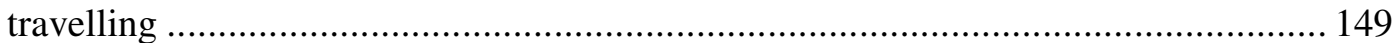

Table 6.4 Actions taken to behave environmentally responsible when holidaying ..... 150

Table 6.5 It makes little difference buying environmentally friendly tourism products

Table 7.1 Objectives of study and main findings ........................................... 171 



\section{Chapter 1 Introduction}

\subsection{Introduction}

Climate change is the general term associated with a range of demonstrable changes in global and regional climatic conditions, including temperature, sea levels, precipitation, and extreme weather events such as droughts, flooding, and storms (IPCC, 2001). There is now little doubt that human activity contributes to climate change (IPCC, 2007). The major human contributions to climate change are made by emissions of greenhouse gases (GHGs) through fossil fuel use, agriculture and land use change (IPCC, 2007). Based on the current emissions made by industrial processes in the world, several scenarios for temperature increase have been developed by the IPCC. Taking these scenarios and the emissions of all the world's nations into account, it has been decided by the UNFCCC in Copenhagen last year that limiting temperature increase to $2^{\circ} \mathrm{C}$ is the most achievable scenario that we can currently aim for (COP15, 2009). To achieve this goal, a significant initiative by the world's governments in terms of reducing emissions of greenhouse gases from energy production, deforestation, transportation and other processes which contribute to climate change is needed. Even this increase in $2^{\circ} \mathrm{C}$ will have a large impact on the climate, and the full repercussions are not yet known. There are however projections which show a number of changes, including an increase in global temperature, change in sea temperature causing sea level rise and increase in storm intensity, and other changes in hydrological patterns which may be devastating to many regions of the World (IPCC, 2007).

Stern (2006) states that climate change will have a profound effect on world economics, and that a delay in addressing the projected problems caused by climate change would lead to great economic loss: although acting now may incur a major economic cost, acting later will be far more costly. As tourism is an economic sector which is to a large degree dependent on the climate, it is evident that climate change will have profound effects on the tourism industry worldwide; both in terms of supply and demand (Fischer, 2007). At current, tourism is responsible for considerable fossil fuel use as transport companies, accommodation establishments, attractions and activity providers are all to a greater or lesser extent dependent on fossil fuels to run their operations, either directly through fuel use or indirectly through energy use. Due to this dependency, GHG emissions attributable to tourism are currently in the range of $4-6 \%$ of total global emissions, and rising (Gössling et al., 2008). At the same time, international tourism arrivals reached 922 million in 2008, a growth of 2\% compared with 2007. This number is forecast to reach 1.6 billion by 2020 (UNWTO, 2009). The current growth rate 
in tourism consumption cannot continue, as a continued rise in GHG emissions would jeopardise the future of the planet (IPCC, 2007).

Considering the severity of climate change and the growth projections in tourism worldwide, it is important to investigate people's behaviours and their willingness to change these for the sake of the environment. It has been argued that the only way of limiting future negative effects of tourism on the global natural environment, is to change current patterns of behaviour, as people travel ever more often and to destinations increasingly further away (Burns \& Bibbings, 2009). This could be linked to lack of awareness of the relationship between tourism and its impact on the environment: Gössling et al. (2006) discovered that tourists often do not see the link between travel and the impact on the global natural environment in terms of emissions of GHGs. Perceptions of negative impacts of tourism among the respondents in their research were focussed on the localised effects on the host destination that they were visiting. Similarly, Becken (2007) found low levels of awareness of environmental impact made by air travel among visitors to New Zealand. It should be noted that both studies were conducted among visitors who already have arrived at a destination, and are as such limited in their methodology as they focus on people who display adverse behaviours. At the time of writing, most of the research that has been done on awareness of the relationship between tourism and the environment has focussed on visitors, and therefore knowledge about people's perception of the relationship between tourism and climate change is limited.

Various aspects of concern for the environment and tourism have been investigated previously, (Dolcinar \& Leisch, 2008; Gonzalez Lopez \& Cuervo-Arango, 2008; Becken, 2007; Schultz et al., 2005; Wearing et al., 2002; Lübbert, 2001; Kaizer \& Shimoda, 1999). Gonzalez Lopez \& Cuervo-Arango (2008) examined environmental values, beliefs and norms in relation to ecological behaviours. They found that intended behaviours were affected by these psychological constructs. Although this study established a connection between concern for the environment and ecological behaviours, there is still doubt whether intended behaviours constitute a useful measurement for predicting actual behaviour. Schultz et al. (2005) found that there is a link between values and their relationship to environmental concern and reported conservation behaviour. Similarly, Kaizer \& Shimoda (1999) examined 'responsibility' as a predictor of ecological behaviour, and found a link between behaviours and feelings of moral responsibility. All of these three studies came to the same conclusions; based upon respondent's values and beliefs compared with either intended behaviour or respondents' ratings of own behaviours on a Likert scale which indicated how often the participated in certain behaviours, they concluded that there is a link between concern for the environment and behaviours. This 
may however not be the case when it comes to actual behaviours. As will be discussed next, research has found that there is a gap between concern for the environment and actual behaviours.

Dolcinar \& Leisch (2008) conducted a study on the relationship between moral obligation and environmental behaviour at home and when on holiday. Their aim was to identify segments for targeting environmental education, however found that such segments were not easily defined and that people have differing levels of obligation to protect the environment. It was also found that people seemed to relax their routines of behaving in an environmentally friendly manner when on holiday, which is an interesting finding when put into the context of the three studies mentioned above.

Becken (2007) explored the relationship between air travel and awareness of the global impacts of air travel on the environment among visitors to New Zealand, and the results from this work show that people value the freedom to travel highly and are therefore willing to sacrifice their concern for the environment in exchange for travelling on holiday, which corresponds well with the findings of Dolcinar \& Leisch, (2008), which showed that people relax their routines when on holiday. As such, a gap exists between concern for the environment and actual behaviours, which has been addressed in the literature (Stoll-Kleemann et al., 2001; Becken, 2007, Dolcinar $\&$ Leisch, 2008). Whether aware of the effects of travelling or not, people still seemingly choose to travel as far and as often as they wish to; other priorities are perceived to be more important than to protect the environment when wanting to take a holiday (Becken, 2007). The findings of these studies contradict the findings from the studies mentioned above, as they clearly show that people do not act in the best interest of the environment even if they are aware that tourism has negative effects on the global natural environment. More research is needed to explore the reason for this gap, but mostly to find solutions for reducing the negative impacts of tourism on the global natural environment when considering this gap.

Hares et al. (in press) and Barr et al. (in press) have contributed to the knowledge concerning the above mentioned fields of research; however, at the time of writing their studies were still in press and not officially published. These two studies were only made available online after the data collection for this thesis was completed, and as such the rationale for this thesis was driven by other factors as outlined above. The findings by these authors are however relevant to this research, and will therefore be referred to in the literature review and in the analysis. 
The body of research as mentioned above has grown much in the last five years, which shows that concern for the environment is becoming an important field of research. This is likely due to the increased focus on the effects of tourism on the global natural environment. As businesses have become more aware of people's concern for the environment, tourism ecolabels and carbon offsetting schemes have emerged. These additions to the tourism product mix have allowed people who are concerned about the impact of their holidays on the environment to adjust their consumption habits to lessen their impact. However, some challenges in regards to increasing consumption have been identified, as will be discussed next.

Tourism ecolabels have existed for approximately two decades (Buckley, 2001). Research has established that consumers are largely unaware of tourism ecolabels (Fairweather et al., 2005; Schott, 2006). Some people are also sceptical as to the positive impact that purchasing such products has, and there is much confusion about tourism ecolabels due to the multitude of various labels that have come and gone (Buckley, 2001). In the years since 2005, limited research has been done regarding consumer awareness and attitudes towards tourism ecolabels. Similar to tourism ecolabels, carbon offsetting schemes are relatively new and have been made available to the public in the last ten years (Gössling et al., 2007). Carbon offsetting schemes are also facing some challenges in terms of widespread understanding and acceptance. Very little research has been done in relation to consumer awareness and attitudes towards carbon offsetting schemes. Becken (2004) explored the perceptions of tourism experts regarding tree planting initiatives, and found that knowledge of carbon offsetting was very limited, and opinions differed widely. However, there is a distinct lack of research conducted on people's perceptions of carbon offsetting schemes. In order to assess whether this practise has support among the general population, more research is needed to inform further development of such schemes, and assess their usefulness as a tool for reducing the negative impacts of tourism on the environment.

Lübbert (2001) explored the importance of environmental factors in the holiday decision making process among tourists in Germany. She found that environmental protection was mentioned by very few of the respondents as an important factor. To this date, few other studies have focussed on the relationship between concern for the environment and holiday decision making. There is very limited knowledge about the influence of environmental protection on decisions about holiday destination, transport mode and accommodation choice.

This study has been developed based on the gaps in the current knowledge in the fields of research introduced above. The purpose is to close these gaps by taking the following steps: 
Firstly, recent holiday behaviours among Wellington residents will be accounted for, including participation in leisure travel, destinations visited and distances travelled, transport and accommodation used. This will establish the estimated impact of transport to and from the main destination on the two most recent holidays taken by the respondents. Also, factors influencing choice of destination, transportation and accommodation will be explored in relation to concern for the environment. Secondly, the study will assess people's perceptions of the urgency of the problems posed by climate change, as this will affect people's inclination to act environmentally responsibly (Lorenzoni et al., 2007). Thirdly, people's frequency of participation in carbon offsetting schemes and purchase of ecolabeled tourism products will contribute to the knowledge about consumer awareness and attitudes towards tourism ecolabels and carbon offsetting schemes. It will then explore people's level of concern for the global natural environment, and whether concern can be seen in different patterns of tourist behaviours. Comparing recent behaviours (as opposed to intended behaviour) with the reported opinions of the respondents will contribute to furthering our knowledge of the influence of concern for the environment on tourism behaviour, in terms of participation in leisure travel, distances travelled and types of tourism products consumed. Lastly, preferred policy options will be investigated, and evaluated against actual behaviours to provide advice to policy makers on which policies that are needed to change adverse behaviours.

These objectives are expounded in full in Section 1.4 below. To achieve these objectives, a mail survey questionnaire was distributed to a selection of households in Wellington City that captured information on past behaviours in terms of tourism consumption, residents' perceptions and opinions about tourism and climate change, and demographic information. 318 people returned questionnaires, however 10 of these were incomplete and could not be used.

This chapter will provide the context of the study, including the current knowledge about climate change and the contribution of tourism to climate change. The selection of Wellington City will be explained, before the hypotheses made and the main objectives are introduced. Finally, a structure of the thesis will be presented.

\subsection{Climate change and tourism}

The two most recent assessment reports of the Intergovernmental Panel on Climate Change (IPCC) (the third and fourth assessment reports, published in 2001 and 2007 respectively) have highlighted the importance of addressing the issue of climate change before it is too late. The fourth assessment report increased knowledge about the wider effects of climate change, and is 
the reference frame that most climate researchers use. "The Fourth Assessment Report (AR4) was released in 2007, and it consists of four volumes: the three IPCC Working Groups (WGs) Reports and a Synthesis Report (SYR)" (IPCC, 2007). According to the AR4, we must expect changes in our future climate: a further warming of about $0.1^{\circ} \mathrm{C}$ per decade would be expected even if the concentration of all GHGs and aerosols had been kept constant at year 2000 levels (IPCC, 2007). As previously mentioned, the UN has stated that the aim for the governments of the world is to keep temperature rise at a maximum of $2^{\circ} \mathrm{C}$. Even at such a seemingly small change in temperature, the scenarios based on this temperature rise show that this change will have large repercussions for many regions in the world. The following section will briefly outline the major changes in climate and natural systems which are projected in the fourth assessment report published in 2007 to emphasise the magnitude of changes that are expected as, these will have profound effects on tourism worldwide.

\subsubsection{Major future changes to the global climate, as projected in the fourth assessment report (AR4) by the IPCC in 2007}

A rise in global average temperature will have a quite large effect on climate systems in the world. More frequent occurrences of heat waves are projected. The areas that are projected to have the highest rise in temperature are the land areas at high northern latitudes. However, even a small rise in temperature in regions close to the Equator will dramatically increase temperature extremes in this area. Temperatures are also expected to increase in Australia, which is the most popular international destination for New Zealanders.

Another effect of temperature rise is a rise in ocean temperature. The most serious knock-on effect of this is a rise in the global sea level. In the AR4, global sea level is projected to rise as much as $0.8 \mathrm{~m}$ by the year 2300 as a result of thermal expansion alone due to the rise in sea temperature. However, melting of glaciers and ice caps also contribute to sea level rise. The projected changes for the $21^{\text {st }}$ century are between $0.18 \mathrm{~m}$ and $0.59 \mathrm{~m}$. An increase in sea level will have a wide variety of effects worldwide. Low altitude areas will be threatened by flooding. The most striking illustration of the potential effects of sea level rise is the Maldives in the Indian Ocean, which will be submerged if the sea level rises by just one metre. Also, sea level rise leads to coastal erosion, and may threaten marine ecosystems. In addition to a rise in sea level, a warming of the ocean would lead to more powerful hurricanes.

Although temperature rise in itself presents several problems as outlined above, changing patterns of precipitation will escalate the problems that some areas of the world are faced with. 
In the warmer regions of the world, an increase in temperature coupled with less precipitation will lead to more frequent and serious droughts. This will further threaten water resources upon which life depends, and lead to more frequent wild fires.

This very brief outline of the major changes in climate makes it clear that tourism will be affected in the future. The effects of climate change on tourism will be further discussed in Chapter two, as well as changes to the climate in New Zealand.

\subsubsection{Tourism and climate change}

The AR4 has also stated that there is little doubt that human activity has contributed to the increase in concentration of GHGs in the atmosphere since the beginning of the industrial revolution in 1750, and GHG emissions due to human activity have grown by $70 \%$ between 1970 and 2004 (IPCC, 2007). In this period of time, the dependence on fossil fuels such as oil and gas has grown rapidly. As the certainty that human activities contribute to climate change has risen, there has been an exponential growth in publications concerning tourism and climate change in the last ten years (Viner, 2007). While much of the earliest writings were focussed on the possible effects of climate change for tourism and challenges that may be faced in terms of adapting to a changing climate, the focus has now shifted to emphasising the importance of mitigating climate change at the same time as accepting that a certain level of change is inevitable.

As has already been established above, tourism is responsible for a large share of total GHG emissions made worldwide. The component of tourism that has the largest share of emissions is transportation of tourists, and it is estimated that transportation is accountable for up to $75 \%$ of the emissions made by the tourism industry worldwide (Gössling, 2008). As societies throughout the world are becoming increasingly affluent, people are expected to travel more often and further than what is currently the case (Yeoman, 2008). This means that the negative impact of tourism on the global natural environment will increase as a result of the increased consumption, given that technological advances in fuel efficiency are not made fast enough to make up for the rate of increase in consumption (Gössling \& Peeters, 2007). In order to lessen the negative impact that tourism has on the global natural environment, a change in current tourism consumption trends is necessary. This change may however be hard to bring about, as people value the freedom to travel highly, and few are willing to make sacrifices when it comes to travelling (Becken, 2007). Preferred policy options will therefore be compared with actual tourism behaviours in this thesis to explore the effectiveness of current policy initiatives. 


\subsection{New Zealand and Wellington City}

New Zealand is located 2000km southwest of Australia's East Coast in the South Pacific Ocean, with a population of approximately 4.2 million people. It is a relatively young nation; the Polynesian Maori reached New Zealand in A. D. 800, and mass immigration from Britain and other parts of Europe started in the mid 1800s (CIA, 2010). The major ethnic groups according to the 2006 census included Europeans (67.6\%) and Maori (14.6\%) (Statistics New Zealand, 2009a). $87 \%$ of the population live in urban areas (CIA, 2010).

Wellington City is located far south on the North Island, with a population of approximately 180000 people (Statistics New Zealand, 2009b). It is the capital city of New Zealand, and home to most major government sectors. Wellington was chosen for several reasons; however, the most important reason was convenience. The researcher lives and studies in Wellington, and given that no city in New Zealand was deemed more appropriate for the type of research which was carried out, there was no reason to exclude Wellington as an option. The budget for this study and the time available for finishing was also limited. Consequently the choice of Wellington City was made as the researcher would then be able to carry out the study in due time and within the specified budget.

New Zealanders are eager travellers: In the year ended in September 2009, 1.9 million trips were taken abroad by New Zealanders, and the five most popular destinations were Australia, Fiji, UK, USA, and China (Ministry of Tourism, 2009b). Australia accounted for 940,891 of the international trips, which constitutes ten times the amount of visits made to the second most visited destination. These statistics show that New Zealanders travel abroad frequently, and many also travel to long haul destinations. However, most of the trips taken by New Zealanders are taken domestically. In the year ended December 2009, New Zealanders took 15.1 million domestic trips where they stayed away from home for a minimum of one night, which indicates that on average New Zealanders take more than 3 domestic trips per year (Ministry of Tourism, 2009c).

New Zealanders travel for a variety of reasons. The three most common reasons include holidaying, visiting friends and relatives (VFR), and business travel. In the year ended November 2007, the most common purpose of travel internationally included holidaying (42.3\%), VFR (31.4\%) and business travel (14.6\%) (Ministry of Tourism, 2009b). Domestic travel have similar figures; the most common purpose of travel in the year ended November 2008 included holidaying (40.4\%), followed by VFR (32.6\%) and business travel $(21.1 \%)$ 
(Ministry of Tourism, 2009c). For the sake of this research, business travel has been excluded due to the nature of such travel (often the travellers do not choose accommodation and transport when travelling for business purposes and they have limited time for visiting attractions at their destination due to work commitments).

Overseas travel from New Zealand incurs a substantial amount of $\mathrm{CO}_{2}$ equivalent $\left(\mathrm{CO}_{2}-\mathrm{E}\right)$ emissions, as there are few options of transport modes to choose from when wanting to go abroad. " $\mathrm{CO}_{2}$-E emission is the amount of $\mathrm{CO}_{2}$ emission that would cause the same timeintegrated radiative forcing, over a given time horizon, as an emitted amount of a long-lived GHGs or a mixture of greenhouse gases" (IPCC, 2007, p.36). When wanting to travel abroad, the main choices available for most people who do not own a private boat include aeroplane or cruise travel, both of which are associated with high $\mathrm{CO}_{2}$-E emissions. In most cases air travel is the only choice. It is therefore necessary to reduce the amount of travel to and from New Zealand to lessen the negative impact of tourism on the global natural environment.

\subsection{Research objectives and hypotheses}

As mentioned above, New Zealand is an island nation, and as such the situation for people wanting to travel abroad is unique; if they truly want to lessen their impact on the global natural environment they cannot travel abroad. This has implications for tourism behaviours and environmental concern. The main objective of this study is to find out whether perceptions of climate change and environmental concern has any influence on the holiday behaviours of Wellington residents. Taking recent holiday behaviour into account, it has the following objectives:

1. Explore whether Wellington residents consider the impacts that their travelling has upon the global natural environment when choosing whether to participate in tourism, and when choosing their destination, transport mode and accommodation.

2. Explore Wellington residents' perception of the significance of impact that climate change will have on their lives, and the extent to which behaviour is influenced by the perceived time frame under which these impacts will come about.

3. Establish whether Wellington residents behave in an environmentally friendly manner when on holiday, by accounting for their actions and their propensity to consume environmentally friendly tourism products and/or participate in carbon offsetting schemes. 
4. Explore respondents' opinions about their own impacts and actual impacts made on the last two holidays, and whether they think that climate change and tourism are related.

5. Identify the measures needed to change adverse tourism behaviours that are considered acceptable by the respondents, and make recommendations to policy makers.

The objectives act as drivers for the study, and the structure of the thesis follows these objectives. Based on the objectives and the literature which has been reviewed, the following hypotheses have been developed:

H1: Given that New Zealanders have few other options for travelling abroad than to travel by air plane, it is likely that concern for the environment does not influence the choices made in regards to participation in international leisure travel and choice of destination, transport or accommodation.

H2: If people think that climate change will have a direct affect on their lives, they are more likely to behave in an environmentally responsible manner by travelling less frequently and over shorter distances.

H3: Concern for the environment has an influence on participation in carbon offsetting schemes and purchase of ecolabeled tourism products

H4: People will not want to be restricted in their travel choices, and will therefore prefer voluntary policy options to regulatory policy options.

The findings in Chapter seven, where these hypotheses will be readdressed, will serve to accept or reject these hypotheses.

\subsection{Contribution}

New Zealand is in a unique situation, as its geographical location does not allow for low impact travel to international destinations. As such, this study will provide valuable information about the travel behaviours and choices of New Zealanders, who have to carefully consider the emissions made on their journeys if wanting to reduce their negative impact on the global natural environment in relation to holidaying. Parallels can be drawn to other island nations and 
isolated locations around the globe, such as the Pacific islands, Iceland and island nations in the Indian Ocean.

There is limited knowledge about people's awareness of tourism and its relation to climate change. As well as investigating levels of awareness, this study will test this knowledge against actual holiday behaviours in order to explore the influence of concern for the environment on tourist behaviours. By comparing actual behaviours, the research will contribute additional knowledge to the research that has been conducted where intended or likely behaviours have been used as a measure (Becken, 2004; Gonzalez Lopez \& Cuervo-Arango, 2008; Kaiser \& Shimoda, 1999).

There is limited knowledge about the influence of environmental concern on the choice processes that people go through when deciding on holiday destinations and components of the trip such as accommodation and transportation. Taking the results from research that has investigated the most important factors that influence such choices (Lübbert, 2001; Bigano et al., 2006; Amelung et al., 2007), this study will focus on the role of environmental concern compared to other factors when going on holiday. This will highlight the importance that people put on protecting the environment when travelling on holiday, with a particular focus on climate change.

Most of the research that has been conducted within this field has been concerned with visitors to a destination (Becken, 2007; Gössling, 2006). This study aims to increase knowledge about a broader segment of people, by adopting a methodology which encompasses household surveys, allowing for a wide spectre of behaviours and opinions to be captured. While visitor surveys add valuable information to the literature, the choices of these respondents have already been made, and certain types of behaviours cannot be captured as a result of the methodology. This study aims to capture all types of behaviours, including non-travellers and people who choose to travel domestically rather than internationally.

Another such type of behaviour which will be explored further is the frequency of participation in carbon offsetting. Carbon offsetting has been available for approximately a decade, although the growth in the amount of organisations that offer voluntary carbon offsetting schemes only started to accelerate in the early 2000s (Gössling et al., 2007). To this date, few studies have focussed on the public opinion about carbon offsetting as a practice which serves to neutralise people's carbon emissions in order to protect the environment. This study contributes to our 
understanding of the general public's awareness of and participation in carbon offsetting, and the barriers for their adopting this practice.

\subsection{Structure of thesis}

This chapter has provided an introduction by outlining the current knowledge about climate change and its relationship with tourism, and by outlining the contribution of the thesis to existing literature. Wellington City was introduced as the study site selected for the research. The hypotheses which were derived from an extensive literature review were introduced, and the main objectives of this study were stated. The objectives of the study will guide the organisation of the findings and the concluding chapter.

Chapter two will provide a review of the related literature to date. The main bodies of literature will be reviewed in sequence of importance, including climate change and its relationship with tourism, concern for the environment and behaviour, holiday destination choice and ecolabels and carbon offsetting. The review of the literature identifies gaps in current knowledge which this thesis is aiming to fill.

Chapter three describes the process of developing the methodology for this study and how it was carried out. A quantitative approach is favoured due to the nature of the information that was needed to fill the gaps identified in the literature review. The questionnaire which was developed for conducting a household survey is outlined and the justification for the chosen study site and sampling technique is provided. The data collection, preparation and analyses used are accounted for, and the strengths and limitations of the methodology are acknowledged.

Chapters four, five and six will present the findings from the survey that was conducted. Chapter four presents the trip characteristics from the two most recent holidays reported on by the respondents. Participation in leisure travel is also investigated in this chapter. Chapter five focuses on the first three objectives, and starts by exploring the role of concern for the environment when choosing a holiday destination, transportation and accommodation. It further investigates observation of climate change to assess the sense of urgency of dealing with this problem and get an overview of people's perception of the affect of climate change on daily life in New Zealand. Lastly, it explores environmentally friendly behaviours in terms of carbon offsetting and purchase of ecolabeled tourism products. 
Chapter six focuses on objectives four and five, and explores the actual behaviours and opinions as recorded by the respondents in relation to concern for the environment, to establish whether concern for the environment does influence behaviours. Concern for the environment was established through multiple variables in Chapter five and six. The chapter begins with calculating impacts in terms of $\mathrm{CO}_{2}-\mathrm{E}$ Emissions generated by transport to and from the main destination, and moves on to explore people's opinions about their own impacts and tourism's contribution to climate change. It then explores respondent's observations of climate change and effect of these on behaviour, and concludes by investigating the link between actual impacts and concern for the environment. This chapter includes deeper analyses of the variables by statistically testing the variables against various demographic segments and behaviours displayed in order to draw out relationships and to increase knowledge about factors which influence opinions and behaviours.

Chapter seven will discuss and draw conclusions from the findings, and put these into the context of other research. The hypotheses and aims will be readdressed, and the main findings will be related to the aims of the study. Implications that arise from the findings will be accounted for, and recommendations will be made for future research and for policy makers. 


\section{Chapter 2. Literature Review}

\subsection{Introduction}

Even though climate change has been a concern for well over thirty years, little research has been undertaken in the area of tourism with respect to climate change. In the last few years, there have been changes in the perception of climate change, and an increasing awareness of the importance of addressing the problems that the world may face as a result of climate change (Becken \& Hay, 2007). The climate change and tourism themed workshop in Milan founded by the European Science Foundation, and the Inaugural Conference on Climate Change held in Djerba, Tunisia by the World Tourism Organisation emphasised the importance of researching the relationship between tourism and climate change, and following these two events the body of research has been increasing rapidly (Viner, 2007).

Early work focussed on the possible effects of climate change on tourism, and recognised that climate change would have an effect on the resources on which people depend for tourism activities, which in turn would necessitate adaptation to these changes by the tourism industry (Wall et al., 1986; Smith, 1990). In recent years, focus has shifted and research is now more concerned with the effects that tourism has on the environment and mitigation of climate change. Most researchers agree that the tourism industry needs to react to the challenges by combining measures for mitigation and adaptation to a changing climate (Becken, 2005). The volume of research conducted on the topic of climate change and tourism has increased greatly in the last couple of years, and several new areas of discussions have emerged, such as the discussion on concern for the environment, carbon offsetting and awareness and consumption of ecolabeled tourism products.

In order to inform this research about the relationship between climate change, concern for the environment and tourism behaviour, several themes within the literature have been reviewed to contextualise the study. The areas related to this study are listed in Table 2.1 on next page. Firstly, the current knowledge about climate change was reviewed to inform the researcher of problems related to climate change and global tourism's contribution to climate change. It became clear that tourism has a profound effect on the global natural environment, particularly in regards to the vast amounts of GHGs which are emitted through tourism activities. The review led to the formulation of objectives 1 and 2, concerning people's actual holiday behaviours and perceptions of urgency to deal with climate change. Secondly, literature 
regarding adaptation to climate change was reviewed to inform the researcher about possible changes in demand and supply that may occur as a result of a changing climate. Adaptation and mitigation have been seen as polar opposites, and the debate has been one of economic gain versus climate change (Patterson et al., 2006). Lately it has become clear that it is most likely that changes to the climate will occur even if mitigation efforts were to be maximised: according to the IPCC, a warming of less than $1^{\circ} \mathrm{C}$ is inevitable at the current levels of atmospheric greenhouse gases (IPCC,2007). Thus, an integrated approach to dealing with climate change is needed.

\section{Table 2.1 Review of literature concerning climate change and tourism}

\begin{tabular}{|l|l|}
\hline 2.2 Context & $\begin{array}{l}\text { Current knowledge about climate change, climate change in New } \\
\text { Zealand }\end{array}$ \\
\hline $\begin{array}{l}\text { 2.3 Tourism as a } \\
\text { contributor to climate } \\
\text { change }\end{array}$ & $\begin{array}{l}\text { Negative impacts caused by activities associated with tourism } \\
\text { activities, such as transport emissions, energy use by } \\
\text { accommodation and activities etc. }\end{array}$ \\
\hline $\begin{array}{l}\text { 2.4 The impact of climate } \\
\text { change on tourism, } \\
\text { adaptation and mitigation }\end{array}$ & $\begin{array}{l}\text { Changes in tourism consumption patterns as a result of climate } \\
\text { change. Adaptation and mitigation is traditionally seen as two polar } \\
\text { opposites, but now researchers are realising that the response } \\
\text { from the tourism industry needs to integrate both }\end{array}$ \\
\hline $\begin{array}{l}\text { 2.5 Concern for the } \\
\text { environment and tourism } \\
\text { behaviour }\end{array}$ & $\begin{array}{l}\text { The relationship between concern for the environment, values, } \\
\text { beliefs, norms and actual behaviours. }\end{array}$ \\
\hline $\begin{array}{l}2.6 \text { Environmental } \\
\text { certifications (ecolabels) } \\
\text { and carbon offsetting }\end{array}$ & $\begin{array}{l}\text { Two new categories of products that have emerged as a result of } \\
\text { people's concern for the environment. Awareness and adoption of } \\
\text { these products. }\end{array}$ \\
\hline $\begin{array}{l}\text { 2.7 Policy environment } \\
\text { Current policies that exist to deal with the problems that climate } \\
\text { change poses, and their effectiveness }\end{array}$ \\
\hline
\end{tabular}

Thirdly, literature regarding concern for the environment was reviewed to inform the researcher about the relationship between values, norms, beliefs and actual behaviours. The review of this literature led to the formulation of objective 3, which aims to explore the extent to which people display environmentally friendly behaviours in relation to tourism and travelling. Based on the literature reviewed concerning actual impacts of tourism on the global natural environment and literature relating to concern for the environment, objective 4 was formulated to explore the link between these two subject matters. Objective 4 aims to explore people's opinions about the impacts that their travelling inflicts on the environment in relation to the actual impacts that they made on their last two holidays. Lastly, literature relating to the current policy environment was reviewed. This led to the formulation of objective 5, which aims to explore the most effective policy options for dealing with the problems that climate change poses. This chapter will provide a systematic review of these themes within the literature by exploring them in consecutive sections. Gaps in the literature which have informed the development of this study will be outlined. 


\subsection{Current knowledge about climate change and its causes}

Climate Change has received an increasing amount of attention in the last decade, and movies such as "An Inconvenient Truth" and the awarding of the Nobel Peace Price to the Intergovernmental Panel on Climate Change and Al Gore in 2007 has made climate change a more accessible topic to the general public. The causes of global warming and climate change have been much debated in the last three decades, and there is still disagreement on the topic. Most researchers however have come to the conclusion that human activities (including tourism) do contribute to climate change, as industrial processes and other activities have increased the concentration of GHGs in the atmosphere since the beginning of the industrial revolution in 1750 (IPCC, 2007); global atmospheric concentrations of $\mathrm{CO}_{2}, \mathrm{CH}_{4}$ and $\mathrm{N}_{2} \mathrm{O}$ have increased markedly as a result of human activities and now far exceed pre-industrial values (IPCC, 2007). This has contributed to a rise in the Earth's surface temperature and the temperature of the sea. Although the full extent of the effects of this increase in temperature is not currently known, a warmer Earth surface temperature may have a series of adverse effects on people's home environments, and the way in which humans live their lives on this planet, including their propensity and ability to travel.

Thousands of researchers worldwide contribute to the body of knowledge regarding the causes and effects of climate change, many of which are united within the leading body for the assessment of climate change, namely The Intergovernmental Panel on Climate Change (IPCC). The IPCC was established in 1988 by the United Nations Environment Programme (UNEP) and the World Meteorological Organization (WMO) to provide the world with a clear scientific view on the current state of climate change and its potential environmental and socio-economic consequences (IPCC, 2009). Researchers contribute to the work of IPCC on a voluntary basis, and because of the large number of professional contributors the quality and accuracy of the work that is compiled by the organisation is significant. Several reports on climate change have been produced by the IPCC, which are some of the most robust sources of knowledge about climate change and human's interaction with the Earth's climate. The latest of these, referred to as the fourth assessment report (AR4), was released in 2007. According to the AR4, the assessed probability that the rise in global temperature is caused by increase in GHG concentrations in the atmosphere attributable to human activities is higher than 90\% (IPCC, 2007). Some scepticism still lingers, but overall there is growing consensus that climate change is strongly linked to human activities. This is also closely linked to tourism: As will be discussed in section 2.3 below, tourism is one of the major sources of carbon emissions, responsible for 4-6\% of current world emissions (Gössling et al., 2008). 
As discussed in Chapter one, climate change will have large effects on climate systems worldwide. These changes will affect tourism flows worldwide, which will be discussed in Section 2.4 below. A rise in global temperature has a series of knock-on effects, which affect several climate systems. Regional projections vary to a large degree, and some world regions will be harder hit than others. The areas which will suffer the most are developing countries, which not only will suffer from increasingly severe climate events, but are also less able to adapt to the changes which will occur (Becken, 2005). The effects of temperature rise which are expected throughout the world were briefly introduced in Section 1.2, and shows an outline of the most relevant changes that to climate that are projected by the IPCC. However, a more detailed account of the impacts of future climate change can be read in the AR4 Synthesis report (IPCC, 2007) which is available to the general public on the internet (the URL is listed in the references under IPCC, 2007). The focus of this research is on domestic and outbound tourism in New Zealand, and as such the local effects of climate change will be investigated more closely.

Although the projected changes for New Zealand are relatively minor, some changes will be noticeable to the residents and may also affect tourism to/from and within the country. In New Zealand, the main body of climate research is the National Institute for Water and Atmospheric Research in New Zealand (NIWA). NIWA has records of New Zealand climate since the 1860s that are readily available to the public through their web pages. The data shows that there is a change in the climate since the 1860s, such as receding glaciers on the South Island, and an increase in temperature. Between the decades 1861 - 70 and 1981 - 90 the average annual temperature increased by $1.1^{\circ} \mathrm{C}$. Data shows that temperatures increased sharply after the $1940 \mathrm{~s}$, but annual mean warming has slowed recently" (NIWA, 2009a). To illustrate how quickly some regional changes have occurred, Figure 2.1 shows the most significant changes in the New Zealand climate over the last 20 years. 


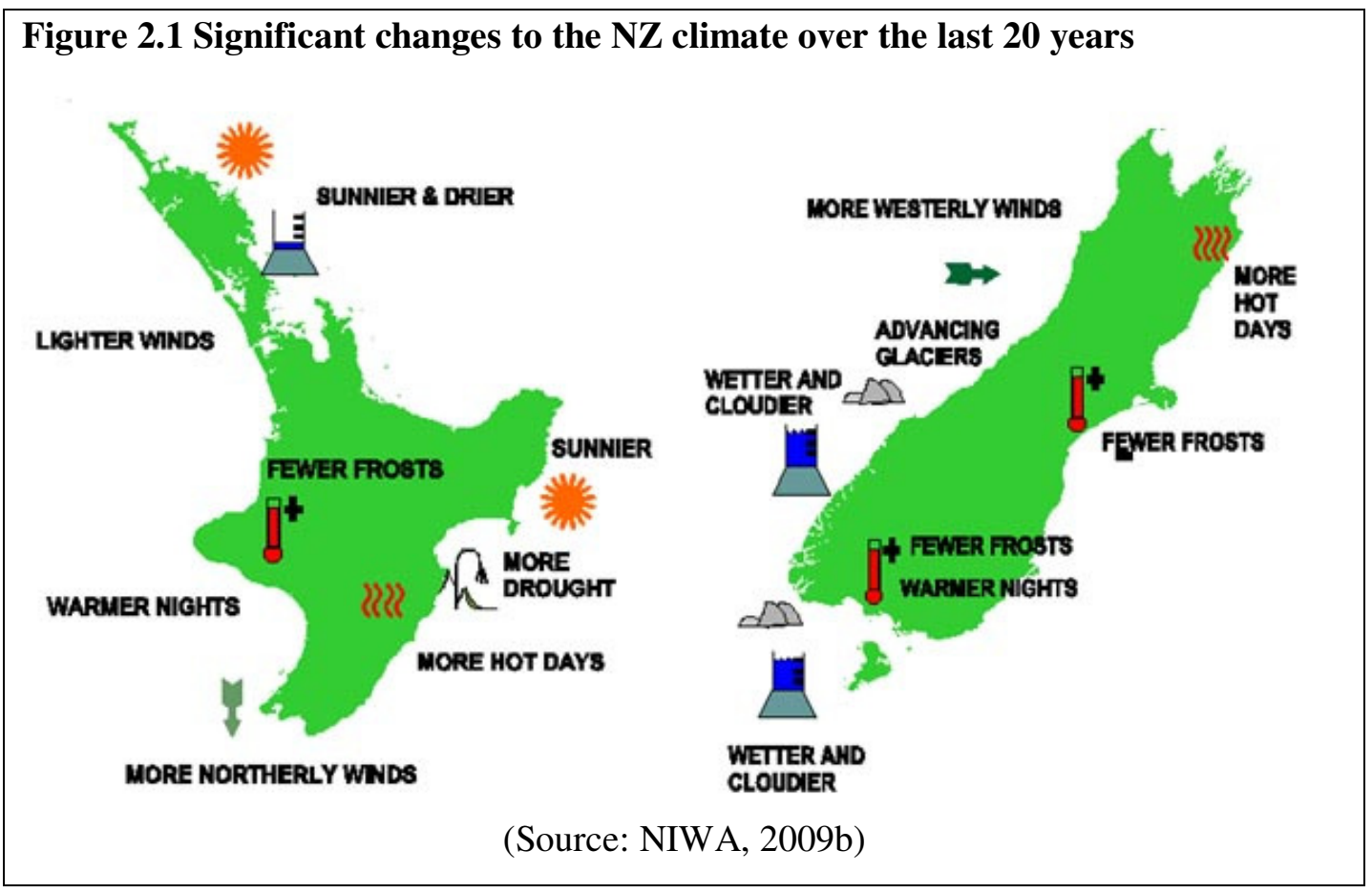

As can be seen in the figure, climate variations differ across various regions in New Zealand. In Wellington, the most noticeable change is the shift in wind direction. While rainfall patterns have changed throughout New Zealand, the Wellington region has only experienced a small increase in precipitation. The average sea level rise has been calculated by means of measurements from four of the main ports (Auckland, Wellington, Lyttelton and Dunedin), and the data shows that average sea level rise for New Zealand has been in the order of $16 \mathrm{~cm}$ over the last 100 years (NIWA, 2009a). Although these changes to date have not had much of an impact on daily life in New Zealand, the changes are visible, and if these trends continue it is likely that they will impact on people's lives to some extent. New Zealand is dependent on nature as a tourism attraction, and changes that may occur to this resource will also have an impact on the tourism sector in the country.

In summation: the world's climate is changing and there is a general agreement that human activities have been a contributor to the changes that we can see now since the industrial revolution. Several changes in climate have been observed to date, as has been outlined above by use of data from NIWA and from the IPCC. Impacts of climate change are diverse, and pose a substantial threat for tourism. In New Zealand the projected changes differ across regions, but in general the expected changes are small; NIWA has downscaled data from the IPCC to New Zealand, which largely shows that the West Coast of New Zealand will become wetter and windier, and the East Coast will become sunnier and dryer (NIWA, 2009a). Although the 
expected changes are small, they may however impact on tourism in terms of encouraging or discouraging people from travelling to certain destinations. The following section will outline the contribution that tourism makes to global climate change in terms of carbon emissions.

\subsection{Tourism as a contributor to climate change}

Tourism contributes to climate change in several ways: by contributing to emissions of GHGs through energy use; by encouraging land use change; and most importantly by contributing to GHG emissions through the burning of fossil fuels in transportation of tourists (Gössling, 2002). Land use change contributes to climate change in the sense that large areas of land are being cleared to facilitate tourism infrastructure development, which changes not only the local ecosystem, but also contributes to deforestation and release of carbon as a result of cultivation of land (Stern, 2006). $\mathrm{CO}_{2}$ emissions attributable to tourism are currently estimated to be $5 \%$ of global emissions, within a range of $4 \%$ to $6 \%$, and transport is estimated to account for $75 \%$ of these emissions (Gössling et al., 2008). People in Westernised societies are becoming increasingly affluent, and the trend shows that as the level of wealth is increasing, people travel more frequently and over larger distances than previously (Yeoman, 2008). This is also evident in the graph shown in Figure 2.2, which was produced by the UNWTO in 2001: Most of the growth in tourism has been in western societies, but a rapid growth is expected from the Asia/Pacific region. As a result, emissions from tourism are projected to grow rapidly as consumption increases. 


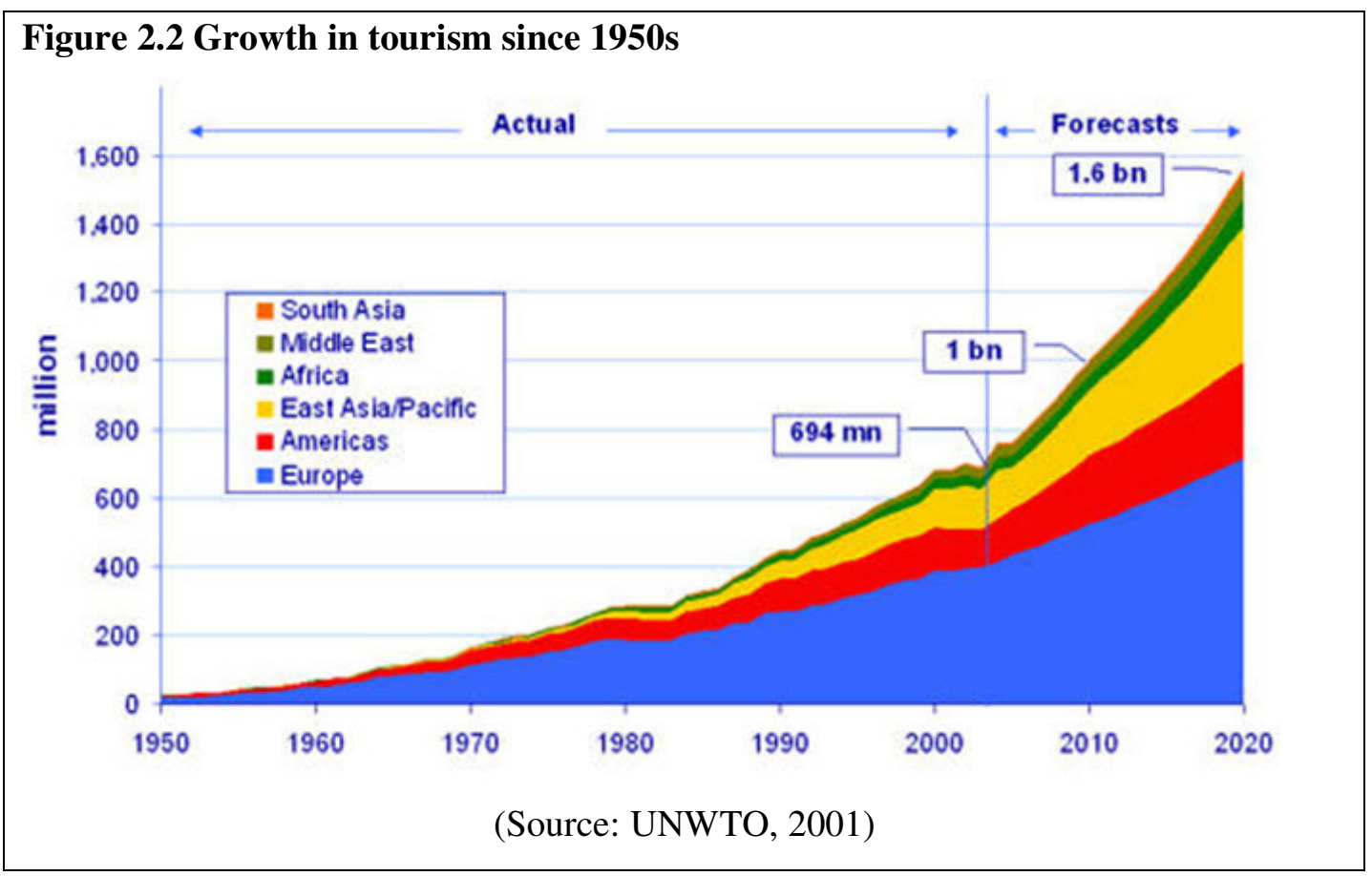

New Zealand is a country from which one cannot travel without emitting a considerable amount of GHGs because of its isolated location. The vast majority of tourists are departing by air (Ministry of Transport, 2009), however a small percentage also departs by sea (Statistics New Zealand, 2009c), the larger share of these travel on cruise ships, but people also make use of private boats. Cruise ships generate larger emissions per person than long haul air travel does (Howitt et al., in press). This means that if wanting to go abroad for a holiday, New Zealanders contribute substantial emissions in relation to travelling to their destination. To illustrate: The closest international airport is Sydney, and a return trip between New Zealand and Sydney causes close to one tonne of $\mathrm{CO}_{2}$-E emissions (CarboNZero, 2009). The total emissions generated by New Zealand residents flying internationally amounted to 3948Gg in the year 2005. This constitutes additional emissions of GHGs in the order of 5\% on top of the current Kyoto-liable emissions produced by New Zealand (Smith and Rodger, 2008).

Not only transport is responsible for the emissions made by New Zealanders who participate in tourism. To compare the emissions generated by the tourism industry to other industries, Becken and Patterson (2006) used data from 1997/1998 to analyse the emissions of the New Zealand tourism sector compared to other sectors of the economy. They found that the tourism industry had emissions of 1438 kilotonnes of $\mathrm{CO}_{2}$ in that year, ranking tourism as $19^{\text {th }}$ worst out of 26 economic sectors. The calculation did however not include international air travel. If the emissions of international air travel had been included in the analysis, it is very likely that the 
tourism industry would achieve a rank much nearer to the bottom compared to the other 25 economic sectors included in the analysis. It can thus be concluded that tourism is a major emitter of $\mathrm{CO}_{2}$ compared to other economic sectors.

Gössling and Hall (2008) further developed the analysis by Becken and Patterson (2006) by including international air travel when calculating the total emissions of the tourism industry in Sweden, with the aim of assessing how big a percentage of the total GHG emissions of Sweden in 2020 that would be attributable to tourism if the current growth within the sector continues. By using bunkered fuel to account for the emissions caused by the tourism industry as a whole, they found that in 2020 the tourism industry alone would account for 16\% of Sweden's GHG emissions, which would cause a considerable challenge in terms of meeting the reduction goals that Sweden has agreed to in the Kyoto protocol. These two analyses are useful for assessing the impacts of tourism within countries, and to emphasise the magnitude of the impacts caused by tourism activity.

Reducing impacts made by tourism is however not an easy task, and there are several issues that have to be faced. One of the problems concerning the reduction of GHG emissions caused by tourism related air travel is that no one is held responsible for the emissions produced by international air travel. As the impacts are rather severe, it is problematic that this type of activity is not included in the Kyoto protocol. In 2005, air transport accounted for $60 \%$ of all transport-related $\mathrm{CO}_{2}$ emissions worldwide, much of which can be attributed to tourism (Gössling et al., 2008). While figures of the actual emissions produced by aviation have been debated, there is agreement that growth rates in the fuel use of the aviation sector are substantial, and in the order of 3\% per year globally, and as high as $4.3 \%$ within the EU25 countries in the period between 1990 and 2003 (Gössling et al., 2007). This shows that transport related to tourism is causing increasingly high emissions of GHGs, and it is necessary to take action to reduce the impacts of tourism transportation on the global natural environment.

While much focus has been on the contribution of transportation to climate change, there has also been research conducted in relation to the energy use of tourist attractions and activities. Becken and Simmons (2001) accounted for the energy use of tourist attractions and activities within New Zealand. There are a wide variety of attractions offered to visitors, and some are more energy-intensive than others. In their study of attractions and activities they found that local operators who offer private air transport as part of the attraction or activity (such as heliskiing or fishing trips with helicopters) account for the largest amount of energy consumed per tourist. They concluded that energy usage of the attractions/activities sector can be reduced by 
restricting extremely energy intensive activities and promoting low energy alternatives such as entertainment attractions, or by improving the energy efficiency of single products. Given that New Zealand is a country which offers many adventure attractions, this would require restrictions on high emitting attractions such as sky diving and heli-skiing and scenic flights. As long as there is still a demand for such attractions, this may prove difficult without putting in place policies (such as extra taxes on high emitting attractions and activities which make these more expensive, and thus more exclusive), to promote attractions with lower energy intensities. Such work could prove fruitful in reducing the emissions from tourism within New Zealand.

Becken et al. (2003) analysed domestic and international tourists' energy use in terms of transport, accommodation and attractions visited/activities undertaken when travelling in New Zealand, and calculated the energy bill of a sample of tourists with the aim of exploring ways of reducing the energy use of visitors. The choices that people make have a large impact on their energy bill. This shows that there is room for improvement when it comes to reducing the energy use of tourists, by influencing the choices that people make in terms of tourism products.

To achieve a reduction in the impact that tourism has on the Earth's climate, a change in the current patterns of behaviour is necessary, both to sustain the future of the tourism industry and the resources on which it depends. The challenge of changing behaviours is however substantial, especially when considering the importance that many people place on travelling. Travelling on holidays is seen by many as a necessity, not only to relax and get a break from daily routine but also to learn about the world. In New Zealand, going abroad on an Overseas Experience (OE) to work and travel for a year or more has become a quite normal practise among young New Zealanders (Wilson et al., 2009). As there are a number of low cost airlines offering very cheap airfares, it is hard to bring about a change in behaviour in terms of reduced frequency of flying (Hares et al., in press). As such, the current situation is that GHG emissions from tourism will continue to rise in the immediate future, and the share of emissions made by tourism in comparison with other economic sectors will continue to grow if the sector is left uncontrolled. However, climate change will impact on current travel flows, and may also have an impact on people's propensity to travel. The future of tourism in a changing climate is uncertain, and a change in the current situation is very likely. The possible impacts of climate change on tourism will be discussed in the following section. 


\subsection{The impact of climate change on tourism}

Climate change will have a profound effect on tourism, both in terms of supply and demand. Richardson (2007) developed a framework for assessing the vulnerability of the tourism sector to climate change, as can be seen in Figure 2.3 on next page. The main focus of this study is on the demand side of domestic and outbound tourism; however demand and supply are closely interrelated. Climate change may have several serious impacts on supply of tourism; including changes in the resources on which tourism depends, and the ability of the tourism industry to adapt to the changes that occur (Becken, 2005).

For the tourism industry in New Zealand, the main risks associated with supply are not as grave as the risks associated with demand. The changes projected to the New Zealand climate as outlined in Section 2.2 are limited, and New Zealand is a wealthy nation which has the means to adapt to the changes that are projected. The main risks for the supply of tourism may be posed by changing policy aimed at reducing national emissions of GHGs: The Emissions Trading Scheme which will include the energy sector in July 2010 will have an effect on prices of energy needed by tourism businesses, which may have no alternative but to pass this cost on to their customers in order to stay in business (TIA, 2009). This increase in price may lead to a change in the current patterns of demand for New Zealand tourism products, and if they become too expensive, people may choose international low cost travel as an alternative to domestic travel when going on holiday. The current policy environment in New Zealand will be further discussed in Section 2.7 below.

Climate change will have a profound impact on tourism demand, mainly in terms of seasonality of tourism and tourism flows (Bigano, et al., 2006). Although predicting changes in demand worldwide may seem like a mammoth task, it should be noted that "The concentration of tourism activity is heavily focussed on relatively few markets and destinations" (Mather et al., 2005). Tourism is a phenomenon that is linked to affluent societies; the majority of tourists come from developed nations, seeking a favourable climate. As New Zealand is an affluent society, and New Zealanders have 4 weeks of statutory holiday per year, this is also the situation for New Zealand. Currently, the most popular international holiday destinations for New Zealanders include Australia, USA, UK and Fiji, however a substantial number of people also travel to other destinations in Asia and Europe (Ministry of Tourism, 2009a). Changes to consumption patterns may occur as a direct or indirect result of climate change. 


\section{Figure 2.3 The vulnerability of tourism to climate change}

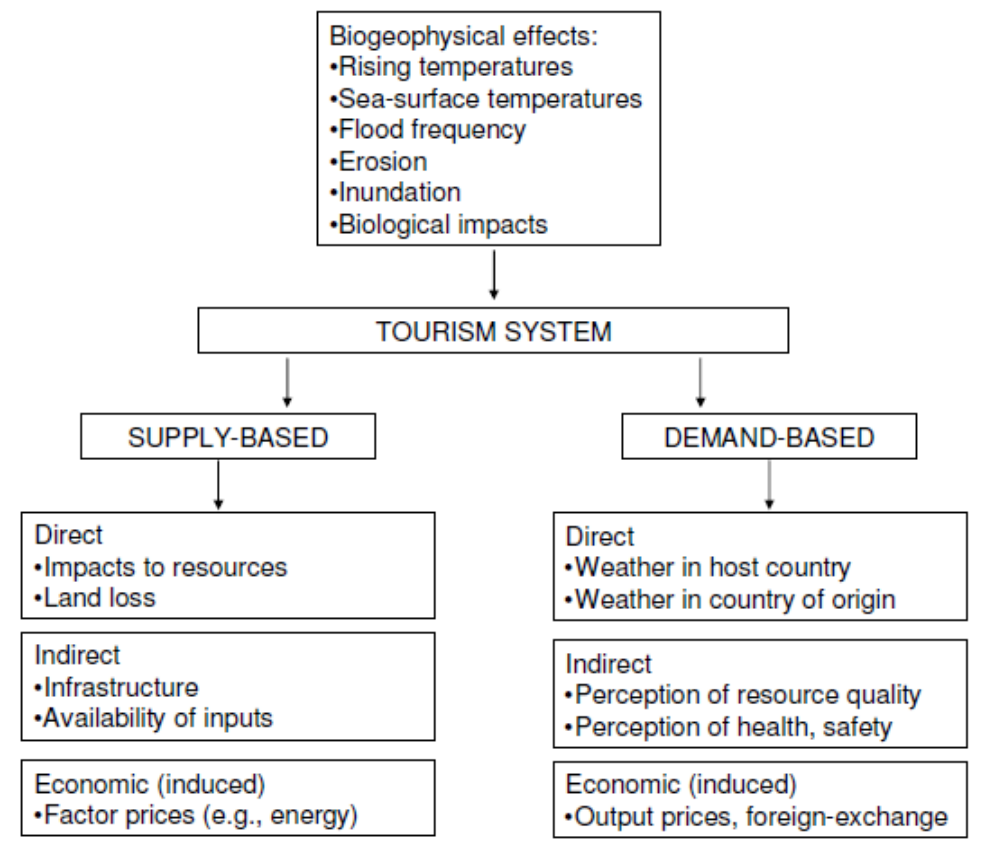

(Source: Richardson, 2007)

As the climate changes, there may be a shift in preferred destinations, and thus major tourism flows may change (Amelung et al., 2007; Gössling \& Hall, 2006; Braun et al., 1999; Giles \& Perry, 1998). It is also noted by several researchers that there are other factors than climate and weather that influence upon an individual's destination choice, making it difficult to single out climate change's impact on flows (Gössling \& Hall, 2006; Bigano et al., 2006). Other factors that have been identified include political stability, disposable income, time, public holidays, coastline, distance from origin etc. It is however assumed that climate change will have some impact on consumer behaviour and destination choice, as the climate both in originating regions and at destinations are important factors that influence holiday behaviour. An example relevant to New Zealand is extreme temperatures that have occurred in Australia in the last couple of years; temperatures of $40^{\circ} \mathrm{C}$ and above have created large problems for people in terms of coping with the heat, spread of diseases, drought and also causing many uncontrollable bush fires (New Zealand Herald, 2009). As most New Zealanders go on holiday during the summer, destinations in Australia that have become too hot are likely to be less attractive destinations during the main school holiday.

Not only changes to the climate themselves have an impact on tourism flows, but also the response to these changes by the tourism industry at the destination. Braun et al. (1999) found 
that any change in climate would lead to less interest in visiting a destination if the response from the tourism industry was non existent or deemed inappropriate. This may affect destinations that are popular with New Zealanders, such as Fiji which is one of the top five destinations for outbound travellers (Ministry of Tourism, 2009a). As noted by Becken (2005) in her research on the tourism industry in Fiji, the industry may not be equipped to deal with changes in the climate, which poses a threat to future visitation for the country if the climate changes dramatically. Lack of response to a hotter and dryer climate with stronger storms as outlined above may cause Fiji to be less popular with New Zealanders. These examples show that changes in climate that does not affect New Zealand directly may affect patterns of outbound travel by New Zealanders. The projected changes in climate as outlined in Figure 2.1 above may also influence domestic patterns of travel.

It can be concluded that climate change will have an effect on tourism supply and demand, both domestically and internationally. Seasonality and flows may change, and it is important for the tourism industry to adapt to these changes by responding in an appropriate manner. This will likely incur a mixture of adaptation and mitigation initiatives. The focus of this research however is on mitigation, which is closely linked to dealing with mass consumption of tourism worldwide. It has been argued by many that the only way to mitigate the negative impacts of tourism on the global natural environment is to reduce consumption of tourism worldwide (Burns \& Bibbings, 2009; Høyer, 2000). However, as long as people do not see the relationship between tourism and climate change, it is doubtful that a change will occur. The next section will discuss the influence of concern for the environment on people's behaviours, and the challenge in changing current holiday behaviours.

\subsection{Concern for the environment and tourism behaviour}

\subsubsection{Role of concern for the environment in holiday destination choice}

Several factors impact on people's choices when deciding where to go on holiday, however, until recently very few researchers have investigated the role of environmental concern in relation to holiday destination choice. The only work known to the author is that of Lübbert (2001), who researched this factor in relation to ecolabel consumption. The factor that has been identified as most influential on people's choices is climate at home and at the destination, and in particular the preferred temperature at the holiday destination (Amelung et al., 2007; Bigano et al., 2006; Giles \& Perry, 1995). Researchers have explored the possible shifts in demand that 
may occur as a result of climate change, and as mentioned in section 2.4, the changes in tourism flows as a result of changing temperatures and weather phenomena may be profound. However, concern for the environment is closely linked with the behaviours that people display (Dolcinar \& Leisch, 2008). Changes in patterns of demand may occur as a result of increased concern for the environment. New Zealander's concern about climate change has been rising lately (NZBCSD, 2009). According to a national survey conducted online by Shape NZ for the New Zealand Business Council for Sustainable Development (NZBCSD) in February 2009, people are quite concerned about climate change, and many believe that the effects of climate change have already begun to occur. However, climate change is less of a concern to people than for example fuel prices, the cost of living, the recession and healthcare, which may have larger effects on their behaviours.

This study is exploring whether changes in demand may occur as a result of concern about the changes that may take place if the current rise in atmospheric greenhouse gases continues. An increase in tourism consumption will lead to further emissions caused by tourism at the current technological capacities of transportation unless a change in consumption habits occur, such as travelling shorter distances and choosing transport modes and products that have lower emissions (Burns \& Bibbings, 2009). However, when it comes to choosing a destination, concern for the environment seem to be less prioritised than other factors for people when choosing where to go: Lübbert (2001) found that environmental protection was the least important factor among German tourists when choosing a holiday destination. The most important factors included landscape/scenery, value for money and hospitality. These findings correspond with later research, which has found that climate and perception of climate are among the most important factors for choosing a destination (Amelung et al., 2007; Bigano et al., 2006). However, these later studies did not focus on concern for the environment.

The literature regarding concern for the environment in relation to destination choice is very limited. Apart from the studies that Lübbert (2001) conducted on ecolabeled tourism products, no other studies have explored this direct link. Most of the literature is focussed on actual behaviours and concern for the environment, rather than the choice processes that people go through when deciding on their holiday destination, transport and accommodation. The next section will review this literature concerning holiday behaviours in relation to concern for the environment. 


\subsubsection{Holiday behaviour and concern for the environment}

Concern for the environment does not automatically translate into environmentally friendly behaviours: although groups of subjects included in research often report concern for the environment, their behaviours are no different from people who report lower levels of concern for the environment (Reiser \& Simmons, 2005). This inconsistency between attitudes and behaviour is commonly referred to as the attitude-behaviour gap, and is mentioned in many studies regarding tourism behaviour and climate change (Hares et al., in press). This section will explore the literature that relates to environmental concern and behaviour.

Firstly, the terminology that will be used throughout the study is clarified. Many terms have been used interchangeably in the literature dealing with concern for the environment and environmentally friendly behaviours. Schultz et al. (2005) called for a common conceptual language, but it seems as though researchers insist on using terms that suit them best. Terms that have been used to describe environmental values, attitudes, norms and beliefs include ecoaltruistic values (Lopez \&Cuervo-Arango, 2008), moral obligation to care for the environment (Dolcinar \& Leisch, 2008), environmental attitudes (Schultz et al., 2005) and environmental concern, to mention just a few. Likewise, many different terms have been used to describe 'environmentally friendly behaviours': Ecological behaviour (Kaizer and Shimoda 1999), environmentally friendly behaviours, conservation behaviour, environmental behaviour (Schultz et al., 2005; Fraj-Andres \&Martinez-Salinas, 2007), pro-environmental behaviour (Dolcinar \& Leisch, 2008) eco-altruistic behaviours and eco-centric behaviours (Higham et al., 2002). In spite of the multitude of terms used, the underlying theory remains the same. For the sake of this thesis, the terms 'concern for the environment' will be used together with 'environmentally friendly behaviour' which will refer to behaviours that aim to limit the negative impact of the respondents on the global natural environment.

Most of the literature pertaining to concern for the environment and behaviour has concluded that some form of attitude-behaviour gap exists. There has been much speculation regarding the reason behind the attitude-behaviour gap, and a range of suggestions have been proposed (Gössling, 2002; Stoll-Kleemann et al., 2001) Gössling (2002) argues that over the last couple of hundred years there have been profound changes in human-environmental relations; our dependency on nature has diminished, and this has led to the development of cosmopolitan identities. In many ways we have lost touch with nature so to speak, and so an increase in consumption is not seen as a threat to the natural balance. It becomes easier for people to increase consumption, and more difficult to see the connection between mass consumption and 
detrimental effects of consumption on the global natural environment (Gössling, 2002). StollKleemann et al. (2001) claim that there are a number of psychological mechanisms, including displacement and denial which contribute to maintaining the gap between attitudes and actions in relation to climate change mitigation. The researchers stated that "The most powerful zone for denial is the perceived unwillingness to abandon what appear as personal comfort and lifestyle-selected consumption and behaviour in the name of climate change mitigation" (StollKleemann et al., 2001 p. 113). When a consumption habit does not correspond well with the personal values of an individual, mechanisms of denial are formed to defend the current consumption habit, which lead to various barriers to action when it comes to changing behaviours to mitigate negative effects of consumption habits on the global natural environment. The researchers found several barriers, including 'the comfort interpretation' (unwillingness to abandon what appears as personal comfort and lifestyle-selected consumption and behaviour in the name of climate change mitigation), 'The tragedy-of-the-commons interpretation' (belief in the insignificance of individual action to change the order of things), 'The managerial-fix interpretation' (The faith in some form of managerial fix, including faith in technological advances), and 'The governance-distrust interpretation' (distrust of government as a reliable locus for pursuing the public interest).

Indeed, such mechanisms for denial to continue mass consumption of tourism products that have a negative impact on the environment have been identified in research that has been done since the publication of the work by Stoll-Kleeman et al. (2001). Becken (2007) in her study of international visitors' perception of international air travel's impact on the global climate found that the value of freedom to travel is firmly established in the minds of many tourists and as such limiting travel is considered unacceptable. Similarly, Hares et al. (in press) found that participants in their study among residents of Portsmouth in the UK considered holidaying to be too important to them to give up travelling, and the respondents in this research also reported that the responsibility for mitigating the negative effects that tourism has on the global natural environment lies with governments rather than with themselves.

Not only is there an attitude-behaviour gap pertaining to travel behaviour, inconsistencies also exist between behaviour when on holiday and when at home: While many people behave in an environmentally responsible manner when at home, and participate in many practises including recycling, electricity saving, using public transport etc., such behaviours are not an indicator of environmentally friendly behaviour when in the holiday sphere. People tend to relax a bit more when they are on holiday, focussing on unwinding and having a break from routines at home becomes more important to them than behaving in an environmentally responsible manner (Barr 
et al., in press). Habits at home do however influence behaviours at the holiday destination. People who feel morally obliged to behave in an environmentally friendly manner are more prone to behave in a similar manner when on holiday (Dolcinar \& Leisch, 2008; Barr et al., in press). Environmentally friendly behaviour in the holiday environment does however decrease compared to behaviour at home: research has found that environmentally friendly behaviour on holiday is only three quarters of that at home, even among those who feel most obliged to care for the environment (Dolcinar \& Leisch, 2008). There may be a number of reasons for this, including lack of knowledge about local waste management and the availability of recycling facilities. Many do however strive to behave in an environmentally responsible manner at the destination, and educate themselves about local environmental practises, but the choice of the destination in itself is normally not subject to evaluation in terms of the impacts that travelling to and from the destination will have on the global natural environment in terms of carbon emissions (Gössling et al., 2006). Many may see it as a compromise to engage in eco friendly activities at the destination, to make up for travelling to a far away destination. The impact that travelling to far away destinations has on the global natural environment has caused many researchers to call for shorter distance travel to reduce negative impacts (Barr et al., in press; Robbins \& Dickinson, 2007).

The attitude-behaviour gap may also be caused by lack of awareness of the adverse effects that tourism has on the environment. Various stakeholders in the tourism industry may have opposing interests, and are sending out mixed messages which may act to confuse people regarding the effect that tourism has on the global natural environment. Marketing campaigns by airlines have a large influence on people's perceptions of the impact that air travel has on the environment (Gössling \& Peeters, 2007). While marketing campaigns of the airline industry reach most people who travel, the facts and figures produced by research often only reaches those who actively seek these out. What is more, the research regarding climate change and human behaviour is often presented in a manner that is inaccessible to the general public, while marketing campaigns are specifically designed to reach as wide a customer base as possible.

If initiatives to mitigate climate change are to work, it is necessary to find ways to overcome the attitude-behaviour gap when creating policies and campaigns aimed at changing behaviours. More research is needed to explore the opinions among residents in their home environment, to capture a broad range of behaviours. Much of the research referred to above is conducted at destinations, which narrows the scope of behaviours that can be captured; the people included in destination research have already chosen to travel. To inform policy development, a cross section of the population is needed, including people who do not travel for leisure, and people 
whose concern for the environment limits their propensity to travel for leisure. Policies need to address behaviours that are particularly harmful to the environment, and at the same time leave no room for denial to keep acting as a hindrance to behavioural change. Some studies have found that people want governments to force behavioural change through legislation (Hares et al., in press). This may indeed be the only solution to the problem. Meanwhile, many voluntary initiatives are available to those who wish to reduce their impact on the global natural environment while continuing to travel, such as purchasing environmentally friendly tourism products and participating in carbon offsetting. These initiatives will be discussed in the following section.

\subsection{Environmental certifications and carbon offsetting}

\subsubsection{Environmental certifications for tourism or 'tourism ecolabels'}

Ecolabels and environmental certifications are defined as written and visible statements or labels that give assurance that the tourist operation or activity is conducted according to a known standard that enhances the environment, or at least minimises the environmental impacts of the enterprise in question (Fairweather, Maslin and Simmons, 2005). Tourism ecolabels have existed for approximately 20 years, and are as such a somewhat new phenomenon. Many ecolabels have come and gone over the past twenty years, which may have led to some confusion among consumers. There has also been a mix of international and national ecolabels as well as localised ones, which may not have had any significance to anybody except local consumers (Buckley, 2001). While some tourism ecolabels apply to all aspects of tourism, there are also ecolabels which are specialised and only apply to hotels, guest houses or other parts of the total tourism product (which is made up of transport, accommodation, attractions, activities and auxiliary services/products).

New Zealand is a destination that promotes itself as 'clean and green,' and the national marketing agency, Tourism New Zealand (TNZ) has branded the country as an environmentally conscious destination through the marketing campaign "100\% pure New Zealand." This brand is a good fit with tourism ecolabels, which are becoming increasingly widespread across the nation. Green Globe and Qualmark Green are the tourism ecolabels that are most frequently used in New Zealand. While Green Globe is an international private company which is based in the USA (Green Globe, 2009), Qualmark Green is a collaboration between the public and the private sector in New Zealand (owned by Tourism New Zealand and the New Zealand Automobile Association (AA)). Green Globe has suffered criticism through the years, as it 
allows companies to use a slightly modified Green Globe logo from the very date that they sign up for the scheme, and the companies only have to comply with approved standard within two years after signing up (Buckley, 2001). This means that companies that are not up to standards may use the logo (however slightly modified). In this case, Qualmark Green is more trustworthy, as it requires assessments to be carried out in order for the businesses to carry the logo (Qualmark, 2009a).

'Green' or environmentally friendly products have become quite common in the westernised world during the last two decades; approximately $70 \%$ of consumers occasionally consider environmental issues when purchasing products or services (Wearing et al. 2002). Although people are being bombarded by a multitude of ecolabeled household products when going grocery shopping, there is still low awareness of tourism ecolabels. Previous research has shown that not only is there a low awareness of tourism ecolabels, but that there is also a poor understanding of what tourism ecolabels are. Schott (2006) found that many people confuse tourism ecolabels with other types of ecolabels that are not at all related to tourism. Also, many people when on holiday do not recall places that they visit that have ecolabels. Research by Fairweather et al. (2005) found that only one-fifth of the respondents in a survey recalled any place with ecolabels, and only $13 \%$ within the same sample had heard of tourism ecolabels; however, 33\% had some experience of ecolabels. There ought to be scope for increasing these figures: About one in three New Zealanders would be more likely to purchase a product if it has an ecolabel (ShapeNZ, 2009).

The findings of low awareness and purchase of ecolabeled tourism products are backed up by other research, for example by Wearing et al. (2002) which showed that people generally tend not to be aware of ecolabeled tourism products before going on holiday, rather they encounter them 'en route,' and as such the purchase decision is often not influenced by environmental concern or 'green behaviour.' Often people may purchase ecolabeled tourism products without even knowing it. The conclusion of the study poses a paradox: The researchers found that people need to be informed of tourism ecolabels in their home environment before making the decisions on which products to purchase in order to make them consciously consume ecolabeled tourism products. The reality however is that most of the ecolabeled tourism products are located at destination and the marketing efforts of the businesses who have achieved such accreditations do not focus on the environmental certification that they have been awarded, but rather the core product that they are offering. Most tourism operators in New Zealand are too small to market themselves abroad, a task which therefore has been assigned to Tourism New Zealand (TNZ). TNZ is however not concerned with marketing ecolabels. While they promote 
the Qualmark accreditation along with the $100 \%$ pure brand on their website, there is no mention of ecolabels made visible to the visitor of the web page. Even Qualmark Green which is owned partly by TNZ is not mentioned on the website (Tourism New Zealand, 2009). Thus, consumers are not being exposed to tourism ecolabel brands before going on holiday, which lead to less awareness and lower consumption. In order to raise awareness of tourism ecolabels, marketing campaigns must originate from the ecolabel providers themselves, to make people familiar with the logos and inform the decision making process when people are choosing components of their holiday.

However, not only awareness is important in influencing purchase of ecolabeled tourism products; several factors are influencing the propensity to consume ecolabeled tourism products. In the 1990s when ecolabels were gaining popularity, research was done to explore which barriers existed for purchase of ecolabeled products. Research found that there was much confusion about the multitude of ecolabels offered, and also distrust in ecolabels was high. The factors that were found to be most influential included price and quality of the product, convenience for purchasing it and perceived value (Roberts, 1996). Although consumers in theory may be willing to pay extra for a 'green' product, they often tend to choose the cheaper option. Research has shown that brand recognition plays a bigger part in people's purchasing decision than environmental concern does (Wearing et al., 2002). This means that awareness of tourism ecolabels needs to be raised, and the benefits associated with purchasing such products needs to be emphasised in order to motivate people to buy ecolabeled tourism products.

Although there are many actions a person can take while travelling to minimise his or her negative impact on the environment, consumption of tourism products that bear an ecolabel can be considered to represent environmentally friendly tourism behaviour that is quantifiable. For this reason, consumption of ecolabeled tourism products is used as a means to explore environmentally friendly behaviour in this study.

\subsubsection{Carbon offsetting}

Certain tourism activities including air travel cause large amounts of GHG emissions, and in the last 40 years the tourism industry has become heavily dependent on the aviation industry. Transport is responsible for a large part of the emissions caused by tourism, yet people do not seem to be deterred from travelling long distance because of this; people travel ever more often, and global annual growth rates for air travel are predicted to be in the order of 5\% until the year 2020 (Gössling \& Peeters, 2007). As such, carbon emissions will continue to increase. It is clear 
that something needs to be done in order to limit future growth of carbon emissions as a result of increased air travel and other tourism activities.

Since the establishment of the Kyoto Protocol which came into force in 2005, carbon emissions trading has been established in many countries in the industrialised world, and as a bi-product of this a wide variety of carbon offsetting schemes have emerged. Companies who undertake projects that offset emissions of GHGs in the long or short term (usually companies concerned with development of renewable energy sources such as wind farms or solar power, or companies that carry out forestation projects which serve to sequester carbon) are in many countries able to 'sell' their future positive carbon balance to third parties, in order to fund projects that will reduce future emissions of a country (Gössling et al., 2007). In the last couple of years, many organisations have been established with the aim of creating projects which reduce future emissions or buying carbon quotas from companies which produce a surplus of emission reduction units, and selling these carbon quotas to people and businesses who wish to neutralise their carbon emissions. It should be noted that future carbon emissions will not actually decrease as a result of these projects being undertaken; rather the reduction is relative to the net emissions that would have been made if a more conservative and higher emitting alternative to the project in question would be undertaken. Carbon offsetting schemes support mainly two project categories: biological sinks that sequester carbon (mainly forestation and reforestation projects), and future emissions savings through projects aimed at developing renewable energy sources as mentioned above (Gössling et al., 2007). In New Zealand, the main carbon offset schemes available through CarboNZero allows consumers to offset through landfill gas recovery in addition to wind farm and native forest regeneration (CarboNZero, 2009). For further detail on carbon credits and standards, see Appendix D.

Carbon offsetting is available both to businesses and to individuals. As such, tourists can act environmentally responsible either by purchasing carbon offsets directly, or by choosing tourism providers who offset their emissions. In New Zealand there are several options for people to offset their carbon emissions in relation to tourism activities. CarboNZero is a programme "established in 2001 by Landcare Research New Zealand Limited, one of New Zealand's leading Crown Research Institutes, owned by the New Zealand government" (CarboNZero, 2009). It offers people the opportunity to calculate their emissions from a range of activities in relation to tourism and travelling, and purchase offsets through the web site. The consumers are able to choose which project they want to support through their purchase of carbon offsets, as outlined above. People have other alternatives as well; several airlines such as Air New Zealand, Jetstar and Pacific Blue offer people the opportunity to offset their carbon 
emissions at the time of booking their flight. In addition to this, there are a number of foreign and international airlines and companies that offer carbon offsets such as Climate Care and Sustainable Travel International, which are making carbon offsetting easily accessible online.

Although widespread online access to these schemes, participation must be considered to be low when taking into account the volume of air travel and other high emitting activities. According to McKenzie (2009) the numbers of people using the offsetting schemes available through the CarboNZero web pages are relatively low. The reasons for this are abundant: Many people are unaware of the impact that their tourism activity (including flying) has on the global natural environment (Gossling et al., 2006). There is low awareness of carbon offsetting schemes (Becken, 2007), people care more about the cost of travel than the impact that they make on the environment (Becken, 2007; Hares et al., in press), and there are also several mechanisms of denial in play that allow people to excuse their behaviours by underestimating their role in reducing emissions or by displacing responsibility (Stoll-Kleeman et al, 2001). In order to reduce these barriers, more knowledge is needed concerning people's opinion on carbon offsetting and willingness to participate in such schemes. This research aims to increase this knowledge by exploring reasons for participation or non participation in carbon offsetting schemes by Wellington residents when taking a holiday, and how much people are willing to pay to offset one tonne of $\mathrm{CO}_{2}$-E emissions.

While some people value the opportunity to offset their emissions by purchasing carbon offsets, it is a much disputed practise with much confusion surrounding its benefits and usefulness. It is not a permanent solution to the problem of increasing emissions from tourism, and can as such be seen as an easy way of ridding oneself of a guilty conscience (Hari, 2009). There has also been criticism of the assurance of carbon offsetting that is given by creating biological sinks: Forests have to live for a certain length of time in order to offset substantial emissions, and providing a guarantee that forests will not be harmed by human action or natural disasters is difficult. Therefore, it can be argued that investing in projects focussed on developing renewable energy sources is 'safer' than to invest in projects that create carbon sinks. No matter which type of project that is being supported through purchasing offsets, the practise of carbon offsetting does not eliminate the emissions that are being made, and allow people to continue behaving in a manner that is unsustainable. Many critics are naming this practise as unsustainable and as a method for avoiding facing the real problem that reducing emissions incurs (Taylor, 2009; Hari, 2009). 
Another weak point of carbon offsetting is that it would not be possible to offset emissions from all activities worldwide; the schemes only work as long as usage is kept at a low frequency. Researchers have attempted to calculate the emissions from aviation to/from and within New Zealand to investigate the possibilities to offset these emissions within the country (Hart et al., 2004; Smith \& Rodger, 2008). Smith and Rodger (2008) calculated that to offset emissions from national and international aviation in New Zealand in 2005 by regenerating bush would require the equivalent of $10 \%$ of New Zealand total landmass. Similarly, to offset these emissions by installing energy efficient light bulbs would require 248 million light bulbs to be replaced, in a country which only has 1.48 million dwellings. Investing in wind farms and reducing land transport would also be unachievable. It is clear that with the current volume of air travel to/from and within the country it would be impossible to offset the emissions from aviation within the country's boundaries by means of current offsetting alternatives, and thus projects in other countries must serve as a resource for offsetting carbon emissions caused by air travel if such an initiative should ever be undertaken. When considering the volume of air travel and other activities responsible for carbon emissions worldwide, carbon offsetting is not a feasible solution to the problem of high emissions from tourism. It is however at current the largest initiative taken to address carbon emissions made by companies and individuals, and it does provide funding for projects that will reduce future emissions from energy production, and that benefit developing countries which are able to sell carbon credits.

This study recognises that carbon offsetting is not a permanent solution. However, the act of offsetting emissions is certainly an indicator of the desire to limit one's negative impact on the environment, and as such this study uses participation in carbon offsetting as a measure to assess environmentally friendly behaviour among the subjects.

\subsection{Current policy environment}

Policies are defined in the Oxford English Dictionary (1995) as a plan of action or a statement of ideas adopted by a government or other party. Governments use laws and regulations to guide people in the direction that they think is right for the nation that they govern. Policy is therefore an important influence on people's behaviours, and stipulates what they can and cannot do. Influencing people's behaviours can be achieved either by encouraging good behaviours or by punishing undesirable behaviours. Governments around the world have started responding to the challenges that are posed by climate change and the importance of addressing this issue was emphasised by the United Nations Framework Convention on Climate Change (UNFCCC) in December 2009. However, no agreement was achieved on how to reduce current 
GHG emissions, and the convention was considered a fiasco by many (Hari, 2009; Clarke, 2010). The main purpose of the convention was to establish a replacement framework designed to reduce GHG emissions, or to commit to a continuation of the Kyoto protocol, which was established in 1997 and came into action in 2005 (UNFCCC, 2009). The Kyoto protocol, which expires in 2012, is an international agreement which sets binding targets for all the countries which have ratified the agreement aimed at reducing GHG emissions, and it has set a price on carbon for the purpose of emissions trading. While domestic tourism is subject to the Kyoto protocol in New Zealand, carbon emissions from international aviation are exempt from the agreement, and are as such not being controlled by the agreement. "The Kyoto Protocol commits New Zealand to reducing its GHG emissions back to 1990 levels, on average, over the period 2008 to 2012 or to take responsibility for any emissions above this level if it cannot meet this target" (Ministry for the Environment, 2009b).

As a result of the commitment to the Kyoto protocol, New Zealand Government introduced the Emissions Trading Scheme (ETS) in 2008, with the aim of charging businesses for their carbon emissions. There has been much criticism of the ETS by TIANZ, as it is expected to have a profound effect for small to medium enterprises (SMEs) in terms of inferred costs passed on from participants in the scheme (TIANZ, 2009). Under the new bill that was passed on $25^{\text {th }}$ November 2009, both the transport sector and the electricity production sector are entering under full obligations in July 2010. This will mean increased prices for the consumers of energy and transport, as the costs of carbon will be passed on from the participants in the scheme to the end consumers. The appropriateness of the original ETS was contested by the tourism industry, as it would have a profound effect on tourism in 2010, possibly forcing operating costs up by a considerable amount: As the New Zealand tourism industry is made up of a vast number of SMEs, among which many are struggling to make ends meet, the increase in fixed costs may have profound effects on the tourism industry (TIANZ, 2009). The new ETS passed by the government in 2009 does not have any significant changes that will reduce the negative impact on SMEs. Not only does this mean that SMEs may not be able to stay in operation, it also means that the tourists will have to pay additional costs. Given that most trips taken by New Zealanders for leisure purposes are taken domestically, this will impact on New Zealand residents as well as international tourists. Not only will transportation costs rise, but also the price of accommodation may rise, which in turn will deter people from using publicly accessible transport and commercial accommodation when travelling domestically. The ETS has been criticised for not actually being useful in achieving reductions in national $\mathrm{CO}_{2}$ emissions, which was the main purpose for creating the scheme in the first place (Bertram, 2009; Lawrence, 2009). 
Considering the importance of tourism to the economy, it is of high importance to safeguard the future of tourism businesses in order to achieve the goals of Tourism New Zealand and the Ministry of Tourism. The New Zealand Tourism and Climate Change Plan 2008 (NZTCCP2008) was released by the Ministry of Tourism in 2008. The plan focuses on the implications that climate change will have on tourism. It is stated explicitly in the plan that "New Zealand tourism should actively and credibly contribute to reducing the severity of climate change," however the main focus of the plan is the importance of maintaining growth in visitor numbers, and highlights the importance of marketing as a tool for further attracting visitors in the current customer environment (Ministry of Tourism, 2008). There is as such no encouragement in the plan for people to travel less, or to travel over shorter distances, in fact domestic tourism is hardly mentioned in the plan. There is also no stated commitment to reducing the negative effects that tourism has on the environment.

Further evidence that mitigation is not the main concern for the government can be found in the New Zealand Tourism Strategy 2015 (NZTS2015), which recognises that climate change is a challenge for tourism in New Zealand, and has stated in its aims to "achieve a tourism sector that is environmentally, economically, culturally and socially sustainable" (NZTS2015, 2007). This is to be done by urging operators to become more sustainable by saving energy and adopting best practices. It is also noted in this strategy that responding to people's concerns about their emissions in relation to travelling to and from New Zealand needs to be taken into consideration, in terms of offering a chance for concerned individuals to offset emissions, something that is seen as very important considering the 'green' image of New Zealand that has been promoted through the $100 \%$ pure New Zealand campaign. It is however a slight contradiction that the NZTS2015 aims to increase international tourism arrivals to 3.2 million arrivals by 2013, knowing that this will lead to further emissions of GHGs caused by tourist transportation to and from the country. It can thus be questioned whether the government is committed to mitigating the impacts of tourism on the global natural environment.

The private sector has also started responding to the threat of climate change. The increased concern among the public has caused many businesses to change their practises to reduce their negative impact on the global natural environment, and to remain attractive and marketable. Ecolabels have become more widespread, as businesses are using them to market their environmentally friendly practises. There have however been voices saying that companies are merely pretending to care for the environment to improve their image, a process often called 'greenwashing'. There are certainly international examples that may verify this belief, for 
example Sir Richard Branson's company Virgin. In 2008 Virgin Air executed a test flight using a blend of ordinary jet fuel mixed with bio fuel made by coconut oil and babassu nut oil, showing that it is possible to reduce the use of high emitting carbon based fuels in air travel (Virgin Atlantic, 2008). This test flight was however overshadowed by the personal space flight programme of Virgin Galactic, which was launched in the same year. While insisting that Virgin Galactic's personal space flights are more environmentally friendly than previous space programmes due to the vehicles having re-usable components, there is no doubt that a growth in trips to outer space for a couple of hours will have a negative impact on the global natural environment. The main emissions from space travel include soot emissions. Although these do not stay long in the atmosphere, soot emissions cause a much more rapid warming than other GHGs (Lean, 2009). It can as such seem that some initiatives undertaken in the name of climate change mitigation (such as the Virgin bio fuel test flight) indeed do serve as a gimmick to boost companies' image.

One might argue that even initiatives done in the name of marketing are beneficial as long as they actually make a positive impact. Considering the amount of initiatives that are being undertaken around the world, there is little doubt that perceived concern by consumers about the current state of the environment is having an impact on the environmental practises of companies. Also, when looking at the number of awards for best environmental practises that has been established in recent years, there is no doubt that there has been a change in focus of businesses worldwide.

The main problem posed by the current policies for climate change mitigation both within the public and the private sector is that they do not deter people from travelling, and as such the emissions from tourism are growing rapidly. Voluntary policy measures put in place by governments to mitigate climate change are often ignored, or adopted for other reasons than concern for the environment (Whitmarsh, 2009). There is a need for policy that effectively reduces emissions from tourism, and some argue that voluntary initiatives are not doing this to any extent (Becken, 2007; Lorenzoni et al., 2007). Given that tourism is projected to grow also in the future, one might argue that strict regulation of travel is the only realistic measure to limit emissions.

\subsection{Conclusion}

This chapter has evaluated the topics relevant to climate change and tourism behaviour, which is the main focus of this study. By reviewing the literature, it has become clear that further research is required in the following areas: 
There is limited knowledge about the influence of environmental concern on actual tourism behaviours. While research has been done at destinations, studies taking an origin approach are lacking in the literature. Studies that take a destination approach are limited in scope in the sense that the population included in the research already bear certain characteristics; the people have already chosen to travel, and they have chosen the destination at which the studies have been undertaken. The research that is conducted for this thesis aims to fill this gap by capturing a broad range of behaviours, including non participation in leisure travel, to see whether concern for the environment plays a role in the decision to take part in travel, or whether people actively try to limit their negative impact on the global natural environment by limiting extent of travel. This can only be achieved by taking an approach where people are recruited at their place of residence.

There is also limited knowledge about the consumption habits and support of carbon offsetting by consumers. Given that New Zealand is a country that is geographically far removed from the closest neighbouring countries, the residents cannot easily choose low emission transport alternatives when wanting to go abroad. Therefore, the situation for New Zealand residents is rather different than to residents of other countries where access to international destinations is easy. Until this date, no studies have attempted to account for the opinions of New Zealand residents regarding their impact on the environment when travelling internationally, or their attitudes to and awareness of carbon offsetting schemes. This information is needed to inform legislation on how to reduce the emissions made by the New Zealand tourism industry. This study aims to increase this knowledge by exploring participation in and attitudes towards carbon offsetting among Wellington residents.

Awareness of tourism ecolabels among visitors to New Zealand, and among New Zealanders has been found to be low (Fairweather et al., 2005; Schott, 2006). Recent studies among New Zealand residents have however established that one in three people say that they are more likely to purchase a product if it has an ecolabel (ShapeNZ, 2009). To explore the scope for increasing awareness and purchase of ecolabeled products among New Zealanders, this study aims firstly to explore whether awareness has increased since the last two studies were conducted in the mid 2000s, and whether people purchase ecolabeled tourism products out of concern for the environment.

Based on the literature reviewed and the gaps identified, the objectives and hypotheses for this study as outlined in Chapter one have been developed, and a platform has been created on 
which the methodology can be developed. The next chapter will provide a detailed description of the selection and development of the methodology for this study. 


\section{Chapter 3 Methodology}

\subsection{Introduction}

The previous chapter outlined the literature that is relevant to this study, and the aims derived from gaps in the literature provide a baseline for developing the methodology for this study. There are several aspects that need to be taken into account when selecting the appropriate methodology for a study, which will be discussed in the section below. This chapter will provide a justification and description of the methodology chosen to explore the behaviours and opinions of Wellington residents in relation to concern for the environment. It will outline the sampling technique used, and provide a description of the study area including presentations of the selected suburbs, and a comparison of the sample drawn from the suburbs with data from Statistics New Zealand. The method for data analysis will be outlined, together with an explanation of the various types of statistical and other analyses which were used to extract information from the collected data.

\subsection{Selection of methodology}

There are two broad categories of social research which can be employed to answer a research question, namely qualitative and quantitative methods (Bryman, 2008). The distinction between the two is rather complex, however a broad outline of the two is as follows: While quantitative research methods use measurable data to test a theory by use of the natural scientific model (and positivism in particular), qualitative methods emphasises words rather than quantification in the collection and analysis of data with the aim to inform theory and to emphasise the way in which individuals interpret their social world (Bryman, 2008).

The main research question of this study is concerned with gaining an overview of the current situation in Wellington City, in order to understand the level of concern for the environment among Wellington residents and measure the influence of concern for the environment on travelling behaviours displayed. To maximise the accuracy of the information that was gathered and to be able to generalise the findings of the study to the population in Wellington City, as large a sample as possible was sought to reduce the risk of bias influencing the answers of the sample population as a whole. For this reason, a quantitative approach was chosen for this study, 
enabling statistical tests with a strong validity to be performed. To further explore quantitative variables, some of these were followed up by qualitative questions in the questionnaire.

To further inform the selection of the methodology, the methods used in the literature that is reviewed in Chapter two were assessed. Both qualitative and quantitative methods have been applied: Survey questionnaires have been widely utilised to collect data from the populations in related studies, as well as other methods including in-depth interviews and focus groups. Although qualitative research methods can provide valuable insight into the opinions and behaviours of people, it does not allow the researcher to generalise the findings from interviews or focus groups to the population from which the sample was drawn. The aim of the methodology selected was to get an insight into the current situation in Wellington City and to gather a substantial amount of information from which trends and patterns could be drawn.

After an evaluation of several types of quantitative research designs, the final decision was to use self administered mail back survey questionnaires. There are several advantages associated with using mail surveys which were important for the researcher when choosing the methodology: Firstly, the researcher wanted quite detailed information about the respondents' last two holidays, and as the respondents were able to complete the questionnaire in their own time, at home where they had access to information and to family members who may have accompanied them on their last two trips, the information gathered is of higher accuracy than might have been the case if the respondents were approached on the street by means of an intercept survey technique (Aaker et al., 2004). Also, the amount of information gathered through the questionnaire was deemed too great to be able to collect in a short time as is desirable when doing intercept surveys. Furthermore, the topic is somewhat sensitive, and it is likely that the respondents would be subject to researcher bias if the researcher was present; wanting to answer the questions in a manner that is perceived as pleasing to the interviewer. By remaining anonymous, the respondents are more likely to give information that is accurate rather than what they perceive to be desirable Aaker et al., 2004).

Given that focus was on conducting statistical tests of variables to draw out relationships between opinions and behaviours, the researcher chose to maximise the size of the sample rather than attempt a triangulation approach, where different research methods are combined to extract quantitative and qualitative information (Bryman, 2008). The information extracted from the survey questionnaire would be sufficient to inform the five objectives of this study, and as such no further research was needed to answer the research question. 


\subsection{Research instrument}

The principal research instrument for this study was a self-complete survey questionnaire, distributed by the researcher to households in Wellington. Respondents were given the choice between completing a mail-back survey questionnaire and accessing the questionnaire online. The questionnaire consisted of both open ended and closed questions, which enabled the researcher to supply the quantitative data with qualitative information.

The questionnaire had three main sections:

Section 1 was concerned with the holiday behaviours of the respondents. It included questions about their purchasing behaviours, and aimed to find out whether the participants consume environmentally friendly tourism products when they are travelling for leisure purposes. Section 2 of the questionnaire was concerned with respondents' opinions/attitudes about tourism and climate change, and general holiday behaviours. Included was people's familiarity with and participation in carbon offsetting schemes, their opinions about tourism as a contributor to climate change, and observations of climate change and effect on behaviour. Section 3 of the questionnaire was concerned with respondent demographics, for the purpose of comparing different groups of respondents to find out whether there are differences in behaviour in terms of age groups, household size, income levels and levels of education. The questionnaire can be viewed in its entirety in Appendix B.

\subsection{Selection of study site}

Related research has most commonly taken a destination approach, where tourists have been interviewed while on holiday. Although these studies provide valuable information about people's travel behaviours and perceptions of climate change, the results have been derived from somewhat homogeneous populations, namely tourists who have chosen a particular destination. To date, very few studies on this topic have taken an origin approach, where the population consists of residents within an area. Braun et al. (1999), conducted a pilot study among students of psychology at a German university where they assessed to which extent preferences for a holiday destination would change if the climate conditions at that destination changed. Hares et al. (in press) used focus groups to assess the air travel decisions of local residents in Bournemouth, UK, while Barr et al. (in press) used an administered intercept survey to investigate the difference between behaviours at home and when on holiday. The latter two studies were released after the data collection for this study was completed, and did as such not 
inform the selection of methodology. The study is limited to suburbs within the boundaries of Wellington City, as shown in Figure 3.1 below.

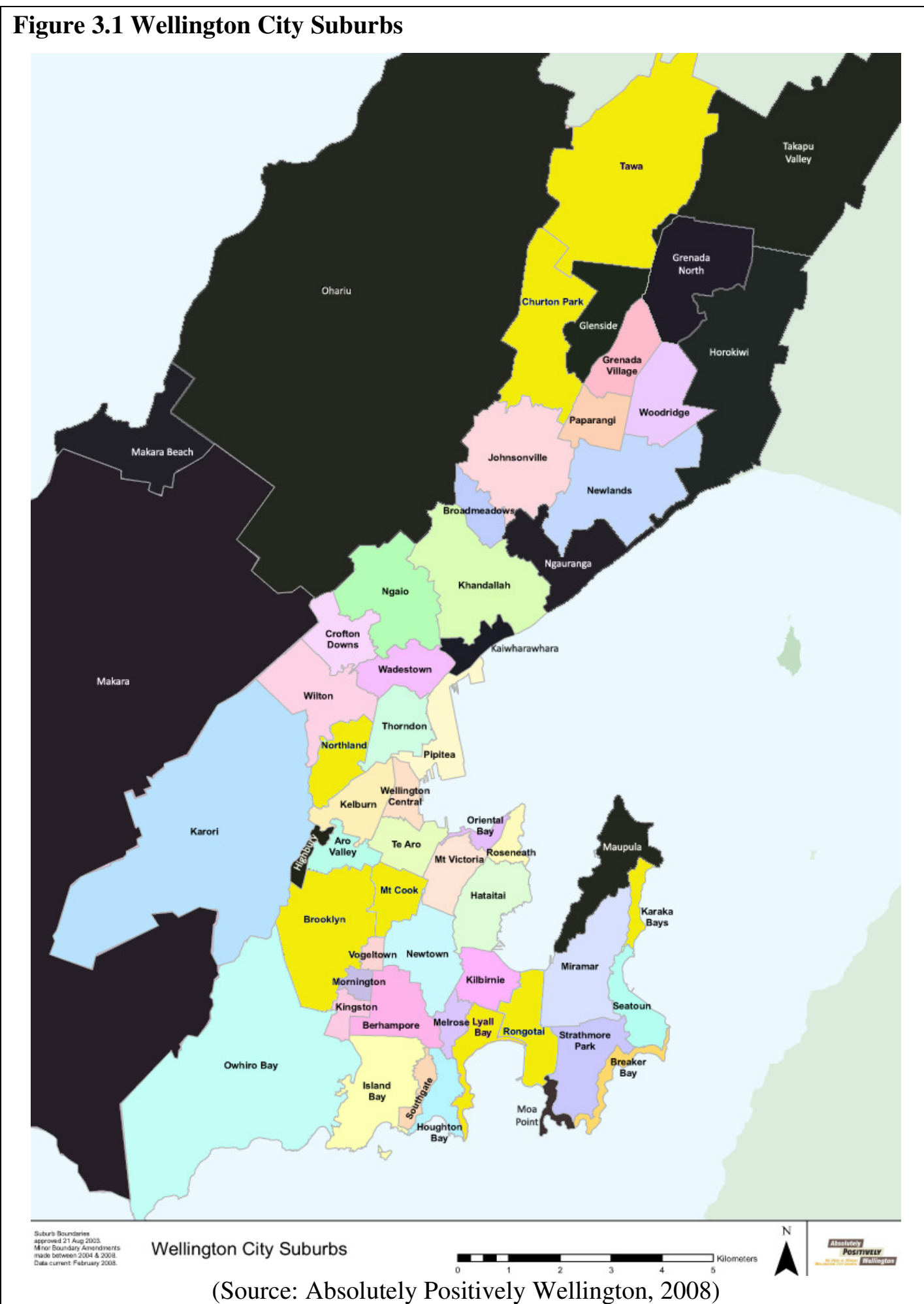


The suburbs included in this study are highlighted in yellow, whereas the excluded suburbs are shaded dark grey. The selection criteria which led to the exclusion of some suburbs will be further discussed in Section 3.7 below.

\subsection{Human Ethics Approval}

Victoria University of Wellington requires that research that involves human subjects undergo a human ethics approval process. The purpose of this policy is "to protect the

rights of individuals and groups who are the subject of research, experiments set up for teaching purposes, and other similar activities conducted under the auspices of the University" (Victoria University of Wellington, 2009, Human Ethics Policy). Human ethics approval was obtained on the $9^{\text {h }}$ of July 2009.

\subsection{Pilot tests}

Two pilot tests were conducted with convenience samples to verify that the questionnaire was comprehensible, and to gain a good estimate of how long it would take to complete it. The online version and the paper version were identical, with the exception that the online version had the option of adding page logics, and could as such skip to the next relevant question where this was applicable.

The first pilot test was conducted between $20^{\text {th }}$ and $25^{\text {th }}$ of June, including 35 people of all age groups. 12 people completed the questionnaire online, and 20 people completed a paper questionnaire. The participants included friends of the researcher and relatives of these friends, and the main purpose of the pilot tests was to verify that the questionnaire was easy to complete and that there were no problems answering any of the questions. The questionnaires were distributed to the participants who brought them home to complete, and these were returned to the researcher by the participants or their friends. 32 of 35 questionnaires were returned to the researcher. Although the methodology was not tried to exact resemblance, the questionnaire was trialled to satisfaction. The researcher asked the participants to make comments about questions that were ambiguous, hard to understand or difficult to answer. Feedback received from the participants showed that there was a need to modify some of the questions in the questionnaire. It should be noted that the population over the age of 70 was underrepresented in this test. After the first test, some of the questions were re-worded, examples were included in two questions, 
and some of the categories were adjusted to better suit the New Zealand context. It also allowed a more accurate approximate time to complete to be included in the information sheet.

The second pilot test was conducted between $5^{\text {th }}$ and $10^{\text {th }}$ of July, including 22 people of most age groups (again a low number of older participants). Again a convenience sample was used including a new group of people that consisted of co-students and their relatives. Questionnaires were given to the students, who took them home and brought them back to the researcher within 5 days. During this test it was established that the questionnaire worked well and was understood, and the online version worked as it should. After this test, the final questionnaire was printed in 1600 exemplars and packaged together with the information sheet (Appendix A) and a postage paid return envelope, ready to be distributed to the sample population.

\subsection{Sample population and sampling frame}

The sample was drawn from Wellington City residents. The total sample included 1600 possible respondents, which with a response rate of $20 \%$ would generate 320 responses. The sample was limited to 1600 dwelling due to financial restrictions. Through the sampling technique that is described below, the final sampling frame was limited to eight systematically chosen suburbs within Wellington City, within which an approximate number of 200 dwellings were systematically selected. After applying the sampling technique described below, 1590 dwellings were included in the final sample. The sampling technique used was multistage cluster sampling, including three stages as described in detail below. This systematic sampling technique ensured that selection bias was minimised in the selection of suburbs, dwellings and recruitment of respondents from the dwellings.

Stage 1: To identify Wellington suburbs, maps produced by Absolutely Positively Wellington (APW) showing official suburb boundaries were downloaded from the internet. APW had identified 57 suburbs within Wellington City, as can be seen in Figure 3.3.1 above. A geographical cluster sampling method was used to extract the sampling frame, whereby each suburb represented one cluster. For the sake of getting as even a distribution of surveys within each suburb as possible, those suburbs that had less than 200 dwellings were excluded from the sampling frame. This was done by means of the maps from APW and detailed street maps and satellite images from Google Earth. The combination of these three maps provided accurate parameters for the researcher to verify the number of dwellings within each suburb. This resulted in the exclusion of 12 suburbs: Grenada North, Glenside, Ohariu, Takapu Valley, Horokiwi, Moa Piont, Makara, Highbury, Kaiwharawhara, Maupuia, Ngauranga and Makara 
Beach. The remaining 45 suburbs were listed alphabetically, and by choosing every $5^{\text {th }}$ suburb on the list, 8 suburbs were included in the final sampling frame. Although no selection criteria were applied to attempt inclusion of suburb with various socio economic profiles, the final sample included suburbs of both high and low socio economic profiles. The final sample included the following 8 suburbs: Brooklyn, Churton Park, Karaka Bays, Lyall Bay, Mt. Cook, Northland, Rongotai and Tawa.

Stage 2: To identify dwellings for inclusion within the eight suburbs, two methods have been applied depending on the size of the suburbs. Two of the suburbs in the sample, namely Karaka Bays and Rongotai are rather small compared to the rest of the suburbs in the sample, with an estimated count of 300 and 350 dwellings respectively. It was therefore deemed appropriate to include all streets in the sample, and exclude every $3^{\text {rd }}$ dwelling on a regular interval until 200 surveys had been distributed.

The larger suburbs in the sample were divided into a number of smaller sub-areas (Som, 1973). A grid was drawn on top of each of the six suburbs, ensuring that most of the squares covered an approximate of 20 dwellings (See example in Figure 3.2.1 below). This method was appropriate as the geographical area to be covered was large, and there was no list of households available to the researcher (Som, 1973). The size of the squares was determined by using a combination of satellite images and maps provided by Google Earth, along with the maps of the suburb boundaries downloaded from APW. The density of dwellings within the suburb was checked, and the squares were based on the most frequent density of dwellings within the suburbs. This led to some squares containing more than 20 dwellings and some containing less than 20 . Those squares containing less than 12 private dwellings were excluded from the sample, to ensure that enough surveys would be distributed. 


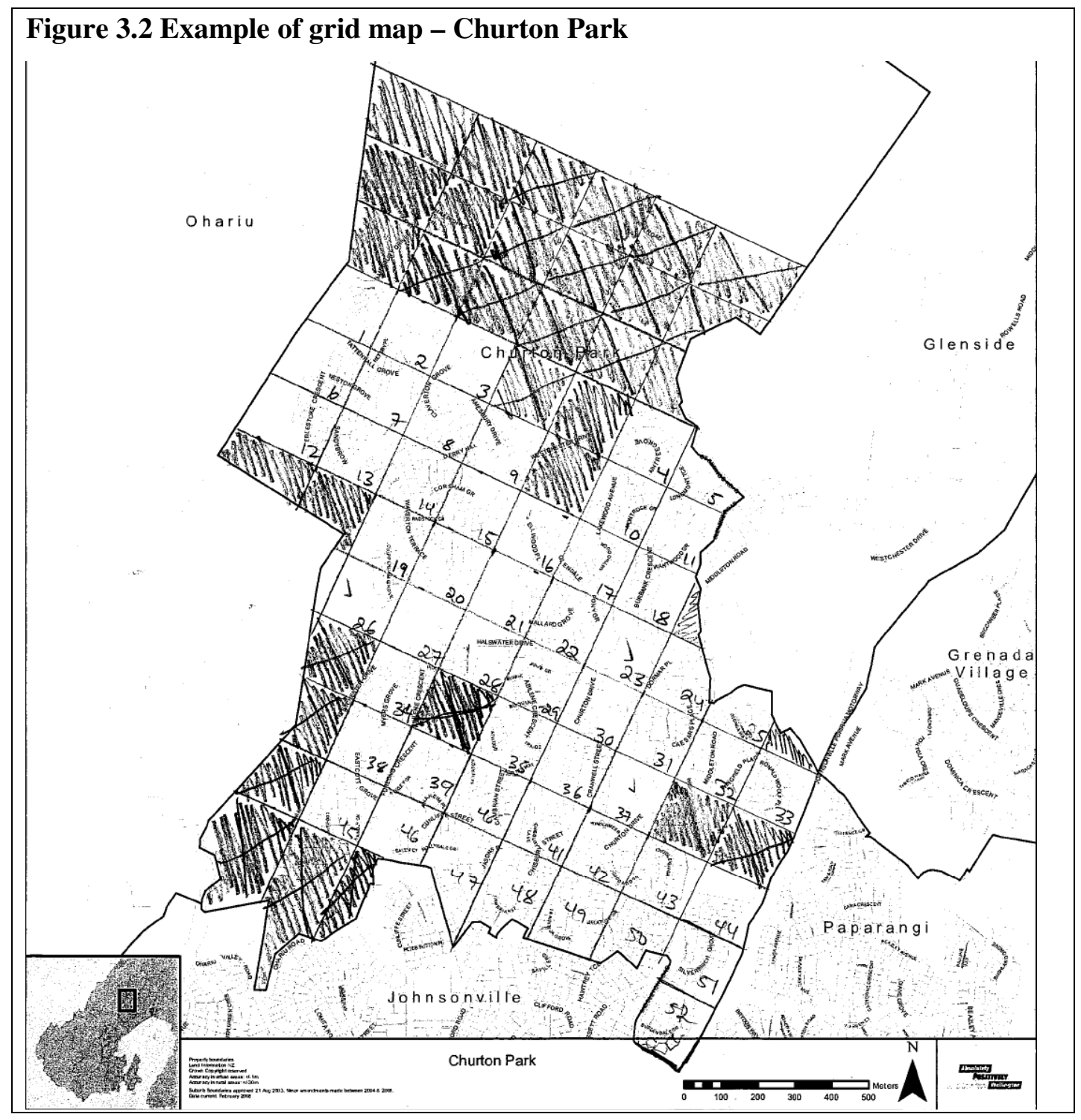

Once the grids had been drawn and the cells with fewer than 12 private dwellings had been excluded, the cells were numbered in sequence from the top left to the bottom right. Ten cells were chosen for inclusion within each suburb, by dividing the total number of included cells within each suburb by ten, and using the result (rounded to the closest number) as an interval for choosing the ten cells. Each cell was carefully drawn by matching the borders of each property within each grid and drawing a square onto a more detailed map (see example in Figure 3.2.2 below). The number of dwellings varied from 187 inclusions in Brooklyn to 205 inclusions in Northland. 


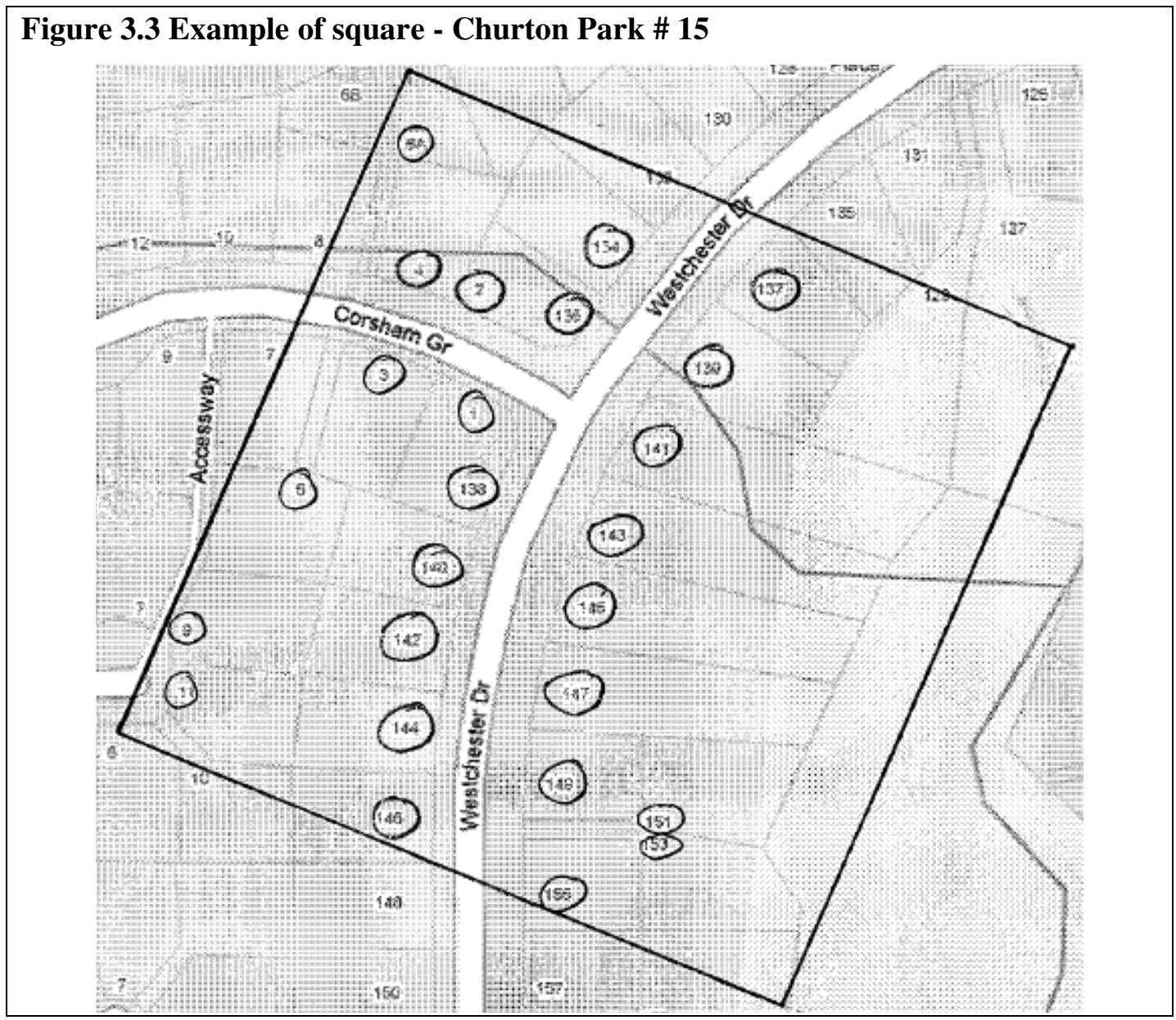

Stage 3: From each dwelling included in the sample, one respondent was chosen based on age (had to be over the age of 18) and birth date (the one person in the household whose birthday was next). There was a good reason for excluding the people who are under 18 years of age: In most cases, people who are under 18 do not make their own decisions when it comes to leisure trips, and would as such not be able to contribute valuable information to the study. Participants were recruited in their homes, and the researcher personally delivered the surveys to the mail boxes of the dwellings included in the sample. The respondents were presented with an information sheet, the questionnaire, and a postage paid envelope to return the questionnaire to the researcher via mail or contribution was made online. To encourage participation the respondents were able to enter a prize draw to win a supermarket gift card worth 200 dollars.

\subsection{Presentation of Suburbs}

Although it would have been beneficial to make sure that the suburbs included in the study had varying profiles, it was decided that such an approach may lead to selection bias, and that a 
structured approach would be more reliable. However, the sampling technique applied did produce a varied sample, and to make the reader more acquainted with the various suburbs included in the sampling frame a short overview of each suburb will be presented in this section. Data from the 2006 census has been used to profile each suburb.

The presentation of each suburb will focus on the three main variables used for analysing the data in this study, namely age, income and level of education.

Although the boundaries used for the census do not exactly match those outlined by Wellington City Council, the census data still provides valuable information about income distribution, occupations, and education. There are however some limitations to the comparisons:

Firstly, distribution of age within the suburbs are not well recorded in the available information about each suburb, as the only categories are under 15 years, 15-64 years and 65 years and above. The people who were under the age of 18 years old were excluded from this study, and as such do not feature in the sample data that was collected, and therefore the percentages may be skewed to reflect the exclusion of the under aged group. Secondly, income data is recorded per individual in the census data from 2006, whereas the data collected for this study was focussed on household income. The reason for using household income is that this is a more useful measure for assessing people's financial situation in relation to tourism. The census data does however give an indication of the economic profile of the residents within each suburb, which is also reflected in the sample data. Thirdly, level of education is recorded differently in the census data than it is in the sample data. These limitations are acknowledged, and may influence the accuracy of the comparisons to some degree, however the comparisons are meant to serve as an indicator of the goodness of fit of the as a representation of each suburb. As participation in the study was on a voluntary basis, some variations are expected. Following the presentation of the suburbs, the data collection, preparation and analysis will be accounted for.

\subsubsection{Brooklyn}

Brooklyn is located in the Lambton Ward of Wellington City, close to the city centre. For people aged 15 years and over, the median income is $\$ 39,300$. This compares with a median of $\$ 28,000$ for all of Wellington Region. It is thus a high income area. (Statistics New Zealand, 2009d). When compared with the data collected for this survey, the respondents generally had a high income, as $20.0 \%$ of the respondents had an annual household income of below 50000 , and $55.5 \%$ of the respondents reported an annual household income of 50001 or above (see Table 3.1). $24.4 \%$ of the respondents chose not to disclose their income. 


\begin{tabular}{|c|c|c|c|c|c|c|c|c|}
\hline \multicolumn{8}{|c|}{ Table 3.1 Overview of income data collected from Brooklyn respondents } \\
\hline Income & $\begin{array}{c}\text { below } \\
20000\end{array}$ & $\begin{array}{c}20001- \\
50000\end{array}$ & $\begin{array}{c}50001- \\
100000\end{array}$ & $\begin{array}{c}100001- \\
150000\end{array}$ & $\begin{array}{c}150001- \\
200000\end{array}$ & $\begin{array}{c}200001 \text { or } \\
\text { above }\end{array}$ & $\begin{array}{c}\text { Undis- } \\
\text { closed }\end{array}$ & \begin{tabular}{c} 
Total \\
\hline$(\mathbf{N})$
\end{tabular} \\
\hline $\mathbf{( \% )}$ & $6.7 \%$ & 6 & 13 & 5 & 6 & 1 & 11 & 45 \\
\hline
\end{tabular}

$66.2 \%$ of people aged 15 years and over in Brooklyn have a post-school qualification, compared with $46.3 \%$ of people throughout Wellington Region. 6.4\% of people aged 15 years and over have no formal qualifications, compared with $19.8 \%$ for Wellington Region as a whole (Statistics New Zealand, 2009d). The respondents in the survey also reported high levels of education; as many as $75.5 \%$ of the respondents from Brooklyn had university degrees or higher qualifications, as can be seen in Table 3.2.

\begin{tabular}{|c|c|c|c|c|c|c|c|c|}
\hline \multicolumn{9}{|c|}{ Table 3.2 Overview of education data collected from Brooklyn respondents } \\
\hline Edu & $\begin{array}{c}\text { Primary } \\
\text { School }\end{array}$ & $\begin{array}{c}\text { secondary } \\
\text { school }\end{array}$ & $\begin{array}{c}\text { high } \\
\text { school } \\
\text { certificate }\end{array}$ & $\begin{array}{c}\text { tertiary/ } \\
\text { trade qual. }\end{array}$ & $\begin{array}{c}\text { Uni. } \\
\text { degree }\end{array}$ & $\begin{array}{c}\text { Postgrad. } \\
\text { degree }\end{array}$ & $\begin{array}{c}\text { Undis- } \\
\text { closed }\end{array}$ & Total \\
\hline $\mathbf{( N )}$ & 0 & 4 & 3 & 6 & 28 & 4 & 0 & 45 \\
\hline$(\%)$ & $0.0 \%$ & $8.9 \%$ & $6.7 \%$ & $13.3 \%$ & $62.2 \%$ & $8.9 \%$ & $0.0 \%$ & $100 \%$ \\
\hline
\end{tabular}

According to the 2006 census data, the share of people under the age of 15 in Brooklyn is $\sim 17 \%$, and the share people aged 65 or above is $\sim 7 \%$ (Statistics New Zealand, 2009d). The respondents from Brooklyn reflected the low percentage of the older age segment, as only $4.4 \%$ of the respondents were over the age of 60 (Table 3.3).

\begin{tabular}{|c|c|c|c|c|c|c|c|c|}
\hline \multicolumn{7}{|c|}{ Table 3.3 Overview of age data collected from Brooklyn respondents } \\
\hline Age & $18-29$ & $30-39$ & $40-49$ & $50-59$ & $60-69$ & $\begin{array}{c}70 \text { or } \\
\text { above }\end{array}$ & $\begin{array}{c}\text { Undis- } \\
\text { closed }\end{array}$ & Total \\
\hline (N) & 9 & 11 & 18 & 5 & 0 & 2 & 0 & 45 \\
\hline$(\%)$ & $20 \%$ & $24.4 \%$ & $40 \%$ & $11.1 \%$ & $0.0 \%$ & $4.4 \%$ & $0.0 \%$ & $100 \%$ \\
\hline
\end{tabular}

The data collected from the residents in Brooklyn seems to fit well with the data from the 2006 census in Wellington, and it can thus be concluded that the sample gives a good representation of the suburb. The response rate for this suburb was $24.3 \%$ which was highest among all the suburbs in the sample. 


\subsubsection{Churton Park}

Churton Park is located in the Northern Ward of Wellington City. For people aged 15 years and over, the median income is $\$ 39,100$. This compares with a median of $\$ 28,000$ for all of Wellington Region, and as such the suburb has a high income profile. (Statistics New Zealand, 2009e). In comparison with the income data collected from Churton Park residents (see Figure 3.3.2.2), $13.5 \%$ of the respondents had an annual household income below 50.000. $73 \%$ reported annual household incomes of above 50001 (see Table 3.4).

\begin{tabular}{|c|c|c|c|c|c|c|c|c|}
\hline \multicolumn{8}{|c|}{ Table 3.4 Overview of income data collected from Churton Park residents } \\
\hline Income & $\begin{array}{c}\text { below } \\
20000\end{array}$ & $\begin{array}{c}20001- \\
50000\end{array}$ & $\begin{array}{c}50001- \\
100000\end{array}$ & $\begin{array}{c}100001- \\
150000\end{array}$ & $\begin{array}{c}150001- \\
200000\end{array}$ & $\begin{array}{c}200001 \text { or } \\
\text { above }\end{array}$ & $\begin{array}{c}\text { Undis- } \\
\text { closed }\end{array}$ & Total \\
\hline $\mathbf{( N )}$ & 1 & 4 & 10 & 14 & 1 & 2 & 5 & 37 \\
\hline$(\%)$ & $2.7 \%$ & $10.8 \%$ & $27 \%$ & $37.8 \%$ & $2.7 \%$ & $5.4 \%$ & $13.5 \%$ & $100 \%$ \\
\hline
\end{tabular}

According to the census data from 2006, 55.3\% of people aged 15 years and over have a postschool qualification, compared with $46.3 \%$ of people throughout Wellington Region. $9.2 \%$ of people aged 15 years and over have no formal qualifications, compared with $19.8 \%$ for Wellington Region as a whole (Statistics New Zealand, 2009e). High levels of education were reflected in the sample: Data collected from the respondents of Churton Park showed that 53.8\% of the respondents had a university degree or higher education levels (see Table 3.5).

\begin{tabular}{|c|c|c|c|c|c|c|c|c|}
\hline \multicolumn{7}{|c|}{ Table 3.5 Overview of education data collected from Churton Park residents } \\
\hline Edu & $\begin{array}{c}\text { Primary } \\
\text { School }\end{array}$ & $\begin{array}{c}\text { secondary } \\
\text { school }\end{array}$ & $\begin{array}{c}\text { high } \\
\text { school } \\
\text { certificate }\end{array}$ & $\begin{array}{c}\text { tertiary/ } \\
\text { trade qual. }\end{array}$ & $\begin{array}{c}\text { Uni. } \\
\text { degree }\end{array}$ & $\begin{array}{c}\text { Postgrad. } \\
\text { degree }\end{array}$ & $\begin{array}{c}\text { Undis- } \\
\text { closed }\end{array}$ & Total \\
\hline $\mathbf{( N )}$ & 0 & 3 & 7 & 7 & 15 & 5 & 0 & 37 \\
\hline$(\%)$ & $0.0 \%$ & $8.1 \%$ & $18.9 \%$ & $18.9 \%$ & $40.5 \%$ & $13.5 \%$ & $0.0 \%$ & $100 \%$ \\
\hline
\end{tabular}

According to the census data from 2006, 26\% of the population in Churton Park is aged 15 and under, and $\sim 6 \%$ are aged 65 and over (Statistics New Zealand, 2009e). The low percentage of the oldest age segment was reflected in the sample data: only $5.4 \%$ of the respondents were aged 70 or above (see Table 3.6).

\begin{tabular}{|c|c|c|c|c|c|c|c|c|}
\hline \multicolumn{1}{|c|}{ Table 3.6 Overview of age data collected from Churton Park residents } \\
\hline Age & $18-29$ & $30-39$ & $40-49$ & $50-59$ & $60-69$ & $\begin{array}{c}70 \text { or } \\
\text { above }\end{array}$ & $\begin{array}{c}\text { Undis- } \\
\text { closed }\end{array}$ & Total \\
\hline $\mathbf{( N )}$ & 5 & 6 & 8 & 11 & 5 & 2 & 0 & 37 \\
\hline$(\%)$ & $13.5 \%$ & $16.2 \%$ & $25.0 \%$ & $29.7 \%$ & $13.5 \%$ & $5.4 \%$ & $0.0 \%$ & $100 \%$ \\
\hline
\end{tabular}


The data collected for this study seems to fit well with the census data for Churton Park collected in 2006, and as such the sample is a good representation of the suburb. Response rate from the suburb was $17.9 \%$.

\subsubsection{Karaka Bays}

Karaka Bays is located in the Eastern Ward of Wellington City, on the Miramar Peninsula at the entrance of Wellington Harbour. The statistics for Karaka Bays is compiled together with statistics for Worser Bay in the census data from 2006, and as such there may be differences due to the fact that Worser Bay was not included in the sample. For people aged 15 years and over, the median income is $\$ 44,000$. This compares with a median of $\$ 28,000$ for all of Wellington Region, and as such this the one suburb in the sample with the highest income profile. (Statistics New Zealand, 2009f). As can be seen in Table 3.7 below, the level of high income was reflected in the sample: $63.6 \%$ of the respondents had an annual household income of more than 50,000. $18.2 \%$ of the respondents chose not to disclose this information.

\begin{tabular}{|c|c|c|c|c|c|c|c|c|}
\hline \multicolumn{10}{|c|}{ Table 3.7 Overview of income data collected from Karaka Bays residents } \\
\hline Income & $\begin{array}{c}\text { below } \\
20000\end{array}$ & $\begin{array}{c}20001- \\
50000\end{array}$ & $\begin{array}{c}50001- \\
10000\end{array}$ & $\begin{array}{c}100001- \\
150000\end{array}$ & $\begin{array}{c}150001- \\
200000\end{array}$ & $\begin{array}{c}200001 \text { or } \\
\text { above }\end{array}$ & $\begin{array}{c}\text { Undis- } \\
\text { closed }\end{array}$ & Total \\
\hline (N) & 1 & 4 & 11 & 9 & 8 & 3 & 8 & 44 \\
\hline$(\%)$ & $2.3 \%$ & $9.1 \%$ & $25.0 \%$ & $20.4 \%$ & $18.2 \%$ & $6.8 \%$ & $18.2 \%$ & $100 \%$ \\
\hline
\end{tabular}

61.2\% of people aged 15 years and over in Karaka Bays have a post-school qualification, compared with $46.3 \%$ of people throughout Wellington Region. $7.6 \%$ of people aged 15 years and over have no formal qualifications, compared with $19.8 \%$ for Wellington Region as a whole (Statistics New Zealand, 2009f). When compared with the data collected for this study, the sample reflects a high level of education: $59.1 \%$ of the respondents have a university degree or higher qualification (see Table 3.8).

\begin{tabular}{|c|c|c|c|c|c|c|c|c|}
\hline \multicolumn{9}{|c|}{ Table 3.8 Overview of education data collected from Karaka Bays residents } \\
\hline Edu & $\begin{array}{c}\text { Primary } \\
\text { School }\end{array}$ & $\begin{array}{c}\text { secondary } \\
\text { school }\end{array}$ & $\begin{array}{c}\text { high } \\
\text { school } \\
\text { certificate }\end{array}$ & $\begin{array}{c}\text { tertiary/ } \\
\text { trade qual. }\end{array}$ & $\begin{array}{c}\text { Uni. } \\
\text { degree }\end{array}$ & $\begin{array}{c}\text { Postgrad. } \\
\text { degree }\end{array}$ & $\begin{array}{c}\text { Undis- } \\
\text { closed }\end{array}$ & Total \\
\hline $\mathbf{( N )}$ & 0 & 4 & 7 & 7 & 16 & 10 & 0 & 44 \\
\hline$(\%)$ & $0.0 \%$ & $9.1 \%$ & $15.9 \%$ & $15.9 \%$ & $36.4 \%$ & $22.7 \%$ & $0.0 \%$ & $100 \%$ \\
\hline
\end{tabular}

According to census data from 2006, 21\% of the population in Karaka Bay/Worser Bay is aged 15 or under, and $\sim 11 \%$ of the population is over 65 years of age (Statistics New Zealand, 2009f). The data collected for this study fits well with the data from the census, although the 
representation of the over 69 age group in the sample is somewhat higher (13.6\%) (see Table 3.9).

\begin{tabular}{|c|c|c|c|c|c|c|c|c|}
\hline \multicolumn{7}{|c|}{ Table 3.9 Overview of age data collected from Karaka Bays residents } \\
\hline Age & $18-29$ & $30-39$ & $40-49$ & $50-59$ & $60-69$ & $\begin{array}{c}70 \text { or } \\
\text { above }\end{array}$ & $\begin{array}{c}\text { Undis- } \\
\text { closed }\end{array}$ & Total \\
\hline $\mathbf{( N )}$ & 4 & 5 & 9 & 12 & 8 & 6 & 0 & 44 \\
\hline$(\%)$ & $9.1 \%$ & $11.4 \%$ & $20.4 \%$ & $27.2 \%$ & $18.2 \%$ & $13.6 \%$ & $0.0 \%$ & $100 \%$ \\
\hline
\end{tabular}

In conclusion, the data collected from the respondents seems to give a good representation of the population in Karaka Bays; however the limitations above are noted. The response rate for this suburb was $22 \%$.

\subsubsection{Lyall Bay}

Lyall Bay is located in the Eastern Ward of Wellington City, close to the airport. For people aged 15 years and over, the median income is $\$ 29,700$. This compares with a median of $\$ 28,000$ for all of Wellington Region (Statistics New Zealand, 2009g). The data collected from the sample shows that $67.8 \%$ of the respondents have an annual household income of more than 50,000 (see Table 3.10). This indicates that the sample data is skewed towards the population within the suburb that has a higher income.

\begin{tabular}{|c|c|c|c|c|c|c|c|c|}
\hline \multicolumn{8}{|c|}{ Table 3.10 Overview of income data collected from Lyall Bay residents } \\
\hline Income & $\begin{array}{c}\text { below } \\
20000\end{array}$ & $\begin{array}{c}20001- \\
50000\end{array}$ & $\begin{array}{c}50001- \\
100000\end{array}$ & $\begin{array}{c}100001- \\
150000\end{array}$ & $\begin{array}{c}150001- \\
200000\end{array}$ & $\begin{array}{c}200 \text { 001 or } \\
\text { above }\end{array}$ & $\begin{array}{c}\text { Undis- } \\
\text { closed }\end{array}$ & Total \\
\hline $\mathbf{( N )}$ & 2 & 4 & 11 & 6 & 2 & 0 & 3 & 28 \\
\hline$(\%)$ & $7.1 \%$ & $14.3 \%$ & $39.3 \%$ & $21.4 \%$ & $7.1 \%$ & $0.0 \%$ & $10.7 \%$ & $100 \%$ \\
\hline
\end{tabular}

According to the census data from 2006, $48.2 \%$ of people in Lyall Bay aged 15 years and over have a post-school qualification, compared with $46.3 \%$ of people throughout Wellington Region. $16.6 \%$ of people aged 15 years and over have no formal qualifications, compared with $19.8 \%$ for Wellington Region as a whole (Statistics New Zealand, 2009g). The data collected for this study varies somewhat from the census data as people with lower levels of education are underrepresented in the sample. The percentage of people in the sample with a university degree or higher qualification is $57.1 \%$ (see Table 3.11 ). 


\begin{tabular}{|c|c|c|c|c|c|c|c|c|}
\hline \multicolumn{8}{|c|}{ Table 3.11 Overview of education data collected from Lyall Bay residents } \\
\hline Edu & $\begin{array}{c}\text { Primary } \\
\text { School }\end{array}$ & $\begin{array}{c}\text { secondary } \\
\text { school }\end{array}$ & $\begin{array}{c}\text { high } \\
\text { school } \\
\text { certificate }\end{array}$ & $\begin{array}{c}\text { tertiary/ } \\
\text { trade qual. }\end{array}$ & $\begin{array}{c}\text { Uni. } \\
\text { degree }\end{array}$ & $\begin{array}{c}\text { Postgrad. } \\
\text { degree }\end{array}$ & $\begin{array}{c}\text { Undis- } \\
\text { closed }\end{array}$ & Total \\
\hline $\mathbf{( N )}$ & 0 & 1 & 3 & 8 & 9 & 7 & 0 & 28 \\
\hline$(\%)$ & $0.0 \%$ & $3.5 \%$ & $10.7 \%$ & $28.6 \%$ & $32.1 \%$ & $25.0 \%$ & $0.0 \%$ & $100 \%$ \\
\hline
\end{tabular}

According to the census data from 2006, 20\% of the population in Lyall Bay is aged 15 and under, and $\sim 10 \%$ of the population is aged 65 and above (Statistics New Zealand, 2009g). When compared to the data collected for this study, it is clear that the data fits well with the age groups in the census (see Table 3.12).

\begin{tabular}{|c|c|c|c|c|c|c|c|c|}
\hline \multicolumn{7}{|c|}{ Table 3.12 Overview of age data collected from Lyall Bay residents } \\
\hline Age & $18-29$ & $30-39$ & $40-49$ & $50-59$ & $60-69$ & $\begin{array}{c}70 \text { or } \\
\text { above }\end{array}$ & $\begin{array}{c}\text { Undis- } \\
\text { closed }\end{array}$ & Total \\
\hline (N) & 6 & 5 & 9 & 5 & 1 & 2 & 0 & 28 \\
\hline$(\%)$ & $21.4 \%$ & $17.8 \%$ & $32.1 \%$ & $17 . \%$ & $3.5 \%$ & $7.1 \%$ & $0.0 \%$ & $100 \%$ \\
\hline
\end{tabular}

There are some variations between the census data from 2006 and the data collected from the respondents. Response rate from this suburb was $15 \%$, which was the lowest response rate among all the suburbs, and could be the explanation for the inconsistency within the data. It can thus be concluded that the characteristics from the sample population is not a good representation of the suburb.

\subsubsection{Mt. Cook}

Mt. Cook is located the Lambton Ward of Wellington City, close to the city centre. At the census home page, Mt Cook suburb is referred to as Mt. Cook-Wallace Street. The area covered does however match the boundaries for the suburb which is mapped by the city council. For people aged 15 years and over, the median income is $\$ 17,500$. This compares with a median of $\$ 28,000$ for all of Wellington Region, and as such the one suburb in the sample with the lowest income profile (Statistics New Zealand, 2009h). The data collected for this study shows that the lower income groups in the suburb is underrepresented; only $9.8 \%$ of the respondents had an annual household income under 50,000 (see Table 3.13 below).

\begin{tabular}{|c|c|c|c|c|c|c|c|c|}
\hline \multicolumn{7}{|c|}{ Table 3.13 Overview of income data collected from Mt Cook residents } \\
\hline Income & $\begin{array}{c}\text { below } \\
20000\end{array}$ & $\begin{array}{c}20001- \\
50000\end{array}$ & $\begin{array}{c}50001- \\
100000\end{array}$ & $\begin{array}{c}100001- \\
150000\end{array}$ & $\begin{array}{c}150001- \\
200000\end{array}$ & $\begin{array}{c}200001 \text { or } \\
\text { above }\end{array}$ & $\begin{array}{c}\text { Undis- } \\
\text { closed }\end{array}$ & Total \\
\hline $\mathbf{( N )}$ & 0 & 4 & 15 & 11 & 5 & 3 & 3 & 41 \\
\hline$(\%)$ & $0.0 \%$ & $9.8 \%$ & $36.6 \%$ & $26.8 \%$ & $12.2 \%$ & $7.3 \%$ & $7.3 \%$ & $100 \%$ \\
\hline
\end{tabular}


According to the census data from 2006, 48.7\% of people aged 15 years and over in Mt CookWallace Street have a post-school qualification, compared with $46.3 \%$ of people throughout Wellington Region. 6.3\% of people aged 15 years and over have no formal qualifications, compared with $19.8 \%$ for Wellington Region as a whole (Statistics New Zealand, 2009h). The data collected from the respondents shows that the people with lower levels of educations are underrepresented: $82.9 \%$ of the respondents had a university degree or a higher qualification (see Table 3.14).

\begin{tabular}{|c|c|c|c|c|c|c|c|c|}
\hline \multicolumn{7}{|c|}{ Table 3.14 Overview of education data collected from Mt Cook residents } \\
\hline Edu & $\begin{array}{c}\text { Primary } \\
\text { School }\end{array}$ & $\begin{array}{c}\text { secondary } \\
\text { school }\end{array}$ & $\begin{array}{c}\text { high } \\
\text { school } \\
\text { certificate }\end{array}$ & $\begin{array}{c}\text { tertiary/ } \\
\text { trade qual. }\end{array}$ & $\begin{array}{c}\text { Uni. } \\
\text { degree }\end{array}$ & $\begin{array}{c}\text { Postgrad. } \\
\text { degree }\end{array}$ & $\begin{array}{c}\text { Undis- } \\
\text { closed }\end{array}$ & Total \\
\hline $\mathbf{( N )}$ & 0 & 0 & 4 & 3 & 23 & 11 & 0 & 41 \\
\hline $\mathbf{( \% )}$ & $0.0 \%$ & $0.0 \%$ & $9.8 \%$ & $7.3 \%$ & $56.1 \%$ & $26.8 \%$ & $0.0 \%$ & $100 \%$ \\
\hline
\end{tabular}

According to the census data from 2006, 4\% of the population in Mt. Cook is older than 65 years, while $\sim 8 \%$ is below the age of 15 (Statistics New Zealand, 2009h). The data collected from the respondents seemed to fit well with the census data, as only $2.4 \%$ of the respondents were older than 59 years old (see Table 3.15).

\begin{tabular}{|c|c|c|c|c|c|c|c|c|}
\hline \multicolumn{7}{|c|}{ Table 3.15 Overview of age data collected from Mt Cook residents } \\
\hline Age & $18-29$ & $30-39$ & $40-49$ & $50-59$ & $60-69$ & $\begin{array}{c}70 \text { or } \\
\text { above }\end{array}$ & $\begin{array}{c}\text { Undis- } \\
\text { closed }\end{array}$ & Total \\
\hline (N) & 10 & 14 & 8 & 8 & 0 & 1 & 0 & 41 \\
\hline$(\%)$ & $24.4 \%$ & $34.1 \%$ & $19.5 \%$ & $19.5 \%$ & $0.0 \%$ & $2.4 \%$ & $0.0 \%$ & $100 \%$ \\
\hline
\end{tabular}

In conclusion, the data collected from the respondents does not seem to give an accurate representation of the population in Mt. Cook. The response rate for this suburb was $21.2 \%$

\subsubsection{Northland}

Northland is located in the Onslow-Western Ward of Wellington City. For people aged 15 years and over, the median income is $\$ 38,800$ compared with a median of $\$ 28,000$ for all of Wellington Region, which constitutes a high income profile (Statistic New Zealand, 2009i). The data collected from the respondents seem to reflect the high income levels; $63.8 \%$ of the respondents had an annual household income of 50,000 or more (See Table 3.16). 


\begin{tabular}{|c|c|c|c|c|c|c|c|c|}
\hline \multicolumn{8}{|c|}{ Table 3.16 Overview of income data collected from Northland residents } \\
\hline Income & $\begin{array}{c}\text { below } \\
20000\end{array}$ & $\begin{array}{c}20001- \\
50000\end{array}$ & $\begin{array}{c}50001- \\
10000\end{array}$ & $\begin{array}{c}100001- \\
150000\end{array}$ & $\begin{array}{c}150001- \\
200000\end{array}$ & $\begin{array}{c}200001 \text { or } \\
\text { above }\end{array}$ & $\begin{array}{c}\text { Undis- } \\
\text { closed }\end{array}$ & Total \\
\hline (N) & 1 & 6 & 8 & 8 & 7 & 0 & 6 & 36 \\
\hline$(\%)$ & $2.8 \%$ & $16.7 \%$ & $22.2 \%$ & $22.2 \%$ & $19.4 \%$ & $0.0 \%$ & $16.7 \%$ & $100 \%$ \\
\hline
\end{tabular}

$69.3 \%$ of people aged 15 years and over have a post-school qualification, compared with $46.3 \%$ of people throughout Wellington Region. 3.8\% of people aged 15 years and over have no formal qualifications, compared with $19.8 \%$ for Wellington Region as a whole (Statistics New Zealand, 2009i). The respondents also reported high education levels: $69.4 \%$ of the respondents had a university degree or higher qualifications (see Table 3.17).

\begin{tabular}{|c|c|c|c|c|c|c|c|c|}
\hline \multicolumn{10}{|c|}{ Table 3.17 Overview of education data collected from Northland residents } \\
\hline Edu & $\begin{array}{c}\text { Primary } \\
\text { School }\end{array}$ & $\begin{array}{c}\text { secondary } \\
\text { school }\end{array}$ & $\begin{array}{c}\text { high } \\
\text { school } \\
\text { certificate }\end{array}$ & $\begin{array}{c}\text { tertiary/ } \\
\text { trade qual. }\end{array}$ & $\begin{array}{c}\text { Uni. } \\
\text { degree }\end{array}$ & $\begin{array}{c}\text { Postgrad. } \\
\text { degree }\end{array}$ & $\begin{array}{c}\text { Undis- } \\
\text { closed }\end{array}$ & Total \\
\hline (N) & 0 & 1 & 3 & 7 & 13 & 12 & 0 & 36 \\
\hline$(\%)$ & $0.0 \%$ & $2.8 \%$ & $8.3 \%$ & $19.4 \%$ & $36.1 \%$ & $33.3 \%$ & $0.0 \%$ & $100 \%$ \\
\hline
\end{tabular}

According to the census data from 2006, $\sim 6 \%$ of the population in Northland is above the age of 65 , while $\sim 18 \%$ of the population is below the age of 15 (Statistics New Zealand, 2009i). The data collected from the respondents seems to fit well with this distribution, as only $2.8 \%$ of the respondents were over the age of 69 (see Table 3.18).

\begin{tabular}{|c|c|c|c|c|c|c|c|c|}
\hline \multicolumn{7}{|c|}{ Table 3.18 Overview of age data collected from Northland residents } \\
\hline Age & $18-29$ & $30-39$ & $40-49$ & $50-59$ & $60-69$ & $\begin{array}{c}70 \text { or } \\
\text { above }\end{array}$ & $\begin{array}{c}\text { Undis- } \\
\text { closed }\end{array}$ & Total \\
\hline (N) & 9 & 4 & 8 & 10 & 4 & 1 & 0 & 36 \\
\hline$(\%)$ & $25 \%$ & $11.1 \%$ & $22.2 \%$ & $27.7 \%$ & $11.1 \%$ & $2.8 \%$ & $0.0 \%$ & $100 \%$ \\
\hline
\end{tabular}

The data collected from the sample seems to be a good representation of the population in Northland. The response rate from this suburb was relatively low at $17.2 \%$.

\subsubsection{Rongotai}

Rongotai is located in the Eastern Ward of Wellington City. It is the connection between the Miramar Peninsula and the mainland, and the airport is located in this suburb. As the populated area constitutes a very small proportion of the suburb, there was not census data collected for Rongotai alone, and so the data presented for this suburb includes part of the neighbouring suburb Kilbirnie. In the census, the area covering Rongotai and part of Kilbirnie is referred to as Kilbirnie East. 
For people aged 15 years and over, the median income is $\$ 23,400$. This compares with a median of $\$ 28,000$ for all of Wellington Region, and as such this suburb has a low income profile (Statistics New Zealand, 2009j). The data collected from the respondents showed that the lower income groups were underrepresented in the sample; $77.2 \%$ of the respondents had an annual household income of 50,000 or more (see Table 3.19).

\begin{tabular}{|c|c|c|c|c|c|c|c|c|}
\hline \multicolumn{7}{|c|}{ Table 3.19 Overview of income data collected from Rongotai residents } \\
\hline Income & $\begin{array}{c}\text { below } \\
20000\end{array}$ & $\begin{array}{c}20001- \\
50000\end{array}$ & $\begin{array}{c}50001- \\
100000\end{array}$ & $\begin{array}{c}100001- \\
150000\end{array}$ & $\begin{array}{c}150001- \\
200000\end{array}$ & $\begin{array}{c}200001 \text { or } \\
\text { above }\end{array}$ & $\begin{array}{c}\text { Undis- } \\
\text { closed }\end{array}$ & Total \\
\hline $\mathbf{( N )}$ & 0 & 4 & 12 & 10 & 4 & 1 & 4 & 35 \\
\hline$(\%)$ & $0.0 \%$ & $11.4 \%$ & $34.2 \%$ & $28.6 \%$ & $11.4 \%$ & $2.9 \%$ & $11.4 \%$ & $100 \%$ \\
\hline
\end{tabular}

38.0 percent of people aged 15 years and over in Kilbirnie East have a post-school qualification, compared with 46.3 percent of people throughout Wellington Region. In Kilbirnie East, 26.5 percent of people aged 15 years and over have no formal qualifications, compared with 19.8 percent for Wellington Region as a whole (Statistics New Zealand, 2009j). This seemed to be reflected in the sample, as $42.3 \%$ of the respondents had university degrees or higher qualifications (see Table 3.20). Although this number is relatively high, it was the lowest percentage of high qualifications among the eight suburbs.

\begin{tabular}{|c|c|c|c|c|c|c|c|c|}
\hline \multicolumn{10}{|c|}{ Table 3.20 Overview of education data collected from Rongotai residents } \\
\hline Edu & $\begin{array}{c}\text { Primary } \\
\text { School }\end{array}$ & $\begin{array}{c}\text { secondary } \\
\text { school }\end{array}$ & $\begin{array}{c}\text { high } \\
\text { school } \\
\text { certificate }\end{array}$ & $\begin{array}{c}\text { tertiary/ } \\
\text { trade qual. }\end{array}$ & $\begin{array}{c}\text { Uni. } \\
\text { degree }\end{array}$ & $\begin{array}{c}\text { Postgrad. } \\
\text { degree }\end{array}$ & $\begin{array}{c}\text { Undis- } \\
\text { closed }\end{array}$ & Total \\
\hline (N) & 0 & 5 & 4 & 11 & 7 & 8 & 0 & 35 \\
\hline (\%) & $0.0 \%$ & $14.3 \%$ & $11.4 \%$ & $31.4 \%$ & $19.4 \%$ & $22.9 \%$ & $0.0 \%$ & $100 \%$ \\
\hline
\end{tabular}

According to the census data from 2006, $\sim 17 \%$ of the population were aged 65 or above, while $18 \%$ of the population were below the age of 15 (Statistics New Zealand, 2009j). The data collected from the respondents shows that the older age group was underrepresented, as only $8.6 \%$ were above the age of 59 (see Table 3.21).

\begin{tabular}{|c|c|c|c|c|c|c|c|c|}
\hline \multicolumn{7}{|c|}{ Table 3.21 Overview of age data collected from Rongotai residents } \\
\hline Age & $18-29$ & $30-39$ & $40-49$ & $50-59$ & $60-69$ & $\begin{array}{c}70 \text { or } \\
\text { above }\end{array}$ & $\begin{array}{c}\text { Undis- } \\
\text { closed }\end{array}$ & Total \\
\hline $\mathbf{( N )}$ & 7 & 9 & 10 & 6 & 3 & 0 & 0 & 35 \\
\hline$(\%)$ & $19.4 \%$ & $25.7 \%$ & $28.6 \%$ & $17.1 \%$ & $8.6 \%$ & $0.0 \%$ & $0.0 \%$ & $100 \%$ \\
\hline
\end{tabular}


The data from the sample population does not seem to give an accurate representation of Rongotai, as it is skewed towards people with higher income levels, and younger age segments. The response rate from this suburb was low at $17.5 \%$.

\subsubsection{Tawa}

Tawa is located in the Northern Ward of Wellington City. It is a large area, and the census chose to divide it in to two areas, namely Tawa Central and Tawa South. The City Council map includes both of these two areas. Therefore the average for the suburb as recorded in the City Council map has been calculated by means of the census data for the two areas.

For people aged 15 years and over, the median income of both census areas is $\$ 29,450$. This compares with a median of $\$ 28,000$ for all of Wellington Region (Statistics New Zealand, $2009 \mathrm{k})$. The data collected from the respondents seems to correspond well with the census data, as the dispersion of annual household income is widespread across the sample (see Table 3.22).

\begin{tabular}{|c|c|c|c|c|c|c|c|c|}
\hline \multicolumn{8}{|c|}{ Table 3.22 Overview of income data collected from Tawa residents } \\
\hline Income & $\begin{array}{c}\text { below } \\
20000\end{array}$ & $\begin{array}{c}20001- \\
50000\end{array}$ & $\begin{array}{c}50001- \\
10000\end{array}$ & $\begin{array}{c}100001- \\
150000\end{array}$ & $\begin{array}{c}150001- \\
200000\end{array}$ & $\begin{array}{c}200001 \text { or } \\
\text { above }\end{array}$ & $\begin{array}{c}\text { Undis- } \\
\text { closed }\end{array}$ & Total \\
\hline (N) & 4 & 5 & 12 & 11 & 2 & 3 & 5 & 42 \\
\hline$(\%)$ & $9.5 \%$ & $11.9 \%$ & $28.6 \%$ & $26.2 \%$ & $4.8 \%$ & $7.1 \%$ & $11.9 \%$ & $100 \%$ \\
\hline
\end{tabular}

$46.7 \%$ of people aged 15 years and over in the two areas have a post-school qualification, compared with $46.3 \%$ of people throughout Wellington Region. $16.3 \%$ of people in the two areas aged 15 years and over have no formal qualifications, compared with $19.8 \%$ for Wellington Region as a whole (Statistics New Zealand, 2009k). The data collected from the sample seems to correspond well with the census data, as the reported levels of education are widespread across the sample (see Table 3.23).

\begin{tabular}{|c|c|c|c|c|c|c|c|c|}
\hline \multicolumn{8}{|c|}{ Table 3.23 Overview of education data collected from Tawa residents } \\
\hline Edu & $\begin{array}{c}\text { Primary } \\
\text { School }\end{array}$ & $\begin{array}{c}\text { secondary } \\
\text { school }\end{array}$ & $\begin{array}{c}\text { high } \\
\text { school } \\
\text { certificate }\end{array}$ & $\begin{array}{c}\text { tertiary/ } \\
\text { trade qual. }\end{array}$ & $\begin{array}{c}\text { Uni. } \\
\text { degree }\end{array}$ & $\begin{array}{c}\text { Postgrad. } \\
\text { degree }\end{array}$ & $\begin{array}{c}\text { Undis- } \\
\text { closed }\end{array}$ & Total \\
\hline $\mathbf{( N )}$ & 1 & 6 & 6 & 9 & 14 & 6 & 0 & 42 \\
\hline $\mathbf{( \% )}$ & $2.4 \%$ & $14.6 \%$ & $14.6 \%$ & $22.0 \%$ & $34.1 \%$ & $14.6 \%$ & $0.0 \%$ & $100 \%$ \\
\hline
\end{tabular}

According to the census data from 2006, 24\% of the residents are aged 15 years and under, while $\sim 13 \%$ are aged over 65 years (Statistics New Zealand, 2009k). The data collected from 
the respondents seem to represent this age dispersion well, as $12.2 \%$ of the respondents are aged 69 and above (see Table 3.24).

\begin{tabular}{|c|c|c|c|c|c|c|c|c|}
\hline \multicolumn{7}{|c|}{ Table 3.24 Overview of age data collected from Tawa residents } \\
\hline Age & $18-29$ & $30-39$ & $40-49$ & $50-59$ & $60-69$ & $\begin{array}{c}70 \text { or } \\
\text { above }\end{array}$ & $\begin{array}{c}\text { Undis- } \\
\text { closed }\end{array}$ & Total \\
\hline $\mathbf{( N )}$ & 2 & 6 & 16 & 7 & 6 & 5 & 0 & 42 \\
\hline$(\%)$ & $4.9 \%$ & $14.6 \%$ & $39.0 \%$ & $17.0 \%$ & $14.6 \%$ & $12.2 \%$ & $0.0 \%$ & $100 \%$ \\
\hline
\end{tabular}

The data collected from the respondents of Tawa seems to represent the population in this suburb well. The response rate from Tawa was $20.8 \%$.

In conclusion, the data seems to overall give a reasonable representation of the suburbs included in the sample; however some of the suburbs (Lyall Bay, Mt. Cook and Rongotai) had an overrepresentation of people with higher education and high levels of income.

\subsection{Data Analysis}

This section will discuss the preparation of the data collected from the respondents and outline the variables used to conduct the statistical analyses. The statistical analyses which were used will be described, and lastly the analytical framework which outlines the way in which analysis was carried out will be presented.

\subsubsection{Data collection and preparation}

The data collection was carried out in late July and early August 2009. To ensure the safety of the researcher, data collection took place during daylight hours. Another person accompanied her to the suburbs and assisted with the distribution of questionnaires. Over a period of 3 weeks 1590 questionnaires were distributed, and 1590 reminders were deposited in the same mail boxes one week after the questionnaire had been delivered. The respondents were given approximately two weeks to complete the questionnaire and put it in the mail. The final response rate was 20\%. 318 questionnaires were returned, and of these 308 were usable. Only 12 respondents completed the questionnaire online.

Each questionnaire was pre-coded prior to the data entry procedure. This was done to lower the error rate, and to make it easier to enter the data into the database. As there were several open 
ended questions, categories needed to be derived from the answers prior to coding. This was done by applying a content analysis technique as described below in Section 3.9.3. This section will outline the variables used for finding variances between populations in the sample, then it will present the various analyses applied, and lastly it will provide a framework which outlines the process of data analysis applied to this research.

\subsubsection{Selection of variables used for statistical analysis}

As mentioned above, the analysis was focussed around three main demographic variables as well as two other variables which were used to explore differences between populations which displayed certain behaviours (participation in carbon offsetting), and populations which had certain perceptions about climate change (likelihood that climate change will affect their lives in a negative manner). This section discusses the selection of these variables.

\subsubsection{Age}

Several researchers have found differences in opinions and behaviours across different age groups (Hares et al., in press; Whitmarsh, 2009; Jagers, 2009). It has been argued that people's behaviours and choices change during the course of a lifetime (Pearce, 1993; Oppermann, 1995; Dellaert et al., 1998). Research has also found that young people are more willing to change their behaviours to protect the environment than are older people (Jagers, 2009). For this reason, age groups within the sample were used to measure differences in behaviours and opinions, to see whether a different approach to changing their behaviours is needed when making recommendations in the concluding sections of the study.

\subsubsection{Income}

Closely linked to age and life stage is discretionary income. As a person moves through different stages in life, he/she has varying amounts of discretionary funds which can be spent on tourism. Discretionary income influences the style of travel, the distances that can be travelled and time that can be spent away from home (Graburn, 1983). Style of travel can be related to the consumption of ecolabeled tourism products and participation in carbon offsetting, given that these components often add to the cost of a holiday, and are not compulsory. For these reasons, annual household income was used to explore the opinions and behaviours of different populations within the sample. One group within the annual household income variable was excluded from the analyses, namely those who chose not to disclose their income. 


\subsubsection{Education}

Education level is a factor that is commonly assumed to be important for the generation of environmentally and socially concerned attitudes and behaviours (Jagers, 2009). It has also been argued that science education has an impact on the understanding of climate change, although this may not be applicable to other education (Whitmarsh, 2009). It can also be argued that people's ability to understand complex phenomena increases with education, and the research conducted on climate change is commonly not communicated in terms that are easy for non experts to understand (Peet, 2009; Carter, 2009). As such, level of education was investigated to explore differences in behaviours and opinions among the respondents. For the sake of the some tests, one population within the level of education variable was excluded, namely primary school. This population consisted of only one respondent, and did as such not qualify for statistical testing.

In addition to the demographic variables, four other variables were used to test for variances between populations:

\subsubsection{Participation in carbon offsetting}

Participation in carbon offsetting was used in a few instances to test for differences in opinions about environmentally friendly behaviour among the respondents. Given that people who participate in carbon offsetting are displaying a behaviour which strongly indicates a desire to lessen their negative impact on the global natural environment in relation to travel, this variable was used to test for differences between participants and non-participants in regards to the difficulty of knowing how to behave in an environmentally responsible manner when travelling, the importance of limiting one's negative impact on the environment when travelling, and the usefulness of purchasing environmentally friendly tourism products. It is however noted that participation was low, and the findings only give an indicator of the variances between opinions of participants and non-participants.

\subsubsection{Likelihood that climate change will have a negative effect on daily life in New Zealand within the next 20 years}

This variable was used to test for differences in opinions. Lorenzoni et al. (2007) argued that there are certain barriers for the public to engage with climate change. Some of these barriers include the fact that other social problems such as health and security are more important to people, and therefore climate change is not prioritised. Also, climate change is perceived as a 
problem that is far removed in space and time, which makes this problem less urgent to people. For this reason, the variable above provides an estimate of people's perception of the severity and urgency of dealing with climate change. The variable was used to test whether the perception that climate change will have a direct affect on people's lives has an impact on their opinions and behaviours.

\subsubsection{Trip Frequency and $\mathrm{CO}_{2}-\mathrm{E}$ emissions made on trips}

Trip frequency and frequencies of $\mathrm{CO}_{2}$-E emissions were used to analyse the relationship between concern for the environment and behaviours. These variables give an indicator of the impact that the respondents have on the environment, and therefore serve as useful measurements of behaviour.

\subsubsection{Types of analyses used}

To find the statistical significant relationships between groups of respondents and their opinions and behaviours, a range of statistical tests were used. This section will introduce the various analyses as well as key statistical terms.

\subsubsection{Statistical significance}

Statistically significance was accepted at the 0.05 level throughout the analysis. This means that an analysis which has a result of 0.05 or lower implies the confidence that its result shows a truly significant relationship lies within 95\% (McCabe \& Moore, 2003). Thus, if a test shows $<0.05$ level of significance, the probability that this result occurred by chance is rejected. The tests which make use of the $<0.05$ level of significance include the chi square test, ANOVA and Levene's test (as described below).

\subsubsection{Normal Distribution}

To be able to use certain tests such as ANOVA and T-tests, the population has to have a normal distribution. A normal distribution describes data that cluster around a mean or average, and that shows a normal bell-curve with no significant skewness (Salkind, 2007). There are several statistical tests that can be applied to check whether the data has a normal distribution. For the purpose of this research, the Kolmogorov-Smirnov test was used in SPSS to test whether the 
population had a normal distribution within the variables that were used in the analysis. Q-Q plots were also used to check for normal distribution within each population in the sample that was used for testing of variances between groups in relation to other variables.

\subsubsection{Chi square}

Chi square test or a 'goodness of fit' test is a non-parametric test that is used to test for variances between populations in a sample when the data is quantitative. This applies to nominal and ordinal variables. Basically, the chi square test shows whether observed distributions of frequencies are different from what would be expected if the results occurred by chance (Salkind, 2007).

The hypotheses used for the chi square tests included the null hypothesis (no difference in the frequency or the proportion of occurrences in the different categories) and the alternative hypothesis (that there is a difference in the frequency or proportion of occurrences between two or more of the different categories) (Salkin, 2007). For the chi square tests used in this study, a significance level of 0.05 was accepted to reject the null hypothesis.

\subsubsection{One-Way ANOVA}

The analysis of variance (ANOVA) test is a parametric test used to test for statistically significant variances between several group means. In order to perform a One-Way ANOVA test (an analysis of variance test based on one sample), there are two basic assumptions that must be fulfilled (Field, 2009):

- Each population from which a sample is taken is assumed to be normal.

- The populations are assumed to have equal standard deviations (or variances).

The Levene's test of homogeneity was used to confirm that the populations had equal standard deviations. The Levene's test also makes use of a 0.05 significance level; if the test shows $<0.05$ significance then the populations do not have equal standard deviations, the test has failed, and other types of analyses must be used.

Although t-tests and ANOVA are not originally designed for use with Likert scale questions, given that these scales produce data that in theory is ordinal data and not interval data, such tests are often used to test for statistically significant variances between means reported by various groups across the sample (Agresti, 2002). Whether the data collected by means of a Likert scale 
is ordinal or interval data has been much debated. The arguments against using Likert based data in the same way as interval data mainly claim that it is impossible to assume that respondents will assume that all pairs of adjacent levels are equidistant. However, when the wording of the categories in the Likert scale implies a symmetry about a middle category, the item would fall somewhere between ordinal and interval level measurements, and the variables will possess important quantitative features (Agresti, 2002 p. 3).

Using ANOVA to analyse variances between group means for variables where Likert scales have been applied is very common in current research - even where as few as four categories have been applied. As such, the researcher felt confident in using ANOVA as a means of finding statistically significant variance between multiple groups in the sample. ANOVA can however only indicate whether the null hypothesis can be rejected or not, so Post Hoc tests were used to further explore variables where ANOVA indicated that such significance was present in order to identify the populations which differed significantly to the rest of the sample.

\subsubsection{Scheffe test}

Scheffe's test is one of the most commonly used post hoc tests in tourism literature where quantitative methods have been applied. As the demographic variables used for comparisons between groups in the population were unequal in size, the Scheffe post-hoc test was used to identify which of the groups that produced significantly different values than the rest (Sirkin, 2006). The Scheffe test as with the other post hoc analyses available in SPSS compares all the groups in the ANOVA tests pairwise to identify differences between groups, and to eliminate groups that do not show statistical variances with the rest of the sample.

\subsubsection{Error bar charts}

Error bar charts showing 95\% confidence intervals were used to provide a visual presentation of differences between groups. Error bars show the mean, and the confidence interval for each population within a sample. A confidence interval is a projection of statistical certainty on the means that are found in a sample of a population (Field, 2009). Confidence intervals show the range of means, within which it is $95 \%$ certain that the true mean of the population from which the sample was drawn will be found. The smaller the population, the bigger the bar will be, which represents the increased level of uncertainty that small populations can induce. 


\subsubsection{Content analysis}

Content analysis was used to analyse the qualitative data gathered in the open-ended questions. This type of analysis is based on examination of the data aimed to identify recurrent instances, which can be grouped together by a coding system for the purpose of quantitative analysis (Silverman, 2004). The coding was completed in two stages: firstly the statements made by the respondents were read and categories were produced as appropriate. Once all of the statements had been read, the categories were finalised, and the statements were coded accordingly. The finished quantifications of these variables were backed up with quotes from the participants in the findings sections.

\subsubsection{Impact assessments}

Assessing the impacts in terms of $\mathrm{CO}_{2}$-E emissions was done in two steps: Firstly, the distances to the destinations reported by the respondents were calculated using an online distance calculator from InfoPlease.com (2009). This calculator would calculate the distance between Wellington and the destination in kilometres using the latitude and longitude value of the destinations. In instances where the respondents had not specified the city which they visited, but only the country or the geographic region, the capital of the country was used as a marker. This happened only in two cases, where the respondents had reported Yukon in Canada and Australia as their holiday destinations. While this technique does not provide exact results, the approximates serve as a good indication of the minimum distance that the respondents travelled on the reported holidays. Secondly, $\mathrm{CO}_{2}$-E emissions were calculated using CarboNZero's (2009b) travel calculators. These calculators take into account the distance travelled and the mode of transportation used.

\subsubsection{Strategy for analysis}

The analysis is focussed on the five objectives of the study which were presented in Chapter one. Each objective has several corresponding variables which served to collect data which informed the objectives, as can be seen in Figure 3.4 below. The data which was gathered for each variable (which represented a question in the questionnaire) was analysed by means of the analyses which all were described in Section 3.9.3 (with the exception of frequencies). Frequencies were used in most cases to get an overview of the data. For many variables where the aim was to identify frequencies of topic, such as questions where the respondents answered yes or no, this was the only form of analysis used. In the case of open ended questions, content 
analysis was used to derive categories from the raw data. This identified the most mentioned terms, and enabled frequency counts.

Cross tabs and ANOVA were used to find relationships between various sets of data. For the most part, these types of analyses were used to identify significant relationships between the variables related to the objectives and populations within the demographic variables, to discover segments which displayed certain types of behaviour or whose opinions varied significantly from the rest of the sample. In addition to the three main demographic variables, some variables which described behaviour or opinions were also analysed with ANOVA to identify groups who displayed significantly different (see section 3.9.2). In order to explore the relationship between behaviours and concern for the environment, ANOVA was used to identify relationships between variables representing concern for the environment (mainly variables related to Objectives 2, 3 and 4), and variables related to behaviour (trip frequency and calculations of $\mathrm{CO}_{2}$-E emissions).

The analytical framework presented in Figure 3.4 on the next two pages shows a full overview of all the variables included in the research, and the various analysed which apply to each variable. 
Figure 3.4 Analytical framework

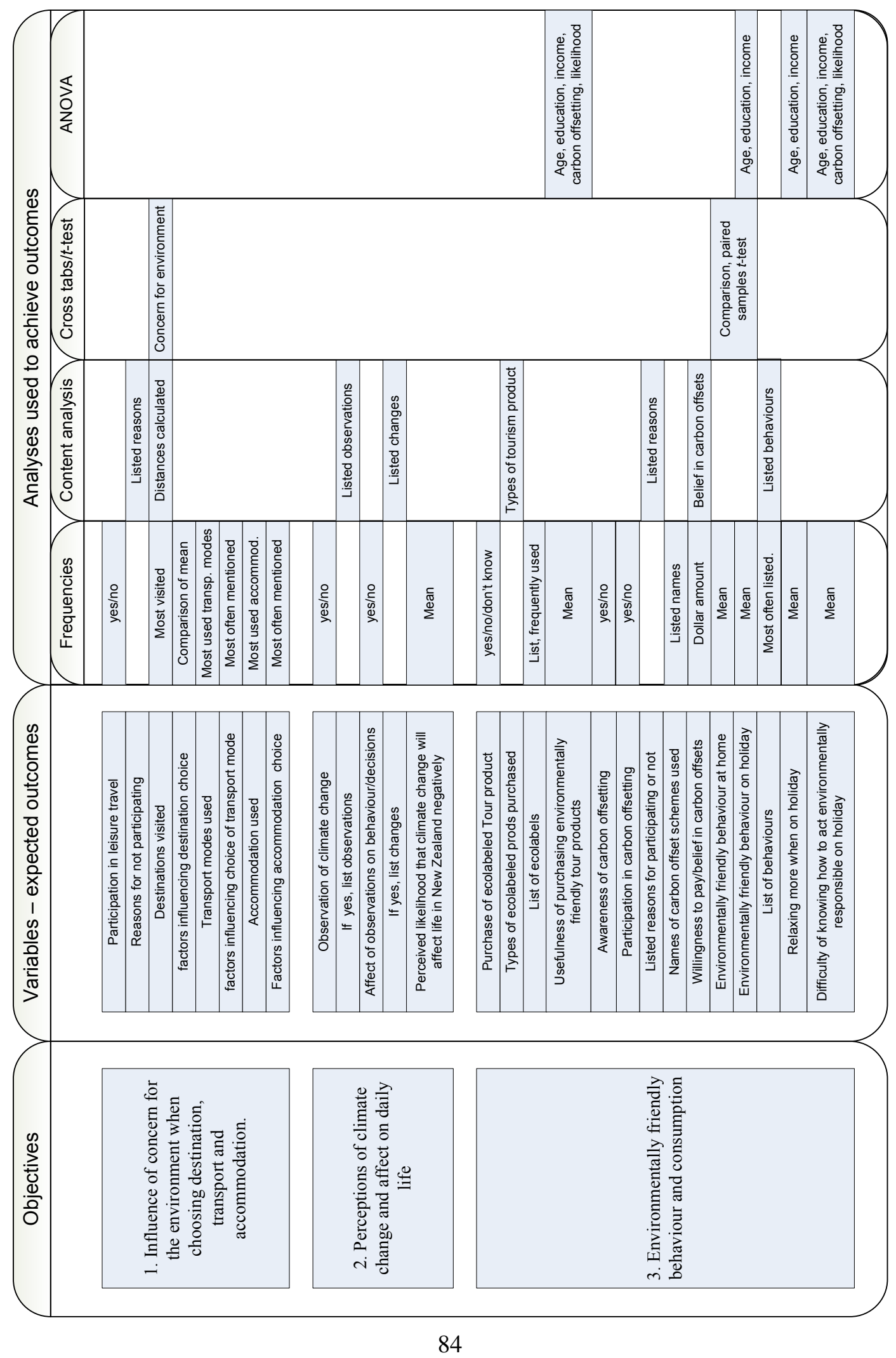


3.4 Analytical framework - continued.

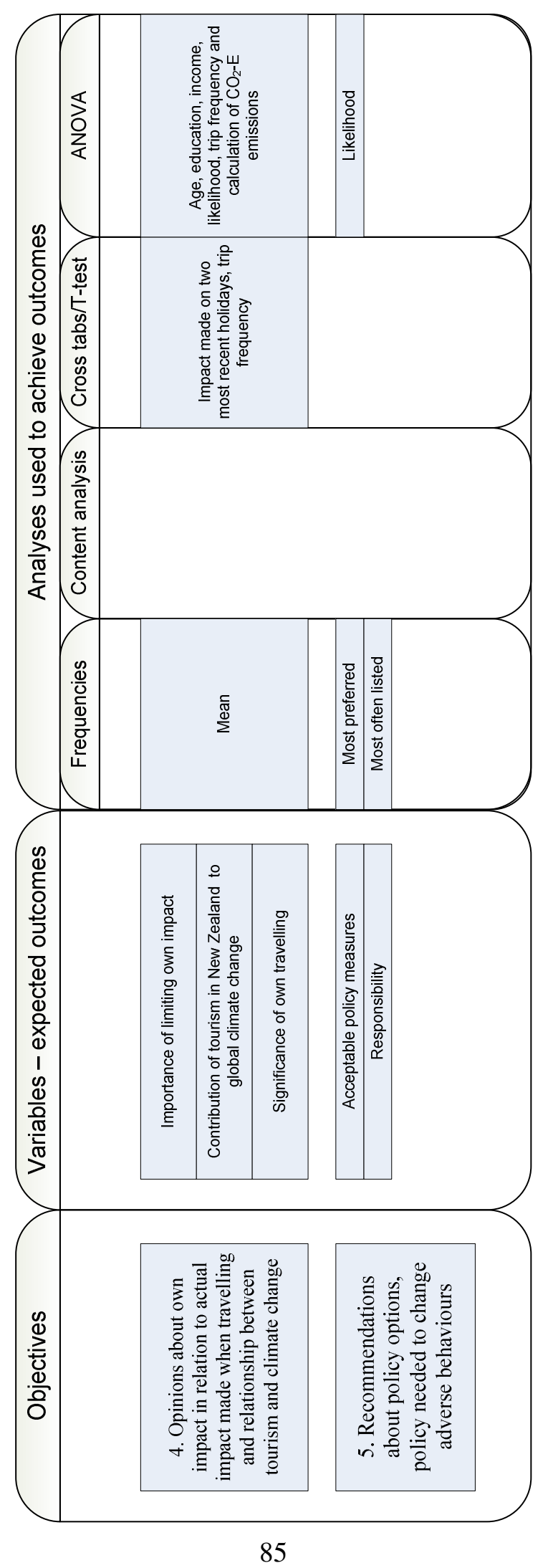




\subsection{Secondary data}

Secondary data was used from two main sources. Statistics New Zealand provided demographic data on the suburbs in the sample; level of education of the residents in the suburbs, the median household income, common occupational groups which enabled the researcher to determine the socio economic profile of the suburbs, and data about the age of the people residing in each suburb. Statistics New Zealand also provided the researcher with valuable data on the population in Wellington City, and national averages that acted as a comparative.

Secondary data from the Ministry of Tourism was used to contextualise the study, and to supply data on New Zealanders' holiday behaviours. The Ministry collects quantitative data on outbound travel and domestic tourism, which shows the frequencies of trips and dispersions of tourists travelling domestically and internationally. It also shows the main purpose of the outbound trips, and the most popular destinations for New Zealanders.

\subsection{Limitations of the research}

The selected methodology has several strengths as well as limitations. While the strengths have been emphasised throughout Chapters two and three, the limitations now need to be recognised, and the findings must be viewed in light of these limitations.

Mail surveys do have some general limitations due to the fact that the interviewer is not present at the scene: The identity of the respondent cannot be checked, and there is no chance for the interviewer to clarify questions which are unclear to the respondents (Aaker et al., 1995). The research topic is one that has been subject to much debate lately, and as such it is possible that the responses were generated among people who felt strongly about the topic. Also, it was not possible to ask respondents to clarify their answers, which led to some confusion regarding the intention behind some of the answers of the open ended questions. Where this confusion was too great, the answer would either be excluded, or recorded in a separate category labelled 'other.'

As the dwellings were identified by use of maps and satellite images, there was a chance that some households remained unidentified. Maps and images are sometimes not up to date, and areas may change to some degree. In addition to some newly built houses that the researcher did not identify through the sampling technique, some of the houses had several apartments, and this was not necessarily visible or recorded on the maps. An attempt to limit selection bias was 
made by being consistent and not deviating from the original sampling procedure. Whenever the researcher encountered a home that had more mailboxes than recorded on the maps, the survey was deposited only in the mailboxes which were originally chosen through the sampling technique.

The response rate was low at $20 \%$. As some of the sample populations included less than 30 respondents, some of the results from this research produced by chi square tests and ANOVA cannot be generalised, as this requires sample populations of 30 or more individuals in each group (Salkind, 2007). The results do however provide valuable information about the sample.

\subsection{Conclusion}

This chapter has accounted for the selection of methodology, and the selection of study site and sampling technique. The suburbs included in the sample have been described to provide context to the reader. Further, the process of collecting and analysing the primary data for this research was described in detail in Section 3.9. The various analyses used have been accounted for and explained, and the limitations of the research have been recognised.

The following three chapters will present the findings from the study. Chapter four concentrates on description of the sample population and trip characteristics. In Chapter five goes one step further, to investigate people's opinions and behaviours, and observation of climate change as well as the effect of observations on people's behaviours. In the final sections of the chapter, participation in carbon offsetting and purchase of ecolabeled tourism products is explored. Chapter six aims to explore the relationships between behaviours and opinions about tourism and climate change, to find explore whether people perceive the two phenomena to be related, and whether opinions about environmental impact of tourism has an effect on their travelling behaviours. Lastly, people's preference for possible policy options is explored. 


\section{Chapter 4 Sample population, participation in leisure travel and trip characteristics}

\subsection{Introduction}

The previous chapter presented the selection of methodology and the process of extracting the sample population from the sampling frame. Through a multistage sampling technique, the final sample consisting of respondents from eight suburbs in Wellington City was selected. This chapter will focus on describing the main demographic characteristics of the sample, and put these into the context of Wellington City. The three main demographic variables which will be used to compare different groups in the sample, namely age, annual household income and level of education, will be explored in relation to census data about the population in Wellington dated to 2006. Other variables related to behaviours were recorded to analyse differences in opinions between populations that display certain behaviours, as outlined in Chapter three. Participation in travel for leisure purposes by people in the sample will be presented, and reasons for non participation outlined, with the aim to explore whether concern for the environment feature as a factor which influences participation in leisure travel. Lastly, trip characteristics from the holidays reported on will be outlined. Trip characteristics outline behaviours that are directly or indirectly related to the impact that people's leisure trips have on the global natural environment, and serve as measurements towards which opinions can be analysed in Chapter six. The trip characteristics reported by the respondents were compared to data from the Ministry of Tourism where this was possible, to put the results into the context of New Zealand.

\subsection{Demographics of the sample population}

The research was conducted in Wellington City, and the following section is concerned with examining the sample population in relation to external data available on the population of Wellington City: Census data from Wellington City collected in 2006 serves as a reference with which the data collected for this research is compared.

\subsubsection{Gender dispersion}

Females made up 64\% of the total share of respondents.According to Statistics New Zealand Census data from 2006, 51.6\% of Wellington's residents are female. This means that the female 
population is overrepresented in the sample. As the sampling procedure within each household did not ensure an equal distribution, the difference between census data and the sample may be coincidental. Separating between males and females may be useful in some types of research; however, climate change affects the entire population, and whereas some demographic variables may be used to segment the population into groups for targeting education initiatives and information campaigns, gender was not deemed to be useful for such a purpose. Thus, this variable was not used for statistical analysis.

\subsubsection{Age dispersion}

The researcher recorded the age of the respondents with the objective of testing various travel behaviours across different age groups. A thorough description of the age categories within each suburb was provided in Chapter three. As can be seen in Figure 4.1, the sample included respondents from all age groups, although the older age-groups contain fewer respondents than those aged less than 59 years. There were few respondents younger than 20 years old (3.6\%), therefore these respondents were combined with the 20-29 years age group. Similarly, there were few respondents that were older than 80 years old $(2.6 \%)$, therefore these respondents were collapsed into the "70 or above" age-group. This resulted in six categories which were used for analysis.

\section{Figure 4.1.Age dispersion across sample}

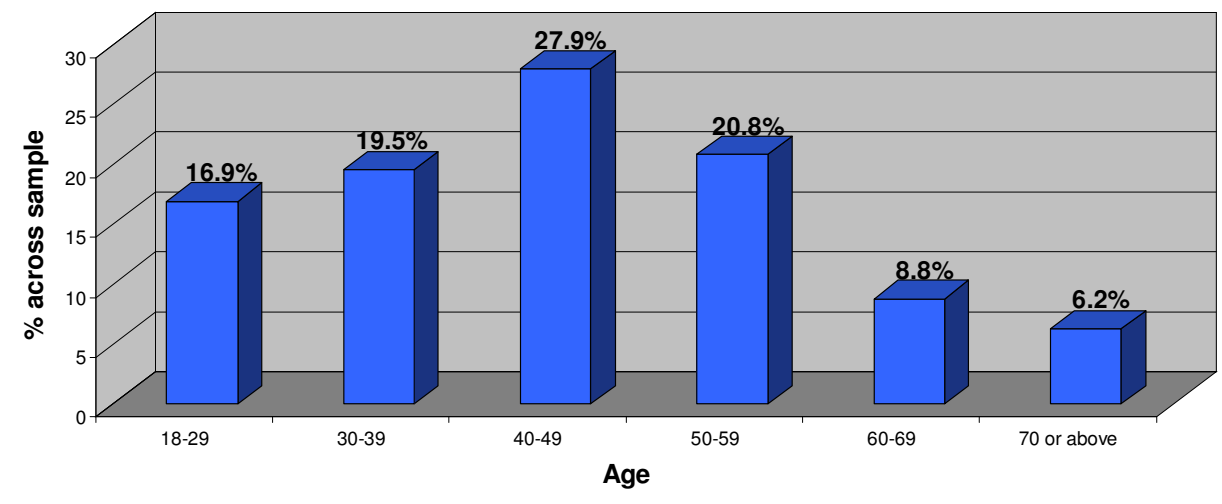

When compared to census data (see Figure 4.2), it is evident that the age dispersion in the sample is slightly different from the age dispersion in Wellington City; the largest difference is in the high percentage of participants within the age group of 20-29 years and 30-39 years of age. In the sample, the age group that has the highest representation is 40-49 years of age (27.9\%), followed by the 50-59 age group (20.8\%). As one of the criteria for completing the 
survey were that the respondents had to be older than 18 , no data was collected from people under 18 years of age even though this age group is populous in Wellington City. This could be a contributing factor to the skewed representation of age in the sample. Another factor includes the voluntary nature of the survey.

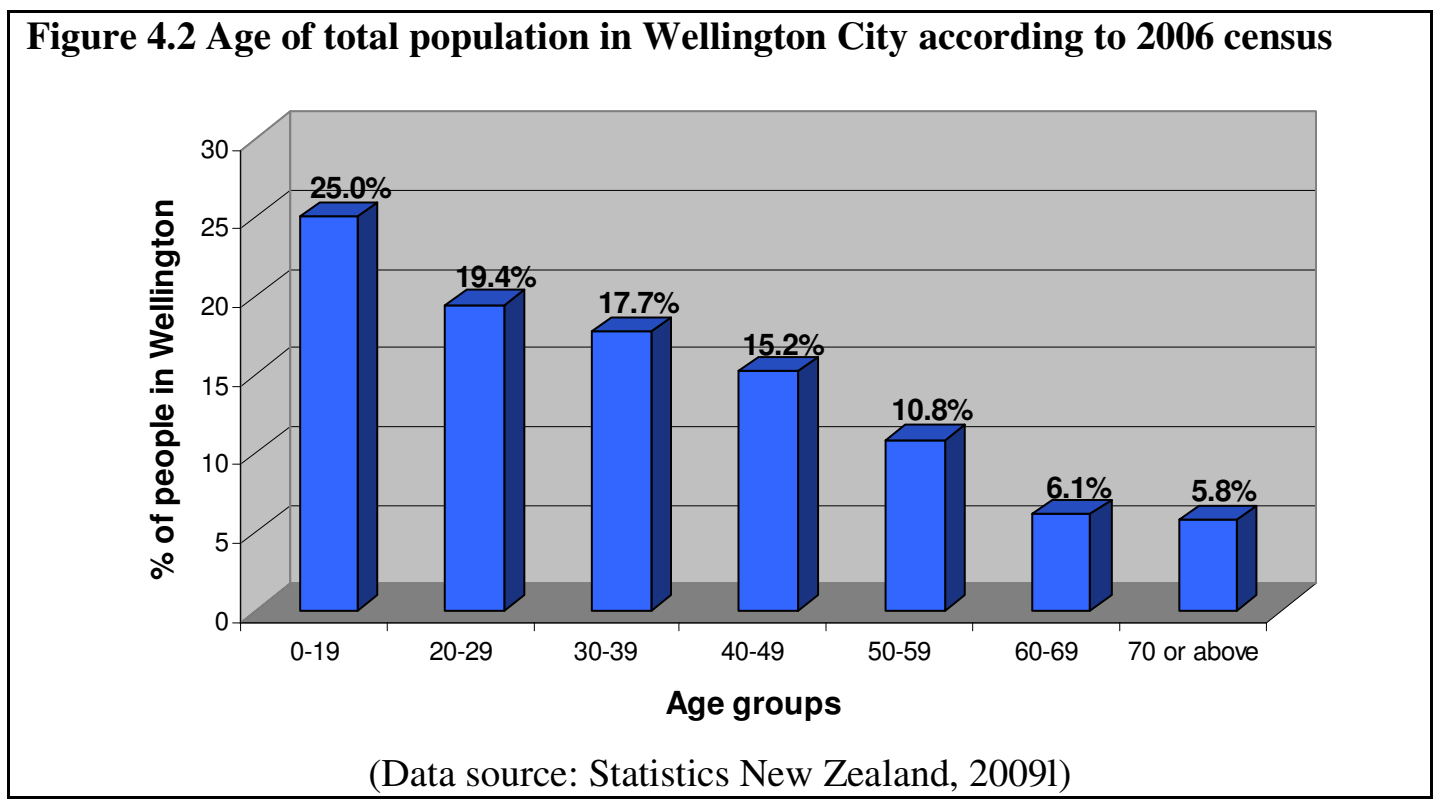

\subsubsection{Household characteristics}

The stage that people are at in their life cycle tends to influence their propensity and ability to travel (Oppermann, 1995, Pearce, 1993). People who have children tend to travel less often, while young professionals without children or so called 'empty nesters' (recently retired with children out of the home) tend to travel more often. While most of the respondents (62\%) lived in households with no children, $31.5 \%$ of the respondents had one or two children under the age of 18. Table 4.1 shows that respondents most commonly lived in households of one or two adults, and most of the respondents who had children lived in households with two adults.

\begin{tabular}{|c|c|c|c|c|c|}
\hline \multicolumn{6}{|c|}{ Table 4.1 Adults and children in the sample households } \\
\hline & \multicolumn{5}{|c|}{ Number of children within households (\% of population) } \\
\hline People in Household & $\begin{array}{l}0 \text { Children } \\
(62 \% \text { of } T)\end{array}$ & $\begin{array}{c}1 \text { Child } \\
(13 \% \text { of } T)\end{array}$ & $\begin{array}{l}2 \text { Children } \\
(18.5 \% \text { of } \mathrm{T})\end{array}$ & $\begin{array}{l}3 \text { or more } \\
\text { children } \\
(6.5 \% \text { of } T)\end{array}$ & $\begin{array}{l}\text { Total }(T) \\
(100 \%)\end{array}$ \\
\hline 1 Adult (N) & 39 & 4 & 5 & 0 & 48 \\
\hline 2 Adults (N) & 105 & 27 & 42 & 16 & 190 \\
\hline 3 Adults (N) & 21 & 7 & 6 & 2 & 36 \\
\hline 4 or more Adults $(\mathrm{N})$ & 26 & 2 & 4 & 1 & 33 \\
\hline Total (N) & 191 & 40 & 57 & 19 & 307 \\
\hline
\end{tabular}


Although the number of children may have an effect on behaviour, the main emphasis of this study was on concern for the environment. Initial tests were run to see whether the variable had any influence on opinions about tourism and its impact on the global natural environment; however no significant relationships were discovered. As such, this variable was abandoned.

\subsubsection{Income dispersion}

A large influence on the propensity to travel is access to discretionary income (Goeldner \& Ritchie, 2006). The sample included suburbs of various socio economic profiles, and the researcher was interested in exploring the influence of income on Wellington residents when making travel choices, given that purchasing environmentally friendly products often incur an additional costs. As can be seen in Figure 4.3, the sample included people from all income brackets, but rather few of the respondents belonged to the lower and higher income brackets, with $3.9 \%$ of the respondents' households earning less than 20,000 and $4.2 \%$ earning more than 200,000 .

\section{Figure 4.3 Household income dispersion across sample}

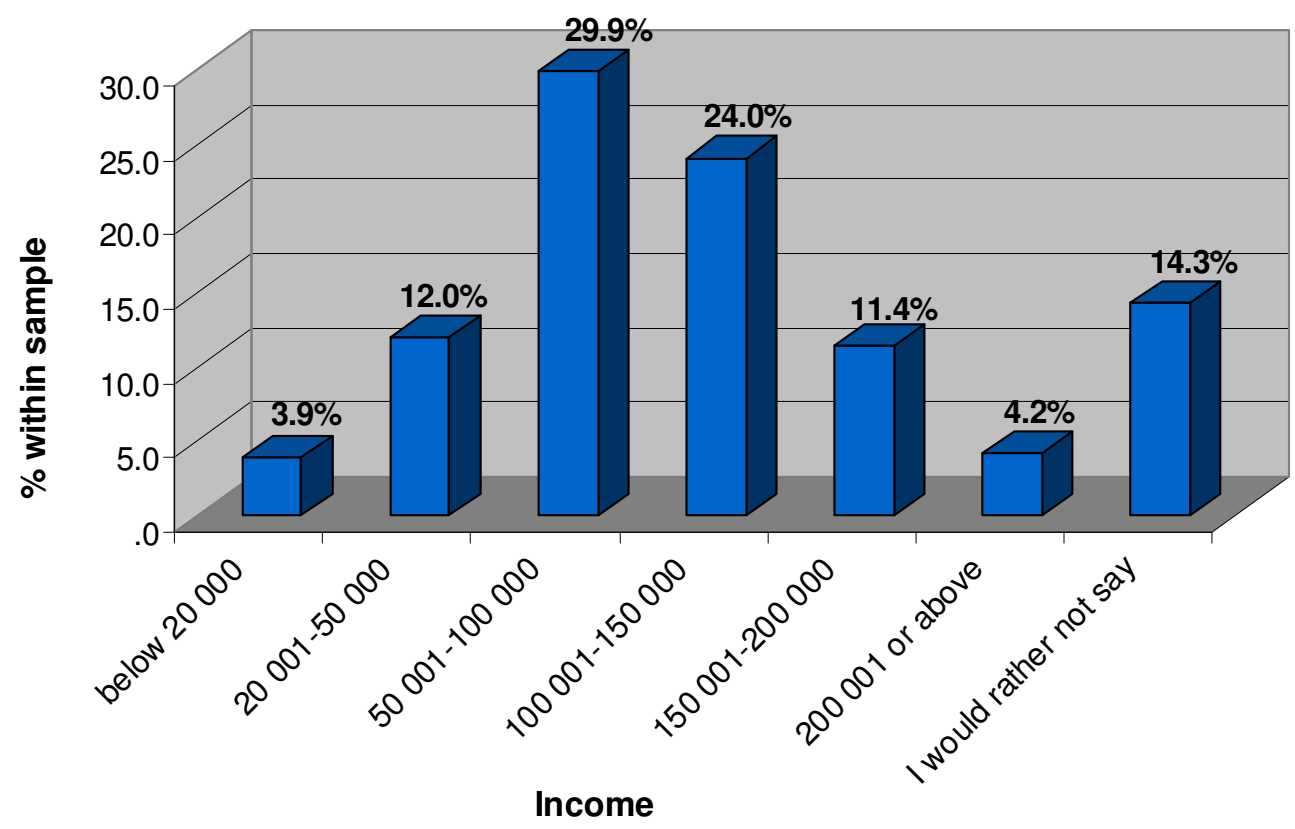

Census data recorded by Statistics New Zealand is rather detailed when it comes to lower income brackets, but the highest income value recorded in the census is "100 001 or above." 
This is due to the fact that the income data recorded by Statistics New Zealand is per individual, while the focus of this study was on household income. As most of the respondents live in households with two or more adults, it is not possible to make a direct comparison between the data collected for this study and the data from Statistics New Zealand. An attempt to make a general comparison between the census data and the data collected from the respondents was made in Chapter three. As can be seen in Figure 4.4 below, the dispersion of income in Wellington City is seemingly different from the dispersion in the sample, as a larger portion of the residents in Wellington City have incomes under 20,000.

\section{Figure 4.4 Income dispersion among Wellington residents according to 2006 census}

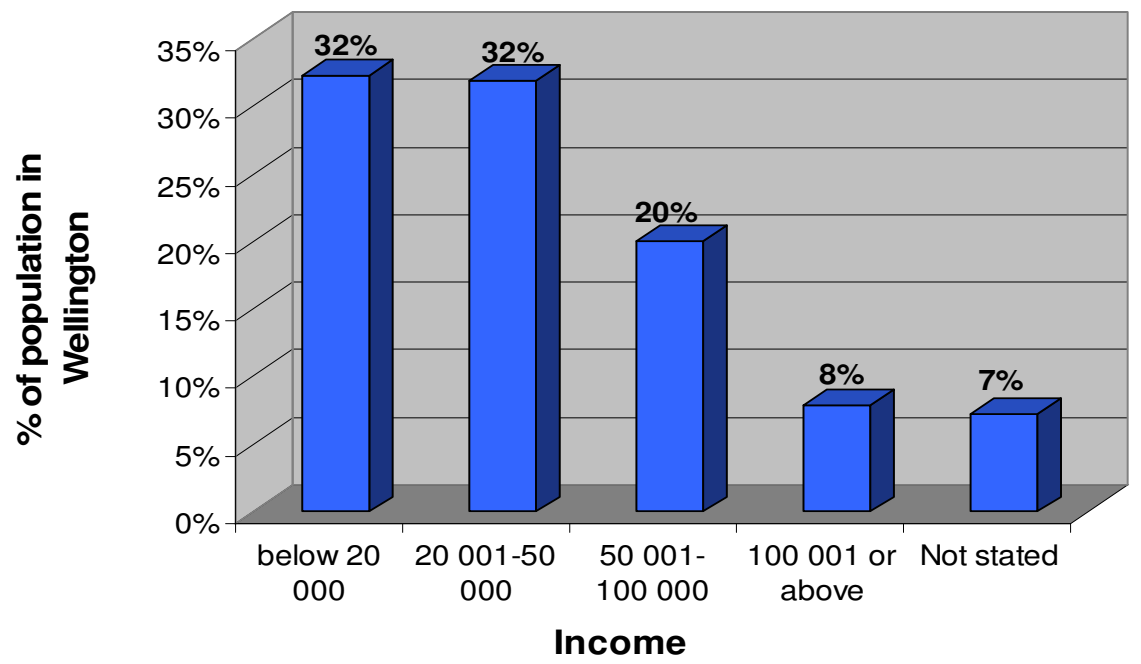

(Source: Statistics New Zealand, 20091)

\subsubsection{Education}

As mentioned in Chapter three, level of education is a variable that is commonly assumed to be important for the generation of environmentally and socially concerned attitudes and behaviours (Jagers, 2009) There has also been much criticism that the research that has been done to investigate the relationship between human activities and climate change is poorly communicated to the general public, and that one has to have a high level of expertise to be able to understand the tables and figures that are presented to show the severity of climate change that is occurring (Peet, 2009; Carter, 2009). Level of education among the survey participants will be used to see if there is a relationship between education and behaviours of the respondents in the sample. In Chapter 3 a thorough comparison was made between census data from 2006 and data collected from the various suburbs included in the sample. Figure 4.5 shows 
the distribution of education across the sample population. A large portion of the responses were generated among people with a university degree or postgraduate degree $(61.1 \%)$, while people with lower education were less frequent respondents.

\section{Figure 4.5 Level of education within sample}

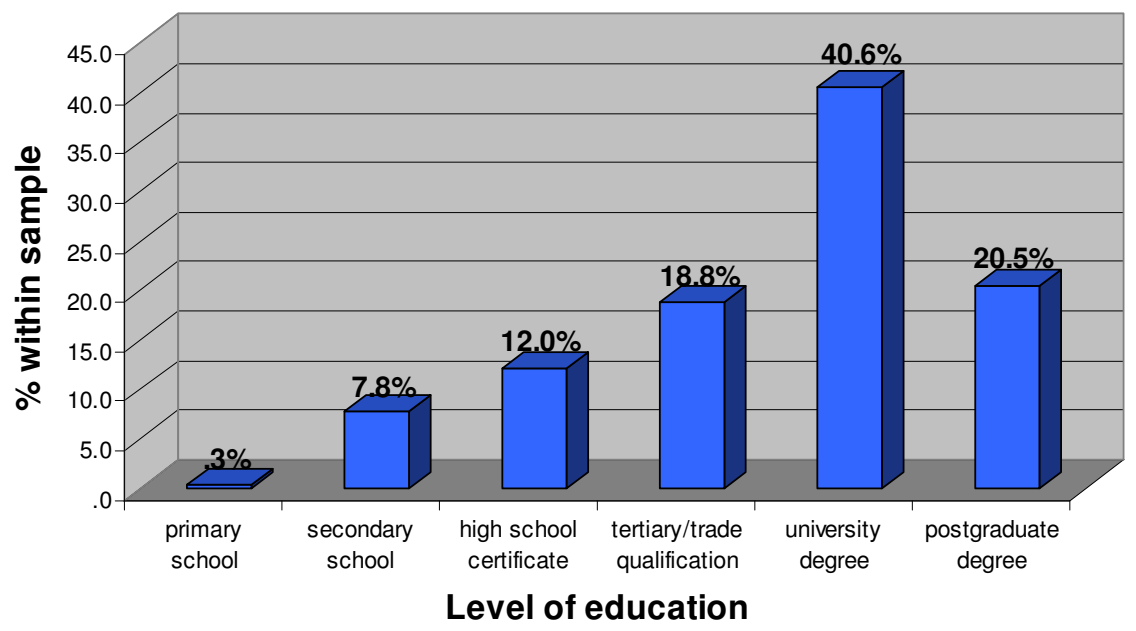

As can be seen in Figure 4.6 below, the high proportion of highly educated people is evident also in the Census data from 2006. The proportion of the population who has completed higher education levels is larger in Wellington than for the rest of New Zealand (New Zealand Statistics, 2009). The census data does however include tertiary and trade qualifications in the post-school qualification category. It is thus hard to estimate how well the sample reflects the Wellington population. It can however be noted that the table below is showing that the amount of people in Wellington with a post school qualification is quite high, which is also the case with the respondents in the sample. 


\section{Figure 4.6 Level of Education of Wellington residents according to 2006 census}

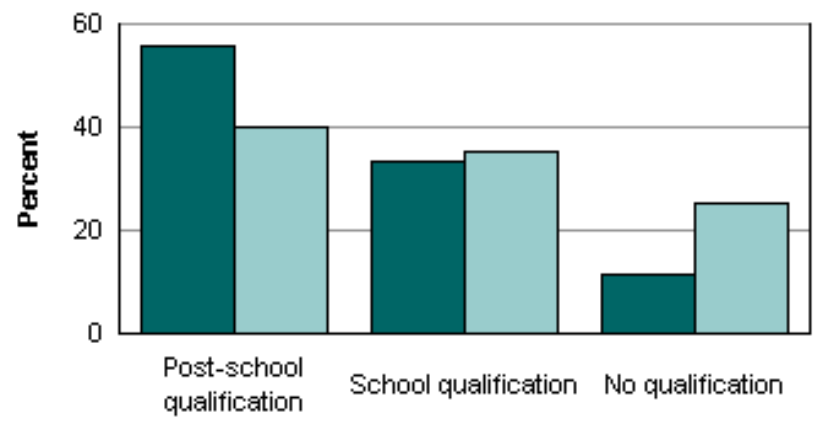

Region/City/District $\square$ New Zealand

(Source: Statistics New Zealand, 20091)

\subsection{Participation in leisure travel}

It has been argued by several authors that current tourism consumption patterns cannot be sustained, as growth in consumption is outpacing current technological advances, which makes it impossible to make up for growing emissions in terms of fuel efficiency and lowering carbon emissions from tourism products (Høyer, 2000; Becken, 2004; Gössling, 2007). In spite of growing awareness about this fact, most people are not willing to give up the freedom to travel when and where they want to (Becken, 2007; Hares et al., in press). Interviews with tourists show that people are willing to offset their carbon emissions and act in an environmentally friendly manner while travelling, but very few point out that one ought to travel less and across shorter distances to lower one's negative impact on the global natural environment (Gössling et al., 2006). It should however be noted that previous research has concentrated on gathering information from visitors, who already have made the decision to travel to the destination at which they were interviewed. This is a limitation of the findings produced by earlier studies, as they do not contribute to the knowledge about concern for the environment as a factor influencing participation in tourism.

For this reason, the researcher chose to approach people in their homes, so as to have the opportunity to capture a range of travel behaviours (refer to Section 3.2 for details). Nonparticipation in leisure travel is indeed interesting to investigate further, so the first questions in the survey were aimed at gathering information about people's participation in leisure travel, and reasons for not participating in leisure travel. Business travel was excluded from the 
research, as this type of travel often leaves the individual with little choice of destination, travel mode and accommodation.

The opening question in the questionnaire was "Do you travel for leisure (not business) purposes when you are free from work or other obligations?" As there is no definite period of time specified, it must be assumed that the respondents at current do or do not travel for leisure purposes. Most people in the sample reported participation in travel for leisure purposes. Only 7 people reported that they do not travel for leisure purposes, making up a share of $2.3 \%$ of the sample. Although people do not travel for leisure purposes, they may travel for other reasons such as business travel; however this was not investigated in this research.

\section{Figure 4.7 Reasons given for not travelling for leisure purposes}

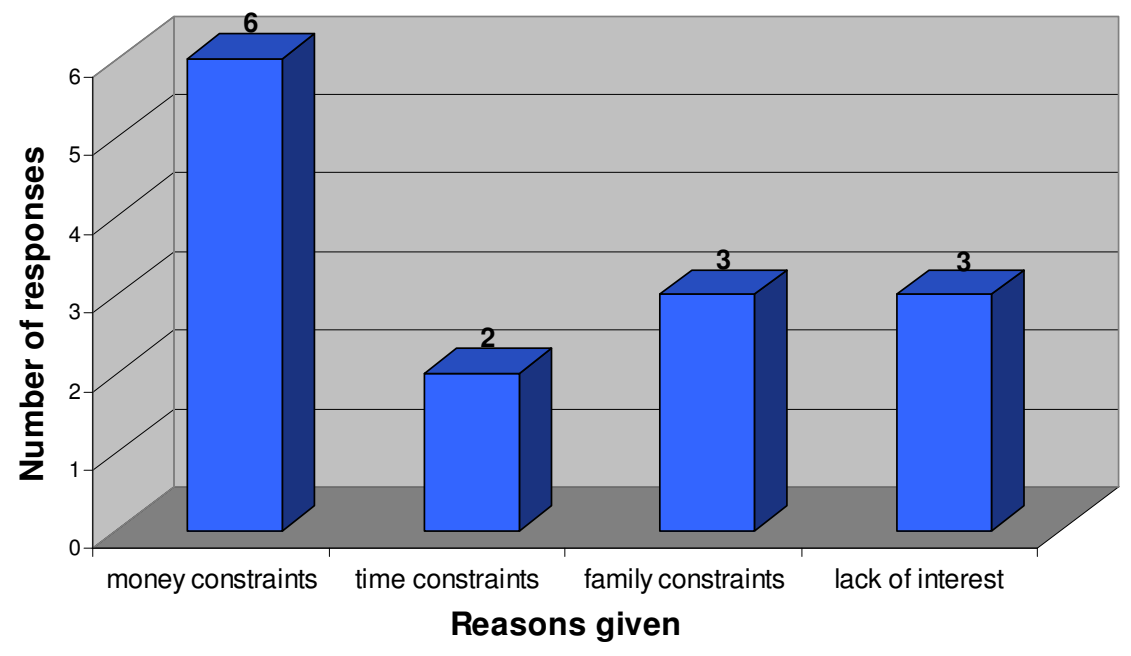

The researcher asked those who did not participate in leisure travel to list reasons for this. This was presented as an open ended question, to find out whether environmental concern was a reason for non-participation in leisure travel. The participants were free to list up to four reasons for not participating in leisure travel, but no one listed more than three reasons. Among the reasons given for not travelling, financial constraint seemed to be the most frequent reason for non-participation in leisure travel (see Figure 4.7). In most of the cases, financial constraints were mentioned together with other reasons, such as the statements below:

"[It is] too expensive, [I'm a] solo mother with a teenager, one income doesn't allow for holidays". 
This statement represented two categories in the analysis, namely 'money constraints' and 'family constraints.'

"Financial, Lack of interest (no desire to travel), Social/Family status (Single so no need to travel with partner/family)"

This statement was interpreted as a representation of 'money constraints' and 'lack of interest.' Although the respondent mentioned the family situation, it is not seen as a constraint in this case, rather a lack of motivation, which was not investigated in this study.

"I travel too much for work, so no interest."

As can be seen in the above statement, 'lack of interest' can have several underlying factors. This respondent claimed that the frequency of work travel deterred him from travelling for other purposes.

What is more important: Concern for the environment was completely absent from the reasons listed by the survey respondents. This indicates that people do not consider the impacts that tourism has on the environment, but rather focus on other issues when deciding whether to travel or not. However, it does show that some people do not participate in leisure travel. This is an important result, which highlights the limitation of research done among visitors to a destination in terms of capturing a wide spectre of behaviours, and providing recommendations based on visitor behaviour. By exploring the most important factors for non-participation in leisure travel, it is possible to identify the most powerful means of encouraging such behaviour. Although concern for the environment was absent from these factors, several other factors which could be used to reduce travel have been identified, most importantly financial disincentives.

\subsection{Trip characteristics}

\subsubsection{Destinations visited}

Among the destinations visited, the most frequently visited were located in New Zealand and Australia. Australia, London and Pacific islands were most popular among the international holiday destinations (for a full overview, see Appendix C). As reported in the outbound tourism 
data on the Ministry of Tourism web page, the four most popular international destinations among New Zealanders in 2009 include Australia, UK, USA and Fiji (Ministry of Tourism, 2009a). The three most visited international destinations match well with the data collected for this research.

\subsubsection{Reason for travelling}

The researcher asked respondents to report facts about the two most recent holidays that they had taken for leisure purposes. Figure 4.8 below shows a compilation of the main reasons for taking the holidays about which data was collected. As can be seen from the table below, most people in the sample travel for holiday purposes (59.5\% of all holidays taken) and to visit friends and relatives (35.5\% of all holidays taken).

\section{Figure 4.8 Main reason for travelling - all holidays compiled}

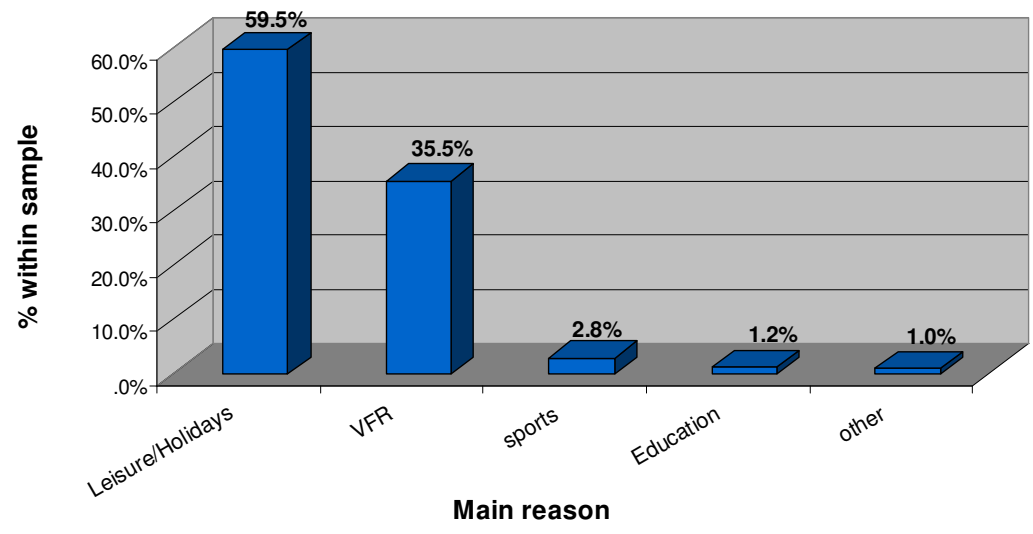

When comparing this data with the data from the Ministry of Tourism (MoT) website displayed in Figure 4.9, it is clear that the data collected from the sample is similar to the data collected by MoT on outbound travel. Most people travel for holiday purposes $(42.3 \%)$, closely followed by visiting friends and relatives $(31.4 \%)$. Business travel was excluded as a category for travel in the questionnaire, and is as such this has likely skewed the results in the sample to show a higher proportion of holiday and VFR travel than what would be reported if business travel was included. It is however noteworthy that a large percent (14.6\%) of New Zealanders do travel for business purposes annually (Ministry of Tourism, 2009a). 
Figure 4.9 Purpose of travel to all countries year ended 2007

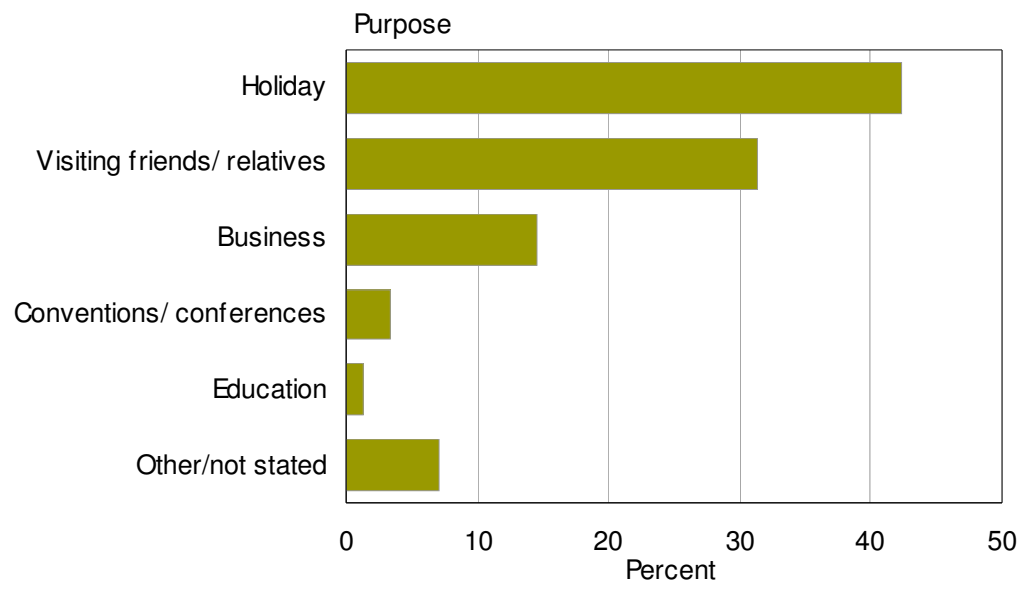

(Source: Ministry of Tourism, 2009a)

\subsubsection{Transport modes and accommodation used}

An important step in estimating the impact on the environment that the respondents make when they are travelling is to see what type of transport mode they choose to get to their destination. As calculated by Becken et al. (2003), the choices that tourists make regarding accommodation, transport modes and activities when holidaying has a large impact on the total environmental impact of each holiday. This section will outline the transport modes and accommodation types used by the respondents on their last two holidays.

\subsubsection{Transport modes}

Various transport modes have differing levels of impacts on the environment (CarboNZero, 2009). Certain types of transportation, especially airplanes and other forms of air transportation are considered to be more harmful to the environment than other types of transportation. That is not to say that air travel always has the most negative impact; when travelling over large distances, travelling by car may have just as large an impact in terms of CO2-E emissions as travelling by air (CarboNZero, 2009). Table 4.2 below shows the impact made by various transport modes when travelling a distance of 500 kilometres. 


\begin{tabular}{|l|r|r|}
\hline \multicolumn{3}{|c|}{ Table 4.2 Impact made by various transport modes } \\
\hline Transport Mode & pkm travelled & CO $_{2}$-E emissions (KGs) \\
\hline Aeroplane, domestic & 500 & 181.52 \\
\hline Rental car & 500 & 120.50 \\
\hline Private car & 500 & 98.01 \\
\hline Sheduled Coach & 500 & 17.72 \\
\hline Camper van & 500 & 182.32 \\
\hline Train & 500 & 13.44 \\
\hline Backpacker bus & 500 & 13.55 \\
\hline Motorbike & 500 & 40.78 \\
\hline Yacht/Boat & 500 & 59.70 \\
\hline \multicolumn{2}{|c|}{ (source: CarboNZero, 2009, calculators) } \\
\hline \multicolumn{2}{|c}{} \\
\hline
\end{tabular}

These calculations are made based on the guidelines developed by the Department for Environment, Food and Rural Affairs (DEFRA, 2008) in the UK for calculating carbon emissions from various transport modes. As can be seen, the two transport modes with the highest emissions are domestic air travel and touring with a campervan. Among the lowest emitting alternatives are train travels and scheduled coach services.

To be able to estimate the minimum impact of the two most recent trips taken by the respondents in the sample, the main transportation modes used when on holiday were investigated.

\section{Figure 4.10 Transport modes used on holidays}

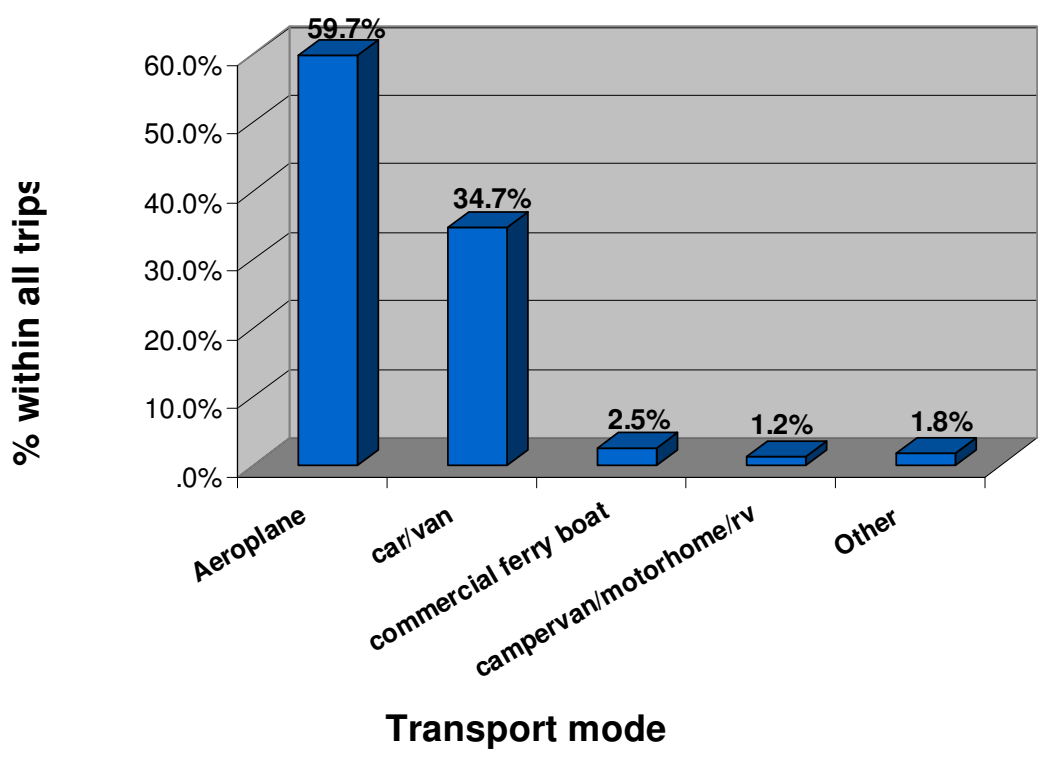

As can be seen from Figure 4.10 above, Aeroplane was the most commonly used transport mode across the sample. As New Zealand is an island nation, there is little choice but to choose 
aeroplane as the mode of transport if wanting to travel overseas. As $43.9 \%$ of all trips included in the sample were to international destinations, the dispersion of transport modes used when travelling domestically varied more compared to those used when travelling internationally.

\section{Figure 4.11 Transport modes used domestically and internationally}

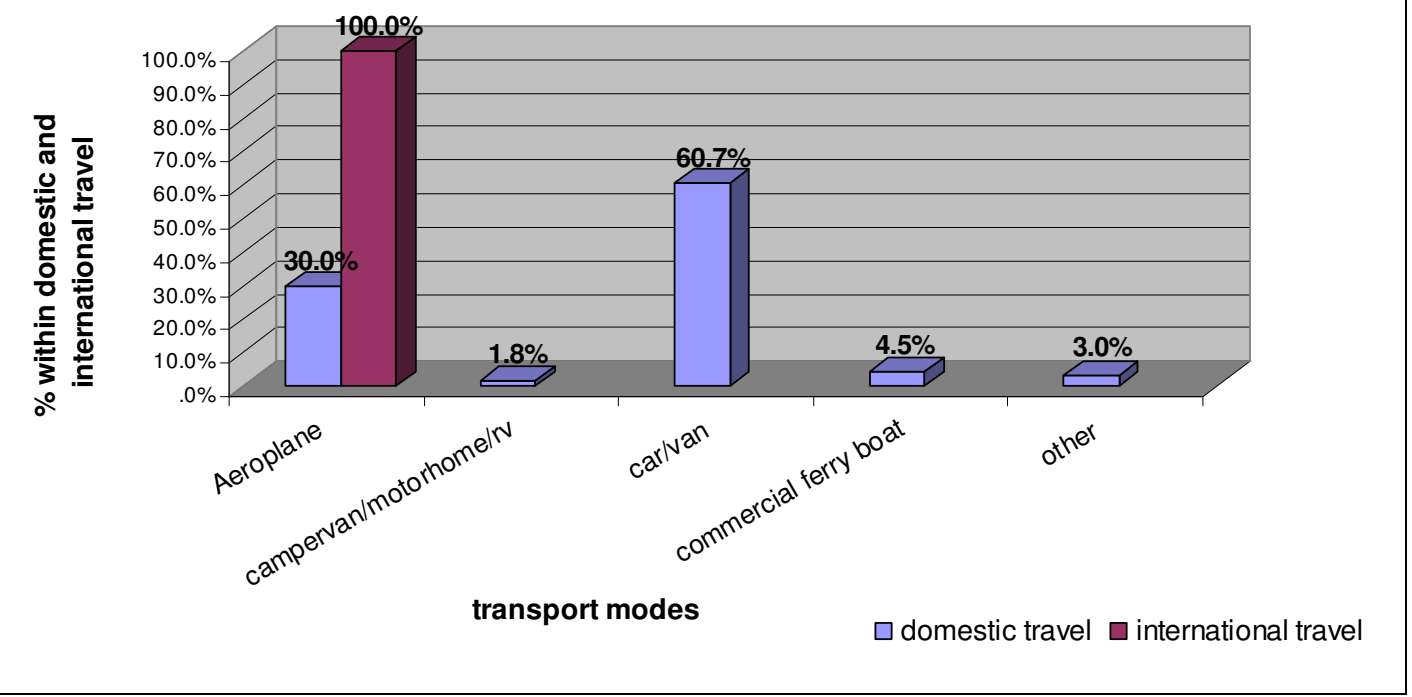

Figure 4.11 shows the different transport modes used for domestic and international travel. Not surprisingly, aeroplanes were used as the main transport mode on all international trips. Aeroplane loses its dominance as the preferred transport mode when other options for travelling are available and convenient, as can be seen from the wider dispersion of main transport modes used on domestic trips.

\subsubsection{Accommodation}

One of the details recorded from the last two holidays included the type of accommodation used by the respondents. It is argued that certain types of accommodation have a larger negative impact on the environment than other types (Gössling, 2005). On CarboNZero's web pages it is possible to calculate one's impact in terms of $\mathrm{CO}_{2}$-E emissions when staying at different types of accommodation establishments, examples are shown in Table 4.3 below. While Hotels, lodges and motor inns have the highest emissions per person per night with $7.97 \mathrm{kgs}$ of CO2-E emissions emitted, private homes have the lowest impacts with only $0.24 \mathrm{kgs}$ of CO2-E emissions per night according to the calculators (CarboNZero, 2009). 


\begin{tabular}{|l|r|r|}
\hline \multicolumn{3}{|c|}{ Table 4.3 Impact made by various accommodation types } \\
\hline Transport Mode & Nights & $\mathrm{CO}_{2}$-E emissions (KGs) \\
\hline Hotel (lodge, motor inn) & 1 & 7.97 \\
\hline Bed \& Breakfast/farm stay & 1 & 4.14 \\
\hline Motel & 1 & 2.56 \\
\hline Hotel/Backpacker & 1 & 2.12 \\
\hline Camping (huts) & 1 & 1.36 \\
\hline Private home & 1 & 0.24 \\
\hline \multicolumn{2}{|c|}{ (source: CarboNZero, 2009, calculators) } \\
\hline
\end{tabular}

It is however hard to estimate the environmental impact of the various accommodations used by the respondents due to the different characteristics of the destinations, and different levels of environmental management that may be in place at the accommodation establishments used. The researcher did however record this information to explore the influence of environmental concern on motivations when choosing accommodation. Table 4.4 shows the accommodation types used by the respondents on their last two holidays.

\begin{tabular}{|l|r|}
\hline \multicolumn{2}{|c|}{ Table 4.4 Accommodation types used on holidays across sample } \\
\hline Accommodation types & $\%$ within sample holidays \\
\hline Private home (friends and relatives) & $38.5 \%$ \\
\hline Hotel & $13.9 \%$ \\
\hline Holiday home & $10.2 \%$ \\
\hline Motel & $9.8 \%$ \\
\hline $\begin{array}{l}\text { Tent, cabin, chalet or similar at a Caravan } \\
\text { Park or Camping Ground }\end{array}$ & $6.3 \%$ \\
\hline Serviced Apartments & $5.8 \%$ \\
\hline Resort & $4.2 \%$ \\
\hline backpacker & $3.6 \%$ \\
\hline Hosted (B/B, Guesthouse or similar) & $2.9 \%$ \\
\hline Camper van at Caravan Park or Camping & $1.7 \%$ \\
\hline Ground & $3.2 \%$ \\
\hline
\end{tabular}

The type of accommodation that was most frequently used across the sample was the homes of friends and relatives. Although VFR was not the main purpose of travel for most of the people in the sample, the people who did travel to visit friends and relatives were more prone to stay at private homes than those who travelled for other reasons. Within the trips taken for VFR reasons, people stayed in private homes in $65.7 \%$ of the cases. The types of accommodation used for other types of travel are much more evenly distributed. 


\subsubsection{Year of travel and trip frequency}

It has been pointed out that consumption of tourism is outpacing technological advances aimed to reduce GHG emissions, which leads to an increase in emissions. In spite of this, people are still unwilling to give up the freedom to travel (Becken, 2007). To gain an overview of how frequently people travel, the researcher asked the respondents to specify which year they took the most recent and second most recent holiday trip.

\section{Figure 4.12 All trips compiled - year travelled}

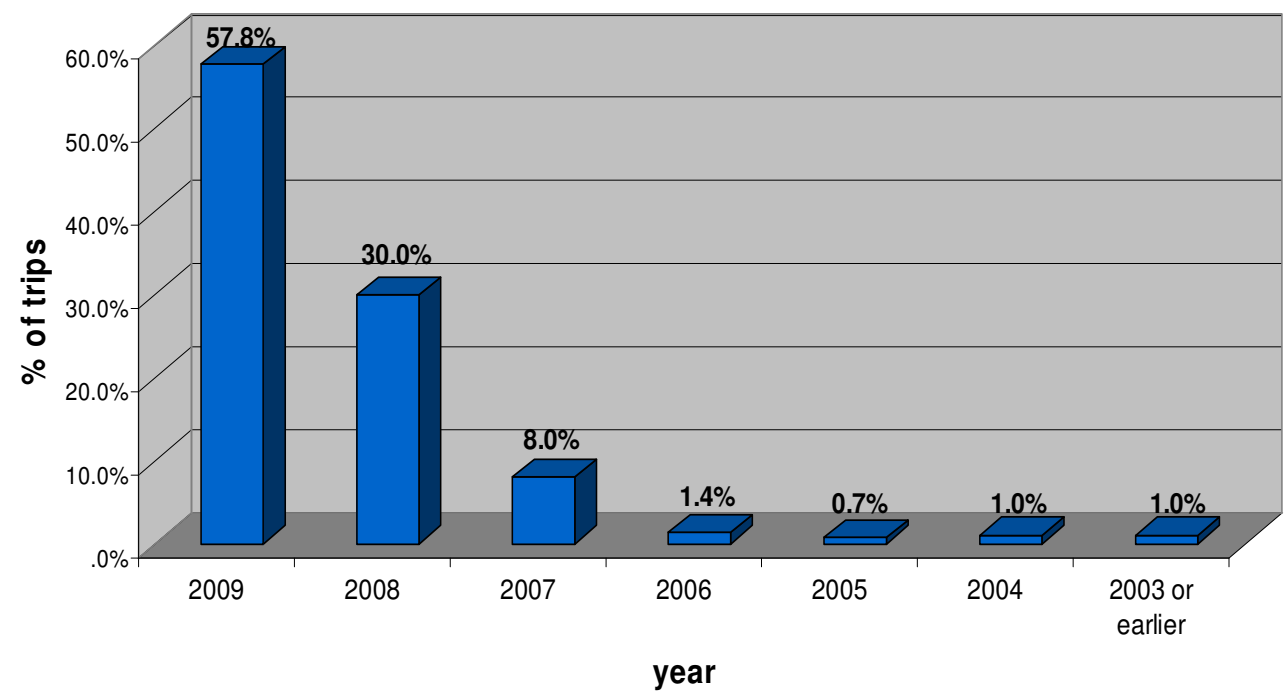

As can be seen in Figure 4.12, most of the trips reported on in the research were taken in the last three years. Only very few of the participants took one or two of their most recent trips prior to 2006 , indicating that most people travel on an annual basis or more often.

While asking the respondents to specify which year they travelled on their most recent trips gives a rough estimate of how often people travel, it is difficult to determine just how often people do travel when considering that only the two most recent trips were included in the questionnaire to capture data on actual travel behaviour. The researcher therefore included a question in the general section of the questionnaire that was unrelated to the two most recent trips, prompting respondents to estimate how many trips that they had taken during the last three years. 


\section{Figure 4.13 Number of trips taken for leisure in the last three years}

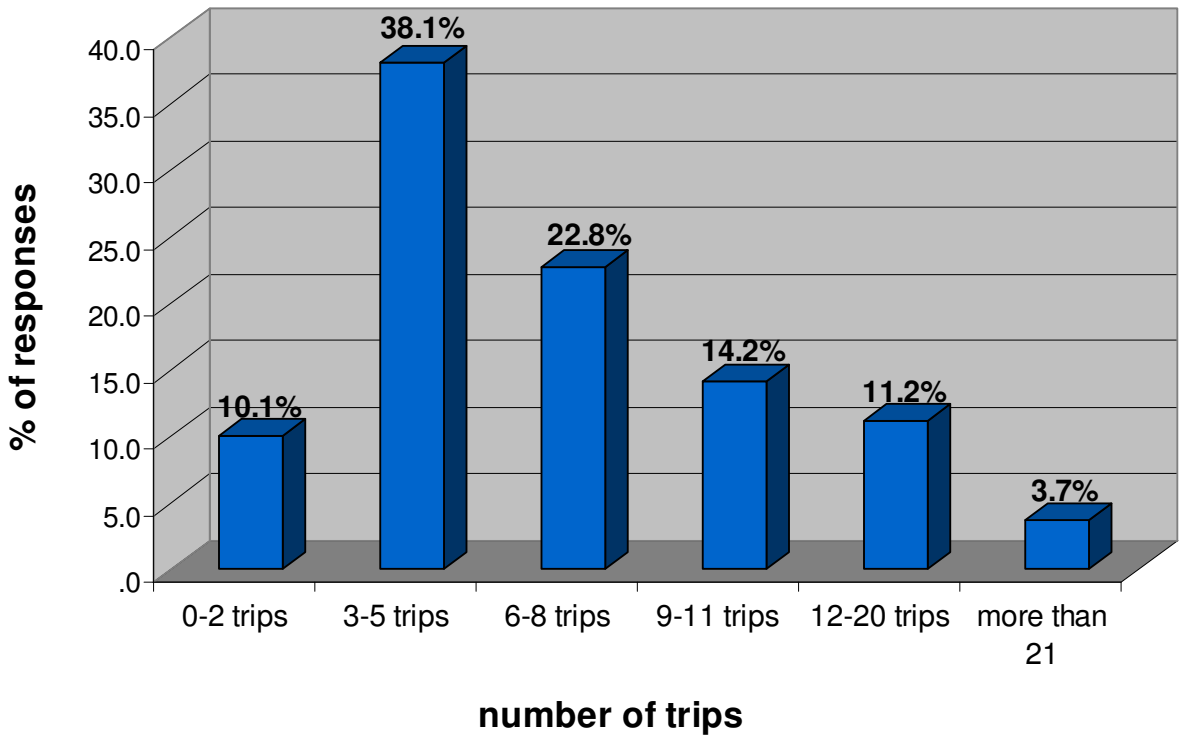

$M=7.58$

As can be seen in Figure 4.13, the largest proportion of people reported that they went on 3-5 trips for leisure purposes during the last three years. In fact, it was more common to travel several times per year than it was to travel once a year or less. The sample mean was 7.58 , showing that people travel more than twice a year on average. The highest number of trips reported was 50 during the last three years, and only one respondent reported that they had not taken any trips during the last three years, and could as such be seen to not participate in leisure travel at current.

It is argued by several authors that trips with a longer duration are more environmentally friendly than trips of short duration, as the impact of the travel is distributed over a longer period of time, and the traveller contributes more to the destination in terms of revenue (Gössling et al., 2005). As can be seen in Figure 4.14, the duration of the holidays taken varied across the sample. Most trips lasted less than 50 days (only 10 trips recorded lasted longer than 50 days); however there were reports of trips that had lasted up to 280 days. 


\section{Figure 4.14 Duration of trips}

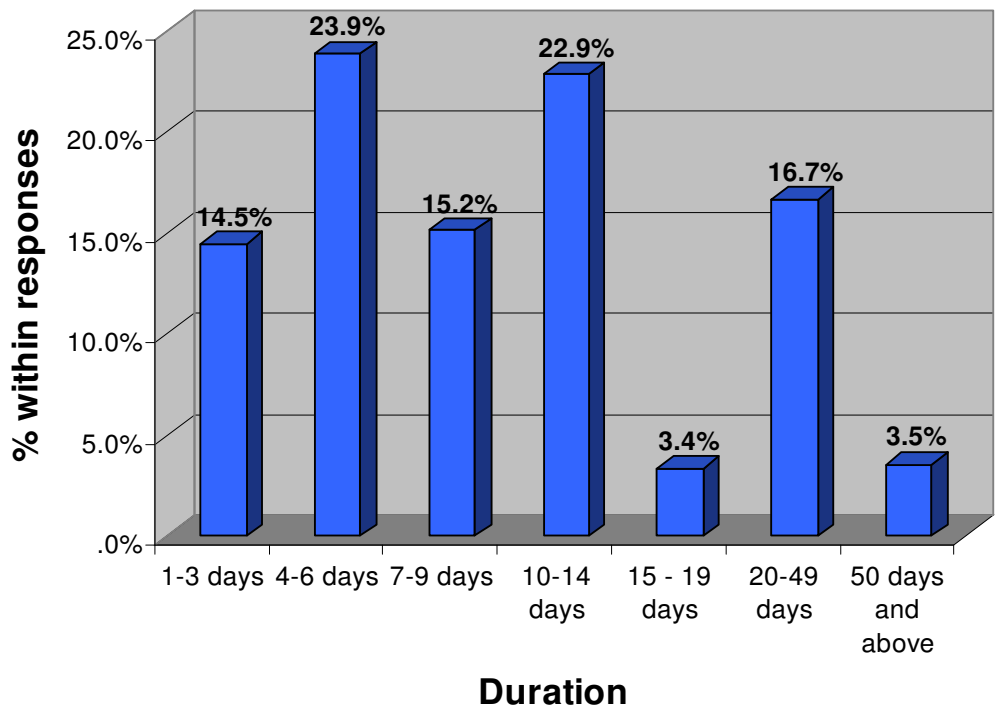

Table 4.5 shows the duration of the trips recorded in the dataset in relation to the distance travelled on the trips. As can be seen the two factors are inversely related; the shorter the duration of the trip, the shorter distance is normally travelled. This phenomenon is commonly referred to as distance decay (Greer \& Wall, 1979). Distance decay refers to the fact that the volume of travel decreases as the distance increases. This is likely due to the fact that people have less time and opportunity to travel to far away destinations than to destinations closer to home. Given that more detailed data is needed to analyse the effect of duration on people's impact, this variable was not included in the main analysis of the data.

\begin{tabular}{|l|r|c|c|c|r|r|r|}
\hline \multicolumn{7}{|c|}{ Table 4.5 Trip duration of holidays in relation to distance travelled } \\
\hline distance & $\begin{array}{c}1-3 \\
\text { days }\end{array}$ & $\begin{array}{c}4-6 \\
\text { days }\end{array}$ & $\begin{array}{c}7-9 \\
\text { days }\end{array}$ & $\begin{array}{c}10-14 \\
\text { days }\end{array}$ & $\begin{array}{c}15-30 \\
\text { days }\end{array}$ & $\begin{array}{c}31 \text { days } \\
\text { and above }\end{array}$ & \multicolumn{1}{c|}{ Total } \\
\hline below $2000 \mathrm{~km}$ & $90.0 \%$ & $78.0 \%$ & $53.3 \%$ & $32.5 \%$ & $20.7 \%$ & $6.7 \%$ & $49.6 \%$ \\
\hline $2001-5000 \mathrm{~km}$ & $7.1 \%$ & $16.9 \%$ & $38.7 \%$ & $36.8 \%$ & $8.0 \%$ & $8.9 \%$ & $21.1 \%$ \\
\hline $5001-10000 \mathrm{~km}$ & $.0 \%$ & $.8 \%$ & $1.3 \%$ & $7.7 \%$ & $19.5 \%$ & $6.7 \%$ & $6.1 \%$ \\
\hline $10001-15000 \mathrm{~km}$ & $1.4 \%$ & $.8 \%$ & $4.0 \%$ & $13.7 \%$ & $21.8 \%$ & $20.0 \%$ & $9.6 \%$ \\
\hline above $15001 \mathrm{~km}$ & $1.4 \%$ & $3.4 \%$ & $2.7 \%$ & $9.4 \%$ & $29.9 \%$ & $57.8 \%$ & $13.7 \%$ \\
\hline Total & $100.0 \%$ & $100.0 \%$ & $100.0 \%$ & $100.0 \%$ & $100.0 \%$ & $100.0 \%$ & $100.0 \%$ \\
\hline$\chi^{2}=0.000$ & \multicolumn{70}{|l}{} \\
\hline
\end{tabular}




\subsection{Conclusion}

This chapter has outlined the main characteristics of the sample, and provided familiarisation with the variables which will be used for further analysis, namely age group, annual household income, level of education and leisure participation. It has been found that people in the sample are wealthier than the population in Wellington as a whole, and that the age dispersion across the sample varies within certain age groups. Education levels of the respondents in the sample seem to correspond with data from Statistics New Zealand. Other variables that will be subject to further analysis in the coming chapters have also been outlined. Chapter five will further explore people's tourism consumption habits, perception of climate change and its impact on behaviour, and the role of environmental concern in choosing destination and tourism products. 


\section{Chapter 5. Reported behaviours and observations of climate change}

\subsection{Introduction}

Chapter four has outlined the sample characteristics and the trip characteristics collected from the respondents in this study, and created a platform for conducting analyses throughout the next two chapters. Chapter five will further explore consumption habits in relation to the two most recent trips taken by the respondents, and explore the perceptions of climate change and tourism consumption habits among Wellington residents, to find out whether climate change is an issue of concern to them.

Climate change has received much attention in the media in the last couple of years, and as such people's awareness of the phenomenon has been raised. Attention has also been directed at the high emissions of GHGs attributable to the transport industry, and a reaction to this can be seen in the initiatives taken by companies in the transport industry to stay marketable and to limit their emissions: Airlines are working hard to find alternative fuel sources, and to improve fuel efficiency (Virgin Atlantic, 2008). Similarly, car manufacturers are competing with each other to improve fuel efficiency to capture consumers who are concerned about their impact on the environment - most prominent among these is Toyota, who has won several environment awards for their initiative to reduce their impact on the environment (Derby Evening Mail, 2009). There are however limits to what the transport industry can do to mitigate the impact on the global natural environment (Høyer, 2000), so what is needed to reduce global GHG emissions is a change in people's consumption habits (Burns \& Bibbings, 2009). There is limited knowledge about tourists' actions in relation to concern for the environment. This chapter aims to increase knowledge about consumption habits and about the role of environmental concern when making choices in relation to consumption of tourism products.

This chapter will firstly focus on the influence of concern for the environment in choice of destination and tourism products. Perceptions and observations of climate change and reported effects on behaviour as a result of observations are explored in depth, and types of behaviours are grouped together to see how people are influenced by their observations. Further, consumption habits in terms of purchase of ecolabeled tourism products and awareness of such products is explored. Lastly, respondents' awareness of and participation in carbon offsetting 
schemes will be accounted for. As carbon offsetting schemes are a relatively new phenomenon, qualitative data has been extracted to get in depth information about the reasoning behind participation or non participation in carbon offsetting.

\subsection{The role of environmental concern in choice of destination, transport mode and accommodation}

\subsubsection{Destination choice}

The choice processes that people go through when deciding on a holiday destination and holiday components has been researched widely (Lübbert, 2001; Bigano et al., 2006; Amelung et al., 2007; Braun et al., 1999). The choice of destination is found to be influenced by many factors, including climate at the destination and at the origin, activities and events, landscape and scenery, and price of the holiday, which is linked to discretionary income and perceived value for money. The researcher wanted to explore the importance of the destination's commitment to protect the environment for the respondents when choosing where to go on holiday, and so decided to measure the importance of this variable against the importance of four other variables that have been explored in previous research, as mentioned above. Respondents were asked to rate the importance of the five factors when choosing a holiday destination on a scale of 1 to 5 , results are listed in Table 5.1 below.

\begin{tabular}{|l|r|r|}
\hline \multicolumn{3}{|c|}{ Table 5.1 Factors influencing choice of holiday destination } \\
\hline & Mean & Std. Deviation \\
\hline $\begin{array}{l}\text { How important is value for money when choosing a } \\
\text { holiday destination? }\end{array}$ & 1.97 & 0.733 \\
\hline $\begin{array}{l}\text { How important is climate when choosing a holiday } \\
\text { destination? }\end{array}$ & 2.06 & 0.807 \\
\hline $\begin{array}{l}\text { How important are activities and events when } \\
\text { choosing a holiday destination? }\end{array}$ & 2.16 & 1.015 \\
\hline $\begin{array}{l}\text { How important is unspoilt landscape/scenery when } \\
\text { choosing a holiday destination? }\end{array}$ & 2.88 & 0.852 \\
\hline $\begin{array}{l}\text { How important is the destination's commitment to } \\
\text { protect the environment when choosing a holiday } \\
\text { destination? }\end{array}$ & & 0.852 \\
\hline (Scale: 1=very important, 2=important, 3=neutral, 4=unimportant and 5=very unimportant) \\
\hline
\end{tabular}

As can be seen in the table, the destination's commitment to protect the environment was deemed to be the least important factor among the five when choosing where to go on holiday. 
This finding supports research that has been done in Germany with a similar focus, however the results from the Wellington study are much more optimistic in the sense that a larger share of the respondents (29.9\%) accredited some importance to this variable (rating it as 'important' or 'very important'), in comparison with $3.85 \%$ in the German study (Lübbert, 2001) It should be noted that this could be a result of the different methodologies, as the German study used an open ended question to extract the important variables. There has also been growing awareness of the impacts of tourism on the environment since 2001. The two most important factors influencing holiday destination choice among the participants were value for money and climate. To further investigate the five factors which were presented to the respondents, each factor will be examined further.

When looking at the distribution of the Likert scale ratings for the variable concerning destination's commitment to protect the environment when choosing a holiday destination, and comparing the means for all the five choice factors, it is clear that most people do not place much importance on this factor: Over half of the sample replied 'neutral' when asked to rate the importance (see Figure 5.1). $25.9 \%$ considered it to be an important factor, and $4 \%$ rated it as a very important factor. This variable also had the highest mean of all the five variables, placing it further down the scale of importance.

\section{Figure 5.1 Importance of destination's commitment to protect the environment when choosing a holiday destination}

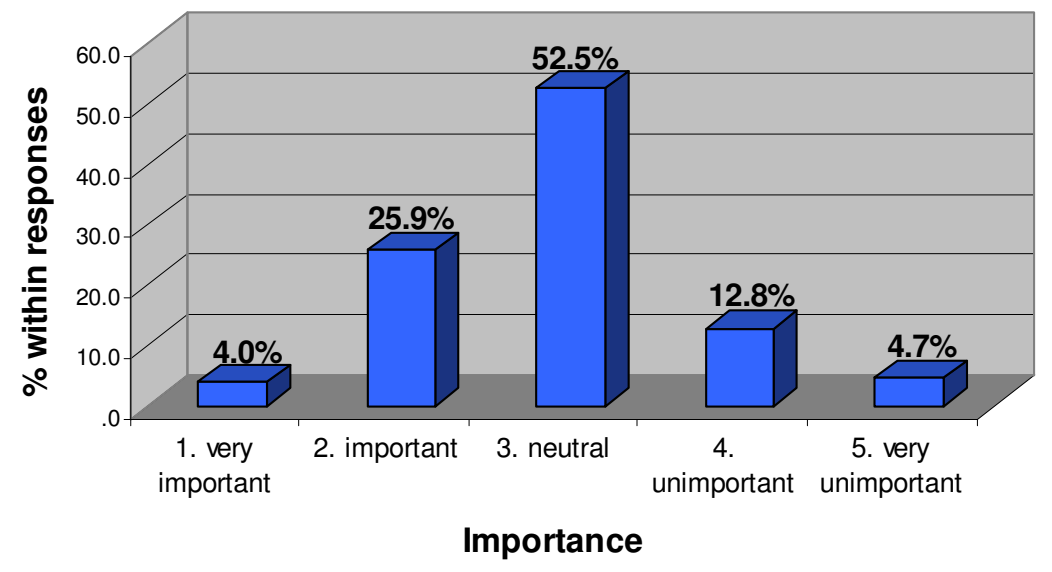

$M=2.88 \quad$ St. $D=0.852$ $\mathrm{N}=297$

When comparing the distribution of ratings against the other four variables, it becomes clear that while the mean is clustered around 'neutral' in Figure 5.1, the mean is clustered around 'important' in the other four variables as can be seen in Figure 5.2- 5.5 below. 
Figure 5.2 Importance of activities and events when choosing a holiday destination

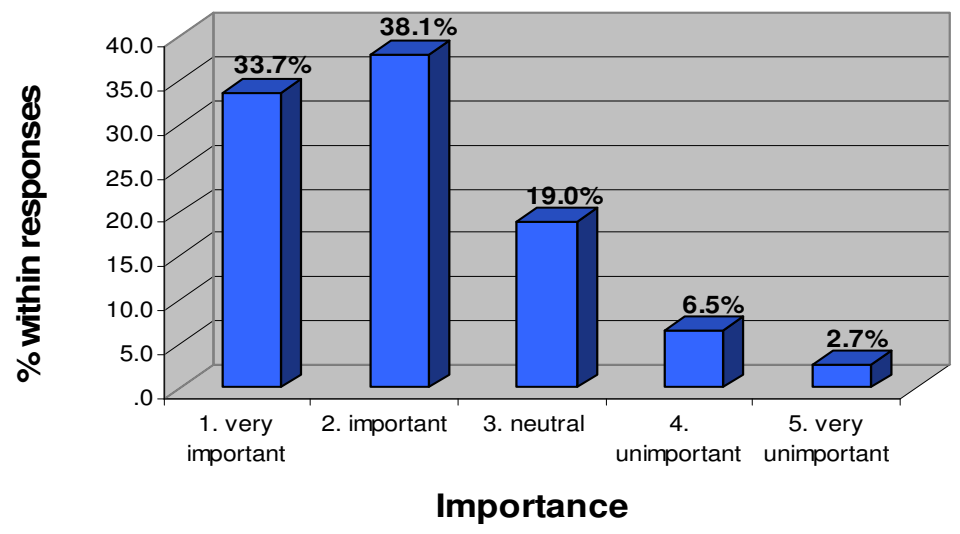

$M=2.06 \quad$ St. $D=1.015$

$\mathrm{N}=294$

Most of the respondents seemed to think that activities and events are important when choosing where to go on holiday. $28.2 \%$ rated this factor as neutral or not important, while $71.8 \%$ rated it as important or very important.

\section{Figure 5.3 Importance of climate when choosing a holiday destination}

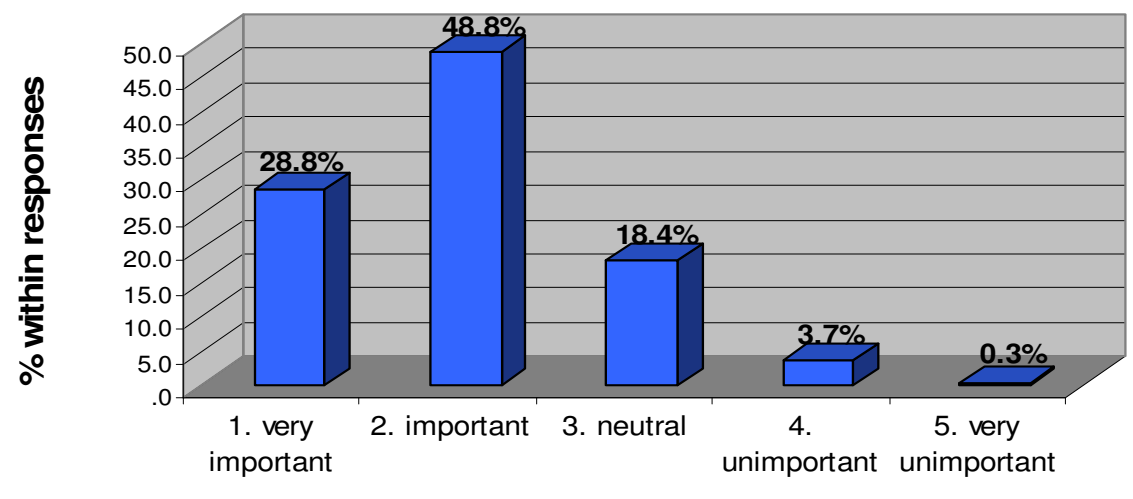

Importance

$M=1.98$

St. $D=0.807$

$\mathrm{N}=299$

Climate was also deemed very important when choosing a holiday destination and this variable was considered to be the second most important factor of the five options (Figure 5.3). Most research regarding holiday destination choice has been focussed on climate and temperature as an influence, and most frequently temperatures have been used as a measurement. The importance placed on climate by the respondents when choosing a holiday destination is 
consistent with the results from previous research on the topic (Lübbert, 2001; Bigano et al., 2006).

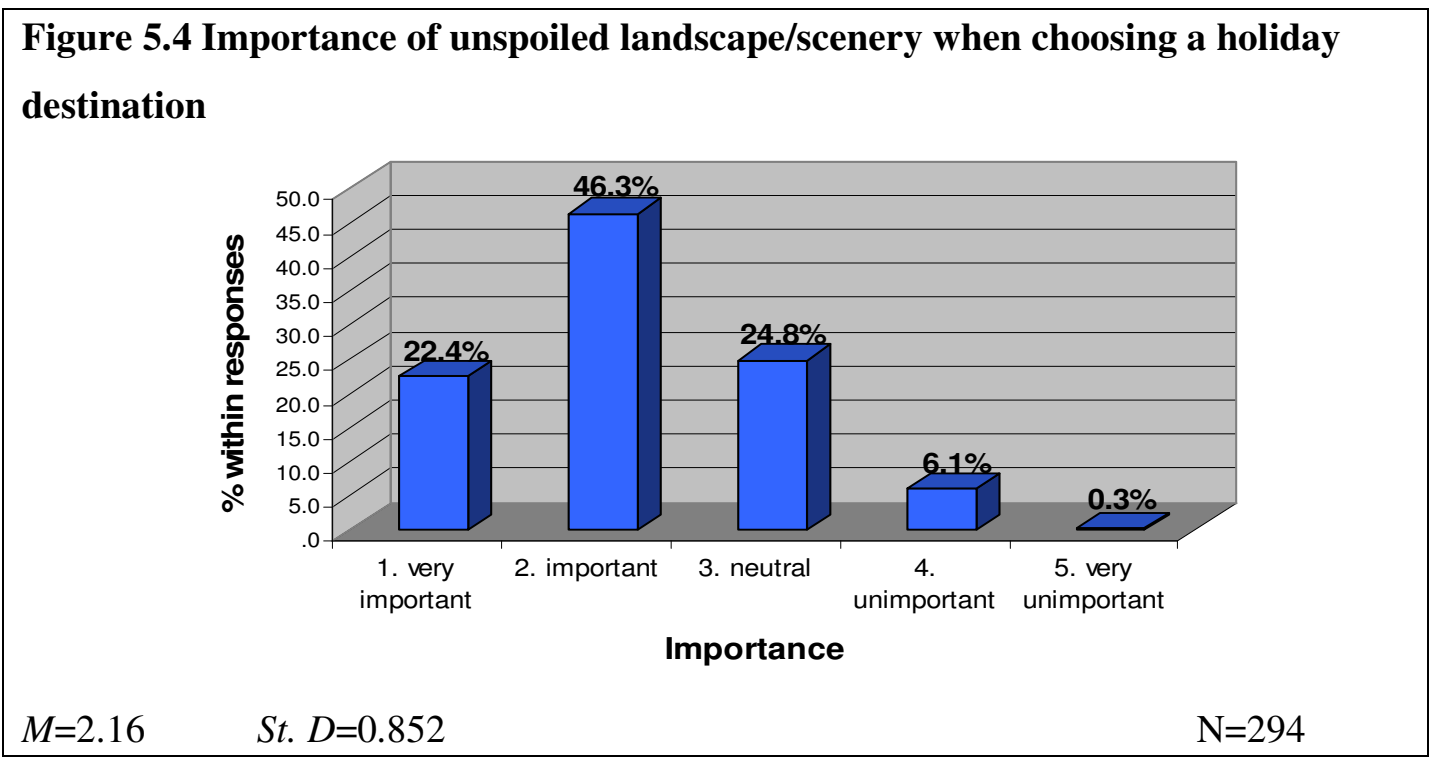

Many holiday brochures feature images of serene landscapes and exciting nature, and to many the natural environment is an important pull factor when choosing a holiday destination (Figure 5.4). Respondents seemed to think that this factor was important, however it was rated second least important compared to the other factors.

Figure 5.5 Importance of value for money when choosing a holiday destination

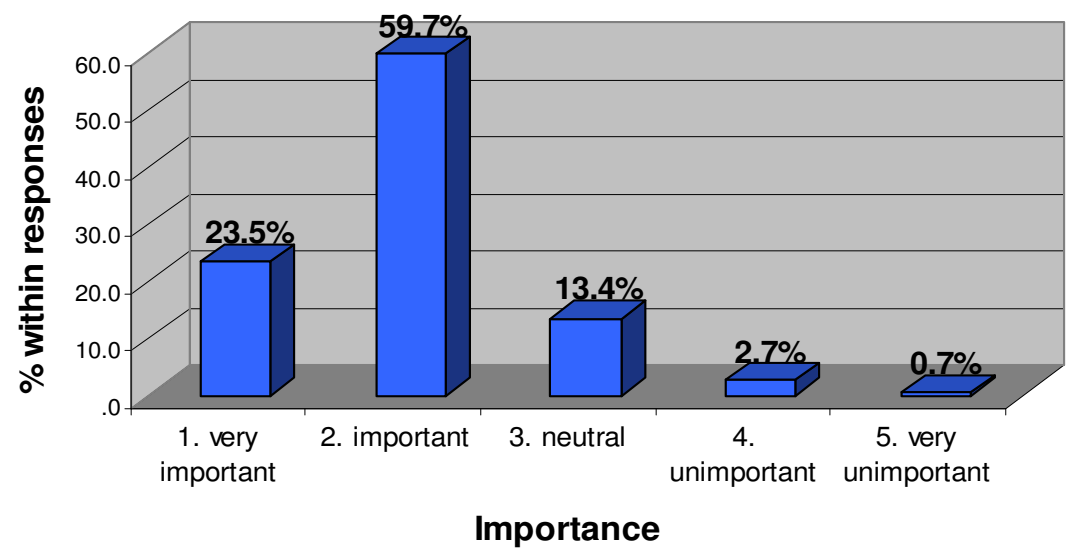

$M=1.97 \quad$ St. $D=0.733$

$\mathrm{N}=298$

The most important factor to the respondents when choosing holiday destination was value for money (Figure 5.5). Although this is a slightly ambiguous term, it does indicate that the price of 
the products features strongly in people's decision making, more so than any of the other components of a tourism product.

In summation, it may seem as though the destination's image in terms of environmental practices does not play a big part in people's decisions when considering where to go on holiday. Given that this factor was explicitly presented to the respondents in the questionnaire, this may have influenced their propensity to place some importance on this aspect of choosing a destination. If this information had been extracted from an open ended question the results may have been rather different, which could explain the relative increase in importance of the destination's commitment to protect the environment in comparison with the research by Lübbert (2001).

\subsubsection{Transport}

Among the components that make up the tourism product, the one component that has the most negative impact on the global natural environment is transportation, and in particular air travel: The transport component of tourism is responsible for up to $75 \%$ of the total emissions attributable to tourism activities worldwide (Gossling et al., 2008). This fact has been advertised quite heavily in the media in the last decade, and should raise awareness of the link between global warming and the burning of fossil fuels. However, the volume of tourism arrivals keeps rising (UNWTO, 2009). The researcher wanted to explore which factors that are most important to the respondents when choosing mode of transportation, and whether they consider the impact of the transport mode on the global natural environment when making their decision. The respondents were asked to rate the three most important factors when choosing transport mode in order of importance, from a list of 12 possibilities including an option to specify their own factor. Given that those who want to travel internationally have very limited options and are

normally forced to choose air travel or cruise travel, the researcher decided to look at the choice factors influencing choice of travel mode on domestic and international holidays separately. 


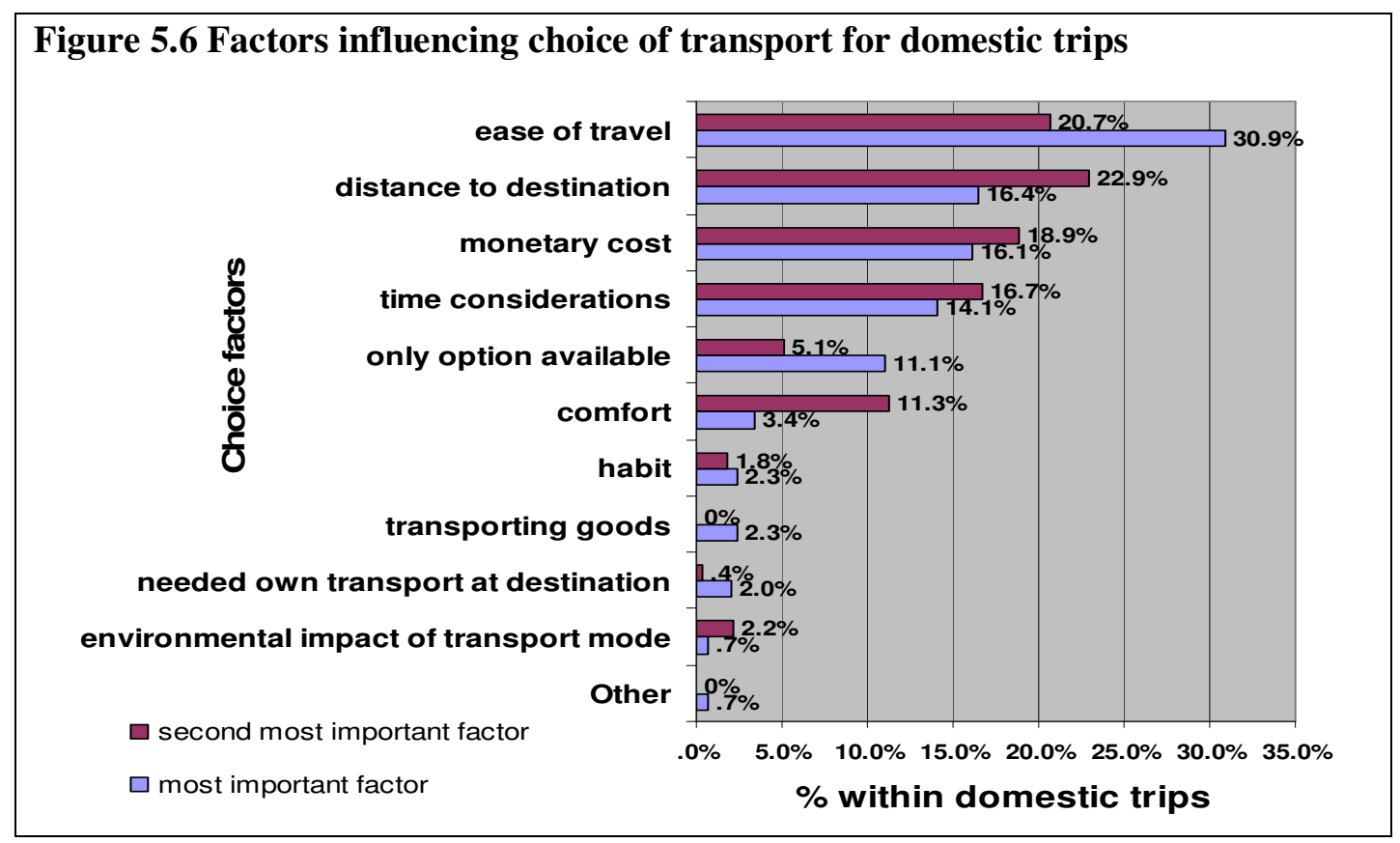

Figure 5.6 shows an overview of the two most important factors influencing choice of transport mode for the trips that were taken domestically, organised in descending order by the most important factor. The most important factors influencing choice of transport mode include ease of travel, distance to the destination, monetary cost and time considerations. The most common transport mode used domestically was car or van (60.7\%) and aeroplane (30.0\%). Many people remarked that their choice was the only one available. In some cases this related to having to cross the Cook Strait, which is the only option if one wants to go from the North Island to the South Island with a car. As can be seen, environmental impact of transport mode was not mentioned by many, and only accounted for $2.9 \%$ within the two most important factors influencing choice of transportation mode.

Figure 5.7 on next page shows the two most important factors when choosing transport mode for international trips, organised in descending order by the most important factor. When comparing the most important factors influencing choice of transportation mode when travelling domestically to those influencing choice of transportation when travelling internationally, some differences are clear. It should be noted that aeroplane was the transport mode used on all the international trips recorded. 


\section{Figure 5.7 Factors influencing choice of transport for international trips}

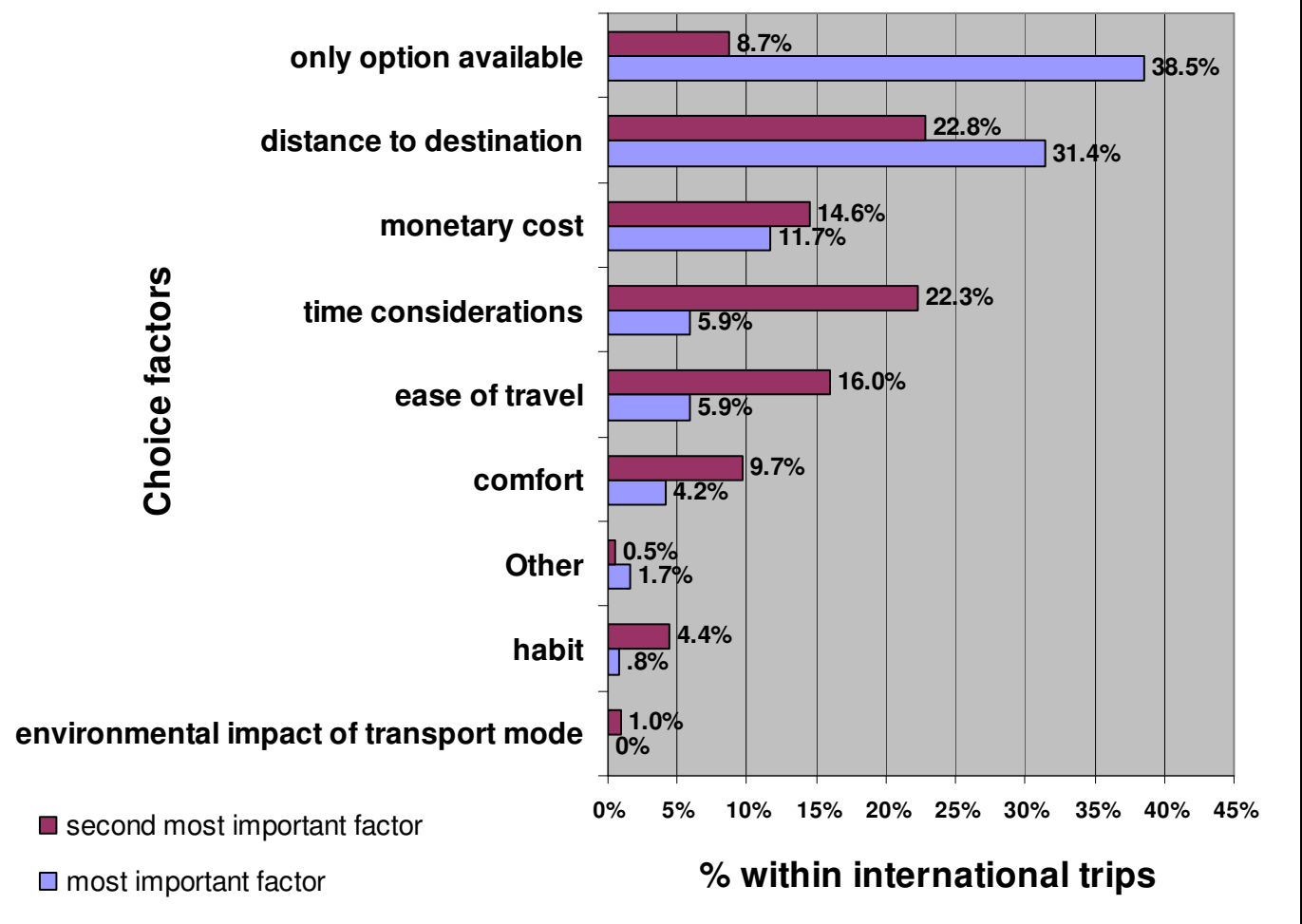

The two most important factors include the transport mode being perceived as the only option available and the distance to the destination. The note that it is the only option available is more factual in this case than it is in the case of domestic travel, as there are a range of other alternatives available to people who want to travel domestically. Monetary cost and time considerations were also frequently mentioned. Also in this case environmental impact of transport mode was largely ignored as a factor influencing choice of transport mode. It can thus be concluded that people do not factor in the environmental impact when making a decision about the transport mode used on their holiday.

\subsubsection{Accommodation}

Different forms of accommodation are generally associated with different amounts of emissions per guest night. On the CarboNZero web site, one can calculate $\mathrm{CO}_{2}$-E emissions from a range of accommodation types, as mentioned in Section 4.4.3 (CarboNZero, 2009). It is however difficult to assume that all hotels and all private homes have the same levels of emissions, as various establishments have differing levels of environmental practises in place to reduce their emissions. The focus of this section is thus not on the emissions associated with accommodation 
choice, but on investigating whether concern for the natural environment played a part in choosing type of accommodation. To explore this variable, respondents were asked to list the three most important factors in order of importance influencing their decision when choosing type of accommodation for their trips.

As can be seen in Figure 5.8 below, the most important factor influencing accommodation choice was location, followed by value for money and expectations of friends and/or family to board with them. The least important factor was the establishment's commitment to reduce their impact on the environment, proving that this is not something that most of the respondents took into consideration when choosing their accommodation.

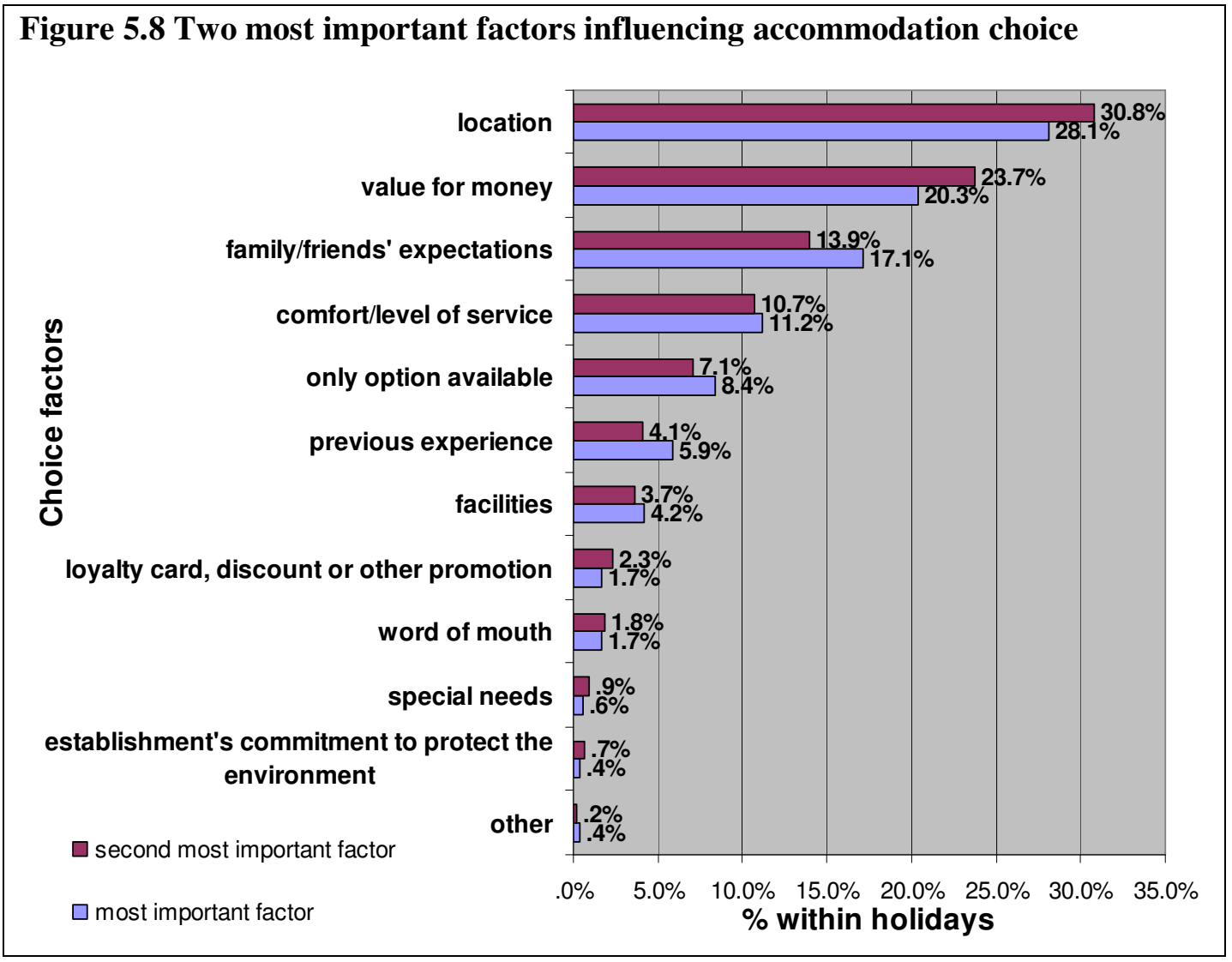

It can be concluded that people do not place emphasis on limiting the negative impacts that individual components of a tourism product have on the global natural environment. When deciding on destination, transport mode and accommodation, other factors play a larger role in evaluating various choices. 


\subsection{Reported observations and effects on behaviour}

\subsubsection{Observations of climate change in home environment}

To investigate whether climate change is a major concern for people, a question was asked to establish whether people felt that they had witnessed any evidence of climate change in their lifetime. Data from NIWA (2009a) shows that changes to the New Zealand climate have occurred in the last 100 years, including a rise in average temperature of 0.9 degrees, a $16 \mathrm{~cm}$ rise in sea level averaged over the four main ports (Auckland, Wellington, Lyttelton and Dunedin), and changes in frost and snow cover including glacial retreat. What is more, changes such as these have occurred throughout New Zealand in the last 20 years, as detailed in Figure 2.1 in Chapter two. It should therefore be possible for people to have observed some, if minor, changes to their home environment.

\section{Figure 5.9 Observation of climate change in people's home environments}

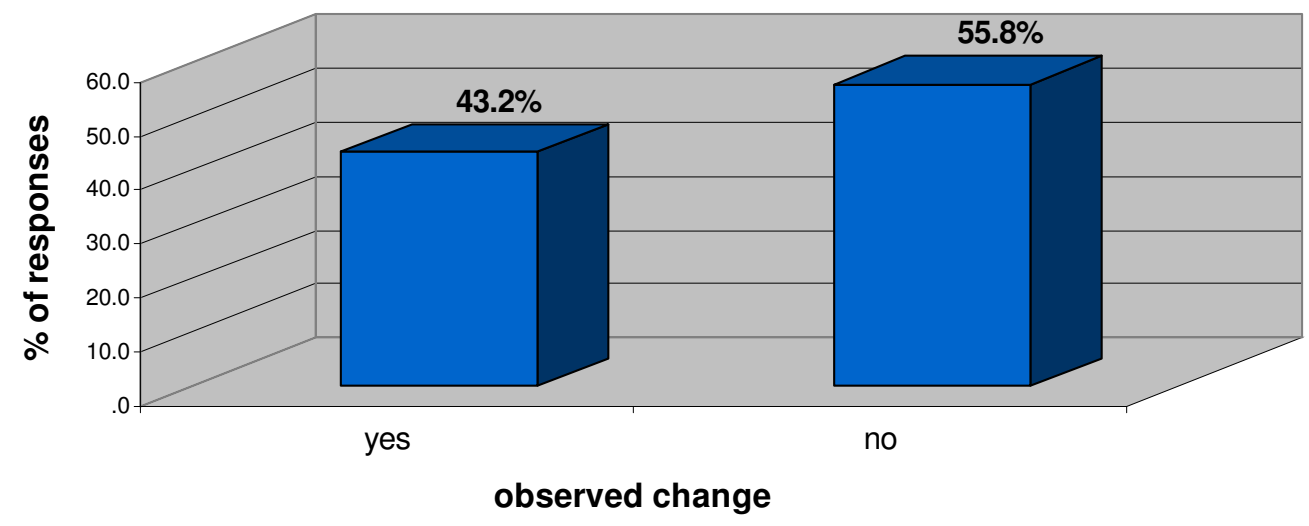

$\mathrm{N}=308$

As can be seen in Figure 5.9, over half of the sample (55.8\%) reported that they had not seen any evidence of climate change during their lifetime. While the influence of age, annual household income and level of education was explored with One-Way ANOVA tests to see whether some groups more often observed evidence of climate change than others, no statistically significant variances between groups were found.

Those who felt that they had observed climate change during their lifetime $(\mathrm{N}=133)$ were asked an open ended question, where they were prompted to describe the observations that they had made. Content analysis was utilised to deduct codes for this answer from the raw data in order to quantify the responses by the participants, and the results can be seen in Figure 5.10 below. 


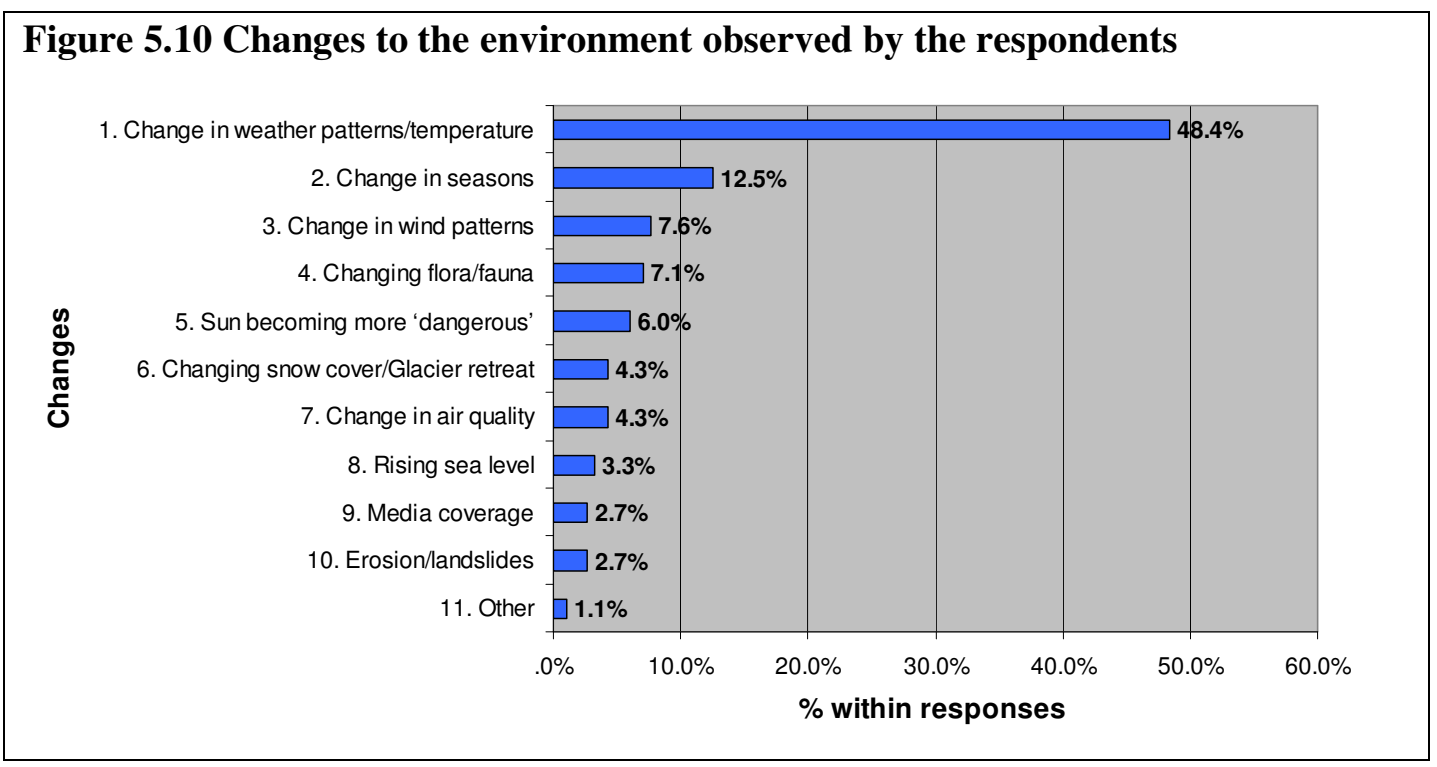

The most commonly reported observation was change in weather patterns and/or temperature. People remarked that winters have become colder; some said that summers have become hotter and some remarked on the increase in rain and/or wind in Wellington. While this does not correspond perfectly with the data concerning temperature rise produced by NIWA, it should be noted that the data from NIWA is based on averages and that annual variations can be substantial and are quite common. Also, a rising temperature has a series of effects on the climate, which may be observed as other types of phenomena, such as changing snow cover receding glaciers and drought etc. Some of the statements from the respondents will be presented below. The numbers in front of each statement correspond with the phenomenon observed, as presented in Figure 5.10.

The most significant change to the climate in Wellington over the last 20 years is the increase in wind from the north (NIWA, 2009a). Changes in wind patterns were mentioned by several respondents, with comments such as:

3.1. "The weather is worse. Winter used to have a lot more calmer days. We have more gale force winds. Spring is unbearably windy."

3.2. "There is a continuous cycle of temperature rainfall and wind speed changes (both up and down) occurring over successive years."

People also expressed concern that the time that it takes to get sunburnt has gone shortened summer, so that it is now easier to get sunburnt, and thus more protection is needed. They 
interpreted this as a sign of climate change. Some people also mentioned that the issue of climate change has received much attention in the media. It is not clear whether they understood the question correctly.

Change in flora/fauna was mentioned by people who regularly tended to gardens, with statements such as this from a respondent in the 30-39 age group:

4.1. "Particularly in my garden pests no longer die out, esp aphids, flies, white butterflies..."

The IPCC (2007) has stated that a warmer climate will cause species to migrate to new areas, and pests that were not common in some areas may be introduced, giving support to the above observation. Changes in fauna were also noticed by respondents, with comments such as the following by a respondent in the 40-49 age group:

4.2. "[There has been a] decrease in number of frogs on my brother's farm - no longer hear them croaking on a hot summer night."

It should be emphasised that the observations above are based on respondents' perceptions, and do therefore not necessarily give an accurate depiction of the current situation. The range of observations made however does give an indication that some respondents are concerned about the environment.

\subsubsection{Effects of observations on behaviour}

Several researchers have pointed out that environmental concern does not necessarily translate into environmentally responsible behaviour (Dolcinar \& Leisch, 2008; Lopez \& Cuervo-Arango, 2008; Fairweather et al., 2005; Stoll-Kleemann et al., 2001). People who report eco-altruistic values and beliefs do not necessarily act in a manner that is in the best interest of the global natural environment. To further investigate the effect of observing climate change on people's behaviour, the participants were asked whether the observations that they had made had influenced their travel decision making or behaviour. Keeping in mind that only $43.2 \%$ (a total number of 133 people) of the total sample reported observations of climate change, a low

number of people responded positively to this question. 31 people who had observed changes to the climate in their home environment said that their observations had made them change their travel and decision making behaviours. Table 5.2 shows the range of changes that were reported 
by the respondents. The codes for this table were deducted from the raw data in order to quantify the responses by the participants.

\begin{tabular}{|l|l|r|r|}
\hline & \multicolumn{2}{|c|}{$\begin{array}{c}\text { Table 5.2 Change in travel and decision making after observing } \\
\text { effects of climate change }\end{array}$} \\
\hline \multirow{2}{*}{ Group 1 } & \multicolumn{1}{|c|}{ Changes made to behaviour and decision making } & $\mathrm{N}$ & Percent \\
\cline { 2 - 4 } & Travel more to escape from bad weather & 5 & $16.7 \%$ \\
\cline { 2 - 4 } & Go before it's too late & 2 & $6.7 \%$ \\
\hline \multirow{2}{*}{ Group 2 } & Travel at different times (seasons for travelling has changed) & 5 & $16.7 \%$ \\
\cline { 2 - 4 } & Re-consider going to some destinations that used to attract & 3 & $10.0 \%$ \\
\hline \multirow{2}{*}{ Group 3 } & Choose eco-friendly tour companies & 4 & $13.3 \%$ \\
\cline { 2 - 4 } & choose eco-friendly destinations & 2 & $6.7 \%$ \\
\cline { 2 - 4 } & Using public transport/low emission transport & 2 & $6.7 \%$ \\
\hline Group 4 & Reduced frequency of travelling & 3 & $13.3 \%$ \\
\hline & other & 30 & $10.0 \%$ \\
\hline & Total & $100.0 \%$ \\
\hline
\end{tabular}

The respondents were grouped into four segments according to the changes that they made in their travel and decision making. The statements below are given a prefix which represents the group to which they belong.

Group 1 is made up of the respondents who changed their travel behaviours and decision making in such a way that they have more of a negative effect on the global natural environment than they used to prior to observing evidence of climate change. These people do not seem to take into account that tourism contributes to climate change, as the following statement from one of the respondents proves. This respondent reported that the climate in Wellington had changed and become harsher with colder temperatures and more wind:

1.1. "I now find it important to travel to have a break from the wind, and so factor in travel as a priority, not a luxury"

There was also mention of the fact that some changes may be permanent, and as such it was important to visit destinations before it is too late, as reflected in these statements:

1.2. "There is a sad urgency to get to some places before they disappear."

1.3. "It makes me want to see things before they are gone"

These statements show that some of the respondents may think that no link exists between tourism and climate change; the respondents have seen changes in the climate and have 
interpreted these as evidence of climate change, however do not stop to think that their behaviours could be a contributing factor to the changes that they have observed.

Group 2 is made up of those who changed their behaviour in terms of travelling at other times or to other destinations, however did not make any changes to lessen their negative impact on the global natural environment. Two of the respondents made these statements that verify their desire to get away from the cold winters:

\section{1. "[We] travel more in winter."}

2.2. "I make sure to go somewhere warm in winter."

It is predicted by several researchers that changes to seasonality may occur as a result of a changing climate (Bigano et al., 2006; Amelung et al., 2007). While changes to patterns of demand may be stifled by institutional obstacles such as limited flexibility in terms of holidays, people who have retired such as the respondent who made statement $\mathrm{nr} .2 .2$ will be less subject to such obstacles and may choose to travel whenever it suits them best.

There were also reports of change in travel patterns. Making observations in terms of weather extremes deterred some people from going to destinations that they would otherwise have considered:

2.3. "Some destinations I would rather not travel to now as extreme conditions affect my behaviour. Storms make me feel claustrophobic."

Group 3 is made up of the respondents who insist on going away on holiday, but have started behaving in an environmentally responsible manner when travelling. They may have become aware that they need to change their behaviour to help mitigate the effects of climate change, but are not willing to sacrifice travelling altogether. As was pointed out by Becken (2007), the freedom to travel is ingrained in people's minds, and most would not give up that freedom, even if they do know that they have a negative impact on the global natural environment. Behaving in an environmentally responsible manner thus becomes a compromise. This was evident in the following statement: 
3.1. "Selfishly - I still visit a country or place because I want to, although I did skip a few places in Central America because of their poor environmental policies - among other reasons."

When looking at the actual reported behaviours of this respondent, it was found that he chose to offset his emissions for the flight to Central America, showing that he is concerned about the impact that he makes on the global natural environment. He also chose to avoid certain destinations, and their environmental policies played part role in his decision to do so.

Other statements also supported environmentally friendly behaviour as a compromise for continuing travel:

3.2. "[I] Try to travel on eco-conscious tour companies and take their advice re eco friendly behaviour."

3.3. "I have begun to use carbon offset programme/fly airlines who offer them."

Group 4 is made up of those who have resolved to travel less as a result of having made observations of climate change. These respondents seem to be aware of the link between tourism and climate change, and have chosen to take responsibility for the impact that they make on the environment. The statements below were given by respondents who reported several observations of climate change:

\section{1. "I prefer to remain in Aotearoa and explore our own country."}

4.2. "Fly overseas less, try to use public transport, postpone ferry travel sometimes"

Although this group is small, it is encouraging to find that there are some respondents who are willing to make sacrifices in order to mitigate the negative effects of their behaviours on the global natural environment. 


\subsubsection{Perceived likelihood that climate change will have a negative impact on daily life in New Zealand within the next 20 years}

Researchers have noted that people are less likely to act in an environmentally friendly manner if they do not see the urgency of the threat that global climate change poses (Lorenzoni et al., 2007); people are often more concerned with problems that are seen as more pressing, such as personal health and security (Lorenzoni \& Pidgeon, 2006). The researcher wanted to explore whether the respondents felt that climate change would affect their lives directly. Although there have been many extreme weather events around the world in the last few years, New Zealand has not been particularly hard hit. All the respondents, regardless of whether they had observed evidence of climate change or not, were asked whether they thought it likely that climate change would have a negative effect on daily life in New Zealand within the next 20 years, to assess their perception of urgency of dealing with the problems that climate change poses.

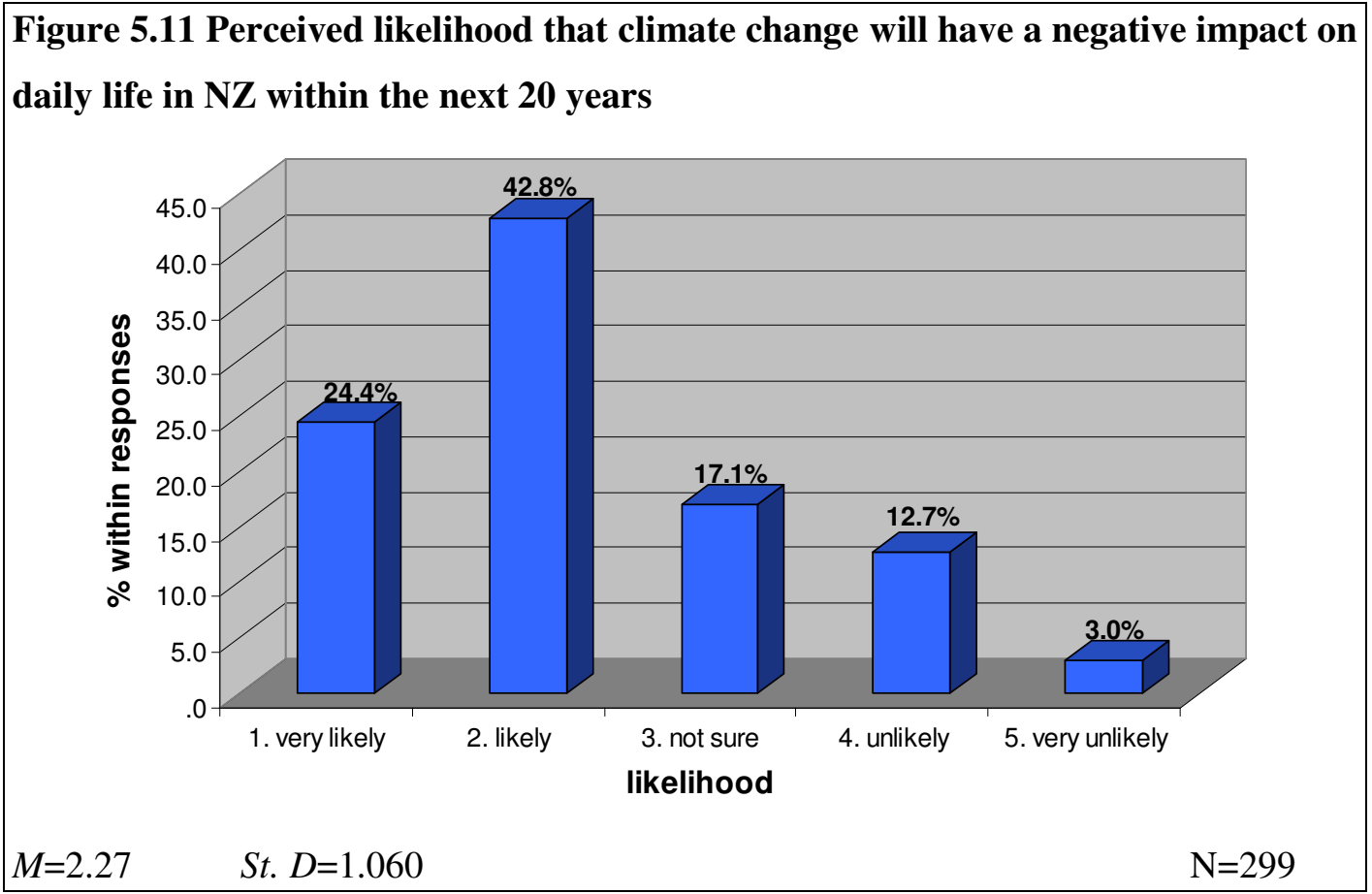

As can be seen in figure 5.11, over two thirds of the sample (67.2\%) reported that they believed that climate change would have an effect on their lives in New Zealand within the next 20 years, this in spite of the fact that most projections made by the IPCC and NIWA are made towards 2050 , which is 40 years ahead in time. In other words, people do think that changes will occur at a rapid pace. A One-Way ANOVA was used to test if there was a statistically significant variance between different age groups, levels of education or levels of annual household income, 
but no significant variance was found between any of the groups. This variable was used to analyse the differences among populations in relation to environmental concern in Chapter six, due to the fact that people are more inclined to act environmentally responsible if they think that climate change will affect them directly (Lorenzoni et al., 2007).

\subsection{Environmentally friendly behaviours}

\subsubsection{Ecolabels}

One way of measuring respondents' commitment to the environment is by measuring their propensity to buy tourism products with environmental certifications. There are several ecolabels specific to the tourism industry; in New Zealand the most recent addition is the environmental certification of the Qualmark brand, namely Qualmark Green. Qualmark is a star rating system which was established in 1993 to help tourists choose between accommodation establishments in New Zealand. Since its establishment, the accreditation has expanded to include other tourism operators as well as accommodation establishments. Qualmark is a partnership between the national tourism marketing agency, Tourism New Zealand, and the New Zealand Automobile Association (Qualmark, 2009a). Starting in 2008, the Qualmark accreditation expanded to include assessments of the environmental performance of the businesses that are certified by Qualmark, this certification is called Qualmark Green (Qualmark, 2009b). To receive a Qualmark Green certification, businesses have to complete a review of their environmental practices, and have to conform to minimum requirements within different key areas to uphold their qualification (Qualmark, 2009b). Another ecolabel operating in New Zealand is Green Globe. Green Globe is a private company, based in USA, which is established all over the world (Green Globe, 2009). In New Zealand the brand is well established, and the township Kaikoura on the South Island carries the Green Globe certification, as well as many tourism operators. Previous research on ecolabels in New Zealand has found that awareness of ecolabels is very low, but slowly increasing (Fairweather et al., 2005; Schott, 2006).

To get an overview of how frequently the participants bought ecolabeled tourism products, they were presented with a short definition of ecolabels and environmental certifications, and asked whether any of the tourism products that they purchased on their most recent or second most recent trip had an ecolabel of any kind. 


\section{Figure 5.12 Consumption of ecolabeled products on two most recent trips}

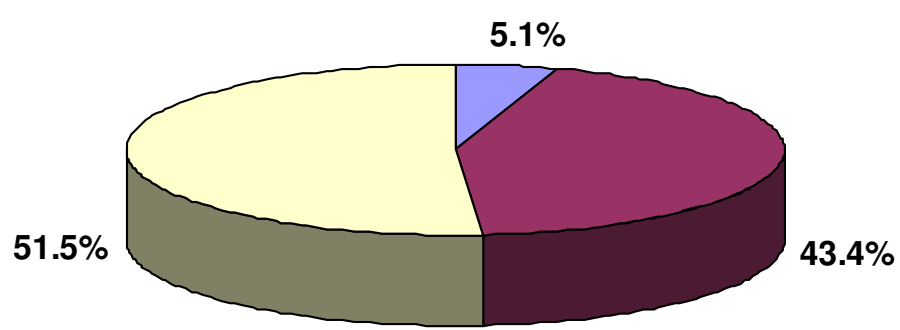

$\square$ Did purchase ecolabelled tourism products

Did not purchase ecolabelled tourism products

$\square$ Unsure

As can be seen in Figure 5.12, most people were not sure whether they had bought any tourism products bearing an ecolabel or not. This is consistent with the research of Wearing et al. (2002) who found that many people may consume ecolabeled tourism products without being aware of it. A large share of the respondents reported that they had not bought any ecolabeled tourism products, and a small proportion (5.1\% or 30 respondents) reported that they had bought ecolabeled tourism products.

As previous research has reported much confusion as to what people consider tourism ecolabels to be (see Schott, 2006; Fairweather et al., 2005; Wearing et al., 2002), the researcher also wanted to explore whether the perception of ecolabels had changed since the latest study in New Zealand conducted three years ago by Schott (2006). The respondents were therefore asked to list the types of ecolabeled tourism products which they had purchased, and write down the name of the ecolabel. The respondents were presented with the following definitions in the questionnaire to answer this question: Tourism products were defined as transport, accommodation, attractions or activities. Ecolabels were defined as "any form of certification giving assurance that the tourist operation or activity is conducted according to a known standard that enhances the environment or at least minimises environmental impacts (Fairweather et al., 2005)." 


\section{Figure 5.13 Types of ecolabeled tourism products purchased by the respondents}

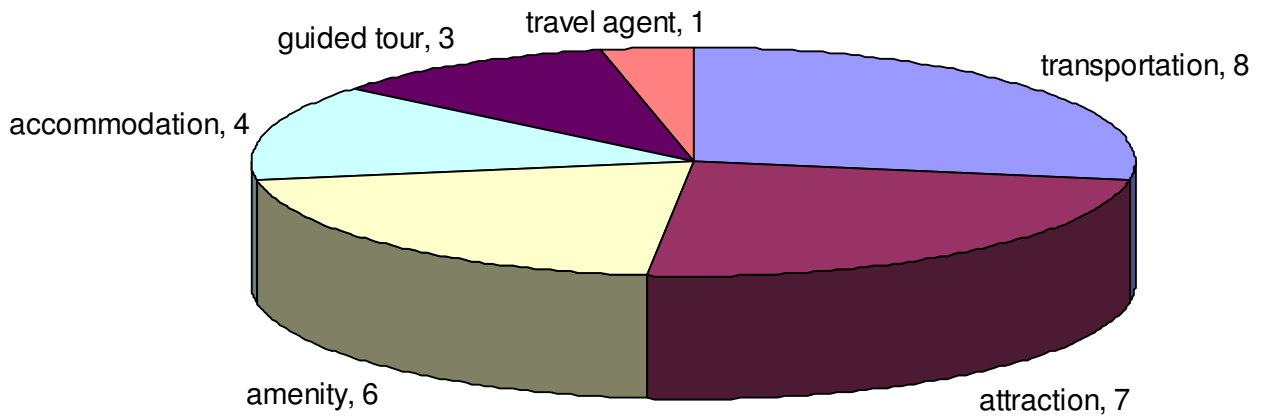

Among the ecolabeled tourism products purchased, transportation and attraction were mentioned the most frequently (see Figure 5.13). Amenities refer to general facilities such as bathrooms and other products not considered as tourism products, but supporting products that are necessary none the less. It should be noted that the above figure is based on a small sample, as only 29 of 30 people who purchased ecolabeled products listed the ecolabeled products that they bought.

When looking at the reported names of ecolabels reported by the respondents, it is evident that there is much confusion about what a tourism ecolabel is. The question that was asked in the questionnaire was open ended, to allow for individual interpretation. This was done on purpose to see which ecolabels were mentioned across the sample. As can be seen in Table 5.3, the respondents had widely differing views of what a tourism ecolabel is.

\begin{tabular}{|l|r|}
\hline \multicolumn{2}{|c|}{ Table 5.3 Respondents' descriptions of ecolabels } \\
\hline Names of ecolabels: & $\begin{array}{l}\text { Times } \\
\text { mentioned: }\end{array}$ \\
\hline Recycling & 3 \\
\hline Air NZ carbon offset & 2 \\
\hline Jetstar carbon offset & 2 \\
\hline PacificBlue carbon offset & 2 \\
\hline Sheets eco laundered & 2 \\
\hline 5 star rating & 1 \\
\hline Architecture, composting & 1 \\
\hline Carbon neutral taxi & 1 \\
\hline Climate care & 1 \\
\hline Eco friendly accommodation & 1 \\
\hline Long drop & 1 \\
\hline Petrol & 1 \\
\hline Recycling at accommodation & 1 \\
\hline
\end{tabular}


Presumably, some of the respondents had forgotten the actual name of the ecolabel and had simply written down a description of what the ecolabel covered, such as taxis and accommodation. Quite a few people mentioned carbon offsetting programmes, and some simply mentioned environmental practises that the tourism businesses had, such as recycling and eco laundering of sheets. Ten of the respondents skipped the question completely. As many as four of the ecolabels mentioned are in fact carbon offsetting schemes, namely the three Airline schemes mentioned and Climate Care. It is not known what the respondents who listed 'Long Drop,' 'Petrol' or '5 star rating' were referring to.

When looking at these results, one may wonder whether any of the respondents actually did purchase ecolabeled tourism products, or only thought that they did. Given that Qualmark Green is rather new, people may not be aware of this brand yet, however Green Globe is well established, and thus it is somewhat surprising that no one mentioned this tourism ecolabel. One might argue that carbon offsetting schemes are similar to ecolabels given that the aim is to lessen the negative impact of a business or an individual on the global natural environment, however offsetting one's emissions does not require any environmental standards. As no one mentioned a known ecolabel, it could indicate that the rate of adoption is even lower than recorded above in Figure 5.2.1.1. This may also have been influenced by the memory of the respondents, as they were asked to provide information from past leisure trips, and may not remember the details clearly. It can be concluded that awareness and purchase of ecolabeled tourism products among the respondents is low, which shows that little has changed since the study by Schott (2006).

\subsubsection{Carbon offsetting}

\subsubsection{Awareness and participation}

In the last few years, several companies have started offering carbon offsets or carbon sequestering, which allow customers to make up for their carbon emissions by supporting environmentally friendly technology or to replant forest that will absorb their carbon emissions over a period of time in the future. There has been much debate about the future sustainability of such schemes, as they can be perceived to allow people to continue their unsustainable consumption habits (Taylor, 2009; Hari, 2009). Thus, the researcher wanted to explore people's usage of such schemes. Respondents were asked whether they were aware of the possibility for offsetting their carbon emissions in relation to tourism activities. Over half of the respondents in the sample (51.7\%) who travel for leisure purposes answered that they were not aware of carbon 
offsetting schemes. To find out whether there were certain groups who were less aware than others; chi square tests were used to find relationships between age groups, annual household income and education levels and awareness of carbon offsetting schemes. Analyses showed that no significant relationship existed between age group or annual household income and awareness of carbon offsetting; however level of education had a clear influence on respondents' awareness levels.

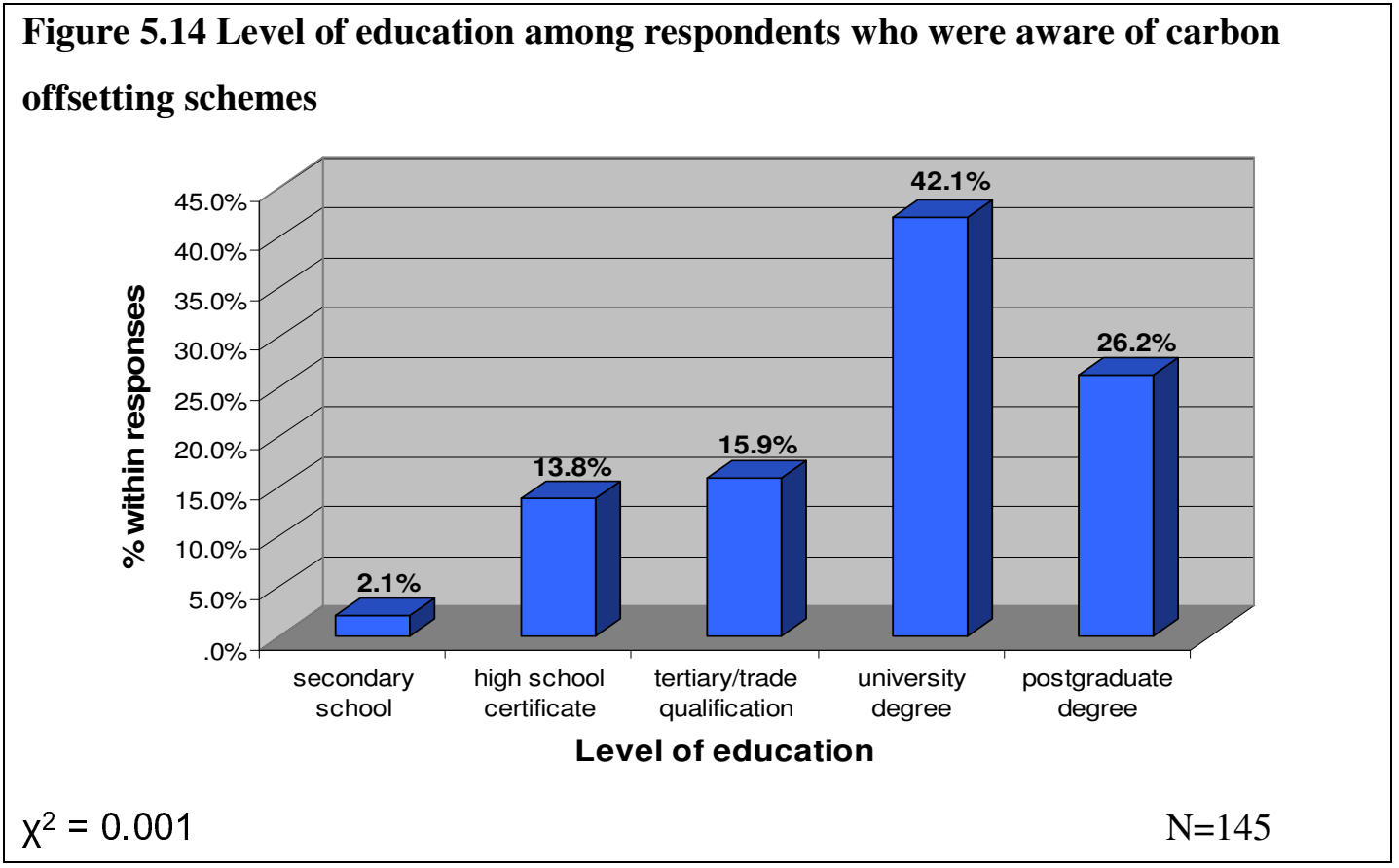

As illustrated in Figure 5.14, awareness corresponds positively with education level; those with higher education levels were more likely to be aware of carbon offsetting schemes than those with lower education levels.

The respondents who were aware of carbon offsetting schemes $(\mathrm{N}=145)$ were asked whether they participated in any of these schemes in relation to their last two trips. 12 people or $3.9 \%$ of the total sample population reported that they had participated in carbon offsetting. To find out which schemes were most popular with the users, the respondents were asked to list the names of the carbon offsetting schemes in which they participated. 


\begin{tabular}{|l|r|}
\hline \multicolumn{2}{|c|}{ Table 5.4 Names of carbon offsetting schemes mentioned } \\
\hline Offsetting schemes participated in & Times mentioned \\
\hline Air NZ carbon offset & 3 \\
\hline Jetstar carbon cffset & 2 \\
\hline PacificBlue carbon offset & 2 \\
\hline Airline carbon offsetting & 1 \\
\hline SAS flight scheme & 1 \\
\hline Tararua Wind Farm & 1 \\
\hline Tree planting, WCC & 1 \\
\hline Climate Care & 1 \\
\hline Total & $\mathbf{1 2}$ \\
\hline
\end{tabular}

As can be seen in table 5.4, those who did participate in carbon offsetting most frequently did so through the airline with which they were flying to go on holiday. This could be due to the ease of offsetting through the airline with which one is flying. Airlines often offer the opportunity to offset emissions in relation to purchasing tickets, which makes it easy for the customer to participate in offsetting schemes. If wanting to offset through other channels, the effort needed to purchase offsets increases. This is reflected in the table, as only three people mentioned other means of carbon offsetting than participating in airline schemes.

\subsubsection{Reasons for participation or non participation}

Those who were aware of carbon offsetting schemes were asked why they did or did not participate in such a scheme in relation to their last two trips. This was presented as an open ended question, and the categories were derived from the raw data. This resulted in 132 responses. As can be seen in Table 5.5 below, reasons for not participating varied across the sample, but most frequently the respondents did not want to pay the extra cost, or they were unaware of or did not believe in carbon offsetting. 


\begin{tabular}{|l|r|r|}
\hline \multicolumn{2}{|c|}{ Table 5.5 Reasons for participating or not participating in carbon } \\
offsetting & $\begin{array}{r}\text { Valid } \\
\text { percent }\end{array}$ & (N) \\
\hline Reasons for not participating & $21.2 \%$ & 28 \\
\hline 1. Cost & $20.5 \%$ & 27 \\
\hline 2. Don't believe in carbon offsetting & $20.5 \%$ & 27 \\
\hline 3. Low awareness of how to participate & $11.4 \%$ & 15 \\
\hline 4. Lack of knowledge about carbon offsetting & $9.8 \%$ & 13 \\
\hline 5. Do not want to make the extra effort & $3.0 \%$ & 4 \\
\hline 6. Not available at the time of travel & $3.0 \%$ & 4 \\
\hline 7. Only travelling a short distance & $2.3 \%$ & 3 \\
\hline 8. Unaware of carbon offsetting & $4.5 \%$ & 6 \\
\hline 9. Other & & $3.8 \%$ \\
\hline Reasons for participating & & 5 \\
\hline 10. Wanting to make up for emissions & & \\
\hline
\end{tabular}

There were many reasons given for not participating in carbon offsetting schemes, and to outline these some of the statements by the respondents will be shown in this section. The statements have been given a prefix which corresponds with the reasons as outlined in Table 5.5.

Cost seemed to be the number one concern for people who did not participate in carbon offsetting schemes. People in the sample seemed to think that it was too expensive (something that was also confirmed by the price that people are willing to pay to offset their emissions, as discussed in the next section).

1.1. "Considered it but cost is prohibiting for a large family flying!"

1.2. "Because of the financial cost. I travel on a tight budget. And to be honest, I have never looked into it"

These two respondents clearly thought that it is too expensive to offset emissions from travelling. This could indicate that people have other priorities when going on holiday, and prefer to spend their money on other things, as previously found for choice of transport.

\section{3. "Not quite prepared to pay at the moment"}

While cost was a factor also in the above mentioned reason for not participating, it seems as though the respondent considered carbon offsetting as something that he or she would do, however were unable to afford in their current situation. This could be related to their current income, or other expenses. 
One might argue that reducing the price of carbon offsets may encourage more people to participate in schemes. However, in doing this the actual cost of offsetting the emissions may not be covered. Some airlines such as New Zealand offer alternatives to carbon offsetting that are less costly: When booking tickets with Air New Zealand one is able to donate a voluntary amount to the Air New Zealand Environment Trust, which is funding conservation programmes around the country (Air New Zealand, 2009). This might be a more affordable option for people who cannot afford the price of offsetting their emissions (which normally is around 30 NZD per tonne of $\mathrm{CO}_{2}$-E emissions). However, a campaign to change attitudes might help in changing the perception that paying $30 \mathrm{NZD}$ for carbon offsetting is too much, when considering the detrimental effects that air travel has on the environment.

The second most frequent reason given for not participating in carbon offsetting schemes the respondents' lack of belief in carbon offsetting. The statements that follow show that there is scepticism about the reliability of the schemes that are available, and that carbon offsetting may not make much of a difference:

2.1. "Because, whilst I certainly believe in reducing pollution and caring for the environment, the whole carbon offsetting/trading schemes is a crock."

2.2. "A useless, politically correct scheme."

These two statements clearly show evidence of distrust in the schemes that are available, as the respondents think that the schemes are either made to lure money out of people, or that the schemes available are made to look good, but make no substantive difference.

2.3. "I object to the moral hazard of buying a clean conscience, buying a carbon off-set has no effect on the carbon impact of your travel"

2.4. "I don't really understand how these schemes actually help the environment. You have still travelled and done the damage, would it not be better to just not travel (for leisure) if you are so concerned for the environment"

The two statements above are touching at the very core of this study, namely knowledge about the impact that travelling has on the global natural environment, and realising that changing behaviours is necessary to reduce negative impacts. However, although these two respondents 
seem to believe that emissions are negative and that they ought to be reduced in some way other than offsetting the emissions, they still chose to participate in leisure travel, and they travelled to far away continents including Africa and Europe. One of these respondents even participated in Air New Zealand's carbon offsetting programme on the most recent holiday, showing that participation is not necessarily an indicator of support for carbon offsetting.

It can be questioned whether enough marketing is done to explain and promote carbon offsetting schemes. While the CarboNZero programme is promoted at airports in New Zealand on billboards and on the side of taxis in Wellington, a large portion of the sample was unaware of such schemes. Among the people who were aware of carbon offsetting schemes, there were many who admitted that they do not know how to participate:

3.1. "All seems far too complicated. Not enough info (marketing) out there about possibilities [for offsetting emissions]."

\section{2. "Did not know what was available/how to do it."}

The two statements above show that some people are calling for more information about carbon offsetting and how to participate. Increased marketing and information may be necessary to increase participation. Two other statements were made that shows the importance of information in raising awareness:

\section{3. "There was no opportunity to do so [offset emissions]."}

\section{4. "There isn't the option to do so."}

Both of these two respondents made their last two trips for leisure in 2008 and 2009, and there were options to offset emissions available to them. However, they were not aware of any schemes, and so interpreted the situation as if there were no options to offset their emissions.

It seems that even if people are made aware of carbon offsetting schemes through marketing campaigns, they have to individually seek out the information on how to participate, which is not something that everyone is willing to do. Participation is generally made easy by airlines in terms of giving the option to offset when purchasing tickets. It is thus somewhat surprising that such a large number of people did not know how to do this. However, carbon offsetting is traditionally associated with air travel, and although other types of transportation may have 
negative impacts on the global natural environment, many people may not be aware that carbon offsets are available for other types of travel. Parallels may be drawn between participation in carbon offsetting schemes and the propensity to purchase ecolabeled tourism products. As pointed out by Wearing et al. (2002) people need to be provided with information before making the decisions about their holiday in order to encourage purchases.

Some respondents also reported lack of knowledge about carbon offsetting schemes in general. They were aware of schemes, however had no idea what they entailed:

4.1. "Although I have heard about offsetting carbon emissions, I am not too sure on what this actually is."

4.2. "I have heard of "carbon emissions trading schemes" but I don't know anything about them in detail whatsoever."

These statements show that the principle of carbon offsetting may not be entirely logical to people. Explaining how such schemes work should be a priority for companies offering carbon offsets. As awareness is raised, trust in schemes and rate of adoption may rise along with it.

Some of the respondents perceived carbon offsetting to be troublesome, and did not want to make the extra effort to participate in schemes:

\section{1. "[It takes] time to implement/be involved."}

5.2. "Considered planting trees to carbon offset but it was too difficult to arrange."

Again, the issue may be one of low awareness about how to participate. When considering that the main cost is financial rather than time consuming, it is difficult to interpret what the participants mean when they say that it took too much of an effort to implement. They may be referring to the time that it would take to educate themselves about carbon offsetting and finding an appropriate scheme to participate in.

Some underlying opinions were discovered when asking for the reasons why people did or did not participate in carbon offsetting. These statements uncovered personal initiatives during 
everyday life that are perceived to help care for the global natural environment and disbelief in the contribution of collective human activity to climate change:

9.1. "I have lots of trees planted on my section, and am involved in local tree planting activities so why should I pay money which may not be fully used for [the purpose] said."

9.2. "I plant trees personally."

These two participants mentioned other initiatives taken to limit their negative impact on the environment, seemingly to justify their behaviour. This could indicate that the respondents felt somewhat guilty about their behaviours, however wanted to prove that they do try to act in an environmentally responsible manner. To which extent the statements reflect actual environmentally friendly behaviours may be questioned. There does seem to be quite a high emphasis on planting trees as a means of neutralising carbon emissions, which is an interesting finding. Only one respondent in the total sample mentioned other means of offsetting, namely supporting the Tararua wind farm. One of the statements also showed that not everyone believes that climate change is influenced by human activity:

9.3. " $[\mathrm{I}]$ Believe climate change is a normal/natural occurrence and that human activity has little impact - however, I regret the massive tropical de-forestation."

There are various reasons for not participating in carbon offsetting schemes. Among the people who did participate in schemes, the reasons given for participating were related to feeling guilty and wanting to make up for the emissions produced when travelling. Carbon offsets as such is seen as an opportunity to clear bad conscience and be able to enjoy the holiday, as can be evidenced in the following statements:

10.1. "I thought I should act environmentally responsible as flights have a huge carbon footprint - Earth shouldn't suffer just because I'm on holiday."

10.2. "I like the idea of being carbon neutral, and for a few dollars I can be for that flight. It's all about doing your bit for the planet." 
10.3. "I feel a bit guilty about plane travel but it's kind of necessary in order to visit family in Christchurch - takes too much time, costs too much and is too hard to travel by car ferry with two young children."

These respondents' opinions are quite the opposite from those of the respondents who do not believe in carbon offsetting, who claim that emissions cannot be neutralised by participating in carbon offsetting. One might wonder whether the participants are using the carbon offsetting schemes to pass on responsibility for their negative behaviours to other parties. As noted by Stoll-Kleemann et al. (2001), a common barrier for action is to place the responsibility for one's negative impacts with someone else when one's attitudes are in conflict with one's actions. Thus, behaviours stay the same, and the trend of increased emissions from tourism continues. One might argue that the carbon offsetting industry has produced agents which are willing to relieve people of the responsibility of their actions in exchange for financial gain.

There are several initiatives in addition to offsetting carbon emissions that a person can take to limit their negative impact on the global natural environment when travelling, and as such one cannot claim that not participating in offsetting schemes constitutes adverse behaviour. It is however interesting to see how this phenomenon is perceived by the general population. Although the sample in this study is relatively small, some insightful findings have been presented that show the opinions of Wellington residents about carbon offsetting schemes.

In conclusion to this section, it is safe to say that there is still low awareness of and much confusion about carbon offsetting, and while some people have adopted this practise as a way of making up for their emissions many others doubt that carbon offsetting is a solution to the negative impacts that emissions from tourism has on the environment. All of the respondents did participate in travelling for leisure purposes, and as such they were all responsible for making emissions. Most seemed aware that travelling did lead to emissions of GHGs, and agreed that this is a problem. Many do however call for a more permanent solution to this problem, as carbon offsetting is perceived as a temporary fix by the respondents in the sample.

\subsubsection{Willingness to pay and belief in carbon offsetting}

The participants were also asked to estimate how much they would be willing to pay per tonne of $\mathrm{CO}^{2}$ equivalent emissions. The question had an example that illustrated the carbon emissions that are associated with travelling between Wellington and Sydney by air, and also had an option to tick a box if the respondents did not believe in carbon offsetting schemes. 
As can be seen in Figure 5.15 on next page, as much as $40.4 \%$ of the sample answered that they do not believe in carbon offsetting. Also, $19.5 \%$ of the respondents did not know what to answer to this question. On carboNZero's web page, it costs $\$ 33.75$ to offset one tonne of $\mathrm{CO}_{2}$ Equivalent emissions (CarboNZero, 2009). The mean sum calculated from the amounts provided by the people who were willing to pay added up to 30.1 dollars per tonne of $\mathrm{CO}_{2}$-E emissions. This means that the price for offsetting emissions on the CarboNZero page is quite appropriate.

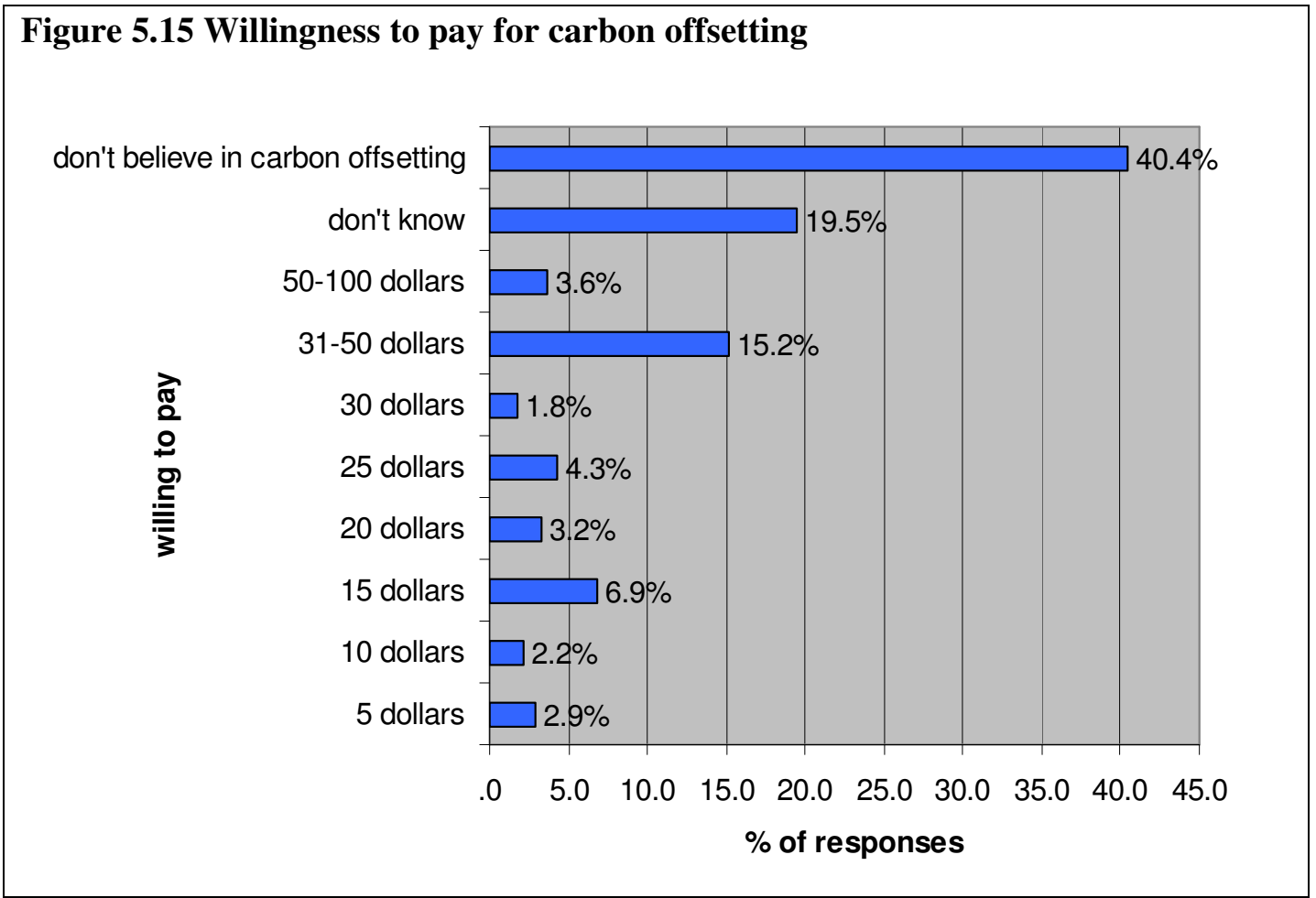

The results from the willingness to pay variable were compressed into three variables: Believe in carbon offsetting (people who recorded a dollar amount that they were willing to pay to offset their emissions), do not believe and do not know. Chi square tests were conducted to measure whether there were statistically significant relationships between age groups, levels of education and annual household income in relation to belief in carbon offsetting as a way of mitigating negative impacts of tourism on the environment. While no significant relationships were found between different levels of education and annual household incomes, a significant relationship was found between different age groups and their reported belief in carbon offsetting $(p=0.008)$. 
As can be seen in Figure 5.16 on next page, reported disbelief in carbon offsetting increases with age. Similarly, reported belief in carbon offsetting decreases with age. As carbon offsetting is a relatively new phenomenon, and most of the information that is available about carbon offsetting schemes is to be found online, this could be a factor that influences people's perceptions of the trustworthiness of such schemes. Older people have less access to internet, and even among those who do have access, there is a lower rate of usage among older age groups than among younger age groups in society (Sourbati, 2009).

\section{Figure 5.16 Belief in carbon offsetting across age groups}

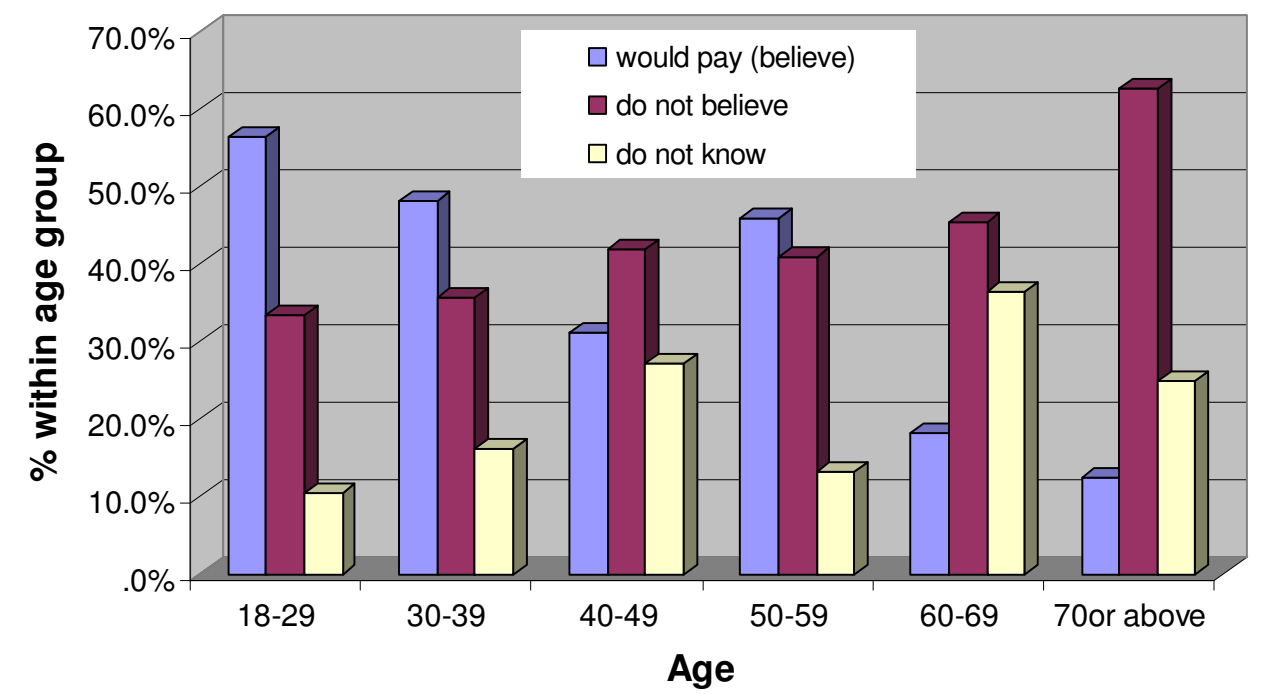

$X^{2}=0.008$

$\mathrm{N}=277$

Cross tabulations were run to explore reasons for not participating in carbon offsetting schemes in relation to age groups in an attempt to account for the lack of belief in carbon offsetting by older age groups. The three most frequently mentioned reasons by the three oldest age groups included 'low awareness of how to participate,' 'lack of awareness' and 'lack of knowledge about carbon offsetting' (Categories can be found in Table 5.2.2.1.2 above). Lack of information about the schemes will necessarily lead to less understanding of carbon offsetting, and subsequently less trust in such schemes. There may however be several factors influencing belief in carbon offsetting across age groups that remain unknown due to the scope of this study. 


\subsection{Conclusion}

This chapter has focussed on the behaviours and observations of people in the sample. Firstly, the role of environmental concern in relation to choice of destination, type of transport and accommodation was accounted for. Environmental concern did not affect the choices that people in the sample made, as other factors were deemed more important when making these choices. Secondly, observations of climate change and effects of observations were explored. While many people reported that they had observed evidence of climate change in their home environment during their lifetime, a limited number of people reported that these observations had made an impact on their behaviours. Thirdly, consumption and awareness of ecolabeled products was explored and found to be low among the respondents. There was also confusion as to what a tourism ecolabel was, as many failed to name tourism ecolabels that they claimed to have purchased. Lastly, participation in carbon offsetting was explored. Few of the respondents participated in carbon offsetting schemes, and awareness of such schemes was relatively low among the respondents, as less than half of the sample was aware of such schemes, and only 12 people reported that they participated in such schemes in relation to their last two trips. The frequency of participation was found to be low, and people seemed sceptical about the legitimacy of available schemes, as well as the ability of carbon offsetting to solve problems associated with emissions that are made in relation to travelling.

While this chapter has focussed on behaviours and observations, the next chapter will further explore respondents' opinions about the link between tourism and climate change, and compare these opinions with the behaviours that have been accounted for in this chapter and in Chapter four. 


\section{Chapter 6 Relationship between environmental concern and behaviours}

\subsection{Introduction}

The previous chapter focussed on respondent's behaviours and choices made when taking trips for leisure purposes, as well as observations of climate change and their effect on people's behaviours. This chapter will focus on exploring the relationship between behaviours, emissions by transport modes on the two most recent trips and opinions about tourism and its contribution to climate change. Firstly, respondents' transport impacts will be calculated by comparing distances travelled and transport modes used on the trips, in order to provide a measurement against which opinions can be compared. Secondly, respondent's opinions about tourism, its impact on the global natural environment and opinions about respondents' own behaviours will be explored. Thirdly, the variables in these two sections will be used to explore the relationship between concern for the environment and actual behaviours when travelling. Lastly, preferred policy options will be explored, which will provide a basis on which the researcher can make recommendations about which policy measures ought to be implemented to achieve a desired pattern of behaviours in the future.

\subsection{Distances travelled and calculations of environmental impact of transport modes used}

\subsubsection{Distance travelled and transport mode}

As previously mentioned, travelling to and from the destination is considered the part of a holiday that causes the largest share of emissions for the entire trip (Gössling, 2008). To assess the impact made by the respondents on their last two trips for leisure purposes, the distances travelled were analysed in relation to transport mode chosen for the trips accounted for by the respondents. This was done in order to provide a basis for comparing actual impacts made by the respondents' travel with their opinions, so the relationship between concern for the environment and travel behaviours could be explored.

Among the destinations visited, the most frequently visited were located in New Zealand and Australia. Australia, London and Pacific islands were most popular among the international 
holiday destinations. In order to make the calculations, the distance between all destinations mentioned in the survey was measured using the co ordinations from all the destinations and calculating the distance between these and Wellington, and subsequently these were split into distance zones consisting of intervals of 2000 kilometres. This was deemed to be an appropriate interval, as there was a clear gap between domestic and international travel where the closest international destination included in the sample was Sydney, at a distance of 2227 kilometres from Wellington. As can be seen in Figure 6.1 below, frequencies of distance travelled varied across the sample, likely because of the location of New Zealand in the World in relation to the location of popular destinations. While all the trips taken domestically belong to the below $2000 \mathrm{~km}$ group, all visits to East Coast Australia belong to the $2001-4000 \mathrm{~km}$ group.

\section{Figure 6.1 Distance travelled on reported holidays}

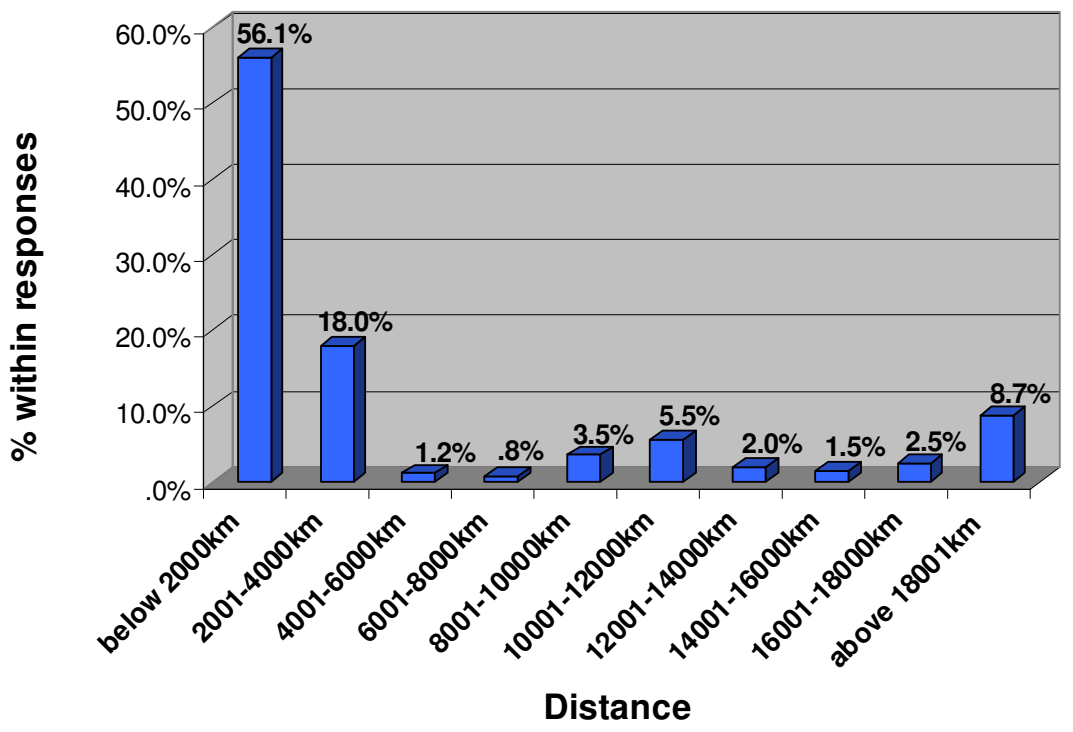

As most people travel domestically and to destinations that are located on the East coast of Australia, the largest peak of visitation shows that people travel below 4000 kilometres. Another peak is visible at $10000 \mathrm{~km}$ to $12000 \mathrm{~km}$, which is the distance to North America and Southeast Asia from New Zealand. The third peak is at $18000 \mathrm{~km}$ and above, which includes most destinations in Europe.

For the sake of analysis, people were divided into three groups according to the distance that they travelled on their last two holidays. Those who only participated in travel below $2000 \mathrm{~km}$ were labelled 'domestic travellers,' those who travelled $2001-6000 \mathrm{~km}$ on their trips were labelled 'medium range travellers within Oceania and Asia,' and those who travelled above 
$6001 \mathrm{~km}$ on their trips were labelled 'long haul travellers.' The distribution can be seen in Figure 6.2 .

\section{Figure 6.2 Groups of respondents according to distance travelled}

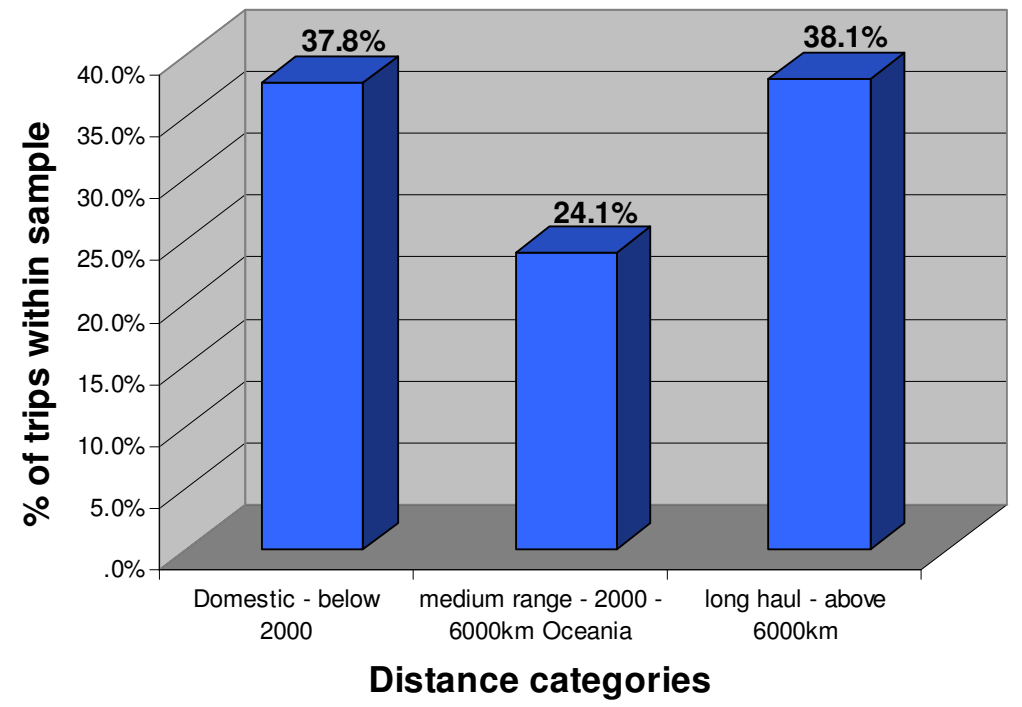

Various transport modes are associated with differing levels of emissions per kilometre travelled; while some modes of transport have relatively low emissions per person (such as trains and scheduled coaches), other modes of transport have relatively high emissions per person (such as air transportation and cars) (CarboNZero, 2009). The distance travelled must therefore be seen in relation to the transport mode used for the trip to estimate the emissions made.

As mentioned above, aeroplane was the main transport mode used for all trips made to international destinations. This is verified in Figure 6.3 on next page, which outlines the transport modes used related to the distance travelled on the trips included in the sample. Only for domestic trips is there an option to choose between a range of different modes of transport (for international travel New Zealanders have few options, including aeroplane, cruise ships or private boats), and for domestic trips car or van was the most frequently used transport mode followed by aeroplane. 


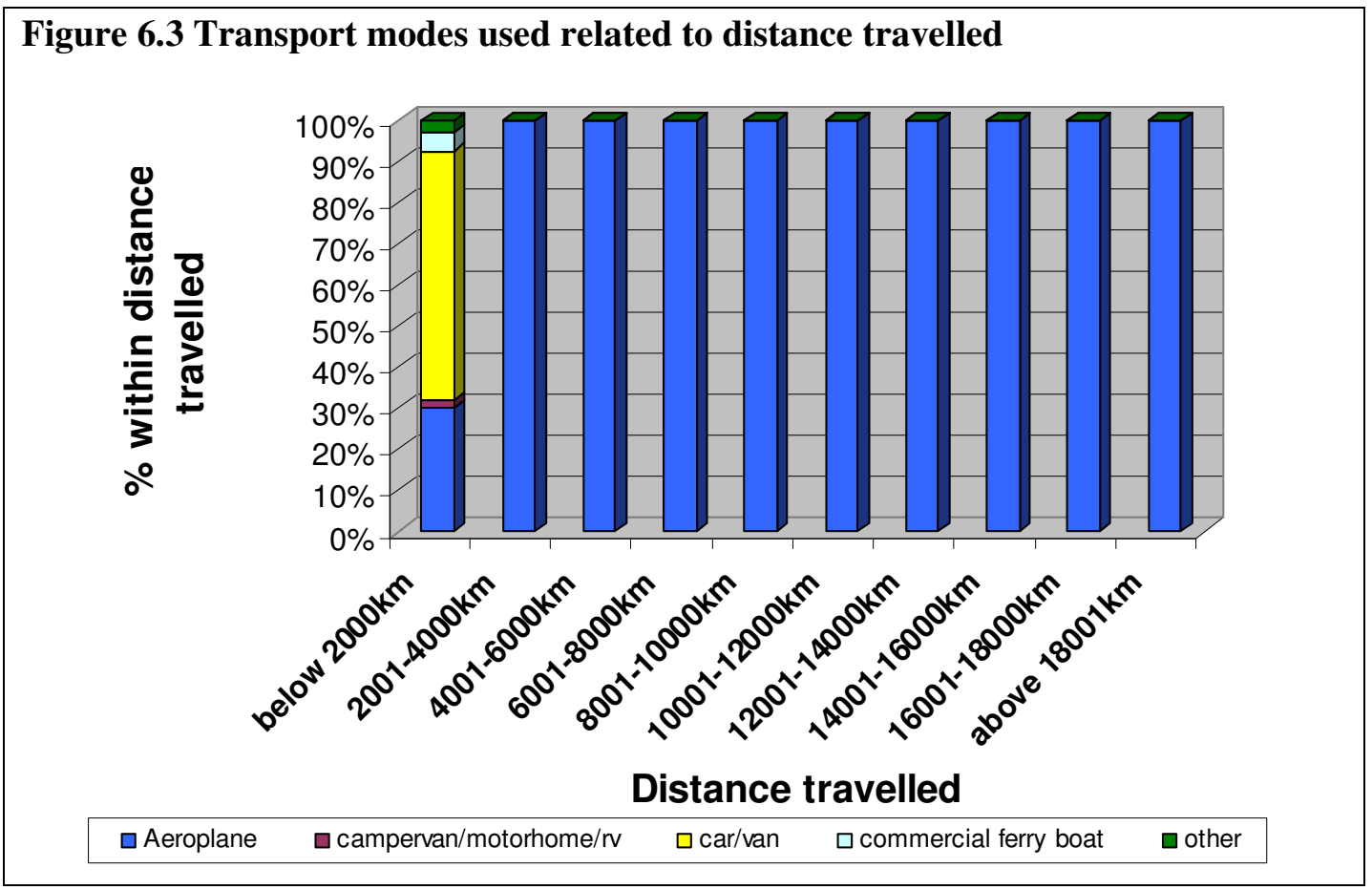

\subsubsection{Impact calculations}

To calculate the $\mathrm{CO}_{2}$-E emissions of the transportation component of the holidays that were reported on in the questionnaire, the GHG emissions calculator from CarboNZero (2009) was used. The carboNZero calculators use emissions factors for domestic and international air travel from the UK Department for the Environment, Food and Rural Affairs (DEFRA) multiplied by the passenger kilometres. For air travel, which was the most frequently used transport mode on the trips reported across the sample, the emission factor for domestic travel is $175.3 \mathrm{~g} / \mathrm{CO}_{2}$ per passenger $\mathrm{km}$, and $110.6 \mathrm{~g} / \mathrm{CO}_{2}$ per passenger $\mathrm{km}$ for international air travel. The reason for the difference in calculations is that domestic travel has a higher proportion of landing and takeoff per $\mathrm{km}$ flown, as the distances travelled are shorter. Takeoff and landing are the two components of air travel that has the highest emissions (DEFRA, 2008). For average petrol cars which was the second most used transport mode used on the trips reported across the sample, the emission factor is $178.2 \mathrm{~g} / \mathrm{CO}_{2}$ per $\mathrm{km}$ (DEFRA, 2008).

The carboNZero programme measures all greenhouse gas emissions and converts them to carbon dioxide equivalents $\left(\mathrm{CO}_{2}-e\right)$. Although most of the emissions measured for travel are carbon dioxide $\left(\mathrm{CO}_{2}\right)$, results from the travel \& tourism calculator also include other relevant greenhouse gases (CarboNZero, 2009). 
The emissions were calculated based on the distance between Wellington and the locations which were recorded as the main destination for the trips. The distances were then multiplied by two to account for the return trip. Although respondents often travel to several destinations when going on holiday, the main destination gives an estimate of their minimum transport emissions for the trip that was recorded in the questionnaire.

\section{Figure 6.4 Impact in terms of kgs of $\mathrm{CO}_{2}-\mathrm{E}$ emissions produced by trips across sample}

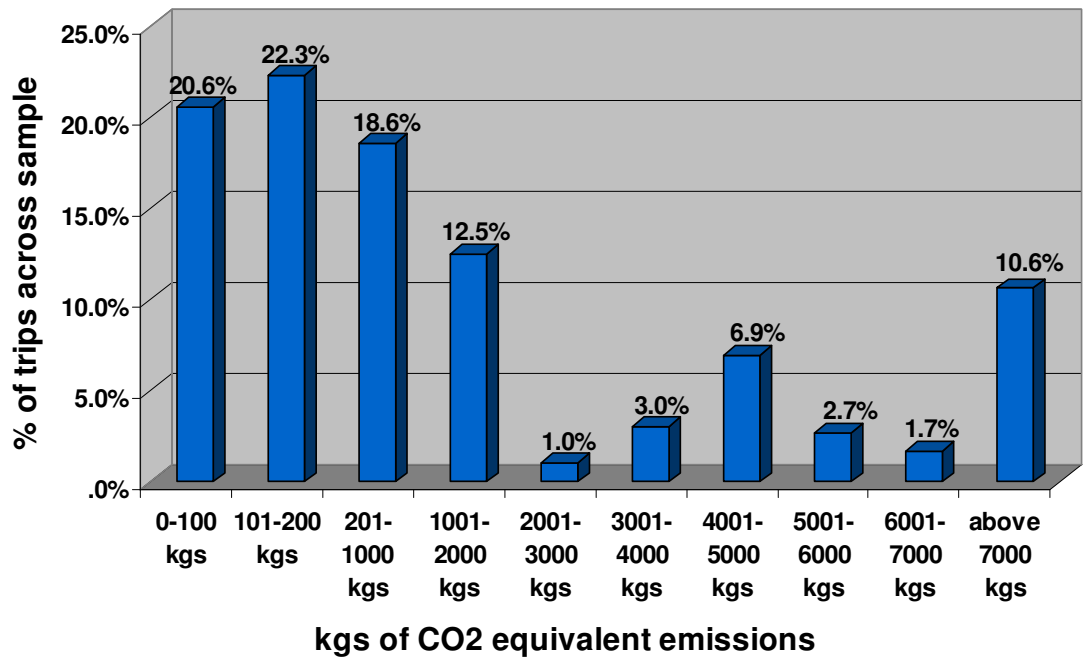

As can be seen in Figure 6.4 most of the trips had emissions lower than $2000 \mathrm{kgs}$, which would be linked to the share of domestic trips and trips to the East Coast of Australia. For all the international trips, the emissions corresponded closely with distances travelled (as can be seen when comparing this figure with Figure 6.2.1.2), given that aeroplanes were the only transport mode used to travel internationally.

Considering the geographic location of New Zealand in relation to the rest of the world, it is logical that international travel has a greater negative impact on the global natural environment in terms of the amount of $\mathrm{CO}_{2}$-E emissions per trip taken. There are no lower emitting alternatives to air travel when going overseas, apart from travelling on a private boat. In total, domestic trips accounted for 333 trips among the two most recent trips reported by the respondents. These trips had a total minimum transport impact of $49336 \mathrm{kgs} \mathrm{CO}_{2}$-E emissions, or an average of $148 \mathrm{kgs}$ per trip. In comparison, international trips accounted for 261 of the two most recent trips reported by the respondents, and had a total minimum transport impact of $1015561 \mathrm{kgs}$ of $\mathrm{CO}_{2}-\mathrm{E}$ emissions, or an average of $3891 \mathrm{kgs}$ per trip. 
As $100 \%$ of the emissions on international trips were made by aeroplanes, only the dispersion of emissions across various transport modes for domestic travel was investigated further. As can be seen in Table 6.1 below, cars/vans had the highest share of emissions made domestically, accounting for $60.7 \%$ of emissions. Aeroplane accounted for $34.4 \%$ of the emissions made on domestic trips. All the trips taken domestically had emissions below 1000kgs per trip. The 'other' category includes camper vans, coach travel, train travel, motor bikes and bicycling.

\begin{tabular}{|l|r|r|r|r|r|}
\hline \multicolumn{6}{|c|}{ Table 6.1 \% share of kgs of $\mathrm{CO}_{2}$-E emissions made by transport } \\
modes domestically \\
\hline Mode of transport & Aeroplane & car/van & $\begin{array}{c}\text { commercial } \\
\text { ferry boat }\end{array}$ & other & Total \\
\hline $\begin{array}{l}\text { \% of CO2-E } \\
\text { emissions made }\end{array}$ & $30.0 \%$ & $60.7 \%$ & $4.5 \%$ & $4.8 \%$ & $100.0 \%$ \\
\hline
\end{tabular}

According to CarboNZero's web pages, the transport modes in New Zealand which have the lowest emissions per passenger kilometre include buses and trains (see Table 2.3 in Chapter two). While researchers are calling for an increase in train travel to increase the sustainability of holiday travel (Böhler et al., 2005), this type of travel is not widely used by the respondents in the sample. Only two people used this mode of transport on their most recent trips.

This section has provided a measurement against which opinions about tourism and climate change can be analysed in order to assess the influence of concern for the environment on actual behaviours. The emissions made by the respondents in the sample shows that over half of the respondents travelled on holidays which had substantial transport emissions $(38.1 \%$ of the respondents travelled further than $6000 \mathrm{~km}$ on one or both of their most recent trips for leisure).

\subsection{Environmentally responsible behaviours}

\subsubsection{Environmentally responsible behaviours when on holiday}

Environmentally responsible behaviour in relation to tourism is defined in this study as attempting to reduce one's negative environmental impact that is caused by one's travelling/holidaying, by choosing products offered by businesses who strive to minimise their negative impacts on the environment; by acting according to local codes of ethics and/or by offsetting one's carbon emissions (adapted from Higham et al., 2005 and Manaktola \& Jauhari, 2007). Researchers have investigated the behaviours of tourists to explore the difference in behaviours at home to those displayed when on holiday (Dolcinar \& Leisch, 2008; Barr et al., in press). While it is beyond the scope of this research to go into such a level of depth to explore 
the divide between behaviours displayed when on holiday and when at home, a question was asked to explore whether people were aware of any difference in behaviour when on travelling and when at home. The respondents were asked to indicate on a scale of 1 to 5 to which extent they behaved environmentally responsible when they were at home, and when they were travelling. The rationale for comparing the two types of behaviours is supported by research showing that people's behaviours at home are the basis for their behaviours when travelling (Barr et al., in press).

\section{Figure 6.5 When I am home I behave environmentally responsible}

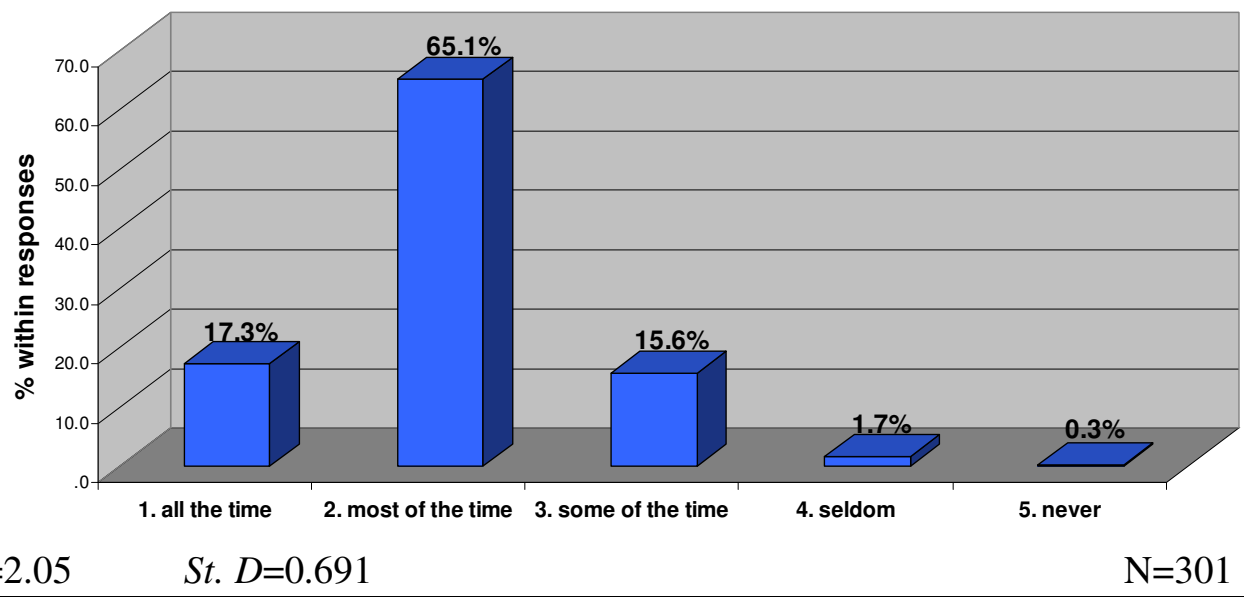

Figure 6.5 shows that most people consider their behaviour to be environmentally responsible most of the time when they are at home. $17.3 \%$ of the respondents reported that they behave environmentally responsible all the time when they are at home, and $65.1 \%$ reported that they behave environmentally responsible most of the time. A limitation to this variable is that it was not defined what behaving environmentally responsible entails, and as such the interpretation of this term is left entirely up to the respondents. It was also not investigated further which actions the participants take to act environmentally responsible when at home.

Figure 6.6 on next page shows that when travelling, most people feel that they behave environmentally friendly to some extent. $10 \%$ reported that they do so all the time, while $47.7 \%$ reported that they do so most of the time. There is a rise in the number of people who feel that they behave environmentally responsible some of the time and seldom, indicating that people feel that they are more relaxed about their behaviour when on holiday. 


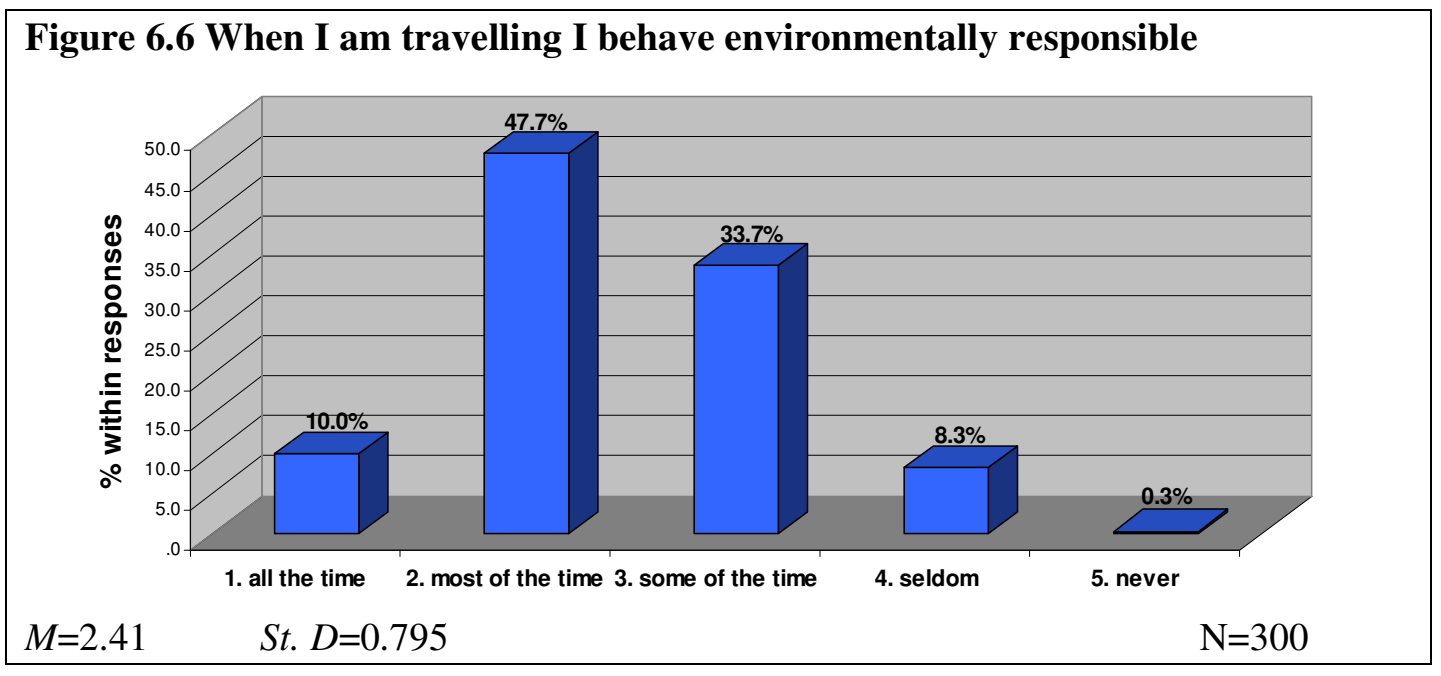

A paired samples t-test was used to compare the two means from the variables. As can be seen in Table 6.2, on average, participants reported that they behaved more environmentally responsibly when travelling $(M=2.41, S E=0.46)$ than when at home $(M=2.05, S E=0.38)$. This proves that people's opinions about their behaviour are in contrast to previous research on actual holiday behaviours versus home behaviours, which found that people's environmentally friendly behaviour while on holiday was only two thirds of that at home (Dolcinar \& Leisch, 2008). However, the mean scores across the sample which are both close to 2 on the Likert scale indicate that the respondents generally seemed to think that they behaved in an environmentally responsible manner in both situations.

\begin{tabular}{|c|c|c|}
\hline \multicolumn{3}{|c|}{ Table 6.2 Reported holiday behaviour versus home behaviour } \\
\hline & mean & standard deviation \\
\hline $\begin{array}{l}\text { When I am at home, I behave environmentally } \\
\text { responsibly: }\end{array}$ & 2.05 & - \\
\hline $\begin{array}{l}\text { When I am travelling, I behave environmentally } \\
\text { responsibly: }\end{array}$ & 2.41 & .795 \\
\hline \multicolumn{3}{|c|}{$\begin{array}{c}\text { (Scale: } 1=\text { All the time, } 2=\text { Most of the time, } 3=\text { Some of the time, } 4=\text { Seldom and } \\
5=\text { Never) }\end{array}$} \\
\hline$t(299)=-10.190, p<.00, r=.25$ & & \\
\hline
\end{tabular}

A one-way ANOVA was used to test for statistically significant variances in environmentally friendly behaviour when on holiday between different age groups, levels of annual household income and education levels when travelling. While no significant variances were found within age groups or levels of education, behaviours differed significantly across the six income categories $\mathrm{F}(5,249)=3.015 p=0.012$. A Scheffe's test was conducted to further investigate the income groups which varied from the rest of the sample. This test showed that the income group $\$ 200001$ or above $(M=3.15,95 \%$ CI $[2.67,3.64])$ varied significantly from three other 
income groups: Below $\$ 20000(M=2.09,95 \%$ CI $[1.62,2.56]), \$ 50001-\$ 100000(M=2.32$, $95 \% \mathrm{CI}[2.15,2.49])$ and $\$ 150001-\$ 200000(M=2.40,95 \% \mathrm{CI}[2.13,2.67])$.

An error bar chart was used to illustrate the differences among the groups. The confidence intervals in Figure 6.7 verifies with a certainty of $95 \%$ that people who earn the most are less likely to behave in an environmentally responsible manner when on holiday than the three other groups identified by Scheffe's test.

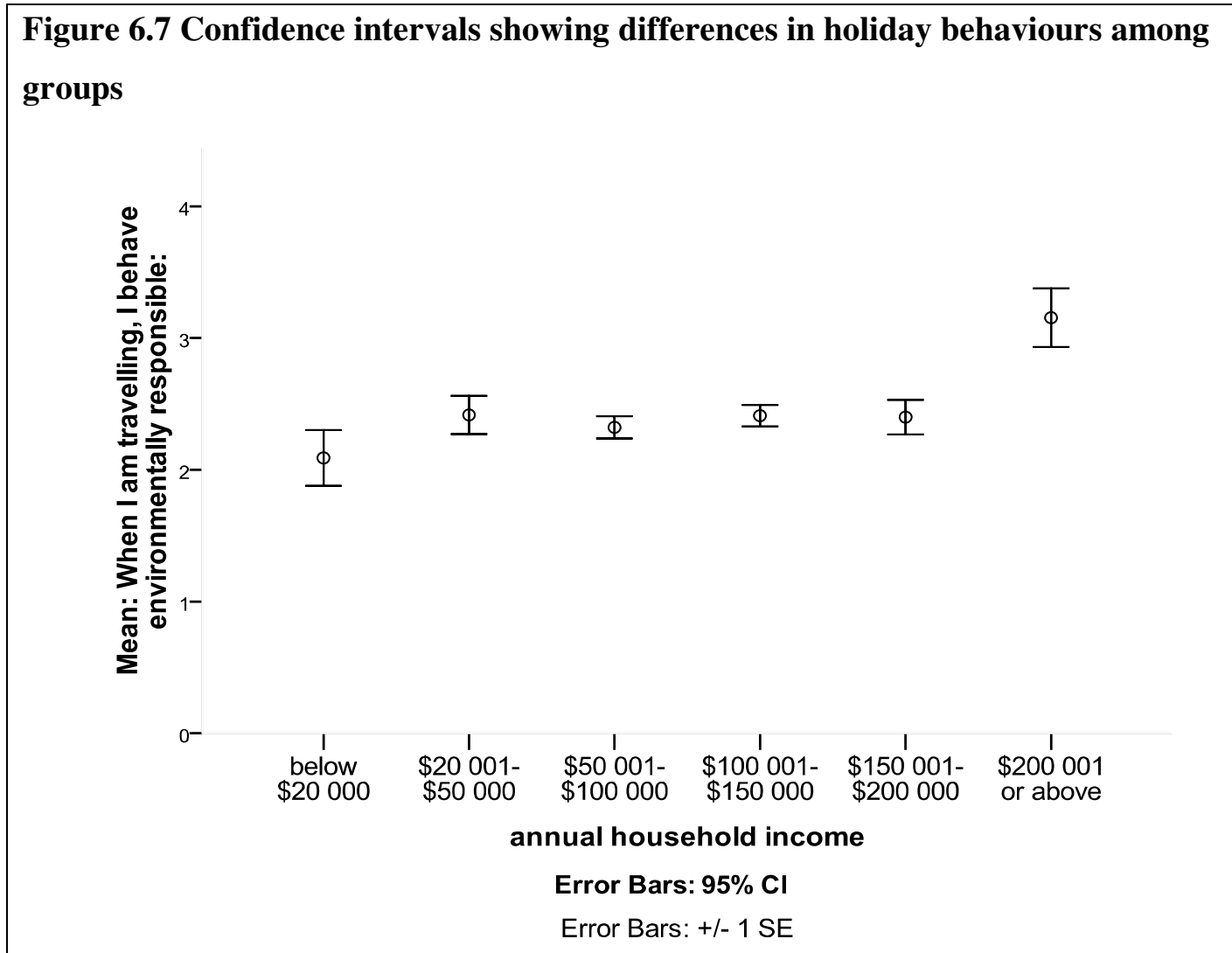

Scale: $1=$ All of the time, $2=$ Most of the time, $3=$ Some of the time, $4=$ Seldom, $5=$ Never

The difference between holiday at home and holiday behaviour has been accounted for by several researchers (Dolcinar \& Leisch, 2008; Barr et al., in press), however this study went one step further to explore whether people were aware of differences in their own behaviours. To explore whether people thought that they behave differently at home than to when they are on holiday, the respondents were asked to indicate on a scale of 1 to 5 whether they relaxed more in terms of environmental concern when on holiday. 


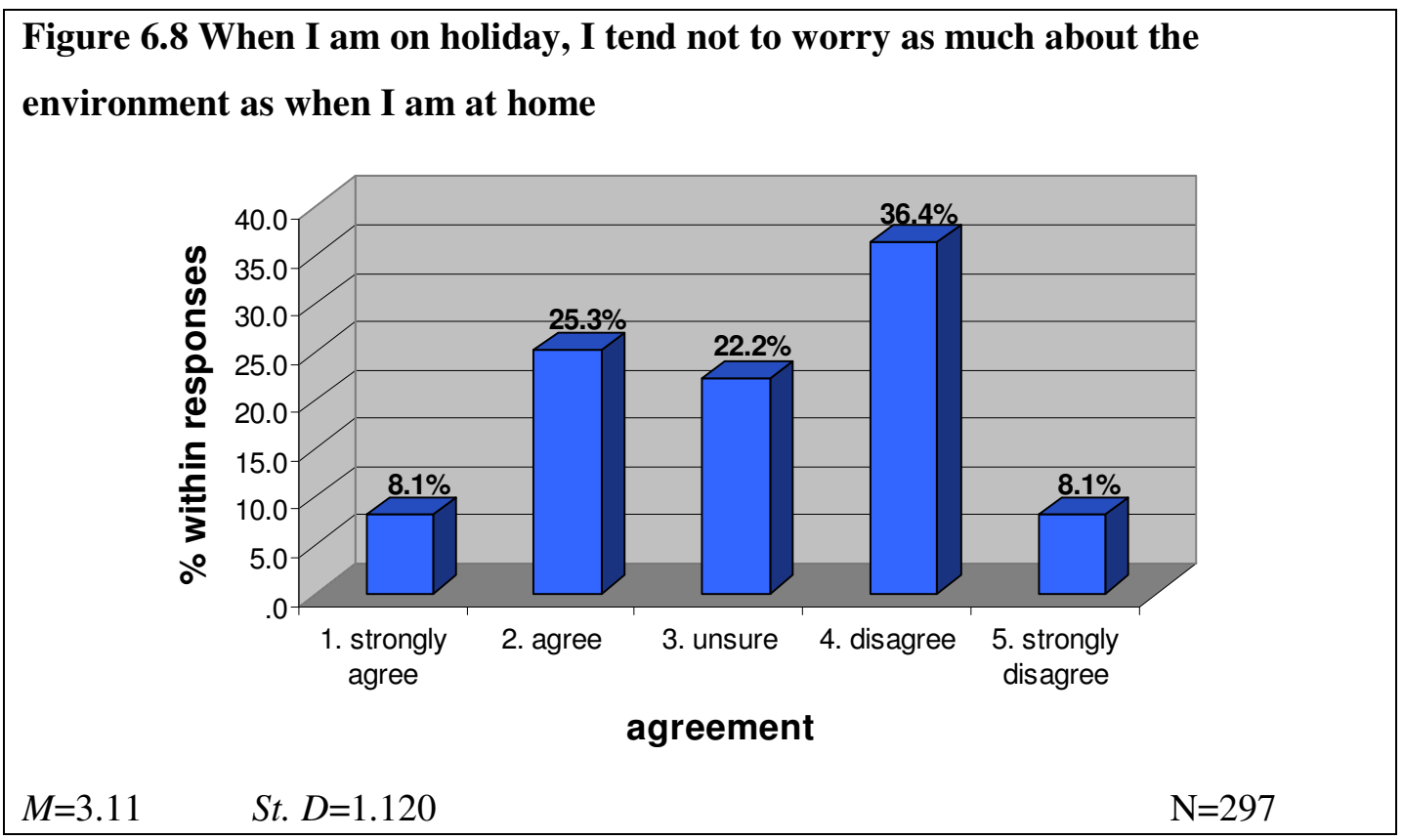

As can be seen in Figure 6.8, opinions were widespread across the sample. Although the mean was clustered around the 'unsure' category, the categories on either side of the neutral point were more populous. People seemed to have distinct opinions on their behavioural patterns. While $33.4 \%$ agreed or strongly agreed with the statement, $44.5 \%$ showed levels of disagreement.

A One-Way ANOVA was used to test for statistically significant variances between different age groups, levels of education and annual household income categories. Whereas no significant variances were found between groups of education and annual household income, the ANOVA showed that there were statistically significant variances between different age groups $\mathrm{F}(5,291)$ $=3.048 p=0.11$. Scheffe's test of the groups did however not identify the significant relationships. As can be seen in the error bar chart in Figure 6.9, there seemed to be two divisions of opinions. Whereas respondents in the age groups 18-29 $(M=2.84), 50-59(M=2.83)$ and 60-69 $(M=2.84)$ reported agreement to the statement, respondents in the age groups 30-39 $(M=3.35), 40-49(M=3.34)$ and 60-69 $(M=3.29)$ reported agreement. 


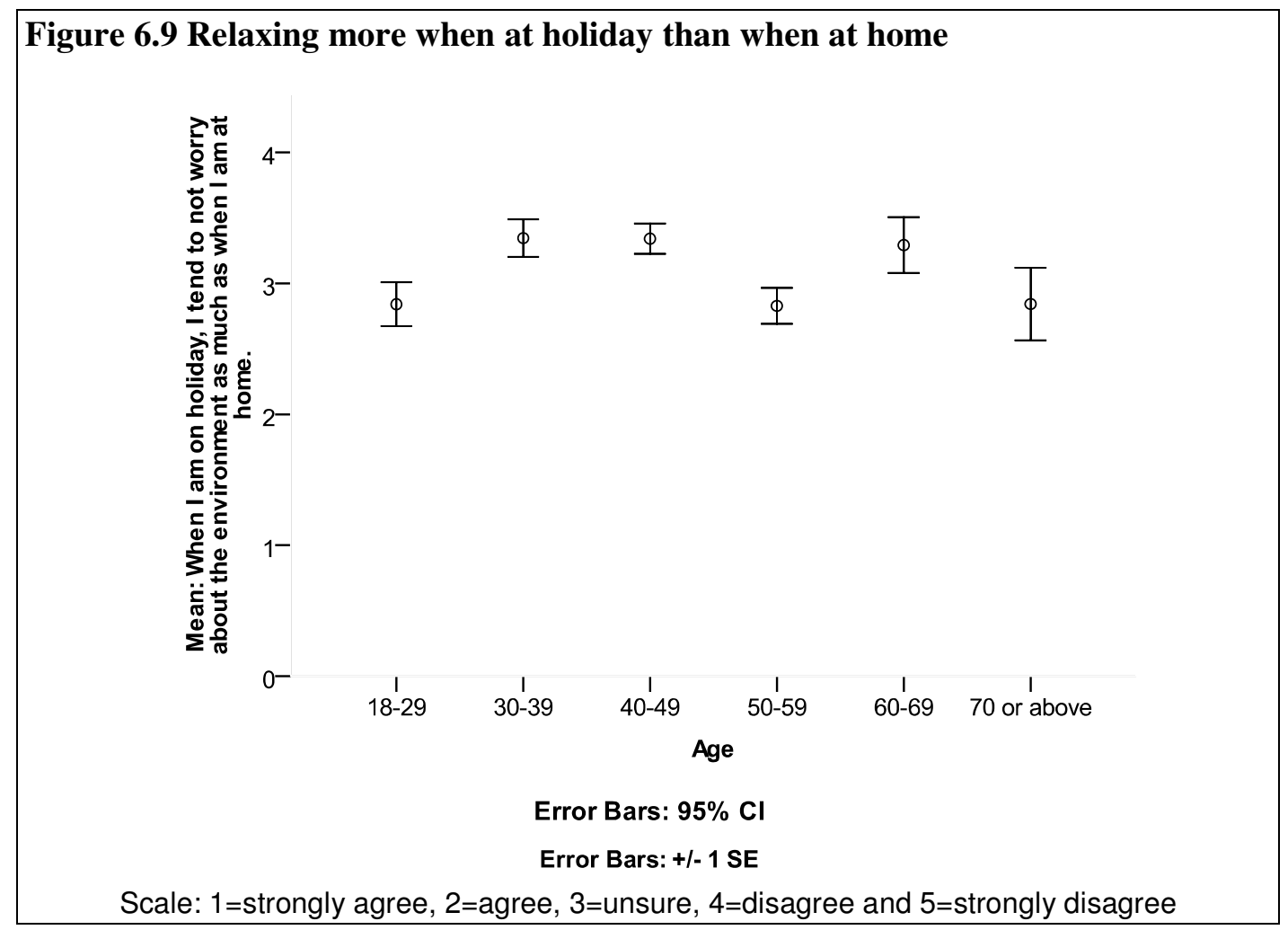

\subsubsection{Perceived difficulty of knowing how to behave environmentally friendly when on holiday}

Several researchers have remarked that although people may know how to act environmentally responsible at home, travelling adds extra difficulties in terms of being in an unfamiliar environment, where the environmental practises of the area one is visiting are foreign (Dolcinar \& Leisch, 2008, Barr et al., in press). To explore whether people thought that it is difficult to know how to act environmentally friendly when travelling, the respondents were asked to indicate on a scale of 1 to 5 whether they agreed or not with a statement positively loaded towards difficulty of knowing how to act. As can be seen in Figure 6.10 opinions were dispersed across the sample; the sample mean was 2.77 with a standard deviation of 1.099 . Many people reported that they do find it difficult to know how to act, as $49.8 \%$ of the sample agreed with the statement to some degree. 


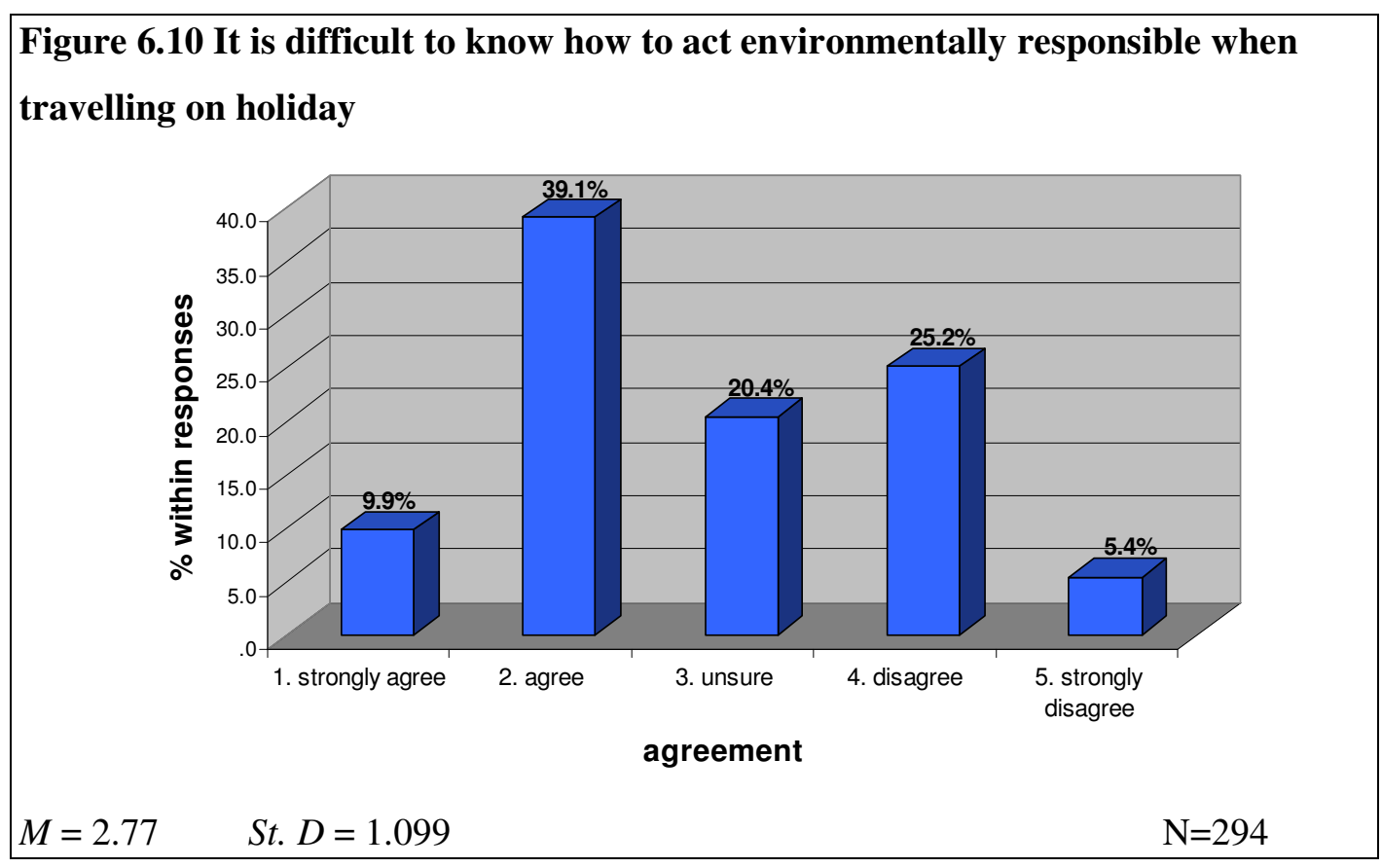

A one-way ANOVA was used to see if there were statistically significant differences in agreement with the statement between age groups, levels of education and annual household income categories. Whereas no statistical significance was found between age groups or education levels, the investigation of annual household income categories showed significant differences between the groups $\mathrm{F}(5,243)=2.493 p=0.032$.

Scheffe's test of the six groups indicate that the people who had an annual household income of less than $\$ 20000(M=3.78,95 \%$ CI $[2.94,4.62])$ had significantly higher disagreement with the statement that it is difficult to know how to behave environmentally friendly when travelling than the rest of the income groups, with the exception of people who earned $\$ 100001-\$ 150$ 000 per year.

A graphic depiction of the agreement with the statement can be seen in the error bar chart in Figure 6.11. It is quite clear that those in the sample who earn the least think it is less difficult to know how to behave. It is beyond the scope of this study to explore the underlying factors that contribute to this, whether it is a result of cost of environmentally friendly tourism products can be discussed. 


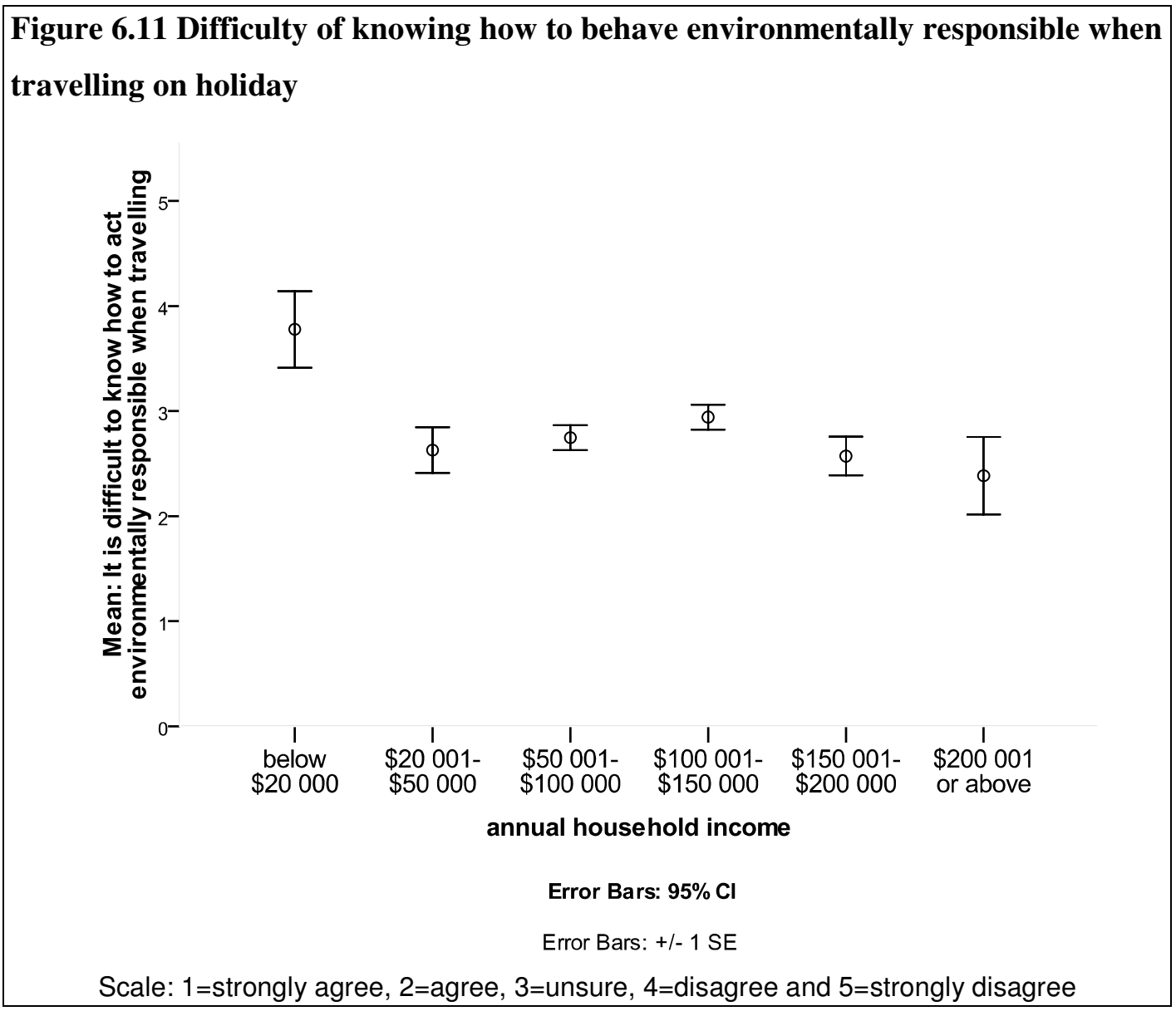

Participation in carbon offsetting schemes can be seen as one way of behaving environmentally responsible when holidaying, although the actual usefulness of carbon offsetting has been debated in the literature review, and not all agree on the usefulness of carbon offsetting. When comparing means across the sample to see whether opinions had any relation to carbon offsetting participation or not, there was a notable difference between those who did participate and those who did not. The mean score among those who participated in carbon offsetting was 3.67, whereas the mean score among those who did not participate was 2.85 (see Table 6.3). Although the number of people who participated was low, these people found it less difficult to know how to act than those who did not participate in carbon offsetting.

\begin{tabular}{|l|r|r|r|}
\hline \multicolumn{4}{|c|}{$\begin{array}{c}\text { Table 6.3 It is difficult to know how to act environmentally responsibly } \\
\text { when on travelling }\end{array}$} \\
\hline Participation in carbon offsetting & Mean & N & Std. Dev \\
\hline yes & 3.67 & 12 & .985 \\
\hline no & 2.85 & 128 & 1.144 \\
\hline Total & 2.92 & 140 & 1.151 \\
\hline \multicolumn{2}{|c|}{ Scale: 1=strongly agree, 2=agree, 3=unsure, 4=disagree and 5=strongly } \\
disagree
\end{tabular}


To investigate what the respondents considered to be environmentally responsible behaviour when travelling on holiday, the respondents who answered that they act environmentally all of the time or most of the time when travelling were asked to list which actions they took. This was an open ended question, to allow for freedom of interpretation, and the respondents were allowed to list up to 6 different actions each. The categories used in Table 6.4 below were derived from the raw data according to similarities. In all, 187 people listed 424 actions that they take to act environmentally responsible when on holiday, as shown in the table.

\begin{tabular}{|l|r|r|}
\hline \multicolumn{1}{|c|}{ Table 6.4 Actions taken to behave environmentally responsible when holidaying } \\
\hline & \multicolumn{2}{|c|}{ Responses } \\
\cline { 2 - 3 } & $\mathbf{N}$ & Percent \\
\hline Dispose of litter appropriately & 123 & $29.0 \%$ \\
\hline Recycle where possible & 72 & $17.0 \%$ \\
\hline Walk short distances & 35 & $8.3 \%$ \\
\hline Reduce waste & 34 & $8.0 \%$ \\
\hline Limit water/electricity usage & 32 & $7.5 \%$ \\
\hline Use public transport & 28 & $6.6 \%$ \\
\hline Keep to designated areas & 17 & $4.0 \%$ \\
\hline Use non-leaded fuel/fuel efficient transport modes & 17 & $4.0 \%$ \\
\hline Buy local food/products & 14 & $3.3 \%$ \\
\hline Keep to speed limits & 13 & $3.1 \%$ \\
\hline Choose environmentally friendly transport companies & 11 & $2.6 \%$ \\
\hline Other & 8 & $1.9 \%$ \\
\hline Re-use towels & 7 & $1.7 \%$ \\
\hline Take part in low-impact activities & 7 & $1.7 \%$ \\
\hline Clean shoes/equipment when tramping & 3 & $.7 \%$ \\
\hline only travel short distances & 3 & $.7 \%$ \\
\hline Total & 424 & $100.0 \%$ \\
\hline
\end{tabular}

Among the actions most frequently mentioned were disposing of litter appropriately and recycling. Many people listed actions which are associated with behaving according to social norms or laws and regulations outlined at the destination, such as disposing of litter in an appropriate manner. Nevertheless, it should be noted that taking these considerations when travelling is a display of concern for the local environment in which the people are holidaying.

Many of the respondents listed actions that are helping in limiting the negative effect of tourism on the environment, and are associated with behaving in an environmentally friendly manner. Some of the actions reported, such as buying local food/products, limiting water/electricity use and reducing waste are often mentioned in codes of conduct for tourists, which are guides for how to behave to limit one's negative impact on the natural environment and culture of a destination at the same time and increasing the economic benefit for the local economy. Such 
codes are easily accessible and often displayed at attractions and destinations to encourage positive behaviours. Among the low impact activities that were mentioned were walking to do sightseeing and bike rides.

Only very few of the respondents mentioned actions to drastically reduce the negative impact that tourism has on the global natural environment, such as travelling only short distances. The three people who reported this type of behaviour are the ones who show the most initiative for reducing the impacts that their travelling has on the natural environment, by recognising that travelling long haul makes a large negative impact and therefore needs to be avoided/reduced. Although most people try to make up for their travelling behaviours in terms of limiting their impact while on holiday, there are not many who would sacrifice the freedom of travelling for the sake of the environment.

\subsubsection{Concern about own impact}

To investigate the level of concern among people regarding the impact of their own holiday travels, respondents were asked to indicate on a scale of 1 to 5 their level of agreement or disagreement with a statement regarding the importance of making sure that their travels were as environmentally sound as possible. This variable was further analysed in relation to reported travel behaviours Section 6.4 below. As can be seen in Figure 6.12 on next page, respondents generally seemed to think that it is important to make this consideration when going on holiday; however a large percentage reported that they were unsure about this. 


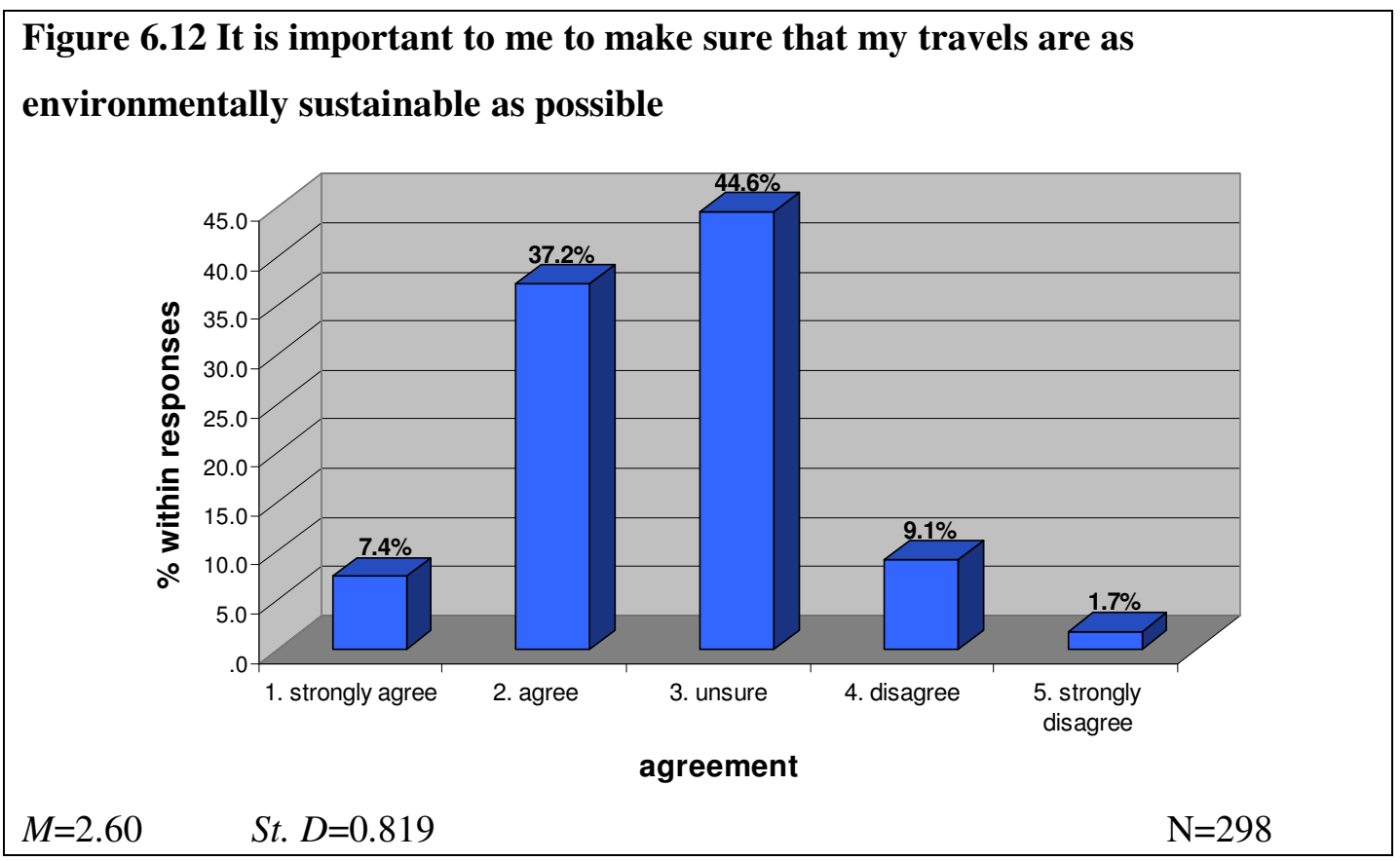

A One-Way ANOVA was used to test for statistically significant variances between different age groups, levels of education and annual household income categories. While no statistically significant variances were found between different age groups or levels of education, variance between different categories of annual household income was found $\mathrm{F}(6,290)=3.485, p=$ 0.002. A Scheffe test showed that respondents who earn less than $\$ 20,000$ feel that it is a much bigger concern to them to make sure that their travels are as environmentally sound than it is for the rest of the groups in the sample.

Figure 6.13 below shows the error bar chart produced for this test. It is quite clear that those who have an annual household income below $\$ 20,000$ have a much lower mean (1.73) than the average mean score across the sample (2.61). 


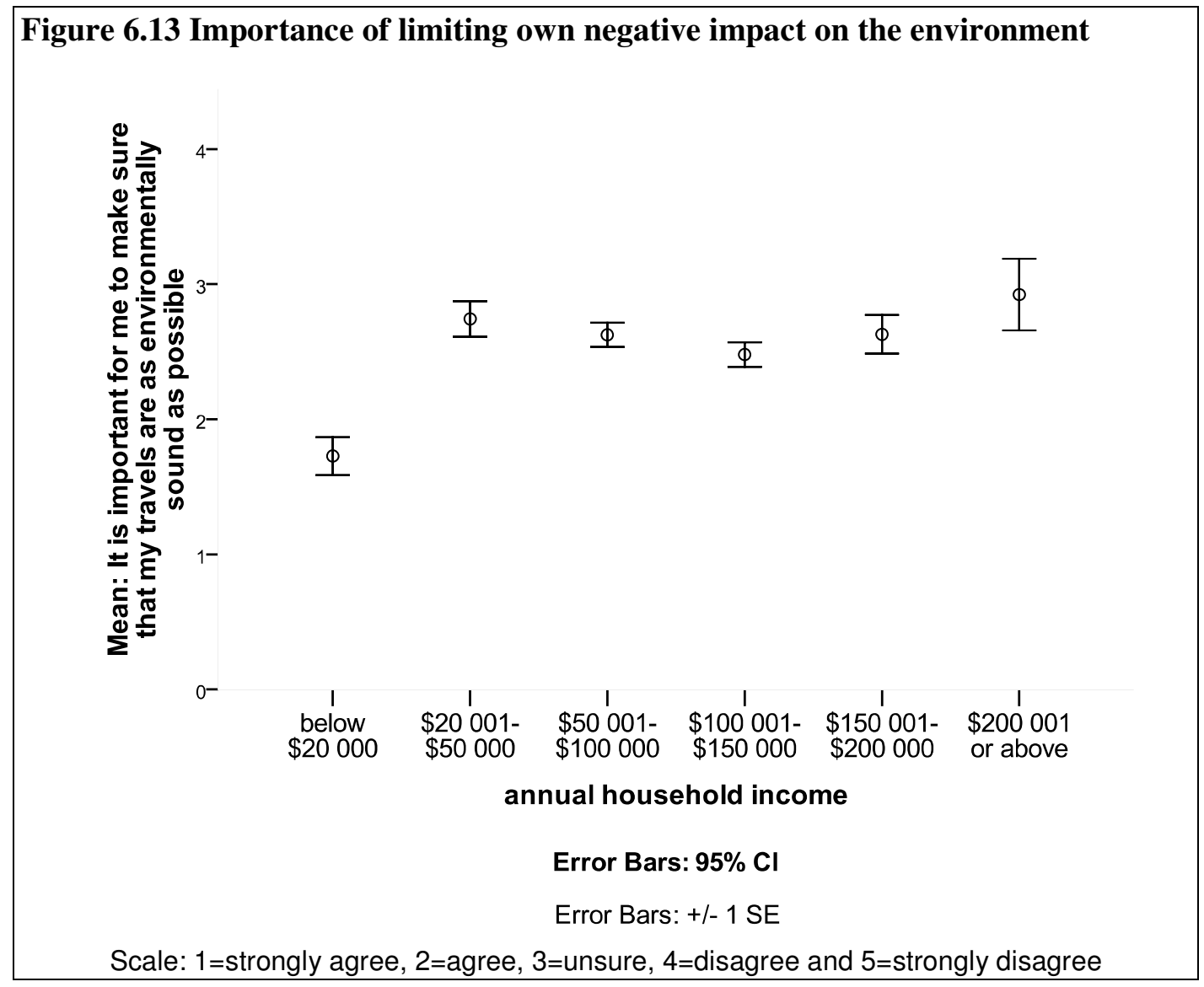

Researchers have noted that people are less likely to see the importance of acting in an environmentally friendly manner if they do not see the urgency of the threat that global climate change poses: Often people are more concerned with problems that are seen as more pressing, such as personal health, security and other social problems (Lorenzoni et al., 2007). Therefore, a One Way ANOVA was used to test for statistically significant variances in relation to perceived likelihood that climate change will impact on people's lives within the next 20 years (for a distribution of opinions on this variable, see Figure 5.11 in Section 5.3). The test showed that perception of urgency does influence people's opinions about limiting own negative impact $\mathrm{F}$ (4, 284) $=9.548, p=0.000$.

A Scheffe's test showed that people who thought it very likely that climate change would impact on their lives $(M=2.21,95 \%$ CI [2.00, 2.42]) were more concerned about making sure that their travels were environmentally sound than the group who was neutral and the two groups who thought it was unlikely that climate change would affect them. 
In sum, several respondents considered it important to make sure that their travels were as environmentally sound as possible, however the largest part of the sample were unsure about this. People who participated in carbon offsetting schemes and people who thought it likely that climate change would affect them were more prone to emphasise the importance of making their travels as environmentally sound as possible.

\subsubsection{Evaluation of own impact}

Although distance is a factor that influences the impacts that a trip has in terms of transport emissions, people are often unaware of the relationship between travelling long distance and negative impacts on the global natural environment (Gossling, 2006). The respondents were asked to indicate on a scale of 1 to 5 whether they thought that their holidays had a negative impact on the environment or not. This variable was further analysed in Section 6.4 below. As can be seen in Figure 6.14 below, the opinions were centred around the neutral point on the scale, with a sample mean of 3.12. Whereas quite a few respondents reported that their travelling did not have much of an impact on the environment, the opinions were widely dispersed across the sample.

Figure 6.14 The impact of my travelling on the environment is insignificant

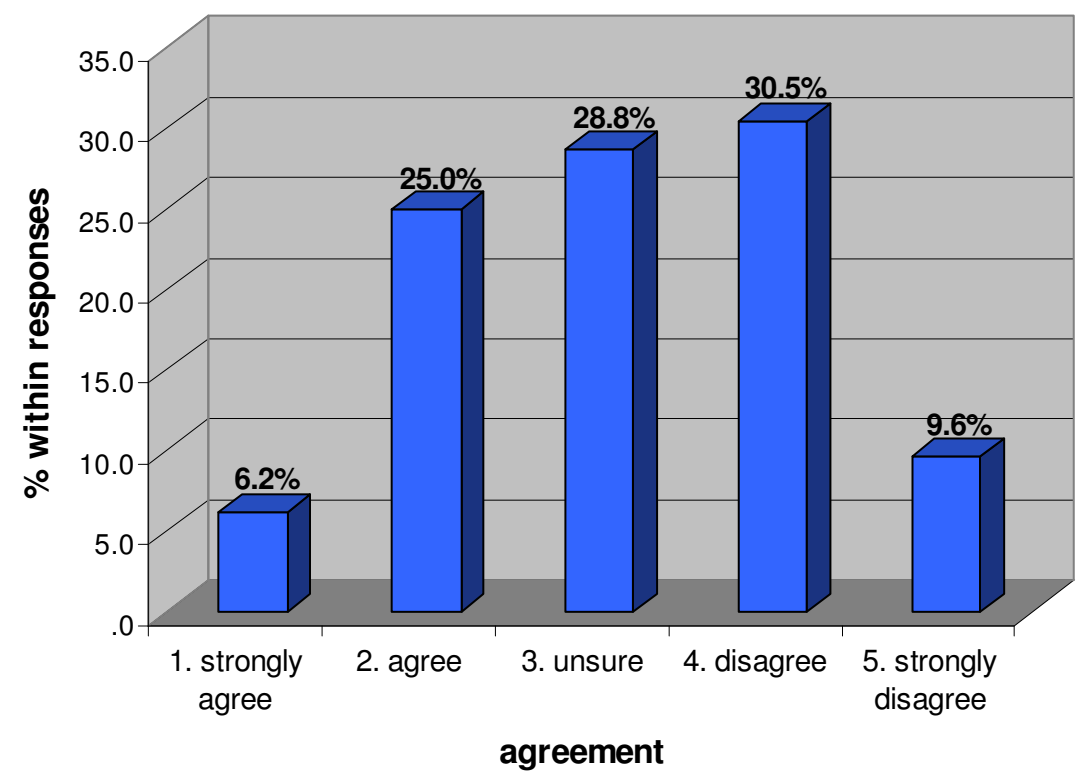

$M=3.12 \quad$ St. $D=1.083$

$\mathrm{N}=292$

A One-Way ANOVA was used to test for statistically significant variances between different age groups, annual household income levels and levels of education to see whether these 
variables had any influence on the opinions reported by the respondents. No significant variances could be found. Tests were also conducted to explore whether there were significant variances between different levels of $\mathrm{CO} 2-\mathrm{E}$ emissions, however opinions about own travel did not seem to be influenced by the actual impact of the respondents' travels. The One-Way ANOVA tests did however show that there were significant variances within perceived likelihood that climate change would affect the respondents' lives $\mathrm{F}(4,278)=10.043, p=$ 0.000. Scheffe's test showed that those who thought it very likely that climate change would affect them $(M=3.63,95 \%$ CI $[3.36,3.90])$ were more likely to assume that their leisure travels caused negative impacts than the two groups who thought it unlikely that climate change would affect their lives.

\subsubsection{The relationship between tourism and contribution to global climate change}

Although there has been much attention drawn to the fact that tourism contributes to global warming in terms of burning fossil fuels, there still seems to be low awareness of the impact of tourism on the global natural environment (Gössling et al., 2006). To investigate whether people thought that tourism and climate change are linked, the respondents were asked to indicate on a scale of 1 to 5 whether they agreed with a statement which argued that tourism within New Zealand does not contribute to global climate change. This variable was further tested against actual reported behaviours of the respondents in Section 6.4 below. The statement was phrased in such a way that people would have to consider the impact that tourism on a local scale has on the overall global climate, and such that disagreement with the statement would leave little doubt that the respondents do believe that there is a link between tourism and climate change. 


\section{Figure 6.15 Tourism in New Zealand does not contribute to global climate change}

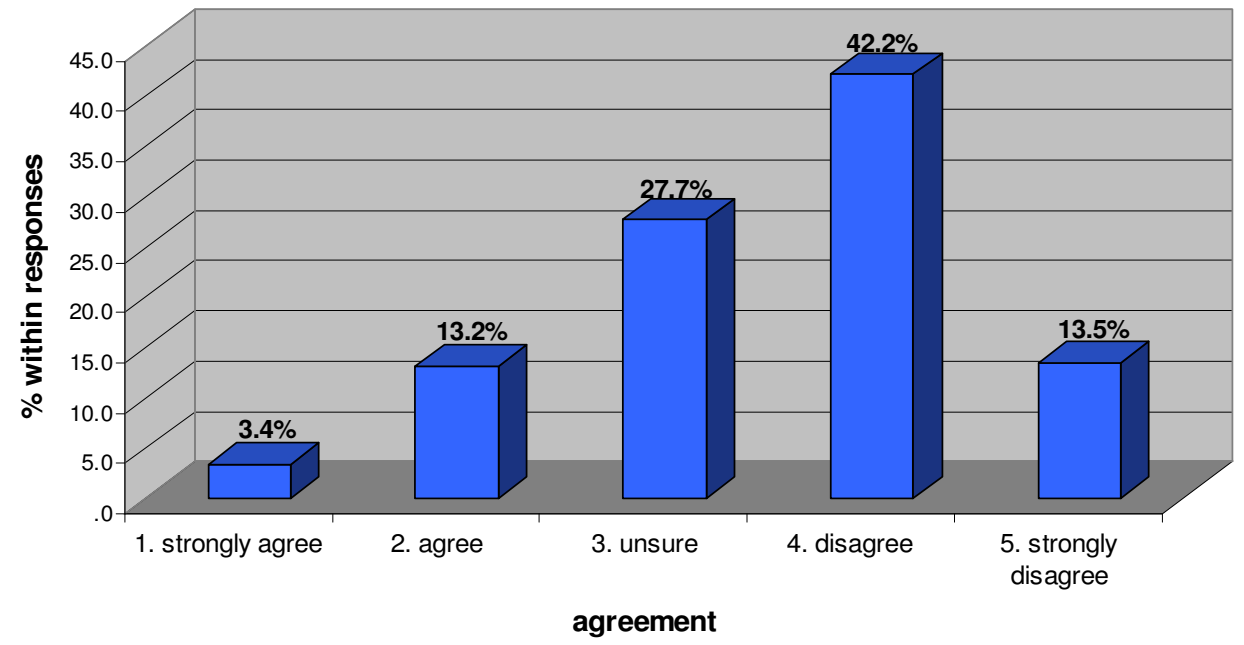

$M=3.49$ St. $D=0.995$

$\mathrm{N}=296$

As can be seen in Figure 6.15, people do think that tourism and climate change are linked. The ratings were clustered around disagree on the scale which accounted for as much as $42.2 \%$ of the responses, indicating that the respondents think that the two phenomena are related.

A one-way ANOVA was used to test for differences in opinions regarding the contribution of tourism within New Zealand to climate change between different age groups, annual household income categories and education levels. While no significant variances were found between different groups of income, agreement with the statement differed significantly across the five education categories $F(4,290)=3.847$ p. $=0.005$. A Scheffe's test of the five groups indicate that the people whose highest level of education is secondary school $(M=2.91,95 \%$ CI [2.52, 3.29]) had significantly less belief that tourism in New Zealand has an impact on the global natural environment than people who had a university degree $(M=3.65,95 \%$ CI $[3.50,3.79])$, and people who had a post graduate degree $(M=3.66,95 \%$ CI $[3.35,3.96])$. Comparisons between other groups did not provide statistically significant results. As illustrated by the confidence intervals in Figure 6.16, the higher the level of education among the respondents, the stronger the statement of disagreement, indicating that the opinion that tourism is contributing to climate change increases with level of education. 


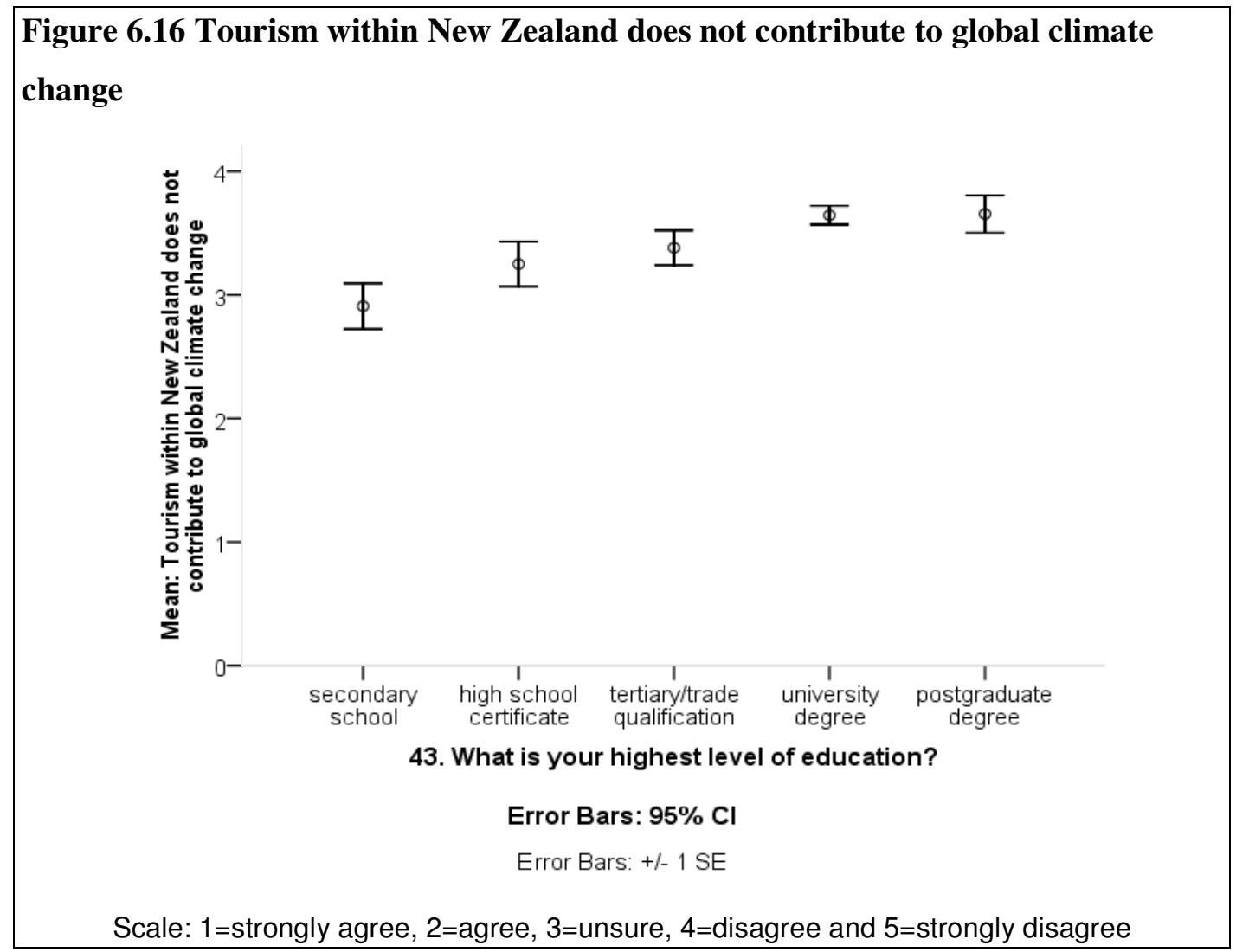

Agreement with this statement also differed significantly across the six age categories $\mathrm{F}(5,290)$ $=3.568 p=0.004$. Scheffe's post-hoc comparisons of the six groups indicate that the people in the sample who are 70 years or older $(M=2.78,95 \%$ CI $[2.25,3.31])$ had significantly less belief that tourism in New Zealand has an impact on the global natural environment than the three youngest age groups in the sample.

As can be seen in Figure 6.17, the older age group is set apart from the rest of the sample by their low mean score. The confidence interval is however larger than the rest of the samples due to the low number of respondents in the group $(\mathrm{N}=18)$. 


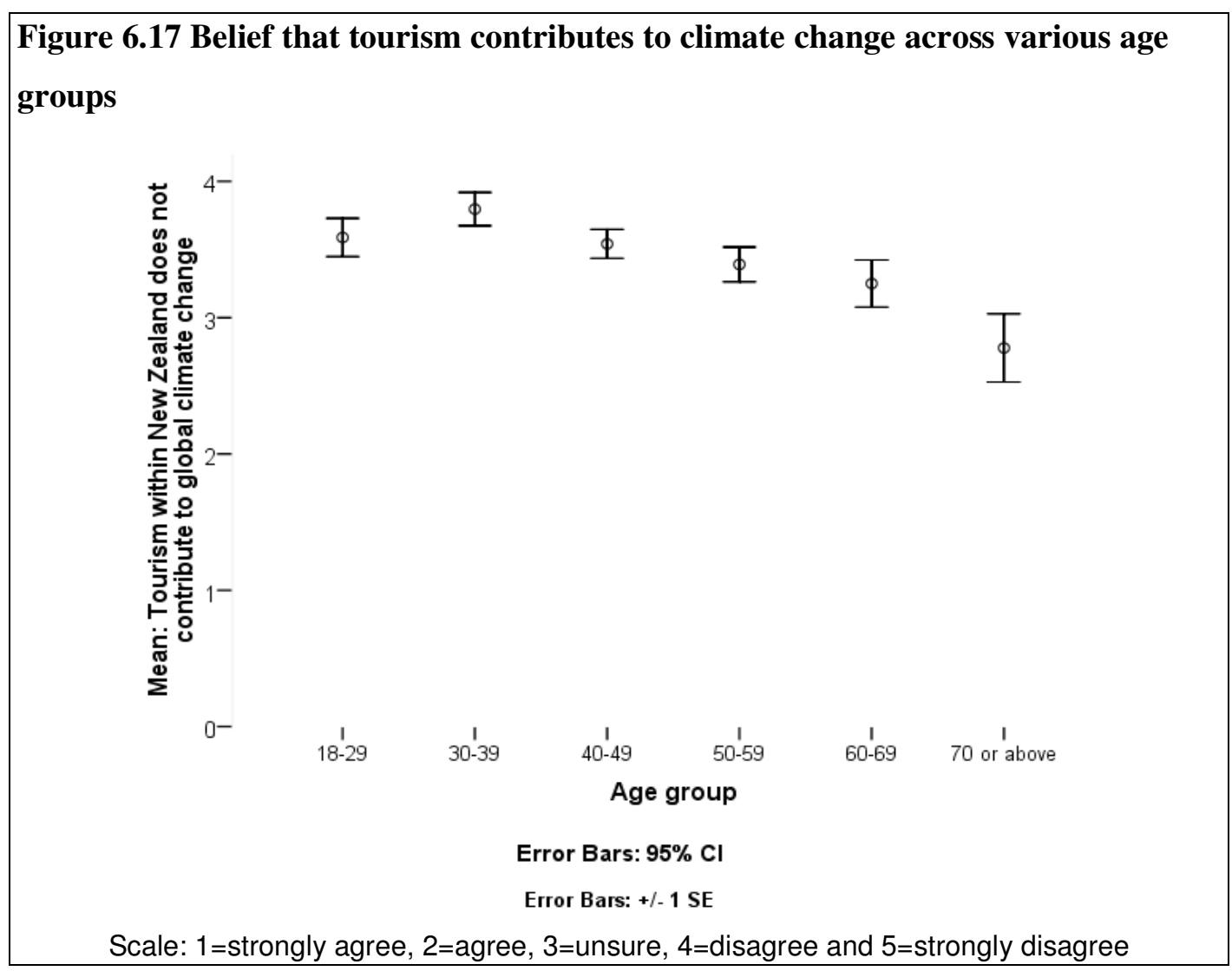

This indicates that younger people in the sample are more aware of the relationship between travelling and negative effects on the natural environment than older age groups are. This is an interesting finding which has possible implications for policy development; it may be appropriate to use various policy options to reach different age segments in society. It is however beyond the scope of this research to investigate the underlying reasons for this finding, and as such the researcher would encourage further research to explore this relationship in more depth.

A One Way ANOVA was used to test for statistically significant variances between different categories of perceived affect of climate change on daily life in New Zealand within the next 20 years, and a significant variance was found $\mathrm{F}(4,282)=6.286, p=0.000$. A Scheffe's test showed that those who thought it was unlikely that climate change would affect them $(M=2.97$ $95 \%$ CI $[2.61,3.34])$ were largely uncertain of the impact of tourism in New Zealand on global climate change, whereas those who thought it very likely that climate change would affect them $(M=3.84,95 \%$ CI $[3.57,4.11])$ do believe that tourism within New Zealand contributes to global climate change. 


\subsubsection{The effectiveness of buying environmentally friendly products in limiting negative impacts of tourism on the environment}

As has been discovered in the findings from the above analyses, more than half of the people in the sample do believe that tourism and climate change are related to some extent, and many are concerned about their own impact when travelling for leisure purposes. However, as has been proven by several researchers, environmental concern does not necessarily translate into environmentally friendly behaviour (Hares et al., in press; Dolcinar \& Leisch, 2008; Becken, 2007; Wearing et al., 2002; Stoll-Kleeman et al., 2001). To explore whether respondents thought that consuming environmentally friendly tourism products (i.e. tourism products provided by businesses who in some way aim at reducing their negative environmental impact) helps in reducing the negative impacts of tourism on the global natural environment, respondents were asked to indicate on a scale of 1 to 5 to which extent they agreed with the following statement: "It makes little difference buying environmentally friendly tourism products compared to buying ordinary tourism products."

\section{Figure 6.18 It makes little difference buying environmentally friendly tourism} products

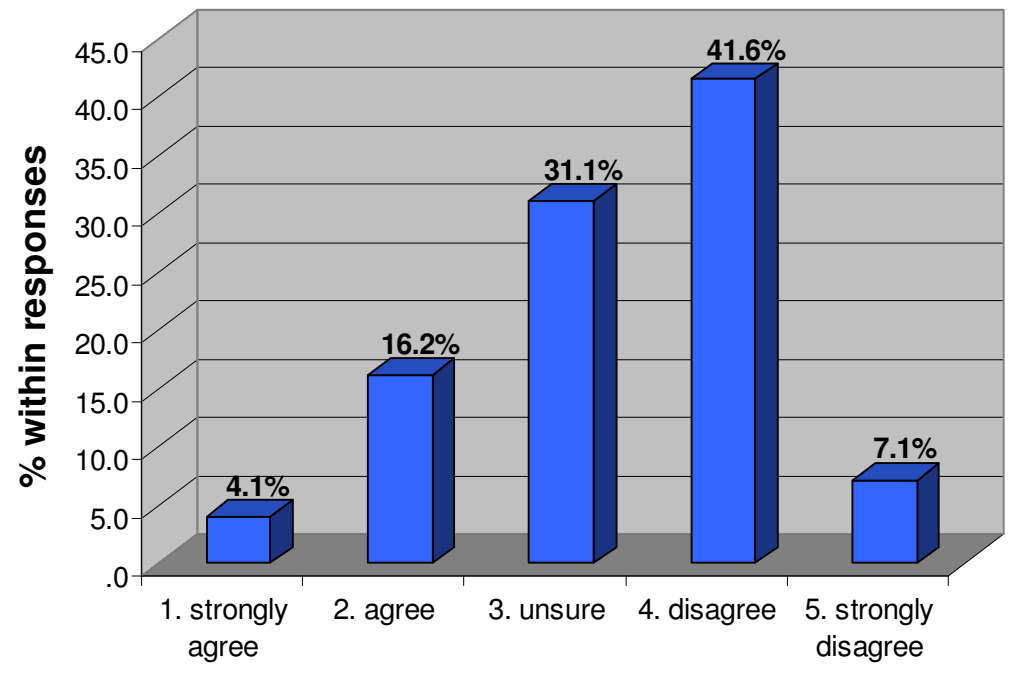

Agreement

$M=3.31$ St. $D=0.963$

$\mathrm{N}=296$

As can be seen in Figure 6.18, the largest discrete variable was 'disagree,' and the mean score of 3.32 shows that people do feel that it does make a difference to buy environmentally friendly products. 
The opinions were tested with a one-way ANOVA to see if there were statistically significant differences between age groups, annual household income categories or education levels. While no statistical significant variance was found between education levels and age groups, agreement with the statement varied significantly when it came to annual household income $\mathrm{F}$ $(5,245)=3.371 p=0.006$. A Scheffe's test showed that those who have an annual household income below $\$ 20,000(M=3.89,95 \%$ CI $[3.18,4.60])$ thought that buying environmentally friendly tourism products made a difference, whereas those who have an annual household income above $\$ 200,001(M=2.62,95 \%$ CI $[1.89,3.34])$ generally thought that it made little difference buying environmentally friendly tourism products.

The error bars in Figure 6.19 on next page show the distribution of the confidence intervals for the means, and an irregular line sloping down can be seen. People who earn the least show the highest disagreement with the statement. It should be noted that both the highest and the lowest income group are small groups. It is therefore significant that they do not overlap. It is thus clear that the group with the highest annual household income is less convinced that buying environmentally friendly products makes a difference, than the group with the lowest household income. 


\section{Figure 6.19 It makes little difference buying environmentally friendly tourism products - Effect of annual household income}

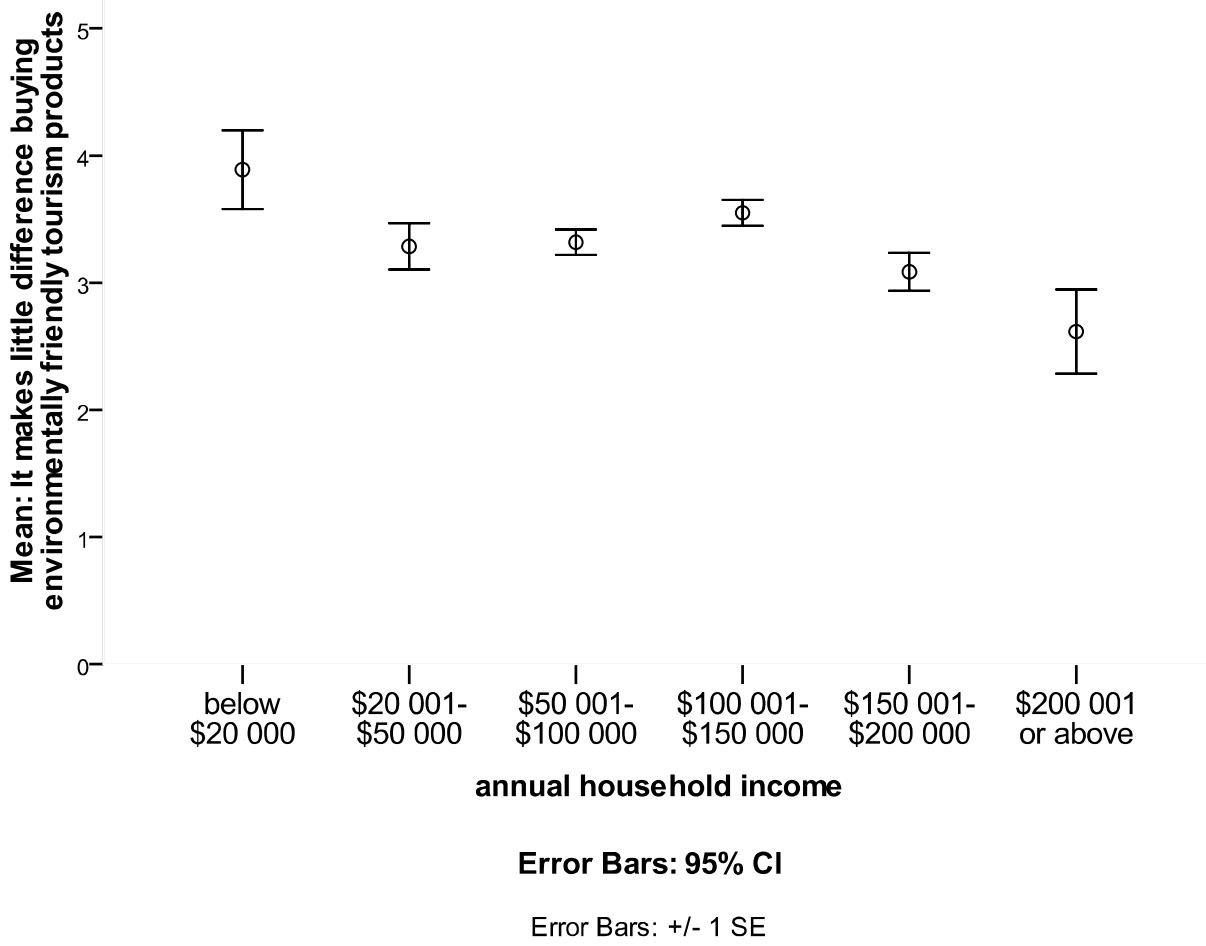

Scale: 1 =strongly agree, 2=agree, 3=unsure, 4=disagree and 5=strongly disagree

Participating in carbon offsetting can be considered one form of purchasing an environmentally friendly product. To explore whether there were differences in opinion between people who participate in carbon offsetting and people who do not, means were compared between the two groups. A One-Way ANOVA was used to test for differences between the two groups, and statistically significant variance was found $\mathrm{F}(1,141)=6.546 p=0.012$.

\begin{tabular}{|l|r|r|r|}
\hline \multicolumn{4}{|c|}{ Table 6.5 It makes little difference buying environmentally friendly tourism } \\
products
\end{tabular}

As can be seen in Table 6.5, those who participate in carbon offsetting schemes have a higher belief in purchasing environmentally friendly tourism products to behave environmentally friendly than those who do not. This is perhaps not surprising, given that carbon offsetting can 
be considered a means of making up for one's negative impact made through travelling, and it is rarely done by people who are unaware of the impact of their travelling in terms of carbon emissions.

A One-Way ANOVA found statistically significant variance between groups rating the statement "It makes little difference buying environmentally friendly tourism products" and the likelihood of climate change having a negative impact on daily life in New Zealand within the next 20 years $F(4,282)=2.485 p=0.44$. A Scheffe't test did however fail to identify the specific groups that led to the statistically significant variance. Figure 6.20 shows error bars of the various means between the different groups. The figure shows that two of the groups had a much higher mean than the rest of the sample; those who thought it unlikely that climate change would have a direct impact on them thought it less important to buy environmentally friendly tourism products than those who thought it likely that climate change would affect their lives.

\section{Figure 6.20 Effectiveness of buying environmentally friendly products}

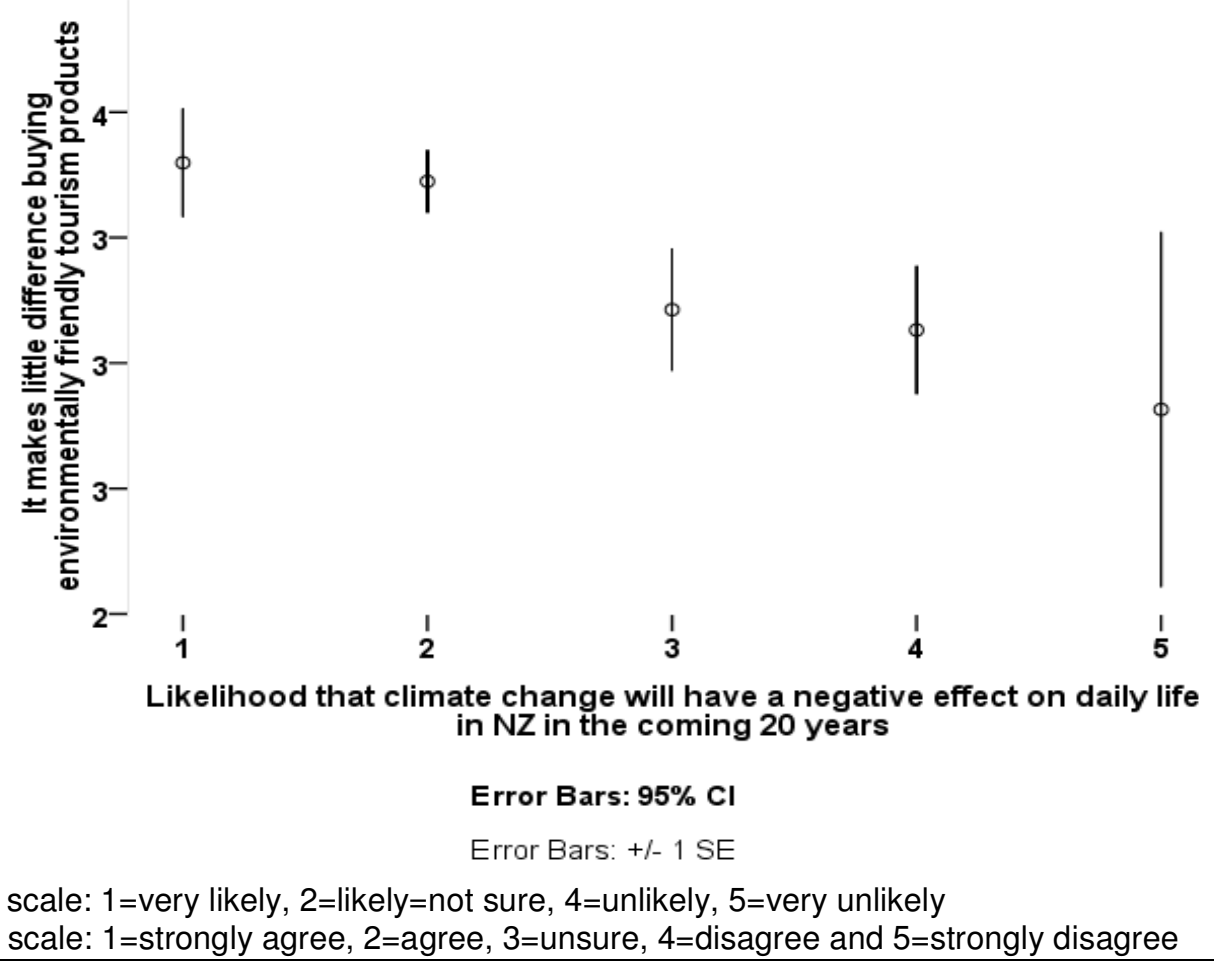

In conclusion, there seems to be a divide between those who think that it makes a difference to purchase environmentally friendly tourism products, and those who do not think that this is an effective measure to reduce the negative impact of tourism on the environment. Given that awareness and frequency of purchase of ecolabeled tourism products was found to be low in 
Chapter five, the findings in this section is likely based on people's perceptions rather than their knowledge about ecolabeled tourism products.

\subsection{Factors influencing distance travelled and impact}

One of the aims of this study was to explore the influence of environmental concern on behaviour in terms of the distances travelled and the actual impact in terms of $\mathrm{CO}_{2}$-E emissions made when travelling to and from their destination. The variables outlined in section 6.3 were analysed to account for people's concern for the environment. In addition to the variables included in Section 6.3, people's perception of the likelihood that climate change will affect them personally as explored in Chapter 5 was included in the variables that accounted for concern for the environment. Although there are differences among people when it comes to age, annual household income and education level, the variables do indicate that people in general are concerned about the environment and wish to limit negative impacts of tourism on the global natural environment.

Analyses showed that the perceived likelihood of climate change having an impact on daily life in New Zealand within the next 20 years had a clear influence on people's opinions. As such, the perceived urgency of the issue does determine how important a priority the issue of climate change mitigation is to the respondents, supporting the findings of Lorenzoni \& Pidgeon, (2006) who found that people considered climate change to be socially relevant, but did not feel that it poses a prominent personal threat.

The variables explored in section 6.2 accounted for the distances travelled and the transport emissions that were made by the respondents on their last two holidays. These two variables are closely related. Aeroplanes were used on all of the international trips, while car/van and aeroplane were the most frequently used transport modes on domestic trips. While car/van accounted for the largest share of emissions (60.7\%), aeroplane accounted for $30 \%$ of the emissions. The frequency of car/van use was twice that of aeroplane use, indicating that the emissions for these two transport modes are comparable when travelling domestically. It should however be noted that the number of people in the car was not recorded, and as such it is not possible to calculate emissions per person in terms of car use.

While other more environmentally friendly alternatives exist for travelling domestically such as scheduled coach services and trains, these were rarely used by the respondents on their trips, giving support to the findings in Chapter 5 regarding choice of transport mode which showed 
that ease of travel, distance to destination, monetary cost and time consideration were the most important factors when choosing transport mode, and environmental concern was one of the least important factors, if not the least important.

Several analyses were run to explore relationships between environmentally responsible behaviours and opinions about tourism and its impact on the global natural environment as outlined in Section 6.3 and distances travelled and emissions made on trips as outlined in Section 6.2. Distance travelled and impacts were compressed into appropriate intervals, and were subsequently analysed using chi square analysis and One-Way ANOVA to identify statistically significant relationships between travel behaviours and opinions. However, no significant relationships could be found. For example, although many agree that tourism within New Zealand does contribute to global climate change, this does not influence the distance travelled by the respondents or their choice of transportation. Similarly, many respondents reported that it is important to them to make sure that their travels are environmentally sound; however this also does not affect distance travelled or choice of transport mode (although choice of transport mode is limited on international trips). Similar results were produced for all variables in Section 6.3. This indicates that people's opinions and awareness of tourism's negative impact on the environment do not influence people's actual behaviours, and as such this research has identified the so called 'attitude-behaviour gap' among the respondents (Barr et al., in press; Hares et al., in press; Dolcinar \& Leisch, 2008; Lopez \& Cuervo-Arango, 2008; Wearing et al., 2002; Stoll-Kleemann et al., 2001).

When considering the frequency of participation in carbon offsetting schemes and purchase of ecolabeled tourism products, one can argue that people do not often act according to the best interest of the environment when holidaying, even if it is possible to do so by consciously choosing environmentally friendly products. One of the reasons for this is low awareness, and in the case of carbon offsetting it is also due to lack of belief in such schemes. While it has been argued that carbon offsetting is not a permanent solution to the problem that GHG emissions pose, it can be argued that at current this is the best alternative for neutralising one's carbon emissions if emissions cannot be avoided in the first place.

In conclusion, people seem to value holiday travels too highly to forgo the freedom of travelling where they want to, and how often they want to. As can be concluded from the high frequency of travel which was explored in Chapter four, people in the sample travel quite often; people in the sample travelled more than twice per year on average. Similarly, people seem to travel to far away destinations on a frequent basis: as many as $38.1 \%$ of the respondents travelled to a 
destination which was more than $6000 \mathrm{~km}$ away on one of their last two leisure trips (see Section 6.2 above). These findings indicate that concern for the environment does not in any way discourage people from travelling.

\subsection{Policy measures}

\subsubsection{Preferred policy}

There has been much debate about which policy measures should be applied to encourage behavioural change. As noted by many researchers, people do not want to give up the freedom to travel as often and as far as they want (Becken, 2007; Lorenzoni et al., 2007; Hares et al., in press). However, in order to reduce the negative impact that tourism has on the environment, there has to be a change in behaviour towards less travel (Burns \& Bibbings, 2009). It is thus clear that current policies are not adequate to deal with the increasing problem that GHG emissions from tourism present. Studies have also found that people are calling for governments to impose regulations to make them act, indicating that they want leadership from the top to guide them (Lorenzoni et al., 2007).

To explore the opinions of Wellington residents, the researcher asked the respondents to list their two most preferred policy options in order of most preferred and second most preferred.

As can be seen in Figure 6.21 on next page, the most preferred policy option was educational campaigns to inform people about the negative impacts that travelling can have on the

environment. This type of policy leaves people the option of maintaining their current behaviour, and will as such not provide a rapid solution to the problem. Educating people about their impacts may however induce gradual change, as environmental knowledge does have an impact on behaviour (Fraj-Andrez \& Martinez-Salinas, 2007). Considering the fact that the findings in section 6.4 .3 showed that many think that there is a relationship between climate change and tourism, and the fact that this did not affect behaviours, it may be argued that educational campaigns will not be effective in inducing change. 


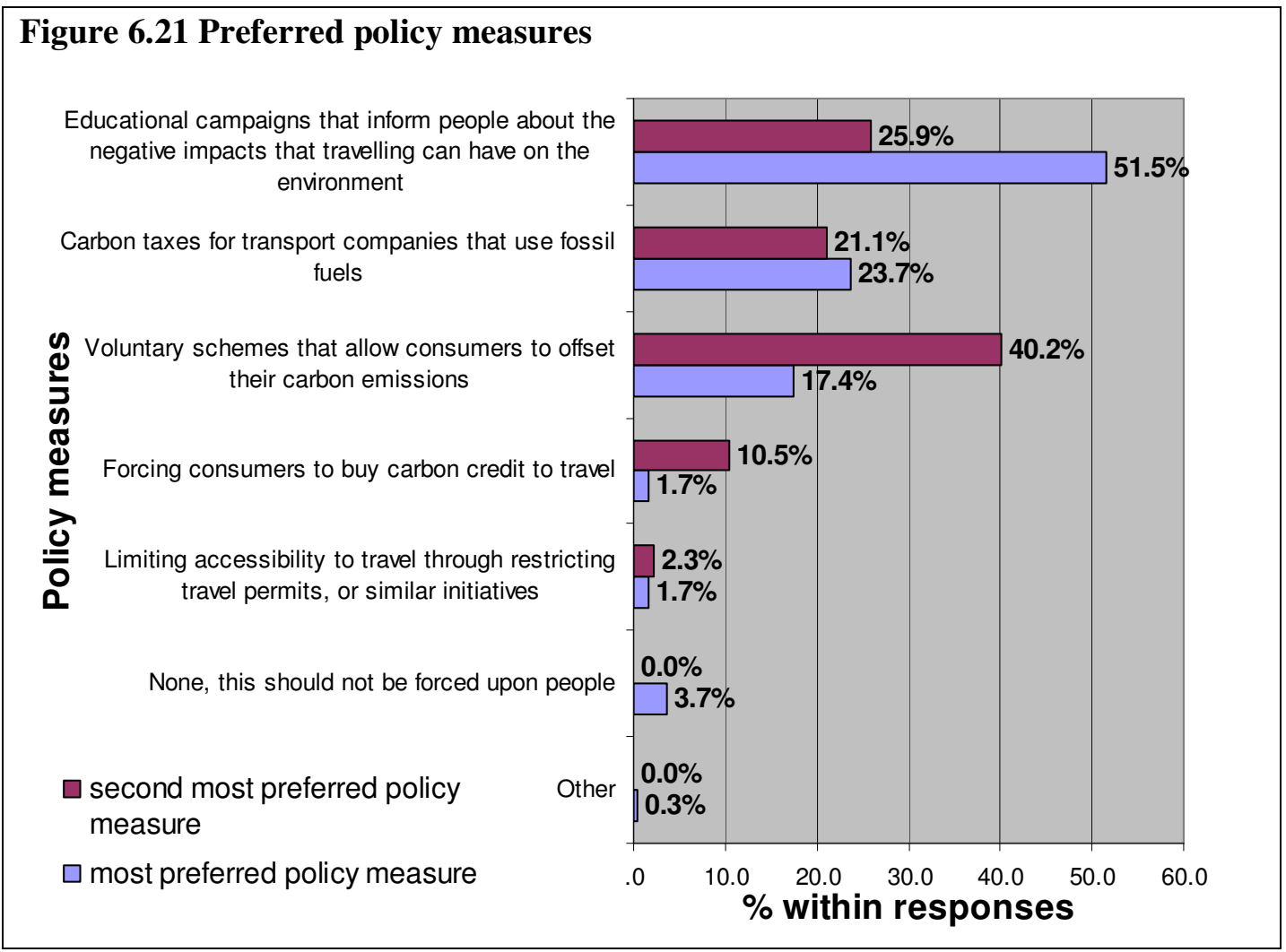

The option that was mentioned second most frequently was voluntary schemes that allow consumers to offset their carbon emissions, in spite of a large degree of disbelief in current schemes, and low awareness of carbon offsetting. As the number of people who participate in carbon offsetting is very low in the sample $(3.9 \%)$, this would again indicate that the most preferred option is one that requires the respondents to put in a minimal effort. The two least preferred options incurred financial or physical implications for people wanting to travel.

A One-Way ANOVA was used to see if there were statistically significant variances in the preferences between different age groups, education levels and different categories of annual household income. No significant variances between the groups were found, however.

Given that the perceived effect of climate change has an impact on behaviour (Lorenzoni et al., 2007), the researcher tested the three most preferred policy measures against people's perceptions about the likelihood of climate change having a negative impact on daily life in New Zealand within the next 20 years. The reason for conducting this analysis was to test whether people who think that climate change will affect their lives are more likely to be willing to accept policy measures that are imposed on them, in comparison with people who do not think that they will be affected by climate change. A One-Way ANOVA was used to check for 
statistically significant variances between the three groups, and significant variance was found $\mathrm{F}$ $(2,267)=4.523, p=0.012$. A Scheffe's test showed that those who wanted carbon taxes for companies who use fossil fuels $(M=1.96,95 \%$ CI $[1.72,2.19])$ thought it more likely that climate change would affect their lives than those who preferred voluntary schemes to offset carbon emissions ( $M=2.48,95 \%$ CI $[2.17,2.79]$ ) (see Figure 6.22). Educational campaigns showed no distinct characteristics in terms of perceived likelihood that climate change would affect their lives.

\section{Figure 6.22 Preferred policy options compared with perceived likelihood that climate change will have a direct impact on people's lives}

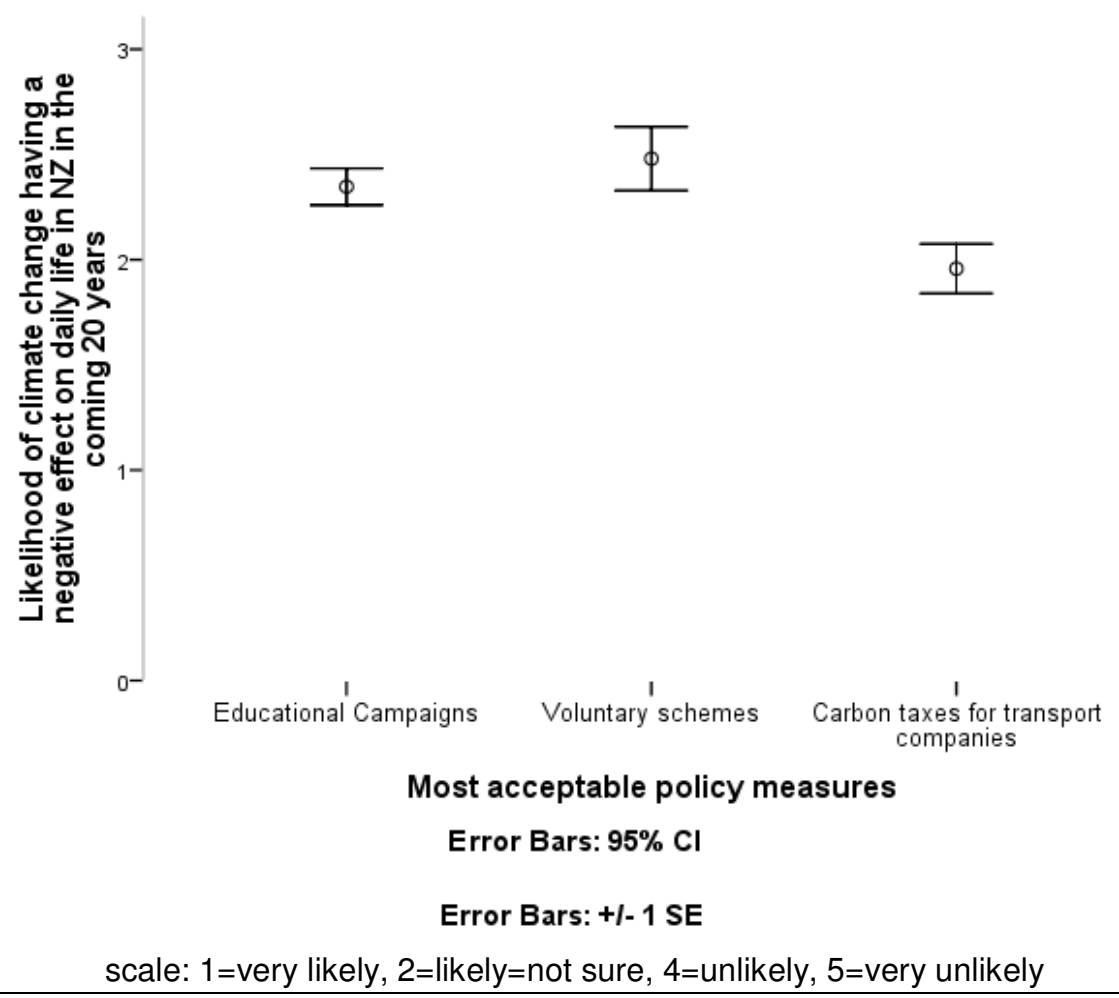

\subsubsection{Responsibility}

A common opinion that people form when faced with changing behaviour that is seen as 'comfortable,' is that the responsibility lies with someone else than with the individual (StollKleemann, 2001). The respondents were asked who they thought should take the main responsibility for mitigating the negative impacts that tourism has on the environment. This was asked as a closed question, with the option of specifying an 'other' category. 


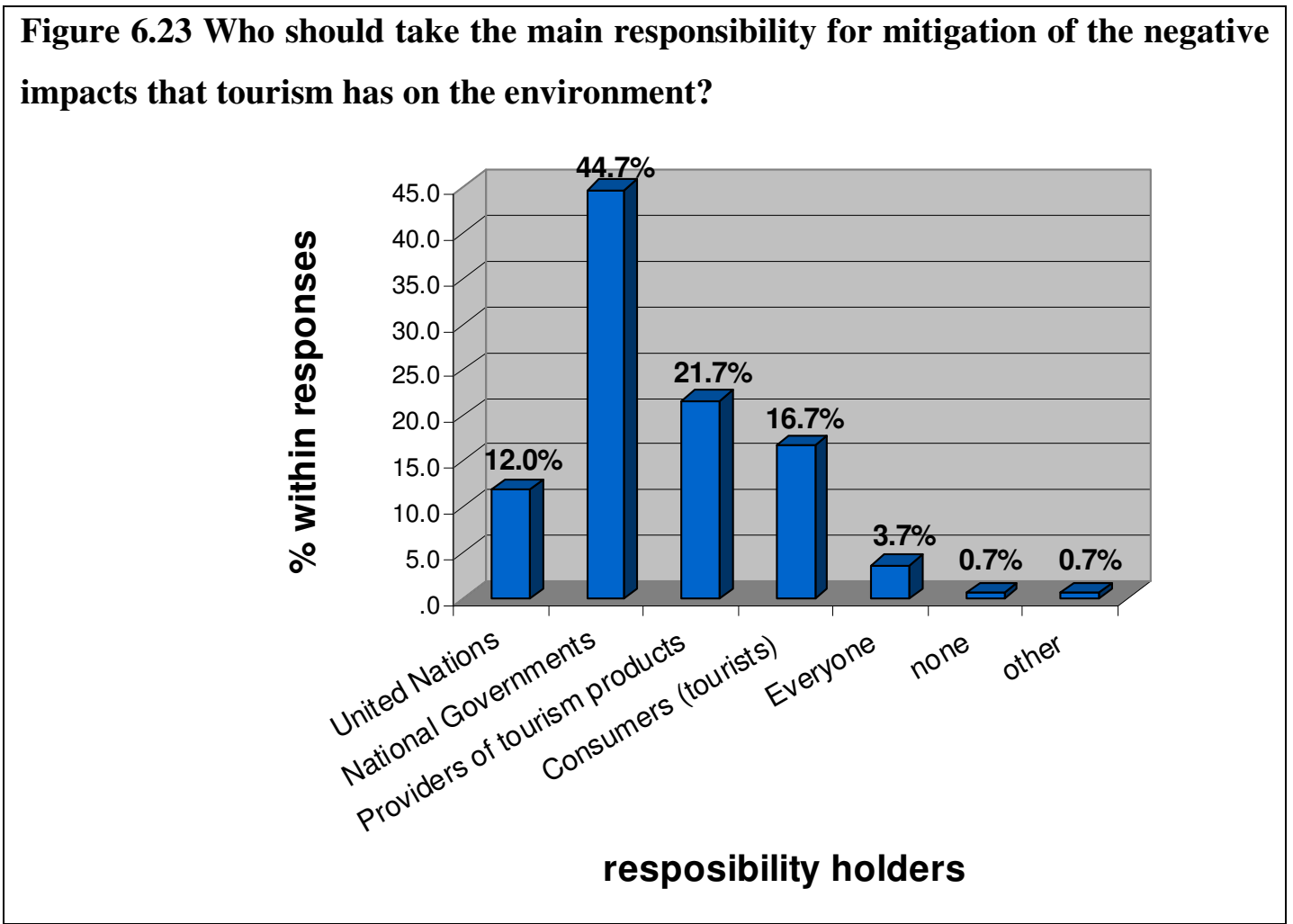

As can be seen in Figure 6.23 above, most people felt that the main responsibility should lie with the national government. A small group of people reported that everyone should take part in this role, and as such specified their own category that most named 'everyone' or similar. It is however clear that a relatively low percentage of people (20.4\%) think that the main responsibility should lie with the individual. As mentioned above, previous research has found that people in the UK call for national governments to take leadership in terms of creating policy to mitigate negative effects of people's behaviours on the environment (Lorenzoni et al., 2009). In reality, this means that governments may have to impose regulation on travel, which limits people's abilities to travel as often as they want or as far as they want to.

\subsection{Conclusion}

This chapter started by accounting for the impacts caused by the transport modes used on the trips recorded by the respondents, which served as a measurement for analysis against which opinions could be tested. Further, people's opinions about own behaviours and about tourism's contribution to climate change were accounted for, which made it clear that people in general are concerned about the environment and their impacts. The relationship between behaviours and concern for the environment was explored, and it was found that no relationships existed 
between concern for the environment and emissions of transport mode or distance travelled. Opinions were affected by people's sense of urgency of the issue, and those who thought it likely that climate change would have a negative effect on their lives showed a higher level of concern than those who did not perceive climate change as a threat to their lifestyle. This was also the case among people who participated in carbon offsetting on their last two trips. However, even among the groups who showed higher concerns for the environment, no effect on behaviours could be seen. This proves that an attitude-behaviour gap exists among Wellington residents.

As far as policy measures were concerned, most people preferred measures that do not impose a change on them, and leaves it up to each individual to take responsibility for their actions. However, when considering the fact that such voluntary initiatives already are in place, and the rate of adoption of these measures, it is clear that voluntary policy measures in their current form are not effective in influencing tourism behaviour to reduce negative impacts of tourism on the environment. When investigating responsibility, it was found that the largest group of respondents want the national governments to take responsibility for mitigating the negative effects of tourism on the global natural environment. These findings provide a platform on which recommendations for future policies can be made.

This chapter concludes the findings from this research. The next chapter will discuss the findings from the last three chapters in more depth, draw conclusions and make recommendations for policy makers and for future research. 


\section{Chapter 7 Discussion \& conclusion}

\subsection{Introduction}

Climate change is becoming an increasingly urgent issue, and the literature concerning tourism and climate change has been expanding rapidly in the last decade (Viner, 2007). Although many initiatives are taken by businesses and government institutions to lessen their negative impact on the environment and thus to mitigate climate change, there is still limited knowledge about the consumers and their perspectives on climate change and mitigation thereof. By better understanding consumers' attitudes and behaviours, policies for limiting the negative impacts that tourism has on the global natural environment can be improved.

This thesis aimed to explore actual tourism behaviours among Wellington residents in terms of estimating GHG emissions made by transport mode and distance travelled on holidays, the factors influencing choices of destination, accommodation and transport mode, and consumption of ecolabeled tourism products as well as participation in carbon offsetting schemes. These behaviours were analysed in relation to the respondents' opinions about tourism and climate change, to see if the respondents were concerned about the impact that tourism and their behaviours have on the environment, and to examine whether there was a relationship between people's behaviours and concern for the environment. Lastly, preferred policy options were explored to make recommendations to policy makers on policies which need to be implemented to change current behaviours. Table 7.1 below summates the objectives and the main findings of this study.

The situation of New Zealand is different from other countries, in the sense that New Zealand's geographical location does not allow for low impact travel to other countries. If wanting to go abroad, people may only travel on aeroplanes or on cruise ships, both of which have large negative impacts on the environment (Howitt et al., in press). There is also the possibility of travelling by private boats, however this is an opportunity reserved for a select few. As such, there is a need for a change of attitudes to travel in order to change current patterns of behaviours identified in this thesis that has a negative impact on the global natural environment.

This chapter will go through the main findings in more depth, and discuss the implications that arise from the findings. The structure follows the outline from Chapters 5 and 6 which corresponds with the sequence of the objectives in Figure 7.1. Sections 7.2 - 7.6 are concerned 
with the objectives outlined in the figure, and discuss the findings in order to make conclusions related to the objectives. Section 7.7 readdresses the hypotheses stated in Chapter one. Section 7.8 lists the implications of the findings for major stakeholders, and Section 7.9 makes recommendations for future research. Section 7.10 concludes this chapter.

\begin{tabular}{|l|l|}
\hline \multicolumn{2}{|c|}{ Table 7.1 Objectives of study and main findings } \\
\hline Objectives & Main findings \\
\hline $\begin{array}{l}\text { 1. Influence of concern for the } \\
\text { environment when choosing } \\
\text { whether to participate in travel, } \\
\text { and when choosing destination, } \\
\text { transport and accommodation. }\end{array}$ & $\begin{array}{l}\text { Concern for the environment did not influence } \\
\text { participation in tourism, choice of destination, transport or } \\
\text { accommodation; other factors such as value for money } \\
\text { and convenience were more important when making these } \\
\text { choices. }\end{array}$ \\
\hline $\begin{array}{l}\text { 2. Perceptions of climate change } \\
\text { and affect on daily life }\end{array}$ & $\begin{array}{l}\text { People thought that climate change would directly affect } \\
\text { their lives within 20 years. Many had observed evidence } \\
\text { of climate change in their home environment, but most } \\
\text { people had not changed their behaviours as a result. }\end{array}$ \\
\hline $\begin{array}{l}\text { 3. Environmentally friendly } \\
\text { behaviour and consumption }\end{array}$ & $\begin{array}{l}\text { Low awareness of carbon offsetting and ecolabels, and } \\
\text { low levels of consumption. Environmentally friendly } \\
\text { behaviours that were listed were mostly modifications to } \\
\text { holiday behaviour rather than travelling less. }\end{array}$ \\
\hline $\begin{array}{l}\text { 4. Opinions about own impact in } \\
\text { relation to actual impact made } \\
\text { when travelling and relationship } \\
\text { between tourism and climate } \\
\text { change }\end{array}$ & $\begin{array}{l}\text { Concern for the environment did not influence } \\
\text { behaviours; most people tried to reduce their negative } \\
\text { impact by modifying their behaviour at the destination, } \\
\text { however did not want to sacrifice freedom to travel. } \\
\text { People did seem to think that climate change and tourism } \\
\text { are related. }\end{array}$ \\
\hline $\begin{array}{l}\text { 5. Recommendations about } \\
\text { policy options, policy needed to } \\
\text { change adverse behaviours }\end{array}$ & $\begin{array}{l}\text { People preferred policy options that were voluntary. It is } \\
\text { however believed that regulatory options are needed in } \\
\text { order to change behaviours. }\end{array}$ \\
\hline
\end{tabular}

\subsection{Role of environmental concern in choice of accommodation, transport and destination}

Objective 1 of this study was to explore participation in leisure travel, and the extent to which Wellington residents consider the impacts that their travelling inflicts upon the global natural environment when choosing their accommodation, transport mode and destination.

It was found that most people in the sample participated in travel for leisure purposes, but 7 of the respondents did not (See section 4.3). Among the reasons mentioned for not participating in leisure travel, were financial constraints, time constraints, family constraints and lack of interest. Concern for the environment was not mentioned by any of the respondents. This finding is quite valuable to policy developers who aim to reduce the frequency of leisure travel as a means of reducing the negative impacts of tourism on the global natural environment: Given that most of the respondents mentioned lack of finances available for leisure travel as a reason for not 
travelling rather than concern for the environment, this factor could be used by policy developers to discourage people from travelling. There has perhaps been too much focus on increasing concern for the environment to reduce frequency of travel. When considering the findings in Section 6.4, where it was established that awareness of the relationship between tourism and climate change did not affect behaviour, it can be argued that increasing concern for the environment through education will not solve the problems posed by mass tourism. The policy implications will be further discussed in Section 7.8 below.

While previous studies have sought to explore which factors are most important when choosing a holiday (Lübbert, 2001; Bigano et al., 2006; Lyons et al., 2009), this study took a different approach, namely estimating the importance that people attribute to limiting negative impacts on the environment when making choices about accommodation, transport mode and destination, and comparing this with the importance placed on other factors that have been found to be most important in the above mentioned research. To this date, little other literature has focussed on the role of environmental concern in choosing transportation and accommodation, and for this reason very little comparison can be made with other research. Overall, the findings from this study suggests that environmental impact is not one of the key issues that people consider when going on leisure trips; other factors are far more important to people, as will be outlined below.

When looking at the results for the choice of destination analysis, some people rated the destination's commitment to protect the environment as somewhat important when choosing a holiday destination, however this factor was rather unimportant when compared to the other factors including activities and events, climate, unspoiled landscape/scenery and value for money. These results correspond well with those of Lübbert (2001), who found a similar result.

While there are several transport options when travelling domestically, the only transport mode available to most when wanting to travel abroad is aeroplane (apart from cruise ships or private boats). This was evident in the factors mentioned by the respondents who travelled abroad; their responses were more unified than the responses from those who travelled domestically. As such, the focus was put on domestic travel. When choosing transportation for domestic travel, the main factors included ease of travel, distance to the destination, time available and value for money. Environmental impact of the transport mode ranked last among the answer options given to the respondents. Although there are many transport modes available when travelling domestically, aeroplane and car/van dominated the responses. Trains and buses were hardly used at all by the respondents on their last two trips. The reason for this may be that these 
modes of transport do not perform to the desired standard when taking the most important factors into consideration.

When choosing accommodation, respondents found location, value for money and the expectation of family and friends to stay with them the most important factors that influenced their decision. They did not consider the establishment's commitment to protect the environment when making their decisions. Although accommodation establishments have various levels of impact on the environment, it is often hard for the public to inform themselves about these impacts. Consumption of ecolabeled products can be considered as one method of choosing environmentally friendly products; however few people are conscious consumers of such products.

When considering the results above, it is clear that people do not take the environment into consideration when making choices concerning their leisure trips. Other factors become more important, and as will be discussed below, people often try to behave in an environmentally friendly manner at the local level in order to make up for the impact that travelling makes on the environment. Although many actions are mentioned including recycling and trying to reduce negative impacts on the environment by acting in an environmentally friendly manner at the destination, no one seems to be willing to sacrifice the freedom to choose whichever destination that attracts them. This finding is consistent with a similar study conducted in Britain in 2008 by Barr et al. (in press), and is also an indicator that voluntary initiatives may not be effective tools for changing current behaviours.

\subsection{Reported observation and effects on behaviour}

Objective 2 of this study was to explore Wellington residents' perception of the speed at which the problems posed by climate change will come about, and explore whether they feel that climate change will have a direct impact on their lives. Previous research has pointed out that concern about climate change is often surpassed by concerns about health, finances and other social issues that are more urgent to the individual, and as such climate change is not a problem that is prioritised as many see it as far removed in time and space (NZBCSD, 2009; Lorenzoni et al., 2007; Lorenzoni \& Pidgeon, 2006). This means that people are less likely to act in an environmentally friendly manner if they do not think that climate change will affect them personally in their lifetime. The respondents were asked whether they had observed evidence of climate change in their home environment during their lifetime. This question was one of the variables used to explore whether climate change was perceived as a real and urgent issue 
among the respondents. Subsequently, they were asked to list observations they had made in their home environment that they tied to climate change, and list any changes in behaviour that they had made as a result of their observations.

A surprisingly high percentage of the respondents (43.2\%) reported that they had observed evidence of climate change in their home environment. Observations mainly included weather phenomena and seasonal variations, but also coastal erosion, receding snow cover and other phenomena were mentioned, which corresponds well with changes in the New Zealand climate over the last twenty years as recorded by NIWA (2009a), as can be seen in Section 2.2. One may think that the oldest age groups would have a higher frequency of observations, however no relationship was found between age and frequency of observations.

In most cases the observations did not prompt respondents to change their behaviours, but among those who did some remarkable results were found: While most people changed their behaviours to act in a way that to some extent lessened their negative impact on the environment, some people opted to increase their frequency of travel as a result of having observed climate change. The reasons given for this change in behaviours included adverse change in climate at home and wanting to see things 'before it is too late.' Clearly, this type of behaviour accelerates the problem rather than brings about a solution, and does bear witness of low awareness or disregard of the contribution of human activities to climate change.

A national survey conducted online by Shape NZ for the New Zealand Business Council for Sustainable Development (NZBCSD) in February 2009 concluded that New Zealanders perceive climate change to be a more serious issue than interest rates and personal employment prospects, but less important than cost of living, crime and the economic recession. The respondents of that particular survey ranked climate change eighth of twelve problems that could affect them and their family, indicating that climate change is not a top priority for New Zealanders. To estimate how severe the respondents thought that the threat of climate change to their lives is, they were asked to rank on a Likert scale how likely they thought it was that climate change would have a negative effect on daily life in New Zealand within the next 20 years. The mean score was higher than expected (2.27 on a scale of 1-5), and this shows that people in general do think that climate change will affect them personally in their lifetime, and that they are concerned about climate change. This result corresponds with the results from the New Zealand Climate Change Survey, which established that $45 \%$ of New Zealanders believe that climate change will be a threat to their personal lifestyle within their lifetime (NZBCSD, 2009, New Zealand Climate Change Survey). However, 67.2\% of the respondents in this study 
thought it was likely that climate change would affect them personally, which is a substantially higher percentage than in the New Zealand Climate Change Survey. The difference between the results may be a result of the phrasing of the questions and the methodologies, however it is clear that people are quite concerned about the impact that climate change will have on their life.

It can be concluded that people do perceive climate change as a threat to their current lifestyle, and some are already starting to change their behaviours to lessen their negative impact on the environment. The current actions taken by the respondents to limit their negative impacts on the global natural environment are however not sufficient, and further changes to current behaviours are needed to limit the negative impact that tourism from and within New Zealand has on the global natural environment.

\subsection{Environmentally friendly behaviours}

Objective 3 of this study was to establish whether Wellington residents consume environmentally friendly tourism products when on holiday, and whether they participate in carbon offsetting schemes. This was done to explore consumption that is considered to be environmentally friendly, including consumption of ecolabeled tourism products and actions taken to behave in an environmentally friendly manner when travelling. Furthermore, offsetting carbon emissions can be considered an environmentally friendly behaviour as it shows that the consumer is willing to take responsibility for the emissions of GHGs that their holiday travels cause, and was investigated in this study.

In line with past research of visitors to New Zealand, Wellington residents also have low awareness of tourism ecolabels (Schott, 2006; Fairweather et al., 2005; Reiser \& Simmons, 2005; Wearing et al., 2002). It was established that a very large part of the respondents were unsure whether they had bought ecolabeled tourism products on their trips or not, regardless of their destination. Even people who visited Kaikoura reported that they were unsure of purchasing ecolabeled tourism products, which is remarkable when considering that the Green Globe certification of the Kaikoura Township is advertised both in and around Kaikoura. This could indicate two things: firstly that tourism businesses that have achieved environmental certifications for their products and services do not have visible displays of the certification or use it as a selling point, and secondly that people are not familiar with the branding of ecolabeled tourism products and therefore do not recognise these when encountering them on their holidays. Given that Qualmark Green is relatively new (only established in 2008), it was perhaps less surprising that no mention was made of this certification. 
The findings of low awareness of ecolabels coupled with the findings of concern for the environment in this study shows that there ought to be room for ecolabeled tourism products to increase adoption and consumption in the domestic market. Also, when considering the findings in Section 6.3.3, which showed that people think that it is important to make sure that their travels are as environmentally sustainable as possible. Certification authorities do however have to evaluate the form of marketing that would be most effective: an exploratory study done in 2003 showed that when on holiday, people with eco altruistic values did not react to marketing campaigns to any greater extent than people who were not concerned about the environment (Reiser \& Simmons, 2005). It has also been established that people are less influenced by marketing that is done at the destination than marketing that target people at home (Wearing et al., 2002), and that people in New Zealand increasingly make purchasing decisions prior to leaving home (Ministry of Tourism, 2009a). This would suggest that increased marketing aimed at reaching people at home would increase awareness of and consumption of ecolabeled tourism products.

Confusion about ecolabels was evident among the respondents, not only among those who were uncertain of having bought an ecolabeled product or not, but also among those who reported that they did purchase ecolabeled tourism products during their last two leisure trips. Many failed to name ecolabels of products that they had purchased, and many of the ecolabels mentioned were in fact carbon offset schemes (see Section 5.4.1). This confusion can be linked to the findings from the study conducted in 2006 by Schott, where the respondents mentioned ecolabels belonging to other types of products not related at all to tourism, and to the findings from the study conducted in 2005 by Fairweather et al., where the people were unable to remember specific tourism ecolabels of products which they had purchased. When considering the frequent references to carbon offsetting schemes, it appears that people see similarities between ecolabels and carbon offsetting schemes, which indicates low awareness or confusion about the two: Ecolabels are awarded to establishments for keeping a certain standard which minimises the negative impact of an establishment's operations, while participation in carbon offsetting schemes are mainly initiatives that consumers have to engage in themselves. The distinction between the two is however somewhat blurry, considering that also companies can be carbon neutral and large marketing campaigns are done by some businesses in Wellington. Wellington Combined Taxis for instance, have logos on the sides of their cars stating that they are New Zealand's first CarboNZero certified taxi service (Wellington Combined Taxis, 2009). The distinction between a CarboNZero certified service and an ecolabeled service may not be explicit to the average consumer. The difference between tourism ecolabels and carbon offset 
certifications is that businesses that have been certified by an ecolabel are taking steps to reduce their actual impact on the environment, rather than purchasing carbon offsets to achieve a somewhat similar outcome. For the purpose of this study, no assumption is made of whether one alternative is better than the other; both are initiatives taken to reduce the amount of GHGs in the atmosphere, and as such they are both initiatives which help make a difference compared to the status quo.

Carbon offsetting is a relatively new practise, which only recently has been made easily available to the public through the booking engines of several airlines and other websites. A large share of the respondents in this study was unaware of the existence of such schemes, which could be due to the fact that carbon offsetting is a relatively new phenomenon. Participation in carbon offsetting schemes was also found to be very low across the sample (only 12 of the respondents had participated in a scheme on their last two leisure trips). Less than half of the respondents (48.3\%) had heard of carbon offsetting. Among those who did not participate, several respondents reported that they did not know how to participate, or that they had limited knowledge about carbon offsetting. Many people reported distrust in the current schemes, and felt that it was not a good solution to the negative impacts that tourism has on the environment. Some argued that carbon offsetting is futile, as the emissions of travelling for leisure could not be erased by participating in such schemes. Others reported that they did not understand how the offsets were made, or questioned the honesty of the companies who offered carbon offsets, wondering whether it was just another way of making extra money (see Section 5.4.2). Carbon offsetting schemes have also been criticised in the media as a tool for enabling current behaviour to continue, given that the emissions from travelling are still being made, and initiatives to reduce combustion of fossil fuels are not prioritised (Hari, 2009; Noble \& Scholes, 2001). Opinions such as these create barriers for participation in carbon offsetting schemes, and as such it is necessary to inform people about the negative impacts that travelling has on the environment, and about carbon offsetting in general in order for people to adopt carbon offsetting as a practise in relation to travelling. As with ecolabels, marketing of carbon offset schemes could increase adoption and purchase of carbon offsets. Information campaigns to make people more aware of the impacts that their travelling has on the environment may also be necessary.

It may also be necessary to address the criticism that has been made about the types of offsets that are provided by some carbon offsetting agents, which offer carbon offsets through sequestering of carbon in forest sinks. Given that the survival of any forest cannot be guaranteed, it may be necessary to phase out this type of carbon offsetting from the schemes as a way of 
gaining support from the public. Gössling et al., (2007) argue that clarity and regulation is required in order to increase support and understanding of such schemes. Among the respondents, distrust in carbon offsetting schemes increased with age, which could indicate that a different approach is needed to reach older age groups.

It should be noted that the future of carbon offsetting may be uncertain. Dependency on other countries is large in order to continue carbon offsetting; it is not viable to offset emissions of air travel and other activities associated with tourism within the borders of New Zealand (Smith \& Rodgers, 2008). If all countries in the World were to rely on carbon offsets to limit the negative impacts of domestic tourism and tourism departures, there would not be sufficient landmass or technological solutions available. Thus, if the aim of lowering the concentration of GHGs in the atmosphere to pre 1990 levels (as was the target for many European nations under the Kyoto agreement) and for New Zealand to achieve a 'downward carbon path' by 2012 (Ministry for the Environment, 2009) is to be achieved, people in western countries cannot continue their current life styles and travel as widely and as often as they do. Businesses also need to make sure that they adopt practises that help limit the extent of their negative impact on the global natural environment.

\subsection{Analysing the influence of environmental concern on behaviour}

\subsubsection{Environmental impact}

Objective 4 of this study was to explore the opinions of Wellington residents about their own holiday behaviours in relation to the impact that they have on the global climate. Previous research has established that many people are unaware of the impacts that their travelling has on the environment, and felt that they were behaving in an environmentally friendly way even when travelling half-way across the world to get to their destination, because they focussed on the local scale (Gössling et al., 2006). Thus, opinions about one's own behaviour and impact does not always reflect reality. Emissions made by transport to and from the main destination were the focus of the analysis, as transport often is the most emitting component of a trip (Gössling et al., 2008; Böhler et al., 2005). Two steps were needed to achieve this objective: firstly the actual environmental impact of the transport component of the holidays that were reported on in the questionnaires were calculated, and secondly opinions were analysed to see if they had any relation to the distance travelled and transport modes chosen for the holidays. This 
section is focussed on the first step, which is to calculate the actual emissions made by the respondents on their last two holidays.

$37.8 \%$ of the people in the sample reported that they had only travelled domestically on their last two trips, while the rest of the sample had travelled to destinations abroad.

Naturally, distance was positively related to emissions of GHGs, and the highest emissions were made on international trips. Aeroplanes were used on all international trips, while car/van was the most used transport mode domestically, followed by aeroplane. Very few people chose to travel by train or scheduled coach services, which were the lowest emitting motored transport modes available in New Zealand at the time of writing (CarboNZero, 2009). The reason for this could be the price of air travel compared with train and intercity buses. In many cases, one can travel to Auckland via air cheaper than with the train service. As mentioned in Section 7.2, the most important factors when choosing transport mode are ease of travel, distance to the destination, time available and value for money. Therefore, the more environmentally friendly transport services need to compete in these areas in order to increase usage.

Frequency of trips was the other variable used to analyse the relationship between opinions and behaviour. Frequency of travel and impact on the environment are also closely related. The more often someone travels, the higher the GHG emissions this person will make. Results showed that people travel quite frequently, and most people take more than one leisure trip per year. In most of the cases, the last two trips were taken either within the current year or the last two years. The highest recorded trip frequency in the sample was 50 or more trips during the last three years, and only eight people did not travel during the last three years.

Non-travellers in the survey only accounted for $2.3 \%$ of the total sample ( 7 respondents), and the reasons given for not travelling for leisure purposes were not related to concern for the environment.

The next section will concentrate on the second step of Objective 3b, namely exploring opinions about respondents' own behaviour and tourism's impact on the environment, and whether these have an impact on the distances travelled and the frequency of trips taken by the respondents. 


\subsubsection{Opinions about respondents' own behaviours and impact}

People in the sample generally thought that they behaved environmentally friendly most of the time when they were at home, but to a lesser extent when travelling. Other research has established that people tend to relax more when they are on holiday, and that it can be difficult to know how to behave when one is in an unknown environment (Barr et al., in press; Dolcinar $\&$ Leisch, 2008). When asked whether they relaxed more when on holiday, the respondents' opinions were divided. They did however agree to some extent with the notion that it is difficult to know how to act environmentally friendly when travelling, which could explain why they act in a less environmentally friendly manner when on holiday. This variable was found to be influenced by the annual household income of the respondents, as those who had the lowest annual income found it less difficult to know how to act in an environmentally friendly manner, and those with the highest annual household income relaxed the most when they were on holiday (see Section 6.3).

People's opinions were divided when asked if it was important to them to make sure that their travelling was as environmentally sound as possible, however the sample mean (2.60 on a scale of 1-5) did suggest that there was some degree of concern. Most people were unsure about this, however concern about own impact was found to be much higher within the lowest income group.

Similarly, people's opinions regarding their own impact when travelling varied widely across the sample, and no relation was established with actual impacts made. Other research has established that many are still unaware of possibilities for limiting their impacts on the environment, and also of having negative impacts at all when going on holiday (Gossling, 2006).The findings from this thesis show that there is still confusion about the negative effects that travelling has on the global natural environment, and as such it may be hard for people to estimate their personal impact.

When asked about the actions that they took when travelling to behave environmentally responsible, most of the respondents mentioned initiatives that most likely have root in actions that they normally take when at home, such as disposing of litter appropriately, recycling, walking/using public transport and saving power and water. Research by Barr et al., (in press) suggests that behaviours at home dictate holiday behaviours, and that people who act in an environmentally friendly manner when at home are more likely to do so when on holiday than those who do not act in an environmentally friendly manner at home. The actions taken by the 
respondents may indeed suggest such a phenomenon. It should however be noted that many of the actions that are encouraged in order to act in an environmentally friendly manner may be taken for other reasons than to protect the environment, such as to reduce expenses (Whitmarsh, 2009). In Wellington City, one has to pay for rubbish that is not recycled, and therefore most people have a strong incentive to recycle other than to protect the environment. If it were free to dispose of rubbish without recycling, the number of people recycling in Wellington might have been rather lower, and in this case the people may not have felt compelled to do this at the destination that they visited.

\subsubsection{Environmentally responsible behaviours - opinions \& reported actions}

People in the sample seemed to agree that tourism and climate change were connected, as the largest share of people (55.5\%) agreed that tourism within New Zealand does contribute to global climate change. The remainder of the respondents were either unsure or disagreed. Most people did however not behave in accord with their opinion, as there was no connection between awareness of tourism's impact on the environment and distance travelled or trip frequency. It is somewhat contradictory that the link between tourism and climate change is made, however no attempts are made to mitigate climate change on the personal level. There were a few people that mentioned that they travel shorter distances to lessen their negative impact when travelling, and this type of behaviour is what the researcher was hoping to find evidence for on a larger scale. One can hardly say that 3 people out of 308 is a positive number; however, it is a start. To increase this number, awareness of negative impacts made by individuals when travelling ought to be raised.

Relationships were found between perceived likelihood of climate change having a negative impact on daily life in New Zealand within the next 20 years and opinions on own behaviours and the impact of tourism on the environment, but the perceived likelihood of climate change affecting their lives did not translate into environmentally friendly behaviours: Although people believe that tourism has a negative impact on the environment and that they think it likely that climate change will have a negative effect on their lives, these variables had no influence on how far people travelled or how frequently they went on leisure trips. These findings are consistent with findings from previous research (Barr et al., in press; Hares et al., in press; Dolcinar \& Leisch, 2008; Lopez \& Cuervo-Arango, 2008; Wearing et al., 2002; Stoll-Kleemann et al., 2001), and proves that an attitude-behaviour gap exists also among Wellington residents. This finding will have implications for policy development, as will be discussed next. 


\subsection{Policy}

Objective 5 of this study was to identify which measures to change adverse tourism behaviours that are considered acceptable by the respondents, and make recommendations to policy makers. Several researchers have come to the conclusion that behavioural change is necessary in order to limit the negative impacts that tourism has on the global natural environment (Burns \& Bibbings, 2009; Smith \& Rodger, 2008; Hoyer, 2000). This change will not happen fast enough without leadership from national governments (Lorenzoni, 2007). Considering the volume of emissions that are made by aviation which is within the range of $4-6 \%$ of all GHG emissions made worldwide, as well as other GHG emitting tourism components, it is clear that the current growth and consumption of tourism products cannot be sustained (Gossling, 2008).

In order to induce change, governments must take responsibility and create policies that help alter the current patterns of consumption. According to Lorenzoni et al (2007) limited political action by local, national and international governments is a significant barrier to engagement with climate change by the public. The largest group of respondents in this research (44.7\%) reported that they wanted the government to take responsibility for limiting the negative effects that tourism has on the environment. This indicates that they do not think that climate change mitigation is achievable by individual actions, and therefore want leadership in dealing with this issue. Guidance and acceptance of responsibility must start at the top and national governments have a crucial role in making change happen; if they do not see the severity and importance of changing current behaviours, it is not likely that the general population will. The problem in New Zealand is that the current government is more committed to reaping the economic benefits from a growing tourism industry rather than limiting the negative impacts that it has on the global natural environment. The government has been criticised by many for not being committed to dealing with climate change issues in an appropriate manner (Fitzsimmons, 2009; Reisinger, 2009; Bertram, 2009; Peet, 2009).

Becken (2007) established that voluntary policy options and educational campaigns were not effective in influencing the behaviour of tourists. Considering the findings of this study, it must be concluded that the current voluntary policies that exist in New Zealand (which are not in abundance, primarily consisting of the option to offset carbon emissions or other voluntary environmental schemes that must be sought out by the individual) are not effective in limiting the negative impact of tourists from New Zealand. The implications for policy development will be discussed in Section 7.8 below. 


\subsection{Hypotheses}

At the start of the thesis, several hypotheses were formed based on the literature reviewed for the study. As a result of the analysis, these hypotheses were either accepted or rejected. This section will outline the results of the hypotheses testing.

H1 stated that no relationship would be found between concern for the environment and participation in international leisure travel, choice of destination, transport or accommodation. It was established that concern for the environment indeed did not influence people's actual behaviours in terms of distances travelled and trip frequency. There was also no relationship established between non-participation in leisure travel and environmental concern. Other factors were more important to the respondents, and as such this hypothesis has been accepted through the results from this research.

$\mathrm{H} 2$ stated that people would be more likely to behave in an environmentally responsible manner (by travelling less frequently and over shorter distances) if they thought it likely that climate change would affect them personally. A large portion of the sample thought it likely that climate change would have a negative affect on daily life in New Zealand within the next 20 years, and this variable did affect the opinions that were reported by the respondents. However, no relationship between actual behaviour and perceived likelihood that climate change would affect the respondents personally could be found. As such, this hypothesis has to be rejected.

H3 stated that concern for the environment would influence the respondents' propensity to participate in carbon offsetting schemes and to purchase ecolabeled tourism products. It was found that awareness of these two options for limiting negative impacts was limited, and as a result adoption among the respondents was low. Concern for the environment did have an effect on carbon offsetting participation, however no such pattern was found between concern for the environment and purchase of ecolabeled tourism products. As such, the hypothesis has to be rejected.

H4 stated that people will prefer voluntary policy options, as this allows for the current level of freedom to continue. Indeed, people opted for voluntary action including educational campaigns and voluntary schemes for offsetting emissions. Thus, this hypothesis has been accepted.

The acceptance of $\mathrm{H} 1$ and $\mathrm{H} 4$ has several implications, as will be discussed below. Most importantly, this means that people at current do not act in line with their attitudes, and that they 
are not committed to changing this behaviour, given that their preferred policy options are voluntary initiatives which do not force them to alter current travel habits. However, seeing as a change in behaviour is exactly what is needed to reduce the negative impacts of tourism on the environment, voluntary policy may not be a realistic option when attempting to induce change.

\subsection{Implications of findings}

Several implications arise as a result of the above findings. This section will present the implications as they relate to different stakeholders, and provide recommendations were appropriate.

\subsubsection{Implications for government}

As mentioned above, the New Zealand government has been criticised for being more focussed on the economic gain of tourism rather than reducing the negative impacts that tourism has on the global natural environment. The traditional view is that one has to choose between economic gain and climate change mitigation (Patterson et al., 2006). However, this is not a choice that can readily be made, as the current situation demands an immediate response in terms of limiting the extent of human induced climate change. Climate change is a threat to all life on the planet, and the possible outlooks if no actions are made to reduce the severity of human induced climate change are grim; without an appropriate reaction, the resources on which tourism itself depends are in danger of being destroyed forever.

Although the respondents preferred policies that were voluntary, such policies may not be effective in inducing behavioural change. Voluntary schemes have been available for many years (Becken, 2007); yet the adoption rate is very low. A survey done for the BBC in Britain in 2004 concluded that many people call for government action, and want strict regulation to induce change (Lorenzoni et al., 2007). Other research done in Britain established that people were not adopting strategies created to mitigate climate change (Whitmarsh, 2009). This may also be the case in New Zealand should the government try and encourage change through voluntary initiatives, given that the respondents prefer voluntary policies but do not make use of the opportunities that currently exist. Also, it is a paradox that the respondents prefer voluntary initiatives, but want the national government to take responsibility for reducing the negative impacts of tourism on the environment, rather than consumers themselves. 
Past behaviour, i.e. habit is one of the most intractable barriers to changing energy consumption (Kollmuss \& Agyeman, 2002). This means that forcing people to change by means of regulation may be the only way to achieve behavioural change in the initial stages, as voluntary initiatives take longer to change the norm than legislative enforcement does. If the global temperature rise is to be kept at a maximum of $2^{\circ} \mathrm{c}$ as is recommended by the IPCC (2007), then an immediate response is needed. As such, legislative initiatives aimed at changing current behaviour are necessary to induce fast paced change.

Domestic tourism expenditure was 12.4 billion in the year ended in March 2009, showing that this is a substantial part of the economy (Ministry of Tourism, 2009b). Encouraging more people to travel domestically would not only benefit the environment, but also further increase the positive balance between tourism import and export. If awareness of the negative impact of travelling is raised and behaviours change accordingly, it will lead to a drop in international visitors, and in that case having a strong domestic tourism industry would lessen the negative impact that this would have on the industry. In order to encourage domestic tourism, some drastic measures might be necessary.

As has been established in Section 4.3, people do not abstain from travelling on holidays due to concern for the environment. Admittedly, the sample is relatively small, however among those who reported that they did not travel for leisure purposes ( $2.3 \%$ of the respondents), other factors than concern for the environment were mentioned as the reason for not participating in leisure travels. The main reason mentioned by the respondents was financial constraints. By focussing on this main factor which currently restrain some people from travelling, policy development could achieve the outcomes sought by other means than by focussing on concern for the environment. If the price of air travel was higher, fewer people would be able to afford going abroad. If people were forced to pay a carbon tax on all personal travel, this would not only decrease outbound travel, but also be beneficial in lessening the negative impact on the global natural environment of those who travel to far away destinations. Although the freedom to travel is highly valued, and this type of policy may be considered to be unfair to people of lower income, the reality is that the planet cannot sustain a world society in which all people participate in travel. Should travelling be a right or a privilege? Some type of measure will be needed to limit the negative impact that tourism has on the global natural environment. Economic measures may be the most feasible to implement and to gain acceptance for.

The opportunity to choose less emitting alternatives to cars and aeroplanes when travelling domestically ought to be increased in order to encourage environmentally friendly behaviour. 
Currently, it is cheaper to travel between Auckland and Wellington via air than it is to travel by train, an alternative that is close to ten times as energy efficient as aeroplanes (CarboNZero, 2009). As people are more concerned about other factors than environmental impact when choosing their transport mode, the attributes related to the most important factors ought to be improved for transport modes that have less an impact on the environment in order to encourage usage. This could be achieved through government subsidies of transport modes such as trains and scheduled coach services, which would allow these transport modes to compete with airlines on price. Improving such infrastructure would also make the transport network more efficient, which would cut down on delays and shorten the time that it takes to travel by train or coach. In order to achieve this, the national government needs to allocate funds to improve the standard of the infrastructure and the transport modes which have a lower negative impact on the environment.

\subsubsection{Implications for the private sector}

Private sector will also ultimately play an important role in educating people about the negative effects of tourism on the environment, and in encouraging environmentally friendly behaviours. It is likely that private sector will resist a dramatic reduction in tourism, as this may affect the bottom line of most tourism operators. However, if domestic tourism is encouraged, the economic impact of such a change may not be devastating to the tourism industry. The private sector can however only reach people after they have chosen to travel, and as such the initiatives taken by the private sector may be of limited effect, when considering the big picture.

As mentioned earlier, consuming tourism ecolabels may be seen as a measure which can serve to reduce people's impact on the environment when on holiday. However, awareness of tourism ecolabels is generally low. It is important that tourism businesses who have achieved an environmental certification use these accreditations to market themselves, and to market the tourism ecolabels, in order to increase brand recognition and to encourage consumption (Roberts, 1996). Given that brand recognition is the most important factor which influences consumption (Wearing et al., 2002), initiatives ought to aim for an increase in the awareness of ecolabels. This can be achieved if the tourism businesses work together with authorities issuing tourism ecolabels.

Not only tourism ecolabels is relevant to this discussion. In general, tourism businesses ought to integrate environmentally friendly practises into the daily operation of their businesses, and communicate their initiatives to their customers. Examples of businesses who already have 
adopted such an approach exist in New Zealand, for example the backpacker brand YHA. The YHA brand has a high commitment to sustainability, and their environmental practises are often communicated to their customers by use of informative signposting in the hostel (YHANZ, 2009). It is through such initiatives of education that the public can be made more aware of the impacts of travelling, however this is not enough. It was established in this study that even those who have high levels of awareness do not act accordingly, and therefore it must be concluded that educating people is not enough on its own to change behaviours. Collaboration between the public and the private sector is thus necessary in order to bring about change.

\subsubsection{Challenges in providing information about tourism and climate change}

People are to a large extent still unaware of the effects that travelling has on the global natural environment. The information about climate change that has been made available to the public is often hard to understand for lay people, and as such more effective communication is needed if people are to understand the science behind climate change and their personal contribution (Carter, 2009). Conflicting messages from companies that benefit from tourism is also a problem in terms of providing a unified message (Gossling \& Peeters, 2007).

Campaigns that are aimed at raising awareness of climate change and travelling ought to reach people in their homes, as it should be available to people for use in their decision making processes when choosing holiday destinations and travel modes. At current, environmental concern does not influence the choices that Wellington residents make when wanting to go on a leisure trip. Although the internet is available to most people in New Zealand (Statistics New Zealand, 2009m), it is easier to exclude information when searching the net. As such, the most effective media would be TV or radio, where the people do not have to actively search for the information themselves. Using other types of media than the internet could facilitate learning about the impacts of tourism on the environment for people of all ages; it was established in this study that older age groups are less aware of these impacts, which could be a result of the high reliance on the internet in educating people about climate change. Older people use internet less often than young people do (Sourbati, 2009).

As could be seen in the results in Chapter six, some groups were more aware of climate change and the relationship with tourism than others. Information campaigns aimed at raising awareness thus need to take into account that there are some demographic segments that are more in need of information than others. As was established in Section 6.3.4, people who have 
lower education, and older age groups are less aware of the negative impacts that tourism has on the global natural environment. Information needs to be targeted at these demographic segments in order to raise awareness and encourage a change in current behaviours.

One of the problems associated with distribution of information is assigning the task of such an initiative. It is unclear who should have the responsibility for informing the public about the negative impacts of travelling. It is not in the interest of businesses to do so, especially if these businesses are dependent on fossil fuels to sustain themselves, such as transport companies and certain activity providers. The responsibility for providing such information should as such lie with a neutral party, which can be hard to find. As already mentioned, the government's willingness to sacrifice economic gain may impede on this process, as well as the interest of the private sector. However, a government agency such as the Ministry of Tourism would be the appropriate agent to distribute such a message. Ultimately, collaboration between the private and the public sector may be the only solution, but this will need a shift in focus of the current government.

\subsection{Implications for future research}

The findings from this research and from related literature suggest that further research is needed in order to provide further understanding and to be able to facilitate the necessary changes to current behaviours. Given that this study took a quantitative approach, in depth detail about relationships could not be captured. This means that some areas are in need of further investigation.

The study established that environmental concern does not translate into environmentally friendly behaviours when making decisions about destination, transportation and accommodation. More research is needed to find the underlying reasons for this attitude behaviour gap. To be able to change behaviours, an understanding of the barriers for changing behaviours and how to overcome these barriers need to be further investigated.

Changing behaviours will likely include a variety of tools for educating people about the severity of climate change and the human contribution to this phenomenon. As has been discovered in this study, there are differences between people of various age groups and between people who have high and low levels of annual household income. More research is needed to find an appropriate mix of education provision and regulation, which will help change 
attitudes and also change adverse tourism behaviours of people. However, the researcher suggests that the role of environmental concern should be less prioritised than in previous studies, as the role of environmental concern in reducing adverse behaviours is minimal. Focus should be on limiting the frequency of travel, at the same time as educating those who travel at the destination that they are visiting. Finding the right balance of mitigation tools will be important, and is a matter for further investigation.

The severity of climate change scenarios implies that major societal changes are needed to limit the extent of the damage to the global natural environment that is caused by human behaviours. This will have large repercussions for both national and international tourism. More research is needed on the economic consequences of reduced in- and outbound tourism and of reduced frequency of travel by the public. Knowledge about possible outcomes is needed to aid the tourism industry in planning for the changes that are inevitable in the long run.

\subsection{Conclusion}

This research has provided valuable information about Wellington residents' behaviours and environmental concern, and the following conclusions have been made as a result of the findings: Firstly, people are concerned about the environment; however this does not influence their choices when wanting to take a leisure trip, even if many seem to be aware of tourism's impact on the global natural environment. Environmental concern also did not have any influence on how far or how often people travelled. Secondly, people do believe that climate change will affect their lives to some extent, which indicates that climate change is a problem that is increasing in importance among people. Thirdly, awareness of and participation in carbon offsetting and purchase of ecolabeled tourism products was found to be very low among the respondents. However, there should be scope for increasing both awareness and adoption of these practises, given that there is a stated concern for the environment. Lastly, people preferred policy options which included voluntary initiatives rather than regulatory ones. However, policy that regulates adverse behaviours is needed, as voluntary initiatives such as carbon offsetting so far have a very low adoption rate.

As has been noted in the literature review and in some of the research findings, climate change will have an effect on tourism demand, and it is possible that the future changes in climate will force changes in tourism behaviours. There is still much uncertainty surrounding the physical changes that will occur as a result of climate change, and this can be a contributing factor to the 
current inaction among people and governments. As the occurrences of extreme weather events due to climate change continue, the awareness of human contribution to climate change may increase, and as a result stricter policy may be implemented to force a change in adverse behaviours. For this to happen, it is paramount that governments of the world respond to the challenges that climate change scenarios have presented, in order to safeguard the future of the planet. This thesis has established that there is still some way to go before the residents of Wellington are willing to limit their negative impacts on the environment by travelling less frequently or shorter distances. The next step forward will be to increase awareness of climate change and human contribution to this phenomenon, as well as increasing awareness of the impact of individual action. However, this is not enough in itself. At the same time as raising awareness, policies which discourage travel on the current scale should be implemented. Mitigating human induced climate change can only be achieved if everyone does their part to protect the environment, but a push in the right direction in terms of leadership by the national government is needed to make a change for the better. 


\section{Appendices}




\section{Appendix A: Information Sheet}




\section{Exploring the relationship between tourism and environmental concern}

\section{Dear Sir/Madam}

My name is Tina R Tiller, and I am conducting research as part of my Master degree in Tourism Management at Victoria University of Wellington. The purpose of this study is to explore the current travel habits of Wellington residents, with a particular focus on the role of environmental concern. Taking part will allow you to voice your opinion as well as provide valuable information that will help improve understanding of the topic. Participants also have the opportunity to enter a prize-draw to win a New-World shopping voucher worth $\$ 200$, see enclosed prize draw sheet for more information about this.

Participation in the study is voluntary. All information colleted will be recorded anonymously, and will only be displayed in non-attributable format so that it will be impossible to identify the individual respondent. The study has obtained ethical approval by Victoria University. Please read the following information carefully:

- The questionnaire should be completed by the person in the household whose birthday is closest to date, and who is over 18 years old.

- The questionnaire will take approximately 20 minutes to complete.

- The data gathered will be stored securely and destroyed after the completion of the research.

- The findings will be presented in a thesis, and may be disseminated at conferences or in academic journals.

- If you would like to see a summary of the findings, please contact the researcher via email or post before 01 . October 2009.

- The completed questionnaire should be sent back to the researcher by $15^{\text {th }}$ of August 2009 by using the enclosed postage paid C5 envelope, OR

- The questionnaire may be completed online before $15^{\text {th }}$ of August, access can be gained through the following URL: http://www.victoriatourismsurvey.ac.nz/

By completing the questionnaire you agree to the terms of participation outlined above.

For more information, please contact me or my academic supervisor, Dr. Christian Schott.

Tina R. Tiller

Student Researcher

Email: tina.tiller@vuw.ac.nz

Contact address:

Victoria Management School

Victoria University of Wellington

PO Box 600

Wellington 6140

Attention: Tina Tiller - Tourism Dept.

Please keep this information sheet for future reference.
Dr. Christian Schott

Senior Lecturer, Tourism Management

Email: christian.schott@vuw.ac.nz 
Appendix B: Questionnaire 
Suburb:

\section{Exploring the relationship between tourism and environmental concern}

- The questionnaire should be completed by the person in the household whose birthday is next, and who is over 18 years of age

- Please read each question carefully before answering.

- Please indicate your answers with a tick $(\checkmark)$ where appropriate, or use the lines to fill in the answers in your own words.

- Try to answer all questions that apply to you, as the information that you can provide is of great value to this research.

1. Do you travel for leisure (not business) purposes when you are free from work or other obligations? (If yes, please proceed to question 3).
$\square$ Yes
$\square$ No

2. If no, please list as many reasons as apply to you for not travelling for leisure (not business) purposes? (Please proceed to Question 33 on page 5 after answering this question)

Reason 1:

Reason 2:

Reason 3:

Reason 4:

\section{SECTION 1: TWO MOST RECENT HOLIDAYS}

The following section is concerned with your last two leisure (not business) trips away from home for which you made most of the decisions. Please only include trips that lasted longer than $\mathbf{2}$ days and less than $\mathbf{1}$ year. Please start with your most recent trip, and continue with the second most recent trip.

\section{MOST RECENT TRIP}

3. Where did you go? (If you visited more than one destination during this trip, please name the main destination city of your trip)

Country (if other than New Zealand):

4. What was the duration of this trip?

City/Town:

Months:

Days:

5. In which year did you take this trip?

6. What was the main reason for taking this trip? (Please tick only one box)

$\square$ Leisure/Holidays

$\square$ Visiting friends or relatives

Education/Study

- Medical/Health

$\square$ Other, please specify:

7. Which was the main mode of transportation used to reach your destination? (Please tick one box only. If there was more than one destination, please tick the most important transport mode in terms of longest distance travelled between home and your main destination).
$\square$ Aeroplane
$\square$ Bicycle
$\square$ Campervan/Motorhome/RV
Hitchhiking
$\square$ Motorbike
$\square$ Scheduled Coach Service
- Car/Van
$\square$ Train
- Coach Tour/Tour Coach
$\square$ Walking/Tramping
Commercial Ferry/Boat
$\square$ Other, please specify: 
8. When choosing this mode of transportation, which were the three most important factors influencing your decision? (Please list your three most important factors in order of importance to you, using numbers where $\mathbf{1}$ was the most important factor, $\mathbf{2}$ the second most important factor and $\mathbf{3}$ was the third most important factor). ( ) Comfort

( ) Habit

( ) Distance to destination

( ) Monetary cost

( ) Ease of travel

( ) Only option available

( ) Environmental impact of transport mode

( ) Time considerations

( ) Other, please specify:

9. What was your main type of accommodation (choose the one type of accommodation in which you used the most during your trip)?

$\square$ Backpacke

$\square$ Motel

$\square$ Camper van at Caravan Park or

$\square$ Private home (friends and relatives) Camping Ground

$\square$ Camper van outside Caravan

Park or Camping Ground

$\square$ Holiday home

$\square$ Hosted (B/B, Guesthouse or similar)

Resort

$\square$ Serviced Apartments

$\square$ Tent, cabin, chalet or similar at a

Caravan Park or Camping Ground

$\square$ Hotel

10. When choosing accommodation, which were the three most important factors influencing your decision? (Please list your three most important factors in order of importance to you, using numbers where 1 was the most important factor, $\mathbf{2}$ the second most important factor and $\mathbf{3}$ was the third most important factor).

( ) Comfort/Level of service

( ) Establishment's commitment to reduce their impact on the environment

( ) Facilities (restaurant, gym, internet, kitchen access etc.)

( ) Location

11. Did any of the tourism products (transport, accommodation, attractions or activities) included in this trip have an environmental certification or ecolabel of any kind? (An ecolabel is any form of certification giving assurance that the tourist operation or activity is conducted according to a known standard that enhances the environment or at least minimises environmental impacts.)
$\square$ Yes
$\square$ No

( ) Loyalty card, discount or other promotion

( ) Only option available

( ) Previous experience

( ) Value for money

( ) Word of mouth/recommendation

( ) Other, please specify:

12. If yes, please list the relevant tourism products and the corresponding ecolabel or environmental certification.

\begin{tabular}{|l|l|}
\hline Tourism Product: & Ecolabel: \\
\hline
\end{tabular}

\begin{tabular}{|l|l|}
\hline Tourism Product: & Ecolabel: \\
\hline & \\
\hline & \\
\hline & \\
\hline & \\
\hline
\end{tabular}

\section{SECOND MOST RECENT TRIP}

13. Where did you go? (If you visited more than one destination during this trip, please name the main destination city of your trip)

Country (if other than New Zealand): 14. What was the duration of this trip?

Months:
City/Town:

15. In which year did you take this trip?

Year: 


\section{What was the main reason for taking this trip? (Please tick one box only).}

$\square$ Leisure/Holidays

$\square$ Visiting friends or relatives

$\square$ Education/Study

$\square$ Medical/Health

$\square$ Other, please specify:

17. Which was the main mode of transportation used to reach your destination? (If there was more than one destination, please tick the most important transport mode in terms of longest distance travelled between home and your main destination).
$\square$ Aeroplane
$\square$ Hitchhiking
$\square$ Bicycle
- Motorbike
- Campervan/Motorhome/RV
$\square$ Car/Van
$\square$ Train
$\square$ Coach Tour/Tour Coach
口 Walking/Tramping
$\square$ Commercial Ferry/Boat
$\square$ Other, please specify:

18. When choosing mode of transportation, which were the three most important factors influencing your decision? (Please list your three most important factors in order of importance to you, using numbers where 1 was the most important factor, $\mathbf{2}$ the second most important factor and $\mathbf{3}$ was the third most important factor).
( ) Comfort
( ) Habit
( ) Distance to destination
( ) Monetary cost
( ) Ease of travel
( ) Only option available
( ) Environmental impact of transport mode
( ) Time considerations
( ) Other, please specify:

19. What was your main type of accommodation (choose the one type of accommodation in which you used the most during your trip)?
$\square$ Backpacker
$\square$ Motel
$\square$ Camper van at Caravan Park or
$\square$ Private home (friends and relatives) Camping Ground
$\square$ Camper van outside Caravan
Park or Camping Ground
$\square$ Resort
$\square$ Serviced Apartments
- Holiday home
$\square$ Hosted (B/B, Guesthouse or similar)
- Tent, cabin, chalet or similar at a
Caravan Park or Camping Ground
$\square$ Other, please specify

$\square$ Hotel

20. When choosing accommodation, which were the three most important factors influencing your decision? (Please list your three most important factors in order of importance to you, using numbers where 1 was the most important factor, $\mathbf{2}$ the second most important factor and $\mathbf{3}$ was the third most important factor).
( ) Comfort/Level of service
( ) Loyalty card, discount or other promotion
( ) Establishment's commitment to reduce their impact
( ) Only option available on the environment
( ) Previous experience
( ) Facilities (restaurant, gym, internet, kitchen access etc.)
( ) Value for money
) Location
( ) Word of mouth/recommendation
( ) Other, please specify:

21. Did any of the tourism products (transport, accommodation, attractions or activities) included in this trip have an environmental certification or ecolabel of any kind?

$\square$ Yes $\square$ No
$\square$ Not sure 
22. If yes, please list the relevant tourism products and the corresponding ecolabel or environmental certification.

\begin{tabular}{|l|l|}
\hline Tourism Product: & Ecolabel: \\
\hline & \\
\hline & \\
\hline & \\
\hline & \\
\hline & \\
\hline
\end{tabular}

\section{SECTION 2: GENERAL}

23. On a scale of 1 to 5 where $1=$ very important, $2=$ =important, $3=$ =neutral, $4=$ =unimportant and $5=$ very unimportant, how important are the following factors to you when choosing a holiday destination?

\begin{tabular}{|l|c|c|c|c|c|}
\hline & $\begin{array}{c}\text { Very } \\
\text { important } \\
\mathbf{1}\end{array}$ & $\begin{array}{c}\text { Important } \\
\mathbf{2}\end{array}$ & $\begin{array}{c}\text { Neutral } \\
\mathbf{3}\end{array}$ & $\begin{array}{c}\text { Unimportant } \\
\mathbf{4}\end{array}$ & $\begin{array}{c}\text { Very } \\
\text { unimportant } \\
\mathbf{5}\end{array}$ \\
\hline $\begin{array}{l}\text { A. Activities and events } \\
\text { sunshinate hours etc) }\end{array}$ & & & & & \\
\hline $\begin{array}{l}\text { C. Destination's commitment } \\
\text { to protect the environment }\end{array}$ & & & & & \\
\hline D. Unspoilt landscape/scenery & & & & & \\
\hline E. Value for money & & & & & \\
\hline
\end{tabular}

24. Approximately how many trips have you taken for leisure (not business) purposes during the last 3 years? (Only include trips of 2 or more nights away from home)

Number of trips:

25. On a scale of 1 to 5 , where $1=$ All the time, $2=$ Most of the time, $3=$ Some of the time, $4=$ Seldom and $5=$ Never, please indicate with a tick $(\checkmark)$ to which extent you behave in an environmentally responsible manner when you travel for leisure, and when you are at home:

\begin{tabular}{|l|c|c|c|c|c|}
\hline & $\begin{array}{c}\text { All the time } \\
\mathbf{1}\end{array}$ & $\begin{array}{c}\text { Most of the time } \\
\mathbf{2}\end{array}$ & $\begin{array}{c}\text { Some of the time } \\
\mathbf{3}\end{array}$ & $\begin{array}{c}\text { Seldom } \\
\mathbf{4}\end{array}$ & $\begin{array}{c}\text { Never } \\
\mathbf{5}\end{array}$ \\
\hline $\begin{array}{l}\text { A. When I am at home, I behave } \\
\text { environmentally responsible: }\end{array}$ & & & & & \\
\hline $\begin{array}{l}\text { B. When I am travelling, I } \\
\text { behave environmentally } \\
\text { responsible: }\end{array}$ & & & & & \\
\hline
\end{tabular}

26. If you chose answer option 1 or 2 for question 25 B above briefly outline which actions you take to behave environmentally responsibly when you are travelling:

27. Are you aware of the possibility for offsetting carbon emissions in relation to tourism activities? (If no, please proceed to question 31 )
$\square$ Yes
$\square$ No

28. During your last two trips, did you participate in any carbon offsetting schemes?
$\square$ Yes
$\square$ No

29. Why/why not? (This information will provide valuable insight into the decision making process regarding carbon offsetting schemes). 


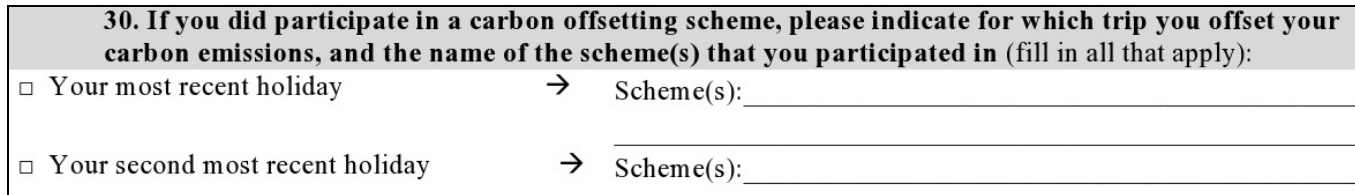

31. If you were to offset your carbon emissions, what do you consider to be an appropriate price to pay for each tonne of carbon emissions caused by your travelling activities? (Example: a one-way flight between Wellington and Sydney costs approximately NZ\$300, and typically generates about 1 tonne of CO2-Equivalent emissions per person)

NZ \$:

$\square$ I do not believe in carbon offsetting

32. This question is concerned with your opinions about tourism and the environment. On a scale of 1 to 5 , where $1=$ strongly agree, $2=$ agree, $3=$ unsure, $4=$ disagree and $5=$ strongly disagree, indicate with a tick $(\checkmark)$ to which extent you agree with the following statements:

\begin{tabular}{|c|c|c|c|c|c|}
\hline & $\begin{array}{c}\text { Strongly } \\
\text { Agree } \\
1 \\
\end{array}$ & $\begin{array}{l}\text { Agree } \\
2\end{array}$ & $\begin{array}{c}\text { Neutral } \\
3\end{array}$ & $\begin{array}{c}\text { Disagree } \\
4\end{array}$ & $\begin{array}{c}\text { Strongly } \\
\text { Disagree } \\
5 \\
\end{array}$ \\
\hline $\begin{array}{l}\text { A: Tourism within New Zealand does not } \\
\text { contribute to global climate change }\end{array}$ & & & & & \\
\hline $\begin{array}{l}\text { B: It is important for me to make sure that my } \\
\text { travels are as environmentally sound as possible }\end{array}$ & & & & & \\
\hline $\begin{array}{l}\text { C: The impact of my travelling on the global } \\
\text { natural environment is insignificant }\end{array}$ & & & & & \\
\hline $\begin{array}{l}\text { D: When I am on holiday, I tend to relax and not } \\
\text { worry about the environment as much as when I } \\
\text { am at home. }\end{array}$ & & & & & \\
\hline $\begin{array}{l}\text { E: It makes little difference buying } \\
\text { environmentally friendly tourism products } \\
\text { compared to buying ordinary tourism products }\end{array}$ & & & & & \\
\hline $\begin{array}{l}\text { F: It is difficult to know how to act in an } \\
\text { environmentally responsible manner when travelling }\end{array}$ & & & & & \\
\hline
\end{tabular}

33. During your lifetime, have you seen any evidence of climate change in your home environment? (If no, proceed to question 37 )

$$
\square \text { Yes }
$$

$\square$ No

34. If yes, which changes have you observed?

35. Have these observations had any effect on your travel decision making and behaviour? (if no, please proceed to question 37).

$$
\square \text { Yes }
$$

$\square$ No

\begin{tabular}{|c|c|c|c|c|}
\hline \multicolumn{5}{|c|}{$\begin{array}{l}\text { 37. On a scale from } 1-5 \text { where } 1=\text { very likely, } 2=\text { likely, } 3=\text { not sure, } 4=\text { unlikely and } 5=\text { very unlikely, please } \\
\text { indicate whether you think it is likely that climate change will have a negative effect on daily life in New } \\
\text { Zealand within the next } 20 \text { years: }\end{array}$} \\
\hline $\begin{array}{c}\text { Very likely } \\
1\end{array}$ & $\begin{array}{c}\text { Likely } \\
2\end{array}$ & $\begin{array}{c}\text { Neutral } \\
3\end{array}$ & $\begin{array}{c}\text { Unlikely } \\
4\end{array}$ & $\begin{array}{c}\text { Very unlikely } \\
5\end{array}$ \\
\hline
\end{tabular}

36. If yes, briefly explain how your travel decision making and behaviours has changed: 
38. In terms of reducing the carbon emissions of tourism to protect the global natural environment, which of the following policy measures is most acceptable to you? (Please list your two most acceptable options in order of acceptability to you, using numbers where $\mathbf{1}$ is the most acceptable option and $\mathbf{2}$ is the second most acceptable option).

( ) Educational Campaigns that inform people about the negative impacts that travelling can have on the environment

( ) Voluntary schemes that allow consumers to offset their carbon emissions

( ) Carbon taxes for transport companies that use fossil fuels

( ) Limiting accessibility to travel through restricting travel permits, or similar initiatives

( ) Forcing consumers to buy carbon credit to travel

( ) Other, please specify:

39. In your opinion, who should take the main responsibility for reducing the impact that tourism has on the global natural environment? (Please tick one box only)

$\square$ United Nations

$\square$ National Governments

$\square$ Providers of tourism products

$\square$ Consumers (tourists)

$\square$ Other, please specify:

SECTION 3: DEMOGRAPHICS

Finally, to be able to compare different groups of respondents, please answer a few questions about yourself: 40. Gender

\begin{tabular}{|c|c|c|}
\hline \multirow{2}{*}{ 41. What is your age? } & $\square$ Male & $\square$ Female \\
\hline & & \\
\hline & ㅁ 18-19 & 50-59 \\
\hline & $\square 20-29$ & $\square$ 60-69 \\
\hline & $\square$ 30-39 & $\square 70-79$ \\
\hline & 40-49 & 80 or above \\
\hline
\end{tabular}

42. How many people are included in this household?

Adults:

Children under 18:

43. What is your highest level of education?

口 Primary School

\begin{tabular}{ll}
$\square$ & Secondary School \\
$\square \quad$ High School Certificat \\
\hline 44. What is the ann
\end{tabular}

Tertiary/Trade Qualification

University degree

44. What is the annual income of this household?

$\square$ below 20000

口 $20001-50000$

口 $50001-100000$

$\square 100001-150000$

$\square \quad$ Postgraduate degree

\section{Please return the survey in the enclosed envelope before August $15^{\text {th }} 2009$.}

- If you wish to receive a summary of the final results of the research, please send an email to the researcher (tina.tiller@vuw.ac.nz) before $01^{\text {st }}$ of October 2009.

- PRIZE DRAW: If you wish to enter the prize draw to win a New World shopping voucher worth $\$ 200$, please use the separate entry form and envelope to make sure that your questionnaire remains anonymous. 


\section{Appendix C: Table of Destinations Visited}

\begin{tabular}{|c|c|c|c|c|c|}
\hline \multicolumn{6}{|c|}{ Appendix C: Overview of destinations visited } \\
\hline Destination & $\mathbf{F}$ & Destination & $\mathbf{F}$ & Destination & $\mathbf{F}$ \\
\hline Auckland & 44 & Mt. Ruapehu & 3 & Southland & 2 \\
\hline Christchurch & 30 & Mumbai, India & 3 & Stockholm, Sweden & 2 \\
\hline Sydney, Australia & 28 & Otaki & 3 & Surat, India & 2 \\
\hline Melbourne, Australia & 21 & Paris, France & 3 & Surfer's Paradise, Austra & 2 \\
\hline Nelson & 20 & Port Douglas, Australia & 3 & Takaka & 2 \\
\hline Taupo & 19 & Reading, UK & 3 & Vancouver, Canada & 2 \\
\hline Brisbane, Australia & 17 & Singapore & 3 & Waipukurau & 2 \\
\hline Hamilton & 14 & Tokyo, Japan & 3 & Wairarapa & 2 \\
\hline London, UK & 14 & Waikanae & 3 & Wanganui & 2 \\
\hline Rotorua & 12 & Wanaka & 3 & Aix en Provence, France & 1 \\
\hline Napier & 10 & Whitianga & 3 & Alexandra & 1 \\
\hline Dunedin & 8 & Abel Tasman & 2 & Amsterdam, Netherlands & 1 \\
\hline Gold Coast, Australia & 8 & Adelaide, Australia & 2 & Aspen, USA & 1 \\
\hline New Plymouth & 8 & Akaroa & 2 & Athens, Greece & 1 \\
\hline Blenheim & 7 & Apia, Samoa & 2 & Banks Peninsula & 1 \\
\hline Marlborough Sounds & 7 & Beijing, China & 2 & Bay of Islands & 1 \\
\hline Martinborough & 7 & Belfast, UK & 2 & Blackburn, UK & 1 \\
\hline Queenstown & 7 & Carterton & 2 & Blue Mountains, Australia & 1 \\
\hline Bangkok, Thailand & 5 & Dallas, USA & 2 & Budapest, Hungary & 1 \\
\hline Masterton & 5 & Dublin, Ireland & 2 & Buenos Aires, Argentina & 1 \\
\hline Ohakune & 5 & East London, South Africa & 2 & Buka, Papua New Guinea & 1 \\
\hline Perth, Australia & 5 & Hastings & 2 & Byron Bay, Australia & 1 \\
\hline Rarotonga, Cook Islands & 5 & Havelock North & 2 & Cable Bay & 1 \\
\hline Suva, Fiji & 5 & Hawke's Bay & 2 & Cambridge & $\overline{1}$ \\
\hline Tauranga & 5 & Kaiteriteri & 2 & Canberra, Australia & 1 \\
\hline Turangi & 5 & Las Vegas, USA & 2 & Cheltenham, UK & 1 \\
\hline Cairns, Australia & 4 & Milan, Italy & 2 & Chiang Mai, Thailand & 1 \\
\hline Castlepoint & 4 & Munich, Germany & 2 & Collingwood & 1 \\
\hline Gisbourne & 4 & Mytilene, Greece & 2 & Coral Coast, Fiji & 1 \\
\hline Hawaii & 4 & Nadi, Fiji & 2 & Coromandel & 1 \\
\hline Palmerston North & 4 & New York, USA & 2 & Courchevel, Fran. & 1 \\
\hline San Francisco, U. & 4 & Nicosia, Cyprus & 2 & Dargaville & 1 \\
\hline Te Horo & 4 & Oxford, North Canterbury & 2 & Darjeeling, India & 1 \\
\hline Bay of Plenty & 3 & Paihia & 2 & Darwin, Australia & 1 \\
\hline Berlin, Germany & 3 & Picton & 2 & Deva, Romania & 1 \\
\hline Bluff & 3 & Pleland le Grand, France & 2 & Dubai, United Arab Emirates & 1 \\
\hline Cape Town, South Africa & 3 & Raglan & 2 & Durban, South Africa & 1 \\
\hline Kerikeri & 3 & Raurimu & 2 & Edinburgh, UK & 1 \\
\hline Los Angeles, USA & 3 & Rio de Janeiro, Brazil & 2 & Giza, Egypt & 1 \\
\hline Manila, Philippines & 3 & Roma, Italy & 2 & Golden Bay & 1 \\
\hline Motueka & 3 & Rome, Italy & 2 & Gothenburg, Sweden & 1 \\
\hline
\end{tabular}

\section{F=Frequency}




\begin{tabular}{|c|c|c|c|}
\hline \multicolumn{4}{|c|}{ Appendix C: Overview of destinations visited - continued. } \\
\hline Destination & frequency & Destination & frequency \\
\hline Greytown & 1 & Phuket, Thailand & 1 \\
\hline Hamner Springs & 1 & Port Vila, Vanuatu & 1 \\
\hline High Wycombe, UK & 1 & Pretoria, South Africa & 1 \\
\hline Himalayas, India & 1 & Rakiraki, Fiji & 1 \\
\hline Hokitika & 1 & Redcar, UK & 1 \\
\hline Hong Kong & 1 & Reykjavik, Iceland & 1 \\
\hline India & 1 & Russell & 1 \\
\hline Istanbul, Turkey & 1 & San Pedro, Chile & 1 \\
\hline Itoigawa, Japan & 1 & Sandspit, Northland & 1 \\
\hline Jakarta, Indonesia & 1 & Scotland & 1 \\
\hline Kadipur, India & 1 & Sicily, Italy & 1 \\
\hline Kaikoura & 1 & Sienna, Italy & 1 \\
\hline Kalamata, Greece & 1 & South Africa & 1 \\
\hline Kapiti Coast & 1 & South Port, Australia & 1 \\
\hline Kawhia & 1 & Stanmore Bay & 1 \\
\hline Kigali, Rwanda & 1 & Stewart Island & 1 \\
\hline Lake Tekapo & 1 & Stoke-on-Trent, UK & 1 \\
\hline Lake Waikaremoana & 1 & Sunshine Coast, Australia & 1 \\
\hline Laos & 1 & Suva. Fiji & 1 \\
\hline Levin & 1 & Tahoe, US & 1 \\
\hline Madras, India & 1 & Taihape & 1 \\
\hline Mana Island, Fiji & 1 & Te Anau & 1 \\
\hline Manchester, UK & 1 & Timaru & 1 \\
\hline Marton & 1 & Toronto, Canada & 1 \\
\hline Matakana & 1 & USA & 1 \\
\hline Methven & 1 & Ventura, USA & 1 \\
\hline Moana & 1 & Waiheke Island & 1 \\
\hline Mooloolaba, Australia & 1 & Waihi Beach & 1 \\
\hline Morocco & 1 & Waitangi & 1 \\
\hline Morzine, France & 1 & Waitarere Beach & 1 \\
\hline Murupara & 1 & West Coast & 1 \\
\hline National Park & 1 & Westport & 1 \\
\hline Nausari, India & 1 & Whangamata & 1 \\
\hline New Orleans, USA & 1 & Whangarei & 1 \\
\hline Noosa, Australia & 1 & Wharemu & 1 \\
\hline Northland & 1 & Yukon, Canada & 1 \\
\hline Northshore & 1 & & \\
\hline Opotiki & 1 & & \\
\hline Otematata & 1 & & \\
\hline Oxford, UK & 1 & & \\
\hline Paekakariki & 1 & & \\
\hline Peru & 1 & & \\
\hline Phnom Penh, Cambodia & 1 & Total & 595 \\
\hline
\end{tabular}

\section{$\mathbf{F}=$ Frequency}




\section{Appendix D - Carbon Credits}

(Sourced from CarboNZero (2009), "mitigate your greenhouse emissions")

About carbon credits

When purchasing carbon credits, it is important to check that the project that created the offsets was validated and that the carbon credits have been verified against a recognised international standard.

- Validation is forward looking - an independent audit is undertaken to confirm that the project has the potential to produce the number of offsets that it claims.

- Verification is backward looking - an independent audit confirms the number of carbon credits already produced by a project.

Offsets from validated projects are often forward sold and this means that the buyer is taking the risk that later verification will confirm that the carbon credits already used to offset emissions were real. A carbon neutral claim cannot be made on the basis of forward purchased carbon credits.

Carbon credits may be Kyoto units or voluntary carbon credits.

- Kyoto units are created from Government-approved projects that have been allocated assigned amount units or AAUs and from clean development mechanism (CDM) projects validated through the United Nations Framework Convention on Climate Change (UNFCCC).

- Voluntary carbon credits are produced outside the regulatory framework and are often created through community projects. These credits may have additional ecological and social value.

Projects that create Kyoto units must meet Kyoto rules related to baseline, additionality, redundancy, permanence and leakage. To ensure that the projects meet these rules, validation and verification is undertaken against recognised international standards such as ISO 14064-2 and those set by the Clean Development Mechanism and the Joint Implementation programme. Voluntary carbon credits can be validated and verified against the Voluntary Carbon Standard or the Gold Standard. 
The New Zealand Government has allocated AAUs to Projects to Reduce Emissions (PRE) and to the Permanent Forest Sinks Initiative (PFSI). Offsets sold by these projects can be both Kyoto units and voluntary carbon credits.

In New Zealand, the ownership of carbon credits is logged by the New Zealand Emission Unit Register (NZEUR) for Kyoto units and by TZ1 Maarket (operated by the New Zealand Stock Exchange, NZX) and The Registry Company (regi) for voluntary carbon credits. TZ1 Market is also a trading platform and provides up to date prices for the different types of carbon credits. When you purchase carbon credits, the change of ownership is registered in one of these three registries.

Additionally, there are carbon brokers and traders who buy and sell carbon credits. Carbon credits can be bought and sold by auction through Trade Me.

(Source: CarboNZero, 2009c) 


\section{References:}

Aaker, D. A., V. Kumar and G. S. Day (2004) 'Marketing Research.’ New York : Wiley and Sons

Absolutely Positively Wellington (2009) Wellington Suburbs - overview Available: http://www.wellington.govt.nz/maps/pdfs/suburbs/suburbs.pdf [15. April 2009]

Agresti, A. (2002) 'Categorical Data Analysis. (2ed)' New York: Wiley-Interscience

Air New Zealand (2009) Enviroment Available: http://www.airnewzealand.co.nz/aboutus/environment/default.htm [10 December 2009]

Amelung, B., S. Nicholls and D. Viner (2007) 'Implications of Global Climate Change for Tourism Flows and Seasonality.' Journal of Travel Research (45) 2007 p. 285-296

Barr, S., G. Shaw, T. Coles and J. Prillwitz (in press) “'A holiday is a holiday': practicing sustainability, home and away.' Journal of Transport Geography

Barrett, R. (2003, May 2) 'Warm winters take tourism toll.' Milwaukee Journal Sentinel, p. 3D

Bay of Plenty Times (2009) 'Young Kiwis still hear the call of the OE.' May 2.

Becken, S. and D. Simmons (2001) 'Understanding energy consumption patterns of tourist attractions and activities in New Zealand.' Tourism Management (23) 2002 p. 343-354.

Becken, S. (2002) 'Analysing International Tourist Flows to Estimate Energy Use Associated with Air Travel.' Journal of Sustainable Tourism (10) 2 p. 114-131

Becken, S., D. G. Simmons and C. Frampton (2003) 'Energy use associated with different travel choices.' Tourism Management (24) 3 p. 267-277

Becken, S. (2004) 'How Tourists and Tourism Experts Perceive Climate Change and Carbon-offsetting Schemes.' Journal of Sustainable Tourism (12) 4 p. 332-344

Becken, S. (2005) 'Harmonising climate change adaptation and mitigation: the case of tourist resorts in Fiji.' Global Environmental Change (15) 2005 p. 381-393.

Becken, S. and J. E. Hay (2007) 'Tourism and Climate Change: Risks and Opportunities.' Clevedon, UK ; Buffalo (N.Y.) : Channel View Publications

Becken, S and M. Patterson (2006) 'Measuring National Carbon Dioxide Emissions from Tourism as a Key Step Towards Achieving Sustainable Tourism.' Journal of Sustainable Tourism (14) 4 p. 323-338.

Becken, S. (2007) 'Tourists' Perception of International Air Travel's Impact on the Global Climate and Potential Climate Change Policies.' Journal of Sustainable Tourism (15) 4 p. 351-368

Bertram, G. (2009) Personal communication. Wellington, November 25.

Bigano, A., J. M. Hamilton and R. S. J. Tol (2007) 'The Impact of Climate on Holiday Destination Choice.' Climatic Change 76 (2006) p. 389-406

Braun, O. L., M. Lohmann, O. Maksimovic, M. Meyer, A. Merkovic, E. Messerschmidt, A. Riedel and M. Turner (1999) 'Potential impact of climate change effects on preferences for tourism destinations. A psychological pilot study' Climate Research (11) April 28. 1999 p. 247-254

Bryman, A. (2008) 'Social Research Methods $3^{\text {rd }}$ Ed.' Oxford: Oxford University Press

Buckley, R. C. (2001) 'Turnover and trends in tourism ecolabeling.' In X. Font and R. Buckley (eds) Tourism Ecolabelling: Certification and Promotion of Sustainable Management. (p. 189-213). Oxon: CABI Publishing 
Burns. P., and L. Pibbings (2009) 'The end of tourism? Climate change and societal challenges.' Twenty First Centuries (4) 1 p. 31-51

CarboNZero (2009) About us Available: http://www.carbonzero.co.nz/about/index.asp [14. April. 2009]

CarboNZero (2009b) travel and tourism calculators Available: http://www.carbonzero.co.nz/EmissionsCalc/tourismeditor.aspx [10. October 2009]

CaroNZero (2009c) mitigate your greenhouse emissions Available: https://www.carbonzero.co.nz/steps/mitigate.asp\#landfill [14 April 2009]

Carter, L. (2009) Private communication. Wellington, November 21.

CIA (2009) World factbook: New Zealand Available: https://www.cia.gov/library/publications/the-world-factbook/geos/nz.html [10 October 2009]

Clarke, S. (2010, Jan 21) 'Climate boss admits Copenhagen failed.' ABC Premium News online. Available: http://www.abc.net.au/news/stories/2010/01/21/ 2797558.htm

COP15 (2009) The Copenhagen Accord Available: http://www.denmark.dk/NR/rdonlyres/C41B62AB-4688-4ACEBB7B-F6D2C8AAEC20/0/copenhagen_accord.pdf [19. December 2009]

DEFRA (2002) '2008 Guidelines to Defra's GHG Conversion Factors: Methodology Paper for Transport Emission Factors.' Available: http://www.defra.gov.uk/environment/business/reporting/pdf/ passenger-transport.pdf [11. October 2009]

Dellaert, B. G. C., D. F. Ettema and C. Lindh (1998) "Multi-faceted tourist travel decisions: a constraint-based conceptual framework to describe tourists' sequential choices of travel components." Tourism Management (19) 4 p. 313-320.

Derby Evening Mail (2009 July 7) 'Environmental Award for Toyota.' p. 3

Dolcinar, S. and F. Leisch (2008) 'An Investigation of Tourists' Patterns of Obligation to Protect the Environment.' Journal of Travel Research (46) 2008 p. 381391.

Dubois, G. and J. P. Ceron (2006) 'Tourism and Climate Change: Proposals for a Research Agenda.' Journal of Sustainable Research (14) 4 p. 399-415.

Fairweather, J. R., C. Maslin and D. G. Simmons (2005) 'Environmental Values and Response to Ecolabels Among International Visitors to New Zealand.' Journal of Sustainable Tourism (13) 1 p. 82-98

Fischer, J. (2007) Current Issues in the Interdisciplinary Research Field of Climate Change and Tourism. Paper presented at the European Tourism and the Environment Conference "Promotion and Protection, Achieving the Balance," Dublin, September.

Field, A. (2009) Discovering statistics using SPSS: (and sex and drugs and rock $n$ roll) / Andy Field. London: SAGE publications

Fitzsimmons, J. (2009) Personal communication. Wellington, November 20.

Giles, A. R. and A. H. Perry (1998) 'The use of a temporal analogue to investigate the possible impact of projected global warming on the UK tourist industry.' Tourism Management (19) 1 p. 75-80.

Goeldner, C. R. and J. R. B. Ritchie (2006) 'Tourism: Principles, Practises, Philosophies.' $\left(10^{\text {th }} \mathrm{Ed}\right)$. New Jersey: John Wiley \& Sons Ltd.

Gössling, S. (2002) 'Global Environmental Consequences of Tourism.' Global Environmental Change (12) 2002 p. 283-302.

Gössling, S., P. Peeters, J. Ceron, G. Dubois, T. Patterson and R. B. Richardson (2005) 'The Eco-Efficiency of Tourism.' Ecological Economics (54) 2005 p. 417-434. 
Gössling, S., M. Bredberg, A. Randow and E. Sandström (2006) 'Tourist Perceptions of Climate Change: A Study of International Tourists in Zanzibar.' Current Issues in Tourism (9) $4 \& 5$ p. 419-435

Gössling, S. and C. M. Hall (2006) 'Uncertainties in predicting tourist flows under scenarios of climate change.' Climatic Change (79) 2006 p. 163-173

Gössling, S. and P. Peeters (2007) 'It Does Not Harm the Environment! An Analysis of Industry Discourses on Tourism, Air Travel and the Environment.' Journal of Sustainable Tourism (15) 4 p. 402-417

Gössling, S., J. B. Broderick, P. Upham, JP. Ceron, G. Dubois, P. Peeters and W. Strasdas (2007) 'Voluntary Carbon Offsetting Schemes for Aviation: Efficiency, Credibility and Sustainable Tourism.' Journal of Sustainable Tourism (15) 3 p. 223-248.

Gössling, S., M. Hall, B. Lane and D. Weaver (2008) 'Report: The Helsingborg Statement on Sustainable Tourism.' Journal of Sustainable Tourism (16) 1 p. 122-124

Gössling, S and C. M. Hall (2008) 'Swedish Tourism and Climate Change Mitigation: An Emerging Conflict?' Scandinavian Journal of Hospitality and Tourism (8) 2 p. 141158.

Graburn, N. H. H. (1983) 'The anthropology of tourism.' Annals of Tourism Research (10) 1 p. 9-33.

Green Globe (2009) About Available: http://www.greenglobeint.com/about/history/ [14. April 2009]

Greer, T., and G. Wall (1979). "Recreational Hinterlands: A Theoretical and Empirical Analysis.” In G. Wall. 'Recreational Land Use in Southern Ontario' (p. 227246) Waterloo, Canada: Waterloo University.

Hares, A., J. Dickinson and K Wilkes (in press) 'Climate change and the air travel decisions of UK tourists.' Journal of Transport Technology

Hari, J. (2009, December 19) 'The Truths Copenhagen ignored' The Independent, p. 32

Hart, P., S. Becken and I. Turney (2004) 'Offsetting carbon dioxide emissions from tourism.' Study carried out for Landcare Research, Lincoln 8152, New Zealand. Available: www.urbanclimate.net/cctr/ws2/report/hartbeckenturney.pdf [14. April 2009]

Haviland, W.A. (2003). Anthropology. Wadsworth: Belmont, CA.

Higham, J. and A. Carr (2002) 'Ecotourism Visitor Experiences in Aotearoa/New Zealand: Challenging the Environmental Values of Visitors in Pursuit of Proenvironmental Behaviour.' Journal of Sustainable Tourism (4) 2002 p. 277-294

Hornby, A. S. (1995) 'Oxford English Dictionary.' Oxford: Oxford University Press.

Howitt, O. J. A., V. G. N. Revol, I. J. Smith and C. J. Rodgers (in press) 'Carbon emissions from international cruise ship passengers' travel to and from New Zealand.' Energy Policy

Høyer, K. G. (2000) 'Sustainable tourism or sustainable mobility? The Norwegian case.' Journal of Sustainable Tourism 8 (2), p. 147-160

Infoplease.com (2009) Distance Calculator Available: http://www.infoplease.com/atlas/calculate-distance.html [17. September 2009]

IPCC (2001) Climate change 2001: Synthesis Report Available: http://www.grida.no/publications/other/ipcc_tar/ [24 February 2009]

IPCC (2007) AR4

Available: http://www.ipcc.ch/ [25 February 2009]

Jagers, S. C. (2009) 'In search of the ecological citizen.' Environmental Politics 18 (1) p. 18-36.

Kaizer, F. G. and T. A. Shimoda (1999) 'Responsibility as a predictor of ecological behaviour.' Journal of Environmental Psychology (19) 1999 p. 243-253 
Lawson, R. (1991) 'Patterns of Tourist Expenditure and Types of Vacation Across the Family Life Cycle.' Journal of Travel Research (29) 4, p. 12-18.

Lawrence, J. (2009) Personal communication. Wellington 2. December.

Lean, G. (2009, Jan 4) 'Soot reduction could help to stop global warming.' The Independent online. Available: http://www.independent.co.uk/environment/ climate-change/soot-reduction-could-help-to-stop-global-warming1224481.html

Lopez, A. G. and M. A. Cuervo-Arango (2008) 'Relationship among values, beliefs, norms and ecological behaviour.' Psicothema (20) 4 p. 623-629.

Lorenzoni, I., and N. F. Pidgeon (2006) 'Public views on climate change: European and USA perspectives.' Climatic Change (2006) 77 p. 73-95.

Lorenzoni, I., S. Nicholson-Cole and L. Whitmarsch (2007) 'Barriers perceived to engaging with climate change among the UK public and their policy implications.' Global Environmental Change (17) 2007 p. 445-459.

Lübbert, C. (2001) "Tourism ecolabels market research in Germany ." In X. Font and R. Buckley (eds) Tourism Ecolabelling: Certification and Promotion of Sustainable Management. (p. 71-86). Oxon: CABI Publishing.

Lyons, S., K. Mayor and R.S.J. Tol (2009) 'Holiday destinations: Understanding the travel choices of Irish tourists.' Tourism Management (30) 5 p. 683-692

Manaktola, K. and V. Jauhari (2007) 'Exploring consumer attitude and behaviour towards green practises in the lodging industry in India.' International Journal of Contemporary Hospitality Management (19) 5 p. 364-377.

Mather, S., D. Viner and G. Todd (2005) 'Climate and Policy Changes: Their Implications for International Tourism Flows,' in Hall, M. and J. Higham (2005)

'Tourism, Recreation and Climate Change.' (p.63-86). Clevedon, Buffalo: Channel View Publications

McKenzie, S. (2009) Personal Communication. Wellington, 15 December.

Ministry for the Environment (2009) 'New Zealand's strategic climate change goal' Available: http://www.mfe.govt.nz/publications/climate/policy-review05/html/page5.html [12. April 2009]

Ministry for the Environment (2009b) Kyoto Protocol Available: http://www.mfe.govt.nz/issues/climate/international/kyotoprotocol.html [19. December 2009]

Ministry of Tourism (2009a) Outbound Travel Key Data Available : http://www.tourismresearch.govt.nz/Data--Analysis/DomesticTravellers/Outbound-travel/Outbound-Travel-Key-Data/ [13. September 2009]

Ministry of Tourism (2009b) Key tourism statistics Available: http://www.tourism.govt.nz/Documents/Key\%20Statistics/ KeyTourismStatisticsNov2009.pdf [5. November 2009]

Ministry of Tourism (2009c) Domestic travel Available: http://www.tourismresearch.govt.nz/Data--Analysis/DomesticTravellers/Domestic-Travel-In-New-Zealand/ [5. November 2009]

Ministry of Tourism (2008) Tourism and Climate Change Plan Available: http://www.tourism.govt.nz/Our-Work/Our-Work-Summary-page/ClimateChange/ [14. April 2009]

Ministry of Transport (2009) Air

Available: http://www.transport.govt.nz/ourwork/air/ [10. October 2009]

Moore, D. S. and G. P. McCabe (2003) 'Introduction to the Practise of Statistics $4^{\text {th }}$ Ed.' New York: W. H. Freeman and Company

New Zealand Tourism Strategy 2015 (2009) Home Available: http://www.nztourismstrategy.com/ [15. February 2009] 
NIWA (2009a) Climate

Available: http://www.niwa.co.nz/our-science/climate/information-andresources/clivar/scenarios [20. April 2009]

NIWA (2009b) Climate change, global warming and greenhouse gases Available: http://www.niwa.co.nz/education-and-training/schools/students/change\#fcc2 [20. April 2009]

Noble, I. and R. J. Scholes (2001) 'Sinks and the Kyoto protocol.' Climate policy (1) 1, p. $5-25$

NZBCSD (2009) New Zealand Climate Change Survey Available: http://www.nzbcsd.org.nz/_attachments/New_Zealanders $\% 27$ _Attitudes_to_Climate_Change_ShapeNZ_Survey_Report_March\%2C_2009.pdf [23. March 2009]

Oppermann, M. (1995) 'Travel life cycle.' Annals of Tourism Research 22 (3) p. 535-552.

Patterson, T., S. Bastianoni and M. Simpson (2006) 'Tourism and Climate Change: Two-Way Street, or Vicious/Virtuous Circle?' Journal of Sustainable Tourism (14) 4 p. 339-348.

Pearce, P. L. (1993) 'Fundamentals of Tourist Motivation.' In Pearce, D. G. and R. W. Butler (Eds). 'Tourism Research-Critiques and Challenges.' (p. 113-134). London: Routledge.

Peet, J. (2009) personal communication. Wellington, November 11.

Qualmark (2009a) About us Available: http://www.qualmark.co.nz/about_us.php [20. October 2009]

Qualmark (2009b) Responsible Tourism - Qualmark Green Available: http://www.qualmark.co.nz/responsibletourism.php [20. October 2009]

Reiser, A. \& D. G. Simmons (2005) 'A Quasi-experimental Method for Testing the Effectiveness of Ecolabel Promotion' Journal of Sustainable Tourism (13) 6 p. 590616.

Reisinger, A. (2009) Personal communication. Wellington, November 20.

Richardson, R. B. (2007) Tourism in Belize: Vulnerability and capacity assessment. Available: http://www.hydromet.gov.bz/Tourism\%20VA\%20Final\%20report \%20_Richardson.pdf [26. April 2009]

Roberts, J. A. (1996) 'Green consumers in the 1990s: Profile and implications for advertising.' Journal of Business Research 36 (1996) p. 217-231

Salkind, N. J. (2007) 'Statistics for people who (think they) hate statistics.' London: Sage Publications

Schott, C. (2006) 'Proactive Crises Management Tools: Ecolabel and Green Globe 21 Experiences from New Zealand.' Tourism Review International (10) 2006 p. 81-90.

Schultz, P. W., V. V. Gouveia, L. D. Cameron, G. Tankha, P. Schmuck and M. Franek (2005) 'Values and their relationship to environmental concern and conservation behaviour.' Journal of Cross-Cultural Psychology (36) 4 p. 457-475

ShapeNZ (2009) Get your eco label right - and grab 32\%+ market appeal Available: http://www.nzbcsd.org.nz/story.asp?StoryID=1048 [29 October 2009]

Silverman, D. (2004) 'Qualitative Research: Theory, Method and Practise.' London : SAGE Publications

Smith, K. (1990) 'Tourism and Climate Change.' Land Use Policy (7) 2 p.176-180

Smith, L. J. and C. J. Rodger (2008) "Carbon emission offsets for aviation-generated emissions due to international travel to and from New Zealand" Energy Policy (37) 9 p. 3438-3447

Som, R. K. (1973) 'A manual of sampling techniques.' London: Heinemann Educational Books Ltd. 
Sourbati, M. (2009) 'It could be useful, but not for me at the moment': older people, internet access and e-public service provision.' New Media and Society (11) 7 p. 10831100

Statistics New Zealand (2009a) Census 2006 quickstats about culture Available: http://www.stats.govt.nz/Census/2006CensusHomePage/QuickStats /quickstats-about-a-subject/culture-and-identity/ethnic-groups-innew-zealand.aspx [11. August 2009]

Statistics New Zealand (2009b) Wellington Available: http://www.stats.govt.nz/Census/2006CensusHomePage/ QuickStats/AboutAPlace/SnapShot.aspx?type=ta\&ParentID=1000009\&tab=Culturaldiv ersity\&id=2000047 [10. August 2009]

Statistics New Zealand (2009c) arrivals and departures by sea Available: http://www.stats.govt.nz/methods_and_services/accessdata/tables/tourism-migration-2007.aspx [16. November 2009]

Statistics New Zealand (2009d) Quickstats about Brooklyn Available:http://www.stats.govt.nz/Census/2006CensusHomePage/QuickStats/AboutA Place/SnapShot.aspx?id=3575600 [26 September 2009]

Statistics New Zealand (2009e) Quickstats about Churton Available:http://www.stats.govt.nz/Census/2006CensusHomePage/QuickStats/AboutA Place/SnapShot.aspx?id=3573512\&tab=\&ParentID=1000009 \&type=au [26 September 2009]

Statistics New Zealand (2009f) Quickstats about Karaka Bay-Worser Bay Avaiable:http://www.stats.govt.nz/Census/2006CensusHomePage/QuickStats/ AboutAPlace/SnapShot.aspx?id=3577400\&amp;type=au\&ampParentID= 1000009 [26. September 2009]

Statistics New Zealand (2009g) Quickstats about Lyall Bay Available: http://www.stats.govt.nz/Census/2006CensusHomePage/ QuickStats/AboutAPlace/SnapShot.aspx?id=3577000\&amp;type=au\&amp ParentID=1000009 [26. September 2009]

Statistics New Zealand (2009h) Quickstats about Mt. Cook-Wallace Street Available: http://www.stats.govt.nz/Census/2006CensusHomePage/ QuickStats/AboutAPlace/SnapShot.aspx ?id=3573300\&amp;type=au\&amp ParentID=1000009 [26. September 2009]

Statistics New Zealand (2009i) Quickstats about Northland Available: http://www.stats.govt.nz/Census/2006CensusHomePage/ QuickStats/AboutAPlace/SnapShot.aspx?id=3575200\&amp;type=au\&amp ParentID=1000009 [26. September 2009]

Statistics New Zealand (2009j) Quickstats about Kilbirnie East Available: http://www.stats.govt.nz/Census/2006CensusHomePage/ QuickStats/AboutAPlace/SnapShot.aspx?type=au\&amp ParentID $=1000009 \&$ tab=PopulationDwellings\&id=3576901 [26. September 2009]

Statistics New Zealand (2009k) Quickstats about Tawa Central Available: http://www.stats.govt.nz/Census/2006CensusHomePage/ QuickStats/AboutAPlace/SnapShot.aspx $?$ id=3572600\&type=au\& ParentID=1000009\&expand=2000047\&scrollLeft=0\&scrollTop=731\&ss=y [26. September 2009]

Statistics New Zealand (2009k) Quickstats about Tawa South Available: http://www.stats.govt.nz/Census/2006CensusHomePage/ QuickStats/AboutAPlace/SnapShot.aspx?id=3572500\&type=au\& ParentID=1000009\&expand=2000047\&scrollLeft=0\&scrollTop=731\&ss=y [26. September 2009] 
Statistics New Zealand (20091) Quickstats about Wellington Available: http://stats.govt.nz/Census/2006CensusHomePage/QuickStats/AboutAPlace /SnapShot.aspx ?ParentID=1000009\&type=ta\&tab=Agesex\&id=2000047\&map=off $[27$. September 2009]

Statistics New Zealand (2009m) Media Release Available : http://www.stats.govt.nz/browse_for_stats/industry_sectNors/ information_technology_and_communications/householduseof informationandcommunicationtechnology_mr06.aspx [10. August 2009]

Steg, L. and C. Vlek (2008) 'Encouraging pro-environmental behaviour: An integrative review and research agenda.' Journal of Environmental Psychology ( $x x x)$ 2008 p. $1-9$.

Stern, N. (2006) Stern Review: Report on the Economics of Climate Change: Full Executive Summary. Cambridge: Cambridge University. Available: http://www.hm-treasury.gov.uk/media/4/3/Executive_ Summary.pdf [25. April 2009]

Stoll-Kleemann, S., T. O'Riordan and C. C. Jaeger (2001) 'The psychology of denial concerning climate mitigation measures: evidence from Swill focus groups.' Global Environmental Change (11) 2001 p. 107-117

Taylor, J. (2009, November 7) 'Ethical Travel Company drops carbon offsetting.' The Independent, p. 2

TIANZ (2009) Submission to the Emissions Trading Scheme Review Committee on the Review of the Emissions Trading Scheme and related matters. Available: http://www.tianz.org.nz/content/library/Emissions_Trading_ Scheme_Review.pdf [15. April 2009]

Tourism New Zealand (2009) index Available: http://www.newzealand.com/travel/International [6. November 2009]

UNFCCC (2009) Kyoto Protocol Available : http://unfccc.int/kyoto_protocol/items/2830.php [19. April 2009]

UNWTO (2009) Index Available: http://www.unwto.org/index.php [5. November 2009]

UNWTO (2001) Tourism 2020 Vision Available: http://unwto.org/facts/eng/vision.htm [20. August 2009]

Victoria University of Wellington (2009) Human Ethics Policy Available: http://policy.vuw.ac.nz/Amphora! policy.vuw.ac.nz POLICY 000000000744.pdf [14. September 2009]

Viner, D. (2006) 'Editorial: Tourism and its Interactions with Climate Change.' Journal of Sustainable Tourism (14) 4 p. 317-322

Virgin Atlantic (2008) All about us Available: http://www.virginatlantic.com/en/au/allaboutus/environment/ biofuel.jsp [15 ${ }^{\text {th }}$ November 2009]

Wall, G., R. Harrison, V. Kinnaird, G. McBoyle, C. Quinlan (1986) Applied Geography Conferences, SUNY, Binghamton 9, p. 124-131

Wearing, S., C. Cynn, J. Ponting and M. McDonald (2002) "Converting Environmental Concern into Ecotourism Purchases: A Qualitative Evaluation of International Backpackers in Australia." Journal of Ecotourism (1) $2 \& 3$ p. 133-148.

Wellington Combined Taxis (2009) home Available: http://www.taxis.co.nz/ [02. November 2009]

Wilson, J., D. Fisher and K. Moore (2009) 'Reverse Diaspora and the Evolution of a Cultural Tradition: The Case of the New Zealand 'Overseas Experience.' Mobilities (4) 1 p. $159-175$

Yeoman, I. (2008) Personal communication. Wellington, October. 
Appendices

YHANZ (2009) Sustainability

Available: http://www.yha.org.nz/Sustainability/ [24 November 2009]

Zografos, C. and D. Allcroft (2007) the Environmental Values of Potential

Ecotourists: A Segmentation Study.' Journal of Sustainable Tourism (15) 1 p. 44-66 